\title{
Die Pfarrchronik der \\ Kirchengemeinde Obernjesa-Dramfeld
}

\author{
Ein Rechnungsbuch mit chronikalischen \\ Notizen 1737 bis 1807
}

Bearbeitet von Dagmar Kleineke

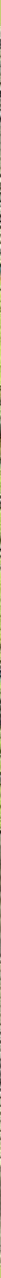


Die Pfarrchronik der Kirchengemeinde Obernjesa-Dramfeld

Dieses Werk ist lizenziert unter einer Creative Commons Namensnennung - Weitergabe unter gleichen Bedingungen 4.0 International Lizenz.

(c) (1) (-) 


\section{cosintir}

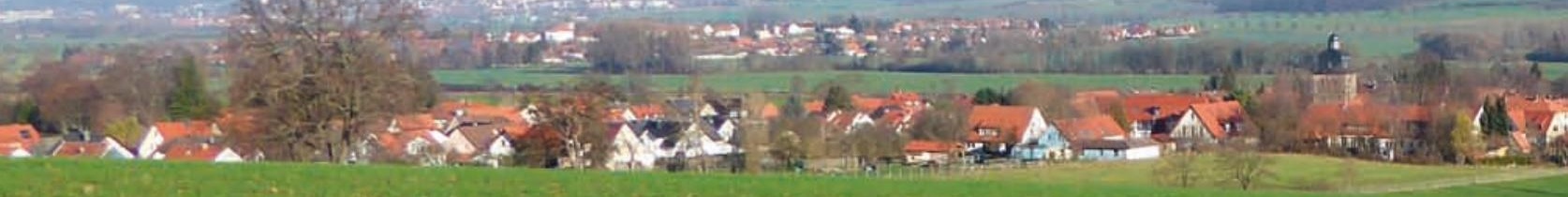

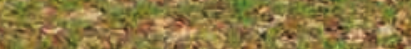

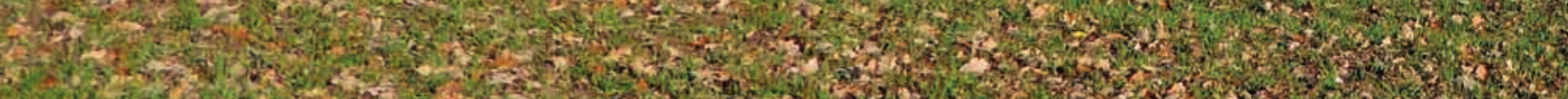

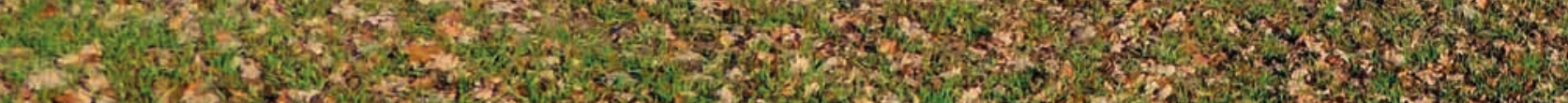

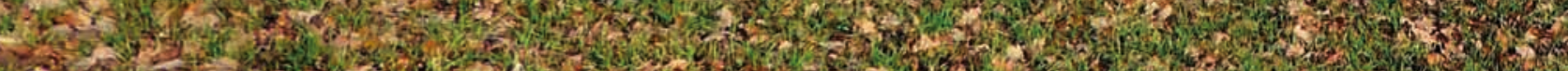

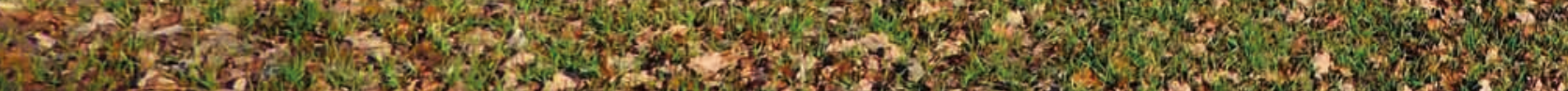

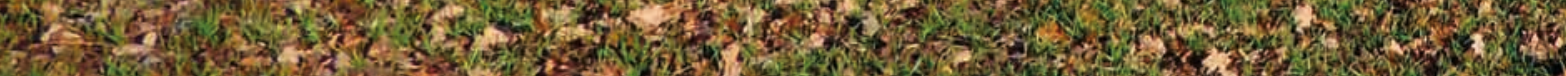

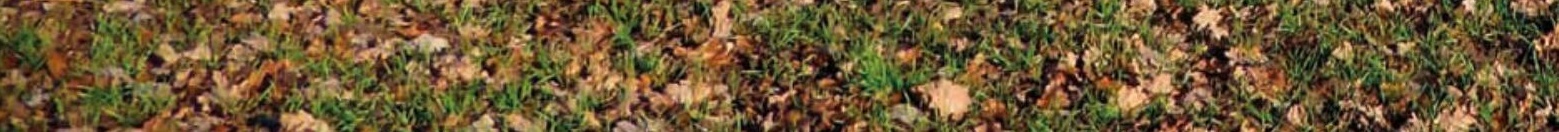
4. Lar

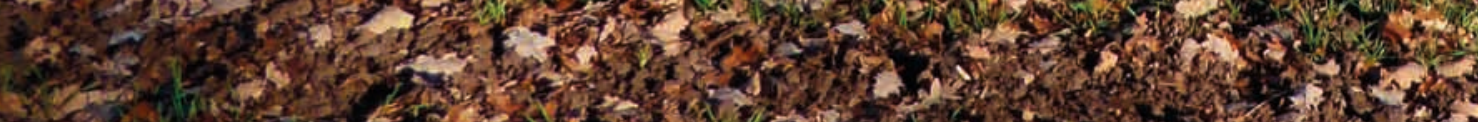
Blick auf Obernjesa vom ägerberg, Quelle: Dagmar Kleineke, Januar 2016 ,

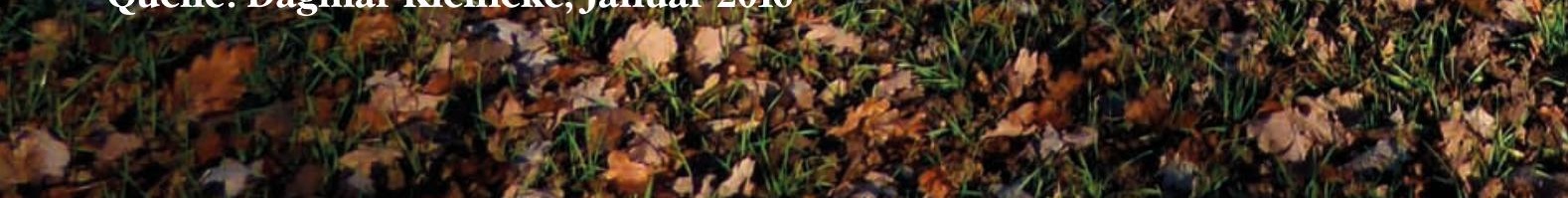




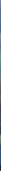

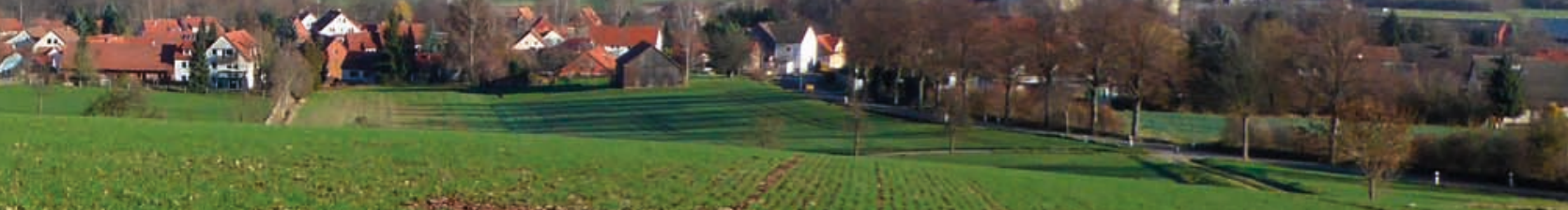

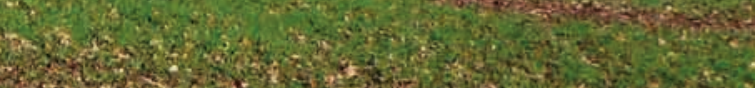

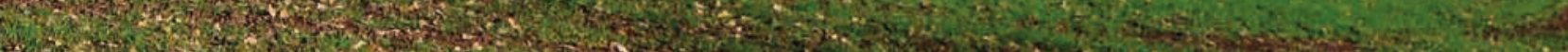

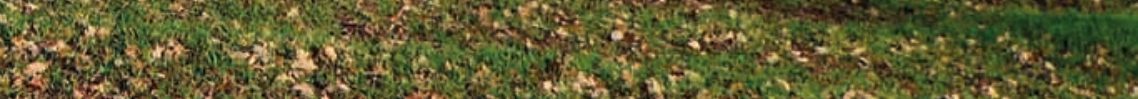
1.7. 6. W

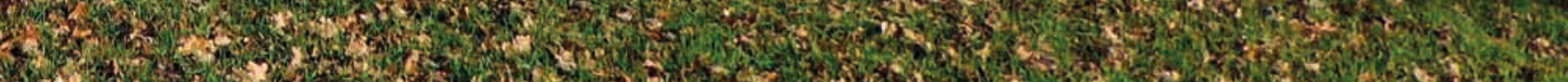

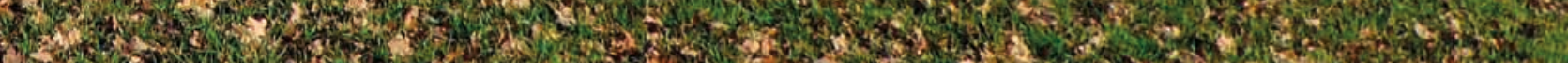
Q150.

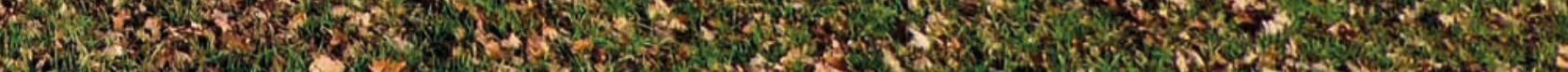

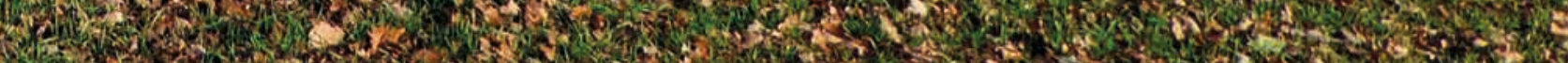

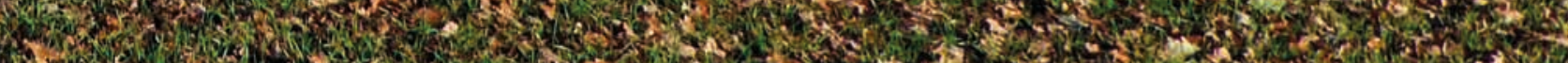
6.

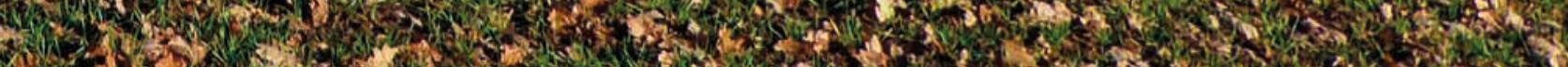

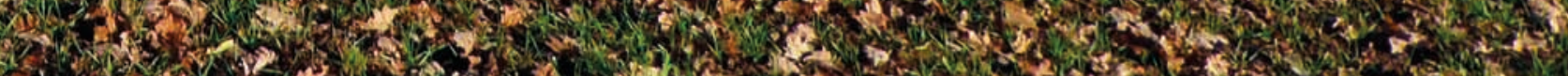
5.

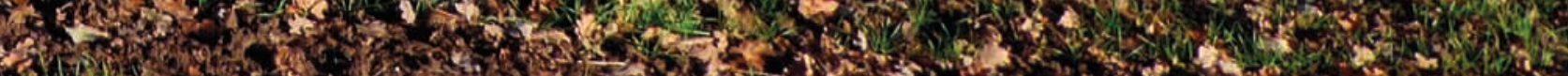

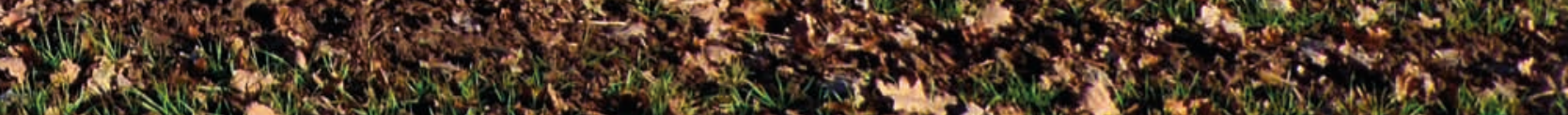
C.

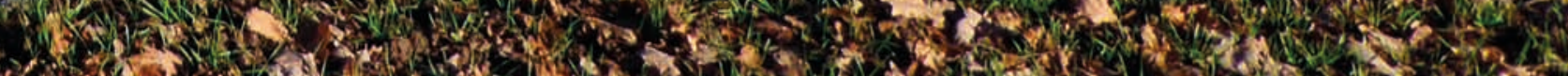

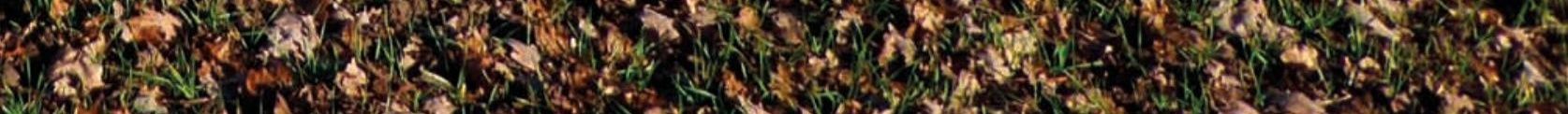



Die Pfarrchronik der Kirchengemeinde Obernjesa-Dramfeld

Ein Rechnungsbuch mit chronikalischen Notizen 1737 bis 1807

Bearbeitet von

Dagmar Kleineke

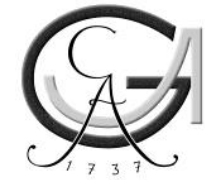

Universitätsverlag Göttingen 2016 


\section{Bibliographische Information der Deutschen Nationalbibliothek}

Die Deutsche Nationalbibliothek verzeichnet diese Publikation in der Deutschen Nationalbibliographie; detaillierte bibliographische Daten sind im Internet über $<$ http://dnb.dnb.de $>$ abrufbar.

Anschrift der Autorin

Dagmar Kleineke

E-Mail: dagmar.kleineke@arcormail.de

Dieses Buch ist auch als freie Onlineversion über die Homepage des Verlags sowie über den Göttinger Universitätskatalog (GUK) bei der Niedersächsischen Staats- und Universitätsbibliothek Göttingen (http://www.sub.uni-goettingen.de) erreichbar. Es gelten die Lizenzbestimmungen der Onlineversion.

Satz und Layout: Katja Töpfer, Freie Kunst \& Grafik, Göttingen Umschlaggestaltung: Jutta Pabst

Titelabbildung: Ausschnitt aus der Kurhannoverschen Landesaufnahme des 18. Jahrhunderts, Blatt 161. (C) 2016 LELN

(C) 2016 Universitätsverlag Göttingen http:/ / univerlag.uni-goettingen.de ISBN: 978-3-86395-278-5 


\section{Inhalt}

Vorrede - VII

Einführung - IX

Die Pfarrchronik im Rechnungsbuch - IX

Die Pastoren - XIV

Kirchliche und weltliche Verwaltung - XIX

Die Pastoren - ihre Stellung - XXV

$\mathrm{Zu}$ den Themen der Einträge:

1. Grenzstreitigkeiten - XXVI

2. Vergütung geistlicher Dienstleistungen - XXIX

3. Meliorationen $-\mathrm{XxX}$

4. Schulunterricht $-\mathrm{XXXI}$

5. Kollekten - XXXV

6. Wetternachrichten - XXXVII

7. Krieg und Frieden - XXXVIII

8. Geld, Preise, Kaufkraft - XLI

Zur Transkription - XLV

Abkürzungen - XLVII

Die Pfarrchronik (Transkription) - 1

Quellen und Literatur - 219

Glossar - 230

Dank - 240 



\section{Vorrede}

In dem relativ umfangreichen Bestand des Pfarrarchivs Obernjesa/Dramfeld fand sich 1957, als ich mit den Vorbereitungen für meine Examensarbeit über Unterrichtsmaterial für den Heimatkundeunterricht befasst war - verborgen in einem Rechnungsbuch vom Beginn des 18. Jahrhunderts - eine Chronik aus den Jahrzehnten vor und nach dem 7jährigen Krieg, die von vier Pastoren der Pfarre Obernjesa/Dramfeld geführt worden war.

Die Eintragungen vermittelten nicht nur einen lebendigen Eindruck von den Umständen, die den Alltag eines Landpfarrers bestimmten, sondern ließen erkennen, welche Stellung die Geistlichen - als letztes Glied in der Hierarchie der kirchlichen Verwaltung - in der dörflichen Gesellschaft eingenommen hatten. Aus Zeitgründen konnten damals gerade diese chronikalischen Aufzeichnungen nur für die Darstellung der Kirchengeschichte ausgewertet werden.

Dr. Dagmar Kleineke hat nun eine zeichen- und buchstabengetreue Transkription angefertigt und damit eine bemerkenswerte Quelle für die Alltagsgeschichte im Bereich des hannoverschen Konsistoriums zur Verfügung gestellt:

Die Chronik bietet Informationen über das dörfliche Elend während des 7jährigen Krieges, darüber hinaus werden Unwetter und Erdbeben, Unglücksfälle und Feuersbrünste, Diebereien und Morde verzeichnet; die Eintragungen belegen, dass man über die Pfarrgrenzen hinausblickte und über die Lebensumstände im Kollegenkreis informiert war.

Da Frau Dr. Kleineke zur Klärung einzelner Sachverhalte sowohl ältere wie auch jüngere Sekundärliteratur verwendet hat, wird die vorliegende Edition von den Regional-Forschern und -Forscherinnen mit Gewinn und mit herzlichem Dank an die Bearbeiterin genutzt werden können.

Karl-Heinz Bielefeld

Göttingen im Juni 2016 



\section{Einführung}

\section{Ein altes Buch, das nicht mehr gebraucht wird}

Im Kirchenkreisarchiv Göttingen wird ein altes, in Pergament gebundenes Rechnungsbuch verwahrt, in das im 18. Jahrhundert über einen Zeitraum von 70 Jahren chronikalische Bemerkungen geschrieben wurden. Diese Pfarrchronik hat bereits vor Jahrzehnten Karl-Heinz Bielefeld als Quelle für seine Examensarbeit über das Dorf Obernjesa genutzt. ${ }^{1}$

Da die Pfarrchronik eine Vielzahl unterschiedlichster Informationen enthält, die sowohl Aspekte der Lokalgeschichte des 18. Jahrhunderts als auch der Landesgeschichte der Zeit aufzeigen, schien es sinnvoll, eine kommentierte Transkription anzufertigen und auf diese Weise einem größeren Kreis interessierter Personen einen eigenen Zugang zum Text zu ermöglichen.

Die vorliegende Arbeit soll eine Chronik der historischen Verhältnisse des Dorfes Obernjesa im 18. Jahrhundert nicht ersetzen; um aber das Verständnis der Chronikeintragungen zu erleichtern, wird in der Einführung auf einige Themen eingegangen, die den Alltag der Obernjesaer (und Dramfelder) Einwohner und seiner Pastoren bestimmten, uns heutigen Lesern aber nicht mehr geläufig sind. Ein geringer Teil der Ausführungen basiert auf meinem Aufsatz Ein altes Rechnungsbuch, das nicht mebr gebraucht wird im Göttinger Jahrbuch 2013, in dem ich Einzelheiten des Alltags der Geistlichen beschrieb; Textpassagen daraus wurden ohne besondere Kennzeichnung wörtlich übernommen.

\section{Die Pfarrchronik im Rechnungsbuch}

Die Chronik entstand in den Jahren 1737 bis 1807: Magister Johann Paulus Stollberg begann die Aufzeichnungen, nachdem er bei seinem Amtsantritt angeblich fast keinerlei Unterlagen über Geschichte und Vermögenslage der Obernjesaer Pfarrstelle und Kirche vorgefunden hatte. Er erkundigte sich bei den Lehrern Schlote in Obernjesa und Curtius in Dramfeld und trug das nöthige was ich erfahren können und was sich zu meiner Zeit zugetragen, in dieses Buch, weil es nicht mehr gebrauchet wird, meinen Herrn Successo-

1 Bielefeld, K.-H.: Obernjesa, eine ortsgeschichtliche Studie. Göttingen 1957. 
ribus zur Nachricht ein (...). Ein Inventar der Bücher und anderer Sachen, welche bey die Pfarr und Kirche gebören, soll sich binten in diesem Buche finden. ${ }^{2}$ Auf 72 Seiten notierte er Ereignisse aus zwanzig Jahren seiner Amtszeit (1737-1761). Sein Sohn und Nachfolger im Amt, Pastor Heinrich Philipp Stolberg (1761-1783), verzeichnete - mit Unterbrechungen - Ereignisse aus neun Jahren auf 43 Seiten; Pastor Johann Christian Bornträger, der nur sechs Jahre in Obernjesa amtierte (1792-1798), begann die Eintragungen erst zwei Jahre nach Amtsantritt und benutzte das Buch überwiegend als Eingangsbuch der bei ihm eingegangenen Konsistorialrundschreiben und -erlasse aus knapp vier Amtsjahren und vermerkte deren Inhalt auf 20 Seiten $^{3}$; dessen Nachfolger Johannes Friedrich Proffen (1798-1819) notierte Ereignisse und den Inhalt von Erlassen und Dekreten aus einem Zeitraum von neun Jahren (1798-1806) auf 45 Seiten des alten Rechnungsbuches.

Der in den acht Jahren zwischen 1784 bis 1792 amtierende D. Magister Johann Friedrich Christoph Gräffe hat die Chronik zwar gekannt ${ }^{4}$, jedoch keine chronikalischen Notizen hinterlassen; seine Spuren finden sich in den Pfarrakten: U. a. hat er die Pfarrregistratur, die zu seiner Zeit relativ umfangreich - aber vermutlich unübersichtlich war, gesichtet, geordnet und ein Inventar zusammengestellt. ${ }^{5}$ Er begründete diese zeitraubende Arbeit, die viel Papier- und Einbindekosten erforderte, in der Kirchenrechnung von 1787 mit der Bemerkung: Zum Nutzen, und zu desto sicherern Aufbewabrung der zu biesiger Pfarr-Registratur gebörigen Schriften, und Documente, habe ich ein doppeltes Verzeichnis der Pfarr-Registratur verfertiget, ein Exemplar für die Superintendentur, und eines für die Pfarre. Selbige einzubinden, jedes Exemplar $2 m g . . .6$

Da Magister Gräffe keine Eintragungen vorgenommen hat, ergibt sich in der Chronik eine Lücke für die Jahre zwischen 1775 und 1794, d.h. für die Zeit vor, während und nach der französischen Revolution. Die Lücke

2 KiKrAGött, P. A. Obernjesa, K. R. I. a.(Pfarrchronik) [108]. Dazu gehört wohl auch das eingeheftete Blatt [144a] bis [144b].

3 Für Dramfeld war ein Copialbuch vorhanden, das Pastor Stolberg (jun.) bereits 1773 angeschafft hatte (Pfarrregistratur Obernjesa, Corpus bonorum Bey der Kirche zu Dramfeld Inspection Münden 2tn. Theils Amts Friedland).

4 KiKrAGött, P. A. Obernjesa A. 120. Pfarr-Registratur zu Obernjesa. Im Abschnitt II. Kirchenrechnungen, findet sich die Eintragung: 1) Die Rechnungen de 1704-1711 in Pergamen gebunden. Auf dem leer gebliebenen Papieren haben die beiden seel. Stollberge eine Chronik angefangen.

5 Vgl. KiKrAGött, P.A. Obernjesa A. 120. Ein blaugebundenes Heft: Pfarr-Registratur zu Obernjesa. Auf der letzten Seite die Bemerkung: Dieses Verzeichnis ist in Ordnung gebracht und aufgeschrieben von J.F.C. Graeffe, Obernjesa, den 20. April 1787.

6 KiKrAGött, P. A.Obernjesa K. R. I. a. 5 1787-1798, Ausgaben Insgemein. 
Zwischen 1768 und 1775 in der Zeit Pastor Stolbergs (jun.) lässt sich dadurch erklären, dass die Amtsgeschäfte ${ }^{7}$ und die Sorgen um die wachsende Familie und um seine eigene Gesundheit den Geistlichen vermutlich ausreichend beschäftigt haben. Nach 1775 dürfte Pastor Stolberg zunehmend durch die Beaufsichtigung der Umbauten der Dramfelder und durch die darauf folgende Planung und Überwachung der Baumaßnahmen an der Obernjesaer Kirche in Anspruch genommen worden zu sein, wie auch durch seine nebenamtliche Tätigkeit als Bausachverständiger.

Die beiden Blätter 43 und 44 in der Zählung von Magister Stollberg - vor [129] - sind zu einem unbestimmten Zeitpunkt herausgeschnitten worden; die noch erhaltenen Sätze deuten darauf hin, dass der Chronist entweder Gerüchte bzw. kompromittierende Mitteilungen niedergeschrieben hatte.

$\mathrm{Zu}$ Dramfeld finden sich in der Chronik nur wenige Eintragungen, obwohl die Dramfelder Kirche als Filia mit der Obernjesaer Kirche bis heute verbunden ist. ${ }^{8}$

Die Zeitpunkte, an denen die Pastoren ihre Eintragungen vornahmen, sind nicht genau zu bestimmen. Manches wurde wohl unmittelbar nach dem Ereignis vermerkt, manches allerdings auch in zeitlichem Abstand zum Vorkommnis.

Im Übrigen gab es für die Führung eines Pfarrarchivs und einer Pfarrregistratur ausführliche Anweisungen: Wie und wo Schriftverkehr und amtliche Verlautbarungen, Urkunden und Inventare abzulegen seien, damit der Nachfolger bei Amtsantritt korrekt informiert sein würde, und auf diese Weise das Vermögen von Pfarre und Kirche besser zusammenhalten könne. Als wichtigsten Bestandteil eines Archivs bzw. einer Pfarregistratur kann man das Corpus bonorum betrachten, das gleich bey Errichtung des neuen Kirchenstaates obligatorisch wurde. In jedem Fall hatte sich der Superintendent bei der Einführung eines neuen Pastors danach zu erkundigen, $o b$

7 Die noch erhaltenen Archivalien belegen, dass die Verwaltung der Pfarrstelle, insbesondere die Rechnungsführung, einen umfangreichen Papierkrieg erforderte; u. a. mussten sämtliche Abrechnungen in drei- bis vierfacher Ausfertigung angefertigt und beim Konsistorium eingereicht werden.

8 Man kann davon ausgehen, dass die Dramfelder Kirche bereits vor der Reformation zur Kirchengemeinde Obernjesa gehörte, ebenso wie Volkerode. Hierzu notierte Magister Stollberg: Zu der Pfarr Obernjesa haben bey der 1588 gehaltenen Landesherrlichen General-KirchenVisitation gehöret die beyden Filial Dörffer und Gemeinden Dramfeld und Volckeroda. Conradus Schlüter 1600. Dieser hat am 11 Martii 1609 das Filial Volckeroda Alters halber an den damabligen Prediger zu Siboldeshausen Justum Gericum abgetreten, doch also, daß es seinen Successoribus nichts schaden sollte. weßwegen er einen Revers hat von sich ins Consistorium geben müssen [112v]. Bei der Aufteilung der Pfarren von 1609 ist es dann geblieben: 1783 wurde Pastor Stolberg (jun.) vom Konsistorium mitgeteilt, dass Volkerode bei Sieboldshausen bliebe (KiKrAGött, P. A. Obernjesa A. 102, Revers von 1609). 
ein klein Archivum in der Kirche vorbanden [sei], worinn die Pfarr-Acten, oder sonsten einige Ubrkunden von Kirchen-Pfarr- und Schul-Gütern; Item die nach und nach ergangene Befeble und Verordnungen [abzulegen seien], (...). Dafern aber kein Archivum sollte vorbanden sein, ist dem pastori anzudeuten, daß er solches anzurichten, auch zum Behueff deßen copiam von allen denen literis circularibus, die etwas Beständiges verfügen, in der Inspection ibm zugesandt werden, ins Archivum legen, oder gar in ein gewißes Buch, wo es nöthig, de verbo ad verbum, wo es aber nicht nöbtig, den kurtzen inhalt derselben verzeichnen, und also nichts von dem, waß dermableins seinem Successori oder der Kirch und Pfarr zur Nachricht dienen kann, von banden kommen laßen solle, wie dann auch zum Bebueff deßen von nun an ein jeder Pfarrer eine Specification von dem seines Orts vorbandenen Kirchen- und Pfarr-Archivo verfertigen und seinem vorgesetzten Superintendenti einbändigen soll. ${ }^{9}$

Diese Vorschriften machen verständlich, warum Pastor Bornträger Inbaltsangaben von amtlichen Schreiben in die Chronik eintrug, und warum Pastor Gräffe das Inventar der Pfarrregistratur aufstellte.

Unabhängig davon wie die Pastoren ihre Bemerkungen in der Chronik bezeichnen - sie waren zur Information der Nachfolger gedacht. Während Magister Stollberg die Chronik explizit für die Successores, also für seine Nachfolger im Amt, anlegte, führte sein Sohn sie als Obernjesische Pfarr Nachrichten bzw. Chronica Obernjesana weiter. Pastor Proffen schrieb über jede Seite seiner Einträge Posteritati Obernjesanae - also den Nachkommen bzw. für die Nachkommen.

Die Themen der Einträge lassen sich grob gliedern; einmal in Vermerke, die unmittelbar die Amtsgeschäfte betrafen, wie Eigentums- und Vermögensverhältnisse der Pfarre, Baugeschichte des Pfarrhauses und des kirchlichen Wirtschaftshofes, Umstände der Amtseinführung, Todesanzeigen von Kollegen, Pfarrregistratur, Schulwesen, Konfirmandenunterricht, Anweisungen von Kollekten und Sammlungen, Verhaltensmaßregeln. Zum andern in Eintragungen, die dem Nachfolger Denkwürdiges aus der Geschichte der Universität und der Umgebung überliefern sollten, wie die Todesnachrichten von bekannten Göttinger Professoren, die ausführlichen Beschreibungen aus und über die Jahre des Siebenjährigen Krieges und der Kriegszüge zur Zeit Napoleons ebenso wie die Vermerke von Wetternachrichten oder die Darstellung der Umstände und Folgen eines Unwetters ${ }^{10}$

9 Siehe u. a. Schlegel, 1. Teil, S. 96; Schlegel, 2. Teil, S. 236-238; Schlegel, 5. Teil, Beylage XIX, S. 586.

10 Pfarrchronik [180v, 181]. 
von 1800 und der Überschwemmungen im Leinetal ${ }^{11}$ von 1805. Einiges scheint einer Eintragung wert gewesen zu sein, weil das Ereignis den Geistlichen persönlich berührt hatte - wie zum Beispiel eine besondere Himmelserscheinung ${ }^{12}$ oder der Tod der Ehefrau eines Bekannten. ${ }^{13}$

Die Hauptquelle vieler Eintragungen waren die zahlreichen amtlichen Mitteilungen und Verordnungen, die das Konsistorium an die Superintendenten schickte und die diese an die Geistlichen weitergaben. Manches erfuhren die Pastoren aus dem Briefwechsel mit Kollegen, einiges wird auch aus den in Göttingen kursierenden Zeitungen der Zeit herausgelesen worden sein; anderes, wie beispielsweise die Preisangaben, gehörte zum Alltagswissen der Menschen. Ob und welche Journale und Zeitungen die Pastoren abonnierten, ist nicht aus der Pfarrchronik zu entnehmen. Immerhin scheint Pastor Stolberg (jun.) Zugang zum Göttinger Intelligenzblatt gehabt zu haben, denn bevor das Pfarrwitwenhaus im Dorf öffentlich vermietet werden konnte, wurde eine Annonce in diesem Blatt veröffentlicht. ${ }^{14}$ Pastor Proffen hatte offenbar Zugang zu mehreren Zeitungen und Zeitschriften: 1799 notierte er: öffentlichen Blättern zufolge ist die Kälte am 7ten Febr. in Hamburg über 10 Grad nach Reaumür... (Hervorhebung D. Kl.), und 1803 berichtete er über die französische Besetzung Hannovers, dass die Proklamation der Kapitulation im Publico, in den hannoverschen Anzeigen sowie in Hamburger Zeitungen veröffentlicht worden sei. ${ }^{15}$ Als Magister Stollberg die Inauguration der Göttinger Universität beschrieb, war er gut informiert; sicherlich kannte er bereits eine der gedruckten Versionen der Beschreibung $;^{16}$ außerdem hatten die Pastoren zwei Wochen vor der Einweihung, unter dem Datum vom 2. September 1737, eine Notiz von der zur Inauguration der Universität Göttingen $z$ u haltenden Solennität erhalten. ${ }^{17}$ Schließlich hatte er mit einem lateinischen Grußwort an den König seinen eigenen Beitrag zur feierlichen Einweihung geliefert. ${ }^{18}$

11 Pfarrchronik [195, 195v].

12 A.a.O. [179hs].

13 A.a.O. [131].

14 KiKrAGött, P. A. Obernjesa K. R. III. 2, Beleg Nr. 8 vom 12. Juli 1780.

15 Pfarrchronik [178hs, 190v, 191, 191v].

16 Vgl. Anmerkung 22 bei Garbe und Wiechert, GöJb 37, 1989, S. 75

17 Vgl. Inventar Graeffe, Pfarr-Registratur Obernjesa, IV Verordnungen, D Licent-Verordnung et alia, in KiKrAGött P. A. Obernjesa A. 120.

18 Defensor fidei populique Georgius alter Pieriis Pindi sicuti Phoebus erit...Hat bey der den 17. Sept. 1737 vor sich gegangenen Inauguration der Universität dieses aufgesetzet. M. Johann Paul Stollberg, Diener des Worts an der Creutz-Kirche zu Göttingen, Hager, Göttingen 1737. 


\section{Die Pastoren}

Da Karl-Heinz Bielefeld die Biographien der vier Chronisten-Pastoren bereits in seiner Examensarbeit dargestellt hat ${ }^{19}$, sollen hier nur die wichtigsten Daten und Stationen erwähnt werden. Die genauen Studienfächer der Geistlichen sind bisher nur teilweise bekannt; infolgedessen weiß man noch nicht, wo Pastor Stolberg (jun.) seine bautechnischen Kenntnisse erwarb; Sprachkenntnisse der modernen Sprachen, d.h. Kenntnisse des Französischen oder Englischen, waren sicherlich vorhanden, sind aber nur durch einige verstreute Hinweise in den Archivalien belegt: ${ }^{20}$ Pastor Proffen wird sich mit den Besatzungsoffizieren auf französisch unterhalten haben, und die Pastoren Stolberg (Vater und Sohn) konnten ebenfalls Französisch schreiben.

\section{Stollberg sen.}

Johann Paul Stollberg wurde am 27. Mai 1701 in Günstedt im Landkreis Sömmerda des heutigen Freistaates Thüringen geboren. Er studierte in Halle und Jena und trat 1727 seine erste Stellung als Rektor der Stadtschule in Hardegsen an. 1728 wurde er zum Cantor figuralis ${ }^{21}$ ans Göttinger Pädagogium berufen, als Lehrer, der neben den anderen Lehrfächern für Musik und Gesang zuständig war. In dieser Funktion hatte er auch für die Vokal- und Instrumentalmusik an allen Göttinger Kirchen zu sorgen. Vermutlich wollte er sich auf Dauer in Göttingen niederlassen, denn er erwarb am 27.2.1731 das Bürgerrecht. ${ }^{22} 1734$ übertrug man ihm die Stelle eines Subkonrektors der Stadt- (bzw. Rats-) Schule, da das Pädagogium zugunsten der Universität aufgelöst wurde. 1735 erhielt er die Predigerstelle an St. Crucis. ${ }^{23}$ Ein Jahr

19 Bielefeld 1957, S. 55-61.

20 KiKrAGött, Dramfeld B. 1 Amt Reinhausen, um 1738.

$21 \mathrm{Zu}$ den Aufgaben eines Figuralkantors siehe Garbe und Wiechert in: GöJb 37, 1989, S. 71-90.

22 Wellenreuther 1988, S. 395.

23 Gemeint ist die Kirche zum Heiligen Kreuz (auch Heilig Kreuz Kirche), die 1395 von der Mutterkirche St. Albani abgesondert und zur Pfarrkirche erboben wurde (BEER, in: GöJb 32, 1984, S. 94). Sie stand mit dem Armenhospital auf dem Grundstück des später erbauten Accouchirhauses, Kurze Geismarstr. 40. Die Heilig Kreuz Kirche gehörte nicht zu den fünf Stadtkirchen Göttingens. Die Gemeinde wurde 1803 aufgelöst und die Kirche in den Jahren 1783-1785 in Teilen abgebrochen, um Material für den Bau des Chemischen Laboratoriums zu gewinnen (BEER, in: GöJb 32, 1984, S. 95). Das Vermögen des Hospitals soll noch 1937 in Form einer Stiftung vorhanden gewesen sein (SAATHOFF, T. 1, S. 153ff). 
später erwarb er den Magistergrad und wurde 1737 an die Marienkirche ${ }^{24}$ nach Obernjesa berufen. 1729, ein Jahr nach seiner Berufung nach Göttingen, heiratete er die Tochter des Göttinger Ratsherrn Henkeln, mit der er fünf Kinder hatte. Er starb im Alter von 60 Jahren nach 22-jähriger Amtszeit am 13. März 1761 in Obernjesa.

\section{Stolberg jun.}

Der Sohn, Heinrich Philipp Stolberg, wurde 1733 noch in Göttingen geboren. Er studierte in Göttingen und wurde Hauslehrer bei einem Baron von Oeynhausen in der Nähe von Paderborn. 1759 machte er sein Examen in Hannover und bewarb sich als Adjunkt des Vaters. Er hat u. a. die Pläne für den Umbau der Dramfelder und Obernjesaer Kirche erarbeitet, die Kosten dafür veranschlagt und die Bauzeichnungen angefertigt. ${ }^{25}$ In der Pfarrchronik erwähnt er von seinen Bauprojekten allerdings lediglich den Bau eines Brunnens und den Bauantrag für eine Sakristei in Dramfeld. Neben dem Pfarrland bewirtschaftete er zeitweise auch Kirchenland. Er war mit einer Tochter des Göttinger Ratsherrn Joachim Winiker verheiratet; wie Quittungen über Zinszahlungen für Kredite an die (Kirchen-)Gemeinde ausweisen, war Frau Stolberg offensichtlich nicht unvermögend und konnte Geld verleihen. ${ }^{26}$ Das Ehepaar hatte neun Kinder. Pastor Stolberg starb am 1. November 1783 im Alter von 50 Jahren - wie sein Vater nach 22 Jahren Amtszeit.

\section{Friedrich Christoph Gräffe}

Der Nachfolger Pastor Stolbergs Friedrich Christoph Gräffe (auch Graeffe) hat zwar aus nicht erkennbaren Gründen keinerlei Eintragungen in die Pfarrchronik vorgenommen; doch belegen die Akten im Kirchenkreisarchiv, dass er seinen Amtspflichten genau so wie seine Vorgänger nachge-

24 Da sich bei Meyer (S. 215) die Eintragung: Obernjesa: St. Johannes (Mitteilung von D. Hennecke) findet, wird die Obernjesaer Kirche gelegentlich auch als Johanneskirche bezeichnet.

25 KLeineke, D.: Zur Reparatur- und Baugeschichte der Dramfelder Kirche, GöJb 63, 2015, S. 45, 46, Anm. 41. Siehe auch Амт, S. 5, der erwähnt, dass Pastor Stolberg (jun.) Entwürfe zum Neubau der Kirche in Dankelshausen und Lenglern vorgelegt habe.

26 Zum Beispiel: KiKrAGött, P. A. Obernjesa Kirchenrechnungsbelege von 1780. 
gangen ist. Darüber hinaus erlaubt eine vor einigen Jahren erschienene Monographie einen genaueren Blick auf seine bemerkenswerte Karriere. ${ }^{27}$

Er wurde am 15. Februar 1754 als Sohn eines Unteroffiziers in Göttingen geboren und starb nach mehreren Schlaganfällen am Reformationstag 1816 im Alter von 62 Jahren in Göttingen. ${ }^{28}$

Nach dem Besuch des Göttinger Gymnasiums studierte er an der Georgia Augusta Theologie; daneben hörte er griechische Literatur, Metaphysik und Mathematik. Es heißt, dass er anfangs wiederholt überlegt habe, ob er Geistlicher oder Soldat werden solle. Nach Studienende arbeitete er acht Jahre als Hauslehrer, bis er 1783 mit 29 Jahren sein Examen pro candidatu$r a$ in Hannover ablegen konnte. Bei dieser Gelegenheit wurde der Abt des Klosters Loccum auf ihn aufmerksam und holte ihn als Hospes [Gastschüler] nach Loccum. Auf Empfehlung dieses Abtes wurde Gräffe 1784 vom Superintendenten Ch. J. Luther in Obernjesa eingeführt.

Während der Amtsjahre in Obernjesa veröffentlichte er bereits mehrere Aufsätze über das Katechetisieren, in denen er seine Erfahrungen mit der eigenen Gemeinde verarbeitet haben soll. Schließlich wurde er im Oktober 1792 auf die Pfarre von St. Nikolai in Göttingen berufen. 1803 wechselte er zu St. Albani, da die Nikolaigemeinde aufgelöst wurde. Im selben Jahr wurde er Superintendent der Inspektion Göttingen III.

Da seine akademische Karriere als Lehrbeauftragter für Katechetik seit 1792 sowie seine Probleme mit der Göttinger theologischen Fakultät und dem Konsistorium in der oben zitierten Monographie detailliert beschrieben werden, sei hier nur vermerkt, dass er 1794, mit 40 Jahren, in Göttingen die philosophische Magisterwürde erwarb und 1797 zum theologischen Doktor an der Universität Helmstedt promoviert wurde. Nach seiner Einführung in Obernjesa/Dramfeld heiratete Gräffe eine Pastorentochter aus dem Lüneburgischen; das Ehepaar hatte jedoch keine Kinder. In einem Lebenslauf beschrieb Pastor Gräffe die Jahre als Landpfarrer in Obernjesa als eine besonders glückliche Zeit. ${ }^{29}$ Doch muss diese Aussage bezweifelt

27 Tütken, Johannes: Privatdozenten, S. 572-595.

28 Diese und die weiteren Informationen wurden - teilweise wörtlich - aus der o.g. Monographie von Johannes Tütken entnommen.

29 UAG, Phil. Dek. 78, Nr. 3: Nachdem ein Jahr und sechs Monate vergangen sind, seit mir die Güte unseres gnädigsten Königs die Pflicht des Amts eines Pastors von Obernjesa 1784 übertrug, habe ich hier glücklich gelebt, umgeben von einem Überfluß an Bequemlichkeiten, welche das Leben sehr angenehm machen, die Gegend ist sehr fruchtbar an Blumen, Wiesen, Bächlein, Bäumen und Früchten und mit Denkmälern geschmückt, sehr gesund wegen der Milde des Klimas, für die Stärkung der Körper- und Seelenkräfte bestens geeignet, die woblbegabten Schüler zeichnen sich durch Geborsam aus, die Nachbarschaft der Freunde ist sehr erfreulich, die Einkünfte sind genügend groß, meine Frau kann ich nicht genügend loben. An Büchern, die zu besorgen mir die berübmten 
werden, da er sich während dieser Zeit vier Mal vergeblich auf eine andere Pfarrstelle bewarb; zum einen, um eine mit weniger Arbeit verbundene Gemeinde, zum andern, um finanzielle Verbesserungen zu erlangen, die es ihm erlauben würden, sich die Bücher selber zu kaufen, die entweder in Göttingen nicht vorhanden oder ständig ausgeliehen waren. Das lässt sich mit schriftlichen Äußerungen Pastor Gräffes belegen, z.B. mit den Antworten auf Monita an den Kirchenrechnungen. Auf die Aufforderung, die Liste der Zinsschuldner rechtzeitig bei den Kirchenkommissarien einzureichen, antwortete er selbstbewusst, dass er die Gelegenheit, an bestimmte Bücher heranzukommen, wahrnehmen müsse sobald sie sich biete, und die Verwaltungsarbeit dann zurückstehen müsse. ${ }^{30}$ An anderer Stelle bat er in den ihm eigenen gewählten Worten darum, dass die sogenannten Mahlzeitgelder erhalten blieben, da ihn dieses Douceur in den Stand setzte, jäbrlich ein Buch mehr anschaffen zu können. ${ }^{11}$ Dass er dies tatsächlich getan hat, belegt der gedruckte Katalog zur Versteigerung seiner Bibliothek ein Jahr nach seinem Tod: er führte 1539 Titel auf.

\section{Johann Christian Friedrich Bornträger}

Johann Christian Friedrich Bornträger wurde am 4. Oktober 1759 als Sohn des Küsters an der Schlosskirche in Osterode geboren. Auch er studierte in Göttingen. Nach einem Aufenthalt als Hospes im Kloster Loccum erhielt er 1792 seine erste Pfarrstelle in Obernjesa, amtierte hier lediglich sechs Jahre und wurde 1800, nach der Aufteilung der Inspektion Münden II, im Alter von 41 Jahren Superintendent in Hedemünden; 1805 übernahm er die Superintendentur in Uslar. Er starb 1833 im Alter von 74 Jahren. ${ }^{32}$

Herren Heyne und Feder gütigerweise helfen, gibt es eine Menge. Meine Gesundheit und Kraft sind unerschöpflich und stabil. O wieviel kostbare Güter! O wie glücklich ich bin, dem die göttliche Vorsehung so viel Wobltaten anhäufte..

30 KiKrAGött, P. A. Obernjesa K. R. I.a. 5, 1787-1789; hier Kirchenrechnung für 1787/1788, ad Mon. 2.

31 A.a.O, hier Kirchenrechnung für 1787/1788, ad Mon. 1 des Konsistoriums auf die Rechnung vom Jahr 1786. Bereits Magister Stollberg hatte beklagt, dass die Einkünfte der Pfarre nur das Nötigste deckten [110v] - ganz abgesehen davon, dass er viel mehr Arbeit als seine Kollegen habe [126].

32 Vermutlich in Stolzenau. 


\section{Johannes Friedrich Proffen}

Der vierte Chronist der Obernjesaer Pfarrchronik, Johannes Friedrich Proffen, wurde am 5. Januar 1746 als Sohn des Stadtbraumeisters in Einbeck geboren. Er studierte ebenfalls in Göttingen und erhielt 1779 seine erste Pfarrstelle in Wulften. Von dort kam er 1798 zweiundfünfzigjährig nach Obernjesa $^{33}$ und amtierte hier 21 Jahre lang bis 1819.

Er war zweimal verheiratet, in zweiter Ehe mit der Tochter des Pastors Thilo aus Landolfshausen. Das Ehepaar hatte fünf Kinder. Er scheint ein überaus sparsamer Mann gewesen zu sein, denn seine Eintragungen in der Chronik fallen vor allem durch die Akribie auf, mit der er die Seiten füllte. Die Aussage des Superintendenten, Pastor Proffen sei vor allem an theologischen Studien interessiert gewesen und habe behauptet, keine Zeit für anderes zu haben, ist nicht zu belegen, da sich bisher nichts Einschlägiges aus seiner Feder fand..$^{34}$ Merkwürdig an seiner Amtsführung erscheint, dass er - im Gegensatz zu seinen Vorgängern - nicht die Kirchenrechnung von Dramfeld geführt hat, und das Inventar der Gegenstände, die er als Pastor aufbewahrte, zeitweise vom Kollegen Schlie aus Klein Schneen abzeichnen ließ ${ }^{35}$

Auch lässt sich bisher nicht erklären, warum Pastor Proffen seine Eintragungen in die Chronik - mitten im Satz - mit der Besetzung Danzigs am 26. Mai 1807 beendete. In der Literatur heißt es, dass die durch die westphälische Regierung ${ }^{36}$ herbeigeführten Änderungen erheblich in die überkommenen kirchlichen Verbältnisse eingegriffen hätten. Für die kirchliche Verwaltungshierarchie bedeutete dies u. a., dass ab dem 17. Dezember 1807 das neugegründete Göttinger Konsistorium und nicht mehr das in Hannover zuständig war. Ob Pastor Proffen auch zum Kreis der Geistlichen gehört hat, die durch die französische Besetzung und die Gründung des neuen Staates in einen kaum lösbaren Loyalitätskonflikt versetzt worden waren, ließ sich aus den erhaltenen Unterlagen bisher nicht erschließen; sie zeigen lediglich, dass er die Amtsgeschäfte in der gewohnten Weise weitergeführt hat. ${ }^{37}$

33 HStAH, Hann. 83III Nr. 417 II, S. 467, 468.

34 Bielefeld 1957, S. 60.

35 Vgl. z. B. KiKrAGött P. A.Dramfeld K. R.I.a. 7 (1812).

36 Kaiser Napoleon verfügte am 18. August 1807 die Bildung des Königreichs Westphalen mit der Hauptstadt Kassel (HammanN, in: Göttingen Bd. 2, S. 558).

37 Hammann, K.: Geschichte der ev. Kirche in Göttingen, in: Gö Bd. 2, S. 559. Bielefeld weist im Zusammenhang mit dem kirchlichen Leben darauf hin, dass die Kirchenvisitationen von etwa 1800 bis 1850 ganz ausgesetzt und durch jährliche Kirchen- und Schulberichte ersetzt worden waren. Bielefeld 1957, S. 69. 


\begin{tabular}{|c|c|c|c|}
\hline Pastor & Lebenszeit & Amtszeit & Eintragungen \\
\hline $\begin{array}{c}\text { Mag. Joh. Paul } \\
\text { Stollberg }\end{array}$ & $1701-1761$ & $1737-1761$ & $\begin{array}{c}1737-1757 \\
{[108-145]}\end{array}$ \\
\hline $\begin{array}{c}\text { P. Heinr. Phil. } \\
\text { Stolberg }\end{array}$ & $1733-1783$ & $1761-1783$ & $\begin{array}{c}1761-1768,1775 \\
{[145 \mathrm{v}-160 \mathrm{v}, 162-166]}\end{array}$ \\
\hline $\begin{array}{c}\text { D. Joh. Friedr. } \\
\text { Christ. Gräffe }\end{array}$ & $1754-1816$ & $1784-1792$ & keine \\
\hline $\begin{array}{c}\text { P. Joh. Christ. } \\
\text { Bornträger }\end{array}$ & $1759-1833$ & $1792-1798$ & $\begin{array}{c}1794-1797 \\
{[166 \mathrm{v}-176 \mathrm{v}]}\end{array}$ \\
\hline $\begin{array}{c}\text { P. Johs. Friedr. } \\
\text { Proffen }\end{array}$ & $1746-1835$ & $1798-1819$ & $\begin{array}{c}1798-1807 \\
{[176 \mathrm{v}-199]}\end{array}$ \\
\hline
\end{tabular}

Tabelle 1: Amts- und Lebenszeiten der fünf Pastoren: Die Zahlen in den eckigen Klammern geben die vom Landeskirchenarchiv gestempelten Seitenzahlen der Pfarrchronik wieder.

\section{Die kirchliche und die weltliche Verwaltung}

\section{Das Konsistorium}

Das Konsistorium, von dem in der Chronik wiederholt die Rede ist, war die den Geistlichen vorgesetzte staats-kirchliche Verwaltungsbehörde, die 1636 vom Landesherrn für die Verwaltung des Kirchen- und Klostergutes sowie für die Ehegesetzgebung geschaffen wurde. ${ }^{38}$ Das Konsistorium residierte in der Landeshauptstadt Hannover. Seine Mitglieder waren sowohl Juristen als auch Theologen.

Das Konsistorium war die Behörde, die Anträge für Kollekten genehmigte oder ablehnte oder selber ausschrieb; es war die Behörde, die die Bautätigkeit der Kirchengemeinden überwachte, die Baupläne und Kostenvoranschläge prüfte ${ }^{39}$, kritisierte und genehmigte; die Behörde, die Neubesetzungen von Pfarrstellen oder Versetzungen von Pastoren veranlasste; die Bußtage, Feiern und öffentliche Gebete verordnete; die sich um das Schulwesen kümmerte und eingehend die Jahresabrechnungen der Gemeinden kontrollierte. Das Konsistorium informierte die Superintendenten und diese wiederum die Pastoren durch Circulare; Entscheidungen bzw. Gebote des Konsistoriums ergingen in Form von Rescripten und Decreten.

38 Krumwiede Bd. 1, S. 116, 130, 192.

39 Kleineke, D.: Zur Bau- und Reparaturgeschichte der Dramfelder Kirche, S. 43ff., siehe die Umbaumaßnahme 1776/77. 


\section{Die Superintendenten}

Mit dem Anfange dieses Jahrs 1742 sind

Herr Pastor Appubn zu Göttingen

und der H. Mag. Hartel Pastor zu

Siboldeshausen über die Mündische In-

spektion Superintendenten geworden.

Der H. Sup. Appubn hat die Leine-

dörffer sammt der Stadt Dranßfeld

bekommen, und der H. Mag. Sup. Har-

tel die ubrigen Dörffer, weil der

H. Superintendens Hagemann zu Mün-

den sebr alt und schwach ist. Obernjesa

ist auf eine Zeitlang anstatt Siboldeshausen

dem Hn. Sup. Doct. Riebow gegeben und

dem Hn. Sup. Appubn für Obernjesa Bühren vor

der (!) Walde gegeben worden, bis der

Herr Pastor und Senior Mengers-

hausen zu Hedemünden nach Gottes

Willen verstirbet, als denn ziehet

der H. Sup. M. Hartel nach Hede-

münden, Siboldeshausen kommt wie-

der an den Hn. Sup. Doct. Riebow

Obernjesa wieder an den Hn. Sup.

Appubn, und Bübren wieder an

den Hn. Sup. M. Hartell. ${ }^{40}$

Da man im Berichtszeitraum einen Rubestand nicht kannte, somit die Amtszeit eines Pastors, auch eines Superintendenten, erst mit dessen Tod endete, war der Geistliche - wenn er alt und gebrechlich wurde - darauf angewiesen, dass die Kollegen seine Amtspflichten ganz oder zum Teil übernahmen oder ihm ein Hilfsgeistlicher zur Seite gestellt wurde. Wie zum Beispiel dem Obernjesaer Pastor Blauel, der von 1820 bis 1862 amtierte $^{41}$, und dem gegen Ende seiner Amtszeit nacheinander zwei Kollegen, die Herren Günther und Breigel, als Hilfspastoren zur Seite gestellt wurden. ${ }^{42}$ Die oben zitierte

\footnotetext{
40 Pfarrchronik [114v].

41 Bielefeld 1957, S. 61.

42 KiKrAGött, P. A. Dramfeld Dr.A 512, 1852 und 1855.
} 
Eintragung in die Pfarrchronik zeigt, dass die kollegiale Übernahme von Amtspflichten ein kompliziertes Vertretungskarussel in Bewegung setzte.

Da die Sprengel oder Inspektionen, d.h. die Amtsbereiche der Superintendenten, im Laufe der Jahrhunderte mehrfach umgebildet wurden, finden sich unterschiedliche Angaben über die Zugehörigkeit der Kirchengemeinde Obernjesa/Dramfeld zu einer Inspektion. 1734 gehörte die Pfarre noch zur Göttingischen Inspektion ${ }^{43} ; 1744$ zur Inspektion Münden II. Teil, 1796 bis 1801 zur Inspektion Göttingen I. Teil, ab 1802 zur Inspektion Göttingen III.Teil. ${ }^{44}$

Die Superintendenten residierten immer an einer der Göttinger Kirchen; grundsätzlich galt (seit 1610), dass die Inhaber der 1. Pfarrstelle an St. Johannis in Göttingen die Superintendenten der Stadt Göttingen und gleichzeitig die Superintendenten eines ländlichen Aufsichtsbezirks wie Münden oder Göttingen Land waren, in verschiedenen Perioden auch die Generalsuperintendenten des Fürstentums Göttingen stellten. ${ }^{45}$ Allerdings scheint es - wie auch aus der Pfarrchronik hervorgeht (s.o.) - kurzfristig Veränderungen gegeben zu haben.

\section{Die weltliche Verwaltung}

Kirchliche und staatliche Verwaltungsbeamte kontrollierten als Kirchenkommissarien gemeinsam das Leben in den Gemeinden; der vom Landesherrn ernannte Geistliche, der Superintendent, und der weltliche Beamte, der Amtmann, also letztlich beides Beamte des Staates, wurden - wie es heißt - zu Instrumenten für die Durchsetzung der Reformation, in der Hand der Obrigkeit lagen Visitation, Kirchenordnung und Kirchenbehörde. ${ }^{46}$ In der Praxis bedeutete dies u. a., dass die landesherrlichen Verordnungen in den Abkündigungen des Gottesdienstes verlesen werden mußten, und damit (...) die Kanzel zum Medium der Herrschaft der weltlichen Obrigkeit über die Untertanen (wurde). ${ }^{47}$

Die Dörfer, die in einem Sprengel zusammengefasst waren, konnten durchaus zu verschiedenen Ämtern gehören: Während die Filialgemeinde

43 KiKrAGött, Sup. Spez. Obernjesa/Dramfeld I. 2.b. Corpus Bonorum Templi Dramfeldensis für die Superintendentur in Göttingen. [1734] Pag. 1 (...) Das Filial Dramfeld davon die MutterKirche Obernjesa ist, lieget in der Göttingischen Inspection und geböret in das Amt FriedLand, ist von der Mutter Kirche 3 ttel stunde entfernt.

44 Vgl. Kirchen-Register der Kirche zu Dramfeld für die entsprechenden Jahre (KiKrAGött, P.A. Dramfeld K.R.I.a. 6).

45 Meyer, Pastoren, S. 327

46 Krumwiede, S. 186.

47 A.a.O., S. 187. Vgl. auch Schlegel 1. Teil, S. 161. 
Dramfeld von jeher unter der Jurisdiktion des Amtes Friedland gestanden hat, gehörte Obernjesa zu Beginn der Amtszeit von Magister Stollberg zum Amt Münden; ab 1743 zum Gericht Leineberg, das 1832 in Amt Göttingen umbenannt wurde. Seit 1852 gehörte Obernjesa (ebenso wie Dramfeld) zum Amt Friedland. ${ }^{48}$

Die Überprüfungen der Kirchengemeinden fanden regelmäßig im Rahmen der Kirchenvisitationen statt; maßgeblich war der jeweilige Amts- bzw. Gerichtsbezirk. ${ }^{49}$ Fand die Visitation in Obernjesa statt, reisten der zuständige Mündener Amtshauptmann bzw. der Gerichtsschulze vom Gericht (Amt) Leineberg und der zuständige Superintendent (Inspektion Münden II, oder St. Johannis I oder St. Albani), nach Obernjesa, besuchten den Gottesdienst des Geistlichen, überprüften die Jahresrechnungen der Kirchengemeinde, genehmigten Anträge ${ }^{50}$, fragten die Gemeindemitglieder, ob es aus ihrer Sicht Probleme gebe - und ließen sich anschließend von der Gemeinde gut bewirten. Die Kosten der Visitationsmahlzeit waren zwar nicht immer so hoch wie die von 1749; doch da die für dieses Jahr erhaltene Einkaufsliste einen Blick auf die Gastlichkeit gewährt, die die Teilnehmer der Visitation geschätzt haben müssen, soll sie an dieser Stelle folgen. ${ }^{51}$

[Siehe Tabelle 2]

Specification der am 29 Maji 1749 zu Dramfeld abgehaltenen

Kirchen-Visitations Kosten. Summa 19rth. 29g. $5 d$

[Wie ein weiterer kleiner Zettel belegt, wurden noch Gewürze, Kaffee und Tabak bestellt, siehe Tabelle 3]

48 Wolters, S. 58.

49 Von Zeit zu Zeit wurden mehrere Dörfer eines Gerichtsbezirks an einem einzigen Termin visitiert, so dass die Dramfelder Rechnung z. B. in Klein Schneen oder in Sieboldshausen präsentiert werden musste.

50 Z.B. Anträge auf Rückzahlung von Krediten bei der Kirche (KiKrAGött, P. A. Dramfeld K.R.III.1, 12. August 1764), oder ein Antrag des Pastors Stolberg vom 27. Mai 1774, neue Evangelienbücher in normaler und in großer Druckschrift anschaffen zu dürfen, der ihm während der Visitation am 16. September 1774 genehmigt wurde (KiKrAGött, P. A. Dramfeld K. R. III, Belege 1734-1788, Beleg No. 20).

51 KiKrAGött, P.A.Dramfeld K. R. III. 1 Belege 1734-1788.

52 Broyhan, gutes Göttinger Bier. 
Rechnung, was Herr Busse bey der am 29t. Maji 1749 zu Dramfeld abgebaltenen Kirchen-Visitation ausgegeben.

\begin{tabular}{|c|c|c|c|}
\hline & Taler & Groschen & Pfennige \\
\hline $41 / 3 \widetilde{m}$ Fische à $6 g$. facit & - & 24 & - \\
\hline Für Sallath & - & 1 & 4 \\
\hline $4 \widetilde{B b}$ Butter & - & 20 & - \\
\hline Semmeln für & - & 2 & - \\
\hline Redibe [Rettiche] für & - & 1 & - \\
\hline $12 \widetilde{\not b}$ Rindfleisch à $22 d$ facit & - & 33 & - \\
\hline $12 \widetilde{B}$ Schweinefleisch à 22d facit & - & 33 & - \\
\hline $6 \widetilde{b}$ Kalbfl. à $20 d$ & - & 15 & - \\
\hline Für Töpfe & - & 15 & 4 \\
\hline $\begin{array}{l}\text { Für einen Tisch aus Lütgen Schneen } \\
\text { abzuboblen }\end{array}$ & - & 2 & - \\
\hline 2 Hübner aus der Müble & - & 12 & $v$ \\
\hline 2 Haasen & - & 24 & - \\
\hline Für Holtz & - & 4 & - \\
\hline Eyer für & - & 3 & - \\
\hline $1 / 2 \widetilde{t}$ Speck & - & 3 & - \\
\hline Saltz für & - & 1 & - \\
\hline $2 \widetilde{B}$ Hirsen & - & 4 & - \\
\hline 25 Kannen Bier aus dem Kruge & - & 31 & 4 \\
\hline 5 Bouteillen Breyban ${ }^{52}$ à 10 Kannen & - & 12 & 4 \\
\hline 1 Kanne Brantwein & - & 11 & - \\
\hline Johannis Lauch à & - & 6 & - \\
\hline 2 Kannen Milch & - & 3 & - \\
\hline 2 Pfund Zwetschen & - & 3 & - \\
\hline $\begin{array}{l}\text { Der Frau Bussen für ibre Mübe und } \\
\text { Reinigung des Tischzeuges }\end{array}$ & 1 & - & - \\
\hline Summa & 8 & 13 & - \\
\hline
\end{tabular}

Daß mir der H. Mag. Stollberg diese 8rth. u. 13g. richtig bezablet habe; Solches wird Durch meine UnterSchrift attestiret und quitiret.

Geschehen Dramfeld den 1Junii 1749.

Ernst Busse

Tabelle 2. Quelle: KiKrAGött, P.A. Dramfeld K. R. III. 1 Belege 1734-1788 
Herr Gevatter Hildebrand sey so gut und schicke mir zur Dramfeldischen Kirchen-Visitation folgendes:

\begin{tabular}{|c|c|c|c|}
\hline & Taler & Groschen & Pfennige \\
\hline $35 / 8$ ד recht guten Zucker .. $10 \mathrm{~g}$ & 1 & - & 2 \\
\hline 1 דo Caffee & - & 16 & - \\
\hline 1/2 loth Muscaten Blumen & - & 3 & - \\
\hline 1/2 loth Canneel gestossen & - & 1 & 4 \\
\hline 1/2 loth gantze Nägelcken & - & 3 & - \\
\hline 1 loth gantzen Ingwer & - & - & 2 \\
\hline 1 loth gestossenen Ingwer & - & - & 2 \\
\hline 4 loth Pfeffer Körner & - & 2 & 4 \\
\hline $1 / 2 \widetilde{\pi}$ grosse $1 / 2 \widetilde{B}$ kleine Rosinen & - & 4 & - \\
\hline $1 / 2 \widetilde{\pi}$ Mandeln & - & 4 & 4 \\
\hline Lorber Blätter & - & - & 4 \\
\hline 1 Citrone & - & 2 & - \\
\hline $1 \widetilde{R}$ Reij & - & 3 & - \\
\hline 1 历o weisse Stärcke & - & 3 & - \\
\hline 1/2 ש Baumöbl ${ }^{53}$ & - & 3 & - \\
\hline 1 Quartier guten Essig & - & - & 5 \\
\hline 12 lange Pfeiffen & - & 9 & - \\
\hline 1 Paquet gelben Toback & - & 2 & 2 \\
\hline
\end{tabular}

zu Danck bezahlt./.3r. 22g. 5d ObernJesa am 28tn Maji 1749 M. JPStollberg.

Tabelle 3. Quelle: KiKrAGött, P.A.Dramfeld K. R. III. 1 Belege 1734-1788

53 Olivenöl. 
War eine Kirchenvisitation in Dramfeld angesetzt, erschienen der Amtmann (auch Amtshauptmann oder Drost genannt) des Amtes Friedland und der jeweils zuständige Superintendent der Mündener bzw. Göttinger Inspektion. Kirchliche und weltliche Verwaltung hatten zusammen zu arbeiten; auf dem Wege der Berichtspflicht ${ }^{54}$ und mittels des Dienstweges, der vom Kirchenvorstand über den Pastor zum Superintendenten und Amtmann führte, von dort zum landesherrlichen Konsistorium in Hannover - und zurück, waren alle Ebenen in die Verwaltungshierarchie eingebunden. Dass es aber auch Ausnahmen von der Regel gab und beispielsweise einzelne Maßnahmen auf einem kurzen Dienstweg bewilligt werden konnten, lässt sich am Beispiel des Kostenvoranschlages von 1752 für eine Reparatur von Kirche und Turm in Dramfeld erkennen. Der seinerzeit amtierende Magister Stollberg beschwor seine Vorgesetzten, die Reparatur zu genehmigen, indem er unter der Zusammenstellung der Kosten notierte: Die Herren Kirchen-Commissarien werden gehorsamst ersuchet, durch Unterschrift diese höchst nöthige Reparation zu genehmigen. Damit dem gäntzlichen Ruin des Thurms, der Kirche und grössere Unkosten möge vorgebeuget werden. Und betonte, dass er mit den Handwerkern hart verhandelt hatte: Zeitiger Prediger hat aufs allergenaueste mit den ArbeitsLeuten contrabiret. Dramfeld am 30tn Dec. 1752.

Die damals amtierenden Kirchenkommissarien, Superintendent Riebow und Amtmann Hartmann, genehmigten die Maßnahme (unter Berücksichtigung der Feiertage) innerhalb von zwei Wochen: Weill periculum in mora ${ }^{5}$; So werden obige Einundfünfzig Rthlr. hiemit bewilliget, und wolle der Herr Magist. Stollberg nebst den Altaristen obigen Bau besorgen, auch nachbero die davon gefübrte Rechnung mit ibren Belegen zu der Kirchen-Commission einsenden. Friedland den 17. Jan. 1753. ${ }^{56}$

\section{Die Pastoren - ihre Stellung}

Kraft ihres Amtes gehörten die Pastoren zwar zu den angesehenen Personen im Dorf - ihre Tätigkeit aber - ebenso wie die der gesamten Kirchenverwaltung - war durch eine Vielzahl von Vorschriften, Verordnungen und

54 SChlegel, 2. Teil, S. 515, 516; 1t. Consistorial Ausschreiben vom 31. August 1736 werden Kirchen- und Schulberichte eingeführt. Magister Stollberg musste im Dezember 1748 12g zahlen, weil er den Auszug aus den Kirchenregistern von 1747 nicht rechtzeitig eingereicht hatte [124].

55 Gefahr bei Verzögerung.

56 KiKrAGött, P. A. Obernjesa Dr. A. 512. 
Gesetzen reglementiert. ${ }^{57}$ Darunter fällt auch, dass die Dienstkleidung, der Kirchenmantel bzw. der Chorrock, von der Kirche bezahlt wurde, Eigentum der Kirche war, und infolgedessen im Inventar aufgeführt wurde. ${ }^{58}$ Allerdings konnten 50 Jahre vergehen, bis einmal ein neuer Mantel angeschafft wurde, und dies auch nur nach vorhergehender Genehmigung durch die Kirchenkommission. Bis es soweit war, wurde das Kleidungsstück verschiedentlich repariert und gewendet: Hochverordnete Kirchen Commission, Wird hiedurch gehorsahmst ersuchet, nachdem der 1713 angeschafte Kirchen-Mantel nunmehro gantz ausgebrauchet, Hochgeneigt zu verwilligen: daß von dem Kirchen Vorrabte wiederum ein neuer angeschaffet werden möge. Supplic. Dramfeld den 21tn Febr. 1769. Henrich Phil Stolberg. ${ }^{59}$

Wenn der Pastor das Schulgeld für arme Kinder aus der kirchlichen Armenkasse oder von den Zinsen einer Stiftung auszahlen wollte, musste er zuvor das schriftliche Einverständnis des Superintendenten einholen, und zwar jedes Jahr aufs neue, separat für jede Kirchengemeinde, und dies in der Jahresabrechnung belegen: Nach dem Willen der Frau Mag. Sieburg als Stifterin eines Legati von 20rth bey Dramfeldischer Kirchen Cassa, sollen von den aufkommenden Zinsen alle Jahre 2 arme Schulkinder frey unterrichtet werden; Diesem zu folge erbitte ich mir von des Herrn Superintendenten Luther Hochehrwürden eine hochgeneigte Bewilligung 1. Für Georg Friedrich Fischer 18g. 2. Für Christina Elisabeth Hartung 18g. als kundbahr arme Schul-Kinder auf das Winter halbe Jahr von Michaelis 1773 bis Ostern 1774 für ibren Schulunterricht. ${ }^{60}$

Unter anderem wurde auch der Verbrauch von Schreibpapier dem Pastor - wie auch dem Lehrer - begrenzt: Die mir allergnädigst vom Königl. Consistorio verwilligten $12 \mathrm{mg}$. für Schreibmaterialien zu Berichten in Amts-Sachen... ${ }^{6}$

Ob die Pastoren die Meinung ihrer Obrigkeit teilten, vielleicht sogar die Notwendigkeit der Erlasse einsahen, lässt sich nur ein einziges Mal aus den Eintragungen herauslesen: Magister Stollberg scheint davon überzeugt gewesen zu sein, dass die Pietisten einen verderblichen Einfluss ausübten; nachdem er mehrere landesherrliche Verordnungen gegen die Pietisten

57 Vgl. u. a. die fünf Bände Churhannöversches Kirchenrecht von Johann Karl Fürchtegott SCHLEGEL.

58 KiKrAGött P. A. Dramfeld K. R. I. a. 7, 1810.

59 KiKrAGött P.A.Dramfeld K. R. III. 1 Belege 1734-1788.

60 A.a.O., hier 1774. Dasselbe gilt für Obernjesa.

61 A.a.O., Belege 1774, Beleg Nro. 17 und 18; in derselben Akte findet sich eine Konsistorialverfügung vom 11. Februar 1772, die eine Höchstgrenze von 9g für alltägliche Schreibarbeit vorgibt. 
kommentarlos vermerkt hatte, lautet die Eintragung der Verordnung vom 31. Oktober $1740^{62}$ bezeichnenderweise: Den 17 Dec. 1740 ist abermahl eine Verordnung unterm 31 Oct. 1740 ergangen, wegen der Pietisten, Indifferentisten ${ }^{63}$ und ander Teuffels Geschmeiß darinnen etliche Kennzeichen ihrer irrigen Lehre angegeben worden. ${ }^{64} \mathrm{Im}$ Gegensatz dazu enthielt sich Pastor Proffen jeden Kommentars als er ordnungsgemäß eintrug, dass die Lektüre der Professoren Fichte und Niethammer bei Strafe von 50 Thalern verboten sei; er vermerkte allerdings, dass für Fachleute wie Pastoren und Amtsanwärter geschmeidigere Regelungen vorgesehen waren: Sie wurden zu sorgfältiger Prüfung und vorsichtigem Gebrauch dieser Schriften angehalten und aufgefordert, diese verbreiteten schädlichen und gefäbrlichen Grundsätze zu widerlegen. ${ }^{65}$

\section{Zu den Themen der Einträge}

\section{Grenzstreitigkeiten}

Die Geistlichen waren zwar studierte Männer, die wie Magister Stollberg den Gebrauch der lateinischen Sprache pflegten und schätzten ${ }^{66}$, und sich mit Ausnahme von Pastor Proffen - als Autoren theologischer Schriften durchaus einen Namen gemacht haben; aber alle - außer Pastor Bornträger bewirtschafteten einen mehr oder weniger großen Teil des Pfarrlandes selbst und mussten sich häufig mit ihren Feldmarks- und Wiesennachbarn auseinandersetzen, die offenbar keine Gelegenheit ausgelassen haben, um den Pfarrer zu schädigen; sei es, dass sie regelmäßig über die Grenzen hinaus ins Land der Pfarre und der Kirche hinein pflügten ${ }^{67}$ sei es, dass sie den Pastor um das ihm zustehende Holz betrügen ${ }^{68} \mathrm{bzw}$. ihm die fälligen Gebühren

62 In einem Konsistorialausschreiben vom 31. Oktober 1740 wurden die hannoverschen Erlasse gegen die Pietisten zusammengefaßt (KRUMWIEDE Bd. 1, S. 230).

63 Hier ist die Gruppe derjenigen gemeint, die gegenüber Religion und Moral gleichgültig sind.

64 Pfarrchronik [114].

65 A.a.O. $[178 \mathrm{v}]$.

66 Z.B. Pfarrchronik [108v], [109], [110], oder [110v]: in der schriftlichen Auseinandersetzung mit dem Konsistorium wegen der sechs Morgen, die er an die Witwe des Vorgängers Lotzius abtreten muss, argumentiert er mit vielen lateinischen Zitaten aus dem Kirchenrecht.

67 Pfarrchronik [121], [167].

68 A.a.O. [185v], [186]. 
vorenthalten wollten oder versuchten, gewohnheitsrechtliche Ansprüche geltend zu machen. ${ }^{69}$

Pastor Stolberg (jun.) schrieb von Zeit zu Zeit Bemerkungen in die Kirchenrechnungen, um auf diese Weise das Konsistorium auf die Probleme aufmerksam zu machen; so zum Beispiel in die Dramfelder Kirchenrechnung von 1769, als die Neuverpachtung der Kirchenwiesen angestanden hatte: Außer diesem wäre nöhtig daß die Wiesen gemessen und versteiniget würden, maaßen die Gräntzen von den Nachbabren alle Jabre überschritten werden..$^{70}$

Obwohl die Amtsführung der Pastoren bis in alle Einzelheiten gesetzlich geregelt war, gab es immer wieder Vorschriften, die unterschiedlich ausgelegt werden konnten; ein Beispiel dafür findet sich in einem Konsistorial-Ausschreiben vom 8. Dezember 1801, in dem bestimmt wird, dass Pfarr-Grundstücke, [...] auf Kosten der Kirche versteint, oder durch Malsteine bestimmt [werden sollen], so weit es thunlich und rathsam ist (Hervorhebung D.Kl.), und darüber ein Riß nebst einer Beschreibung aufgenommen werden [soll], welche letzte von den Interessenten, den Gemeinden oder deren Vorstehern gerichtlich anzuerkennen und zu beglaubigen ist; damit diese Güter sowohl gegen Beeinträchtigungen der Nachbaren, als Vernachlässigungen der Inhaber gesichert werden. ${ }^{71}$

Angesichts der Vielzahl der Acker- und Wiesenstücke, aus denen sich seinerzeit der Grundbesitz von Pfarre und Kirche zusammensetzte, wundert es nicht, dass Grenzverletzungen zu häufigen Klagen Anlass gegeben und Grenzauseinandersetzungen zum Tagesgeschäft der Geistlichen gehört haben..$^{72}$ Es ist schließlich Pastor Stolberg (jun.) gewesen, der sich zwar nicht in der Pfarrchronik über seine Gemeinde beklagte, aber doch in einem Schreiben an den Superintendenten seine Erfahrung ausdrückte, dass die Bauern allgemein die Vermessungen hintertrieben: weil sie bey ungewißen Grentzen mehr Genuß haben, als bey gewißen, .... ${ }^{73}$ Anmerkenswert scheint noch, dass sich der Amtmann auf Kloster Mariengarten als Feldmarksnachbar des Pastors ebenso wie die Bauern verhielt, d.h. sich wenig kooperativ zeigte und die bereits vom Geometer Willig angefertigte Karte von der Mariengarter Feldmark und ihren Grenzen nicht zur Verfügung stellte. Schließlich schrieb Pastor Stolberg, dass es ihm ein Vergnügen ma-

69 Pfarrchronik [168, 168v]. Vgl. KiKrAGött, Sup. Spez. Obernjesa I. 4. b., 30. März 1794

70 KiKrAGött, P. A.Dramfeld K. R. I.a. Kirchenrechnungen 1765-1776.

71 Pfarrchronik [183v] (Vgl. Schlegel, 5. Teil, S. 238).

72 Vgl. KiKrAGött, P. A. Obernjesa A 410.

73 KiKrAGött Sup. Spez. Dramfeld I.2. b., Text von der Hand Pastor Stolbergs nach der Kirchenvisitation 1774. 
chen werde, nächstens einen Anschlag der Kosten, von der Vermeßung und Versteinigung der Wiesen und Länderey, welche es eben so nöbtig hat, ein zu liefern (Hervorhebung D.Kl.). ${ }^{74}$ Immerhin gibt es zu denken, dass bereits 1686 der Abt des Klosters Loccum beim Superintendenten nachfragte, was es mit den Klagen des Pastors Armbrecht (1684-1713) auf sich habe, dass es bei der Verpachtung des Kirchenlandes nicht mit rechten Dingen zugegangen sei. Er forderte den Superintendenten auf, die Angelegenheit gründlich zu untersuchen und Abhilfe zu schaffen. ${ }^{75}$

\section{Vergütung geistlicher Dienstleistungen (Gebühren)}

Ein Beispiel für den Versuch, dem Pastor Gebühren vorzuenthalten, findet sich in einer Eintragung aus dem Jahr 1800. Pastor Heinrich Christoph Schlie aus Klein Schneen hatte die Trauung eines Brautpaares (die Braut stammte aus Dramfeld) für den abwesenden Pastor Proffen vorgenommen, und der Bräutigam weigerte sich, die vom Geistlichen geforderte Traugebühr zu entrichten. Erst auf Anordnung des Leiters des Gerichts Leineberg brachte der Bräutigam Pastor Proffen die schuldige Summe ins Haus. ${ }^{76}$ Dem Pastor wäre es allerdings lieber gewesen, wenn er statt des Geldbetrages eine Naturalvergütung in Form der Hochzeitssuppe erhalten hätte. Um diese Form der Vergütung hat er mehrfach mit dem Konsistorium korrespondiert. ${ }^{77}$ Vor der Umwandlung in einen Geldbetrag gab es nämlich aus Dramfeld statt der Suppe ein Stück Rindfleisch und andere feste Lebensmittel.

Diese Regelung hat in die Schlegelsche Sammlung der kurhannoverschen Kirchengesetze Eingang gefunden. ${ }^{78}$ Im Kapitel über die Tauf- und Braut-Suppe heißt es ${ }^{79}$ : An einigen wenigen der bemeldeten Oerter wird die Braut-Suppe nur dann gegeben, wenn ein ordentlicher Hochzeitsschmauß gegeben wird, mebrentheils aber obne Unterschied. An vielen Orten sind die Bestandtheile dieser Braut-Suppe genauer bestimmt. So steht z.B. in einem

74 KiKrAGött Sup. Spez. Dramfeld I.2.b., Text von der Hand Pastor Stolbergs nach der Kirchenvisitation 1774.

75 KiKrAGött, P.A. Dramfeld Dr. A.410, 16. Dezember 1686 und P.A.Dramfeld K. R.I.a.4, Unbeständige Einnahme von der Kirchen-Länderey... 1766, Schlußbemerkung des Pastors Stolberg.

76 Pfarrchronik [179v]. Vgl. Bielefeld S. 53, 54.

77 Siehe KiKrAGött, P.A.Obernjesa A. 401, Schreiben des Landeskonsistoriums vom 27. November 1804 und Schreiben der Kirchenkommission vom 14. März 1805. Nachdem ein Regulativ erlassen worden war (BIELEFELD 1957, S. 53, 54), fand die Angelegenheit offenbar ein Ende, wie aus einem Schreiben des Consistorial-Departements an das Landeskonsistorium in Hannover vom 10. Mai 1805 hervorgeht (Schlegel, 5. Teil, S. 531).

78 SChlegel, Churhannöversches Kirchenrecht, Teil 1-5, Hannover 1801-1806.

79 A.a.O., Teil 5, S. 95, 96. 
von dem General-Superintendenten Böbmer attestirten Verzeichnisse der Pfarr-Intraden von Dramfeld, welches mit Obernjesa verbunden ist, vom Jabre 1716 \&. 11: Anstatt der Braut-Suppe, weil dieselbe über Feld zu tragen beschwerlich fällt, ist von vielen Jabren ber, ein Stück robes Rindfleisch etwa von 4 bis 6 Pfund, nebst einem Gericht von einer Rinderwurst, und andern Eingeweiden, dabey zwey Hochzeitsbrödte, ein Kuchen und eine Flasche Bier nach Obernjesa auf die Pfarre gebracht. Will der Pastor nach seinem Belieben der Hochzeit mit beywobnen, steht es ibm frey. ${ }^{80}$

\section{Meliorationen}

Im Vergleich mit anderen Pfarrstellen scheint die Obernjesaer Pfarre nicht besonders einträglich gewesen zu sein. ${ }^{81}$ Dennoch - vielleicht auch deswegen - haben die Pastoren so manche Reparatur, so manche Erneuerung und so manche Verbesserung in Haus- und Landwirtschaft aus der eigenen Tasche bezahlt - in der Erwartung bzw. in der Hoffnung, dass ihnen die Kosten einmal ersetzt würden. ${ }^{82}$

Beispiele dafür finden sich in den Eintragungen von Vater und Sohn Stolberg. Während Magister Stollberg auf einem formlosen Zettel gegen Ende seiner Amtszeit festhielt, was ihm privat und was der Pfarre gehörte, spezifizierte Pastor Stolberg (jun.) zwar die Kosten des Brunnenbaus auf dem Obernjesaer Pfarrgrundstück; dass er die beantragte Sakristei in Dramfeld aus eigenen Mitteln vorfinanzieren wollte, vermerkte er in der Pfarrchronik nicht. ${ }^{83}$

Pastor Gräffe, dessen Wirken in Obernjesa in der Chronik lediglich durch einige wenige Bemerkungen seines Nachfolgers belegt ist, hinterließ immerhin ein artiges Dankschreiben an die Gemeinde Dramfeld, die ihn beim Neubau eines Schuppens unterstützt hatte: Hiermit bezeuge ich, daß zur Erbauung eines Schoppen, den ich auf meine Kosten erbaue, die Dramfeldische Gemeine mir aus Liebe einige Eichbäume geschenkt hat, wofür ich biermit meinen Dank Ihr abstatte.J.F.O. Graeffe Pastor. Obernjesa d $19 t$ Novemb. $1790 .{ }^{84}$

80 Gemeint ist wohl: entweder Naturalvergütung oder Teilnahme am Hochzeitsessen. Bei Schlegel werden noch zwei weitere Beispiele für die Naturalvergütung genannt, eines sogar aus der Nachbarschaft: Nach den Verzeichnissen von 1727 besteht sie [die Brautsuppe] (...) in GroßenSchneen in einem guten Stück Rindwurst, Sülze, Schweinefleisch, Kuchen, und einer Portion Bier und Brodt. a. a. O., S. 96.

81 Meyer, Pastoren, S. 215.

82 Dass und wie diese Fragen seit 1738 gesetzlich geregelt worden sind, zeigt U. ScheuerMANN anschaulich am Beispiel des Dorfes Elliehausen (GöJb 61, 2013, S. 183-212).

83 Pfarrchronik [165].

84 OADramfeld IX, 32 (157). 


\section{Schulunterricht}

Die rechtliche Grundlage für das Schulwesen stellte die Calenberger Kirchenordnung dar, die auch Vorschriften für den Schulbesuch enthielt; sie legte eine Schulpflicht vom sechsten bis zum 12. Lebensjahr fest ${ }^{85}$, die 1734 auf das vollendete 14. Lebensjahr ausgedehnt wurde. Die einschlägigen Verordnungen wurden häufig novelliert, weil die Schulordnungen den Verhältnissen der Landbevölkerung angepasst wurden. ${ }^{86}$

Die Eintragungen zum Thema Schule zeigen, dass Pastor und Lehrer einen Unterricht hielten, der in erster Linie Konfirmandenunterricht war, also Unterweisung im christlichen Glauben, daneben aber auch Lesen und Schreiben umfasste; vom Rechnen ist nicht die Rede, auch nicht in den Eintragungen aus der zweiten Hälfte des 18. Jahrhunderts, als das Konsistorium explizit die allgemeine Vermittlung von Grundkenntnissen im Schreiben und Rechnen forderte und festlegte, daß künftighin in allen Schulen auf dem platten Lande wenigstens die vier Species des Rechnen, auch das Schreiben der Buchstaben, Sylben, Wörter und Reihen öffentlich und unentgeldlich gelehret werden sollen. ${ }^{87}$ Allerdings werden gegen Ende der Berichtszeit in den Inventaren der Schulen ${ }^{88}$ eine Landkarte von Europa und eine Globuskarte sowie Anleitungen zum Kopfrechnen und zur Rechtschreibung verzeichnet, so dass davon auszugehen ist, dass diese grundlegenden Fähigkeiten im Unterricht geübt und darüber hinaus noch andere Gegenstände behandelt worden sind.$^{89}$

Mit den Informationen aus den Inventaren und einzelnen Corpora bonorum, die nachweisen, welche Bücher vorhanden - und sämtlich im Eigentum der Kirche - waren, welche davon der Pastor und welche der Lehrer aufbewahrte und für den Unterricht nutzte, lässt sich belegen, dass religiöse Themen im Unterricht im Vordergrund standen. Die Ausstattung des Pastors bestand aus Gesangbuch, Bibel und Katechismus. Ein Kirchenhistoriker nennt in diesem Zusammenhang den 1639 erschienenen Auszug aus der Catechismus- Schule des Justus Gesenius (1601-1673), mit dem Ti-

85 Kruckenberg, S. 31.

86 vgl. Евнавdт, Bd. 2, Abschnitt Schulpflichtigkeit, Schul-Besuch, Schulgeld, S. 707.

87 Eine eingehende Darstellung der Entwicklung und Bewertung der Schulpolitik des Konsistoriums im 18. Jahrhundert findet sich bei Hofmeister, Andrea, S. $23 \mathrm{ff}$.

88 Das Inventarium der der Kirche (...) zugehörigen Sachen, welche der zeitige Prediger in Verwahrung hat...und das Verzeichniß des (...)Kirchen Ornats, und der übrigen Kirchen Sachen, welche der zeitige Schulmeister in Verwabrung hat... mussten seit 1788 in die jeweilige Jahresabrechnung eingefügt werden; vgl. KiKrAGött, P. A. Dramfeld K. R. I.a. 5 , Kirchenrechnung von 1788.

89 KiKrAGött, P.A.Dramfeld K. R.I.a.6, Kirchenregister von 1790. 
tel Kleine (später Kurze) Katechismusfragen über den kleinen Katechismus Lutheri, der als erster Landeskatechismus 1639 eingeführt wurde und bis 1790 in Gebrauch war ${ }^{90}$ und urteilte: Der Katechismus diente zur Disziplinierung der Untertanen und übte somit großen Einfluß auf die Prägung der Mentalität der lutberischen Bevölkerung aus. ${ }^{91}$

Die Bücher wurden lange benutzt und waren teilweise so abgenutzt, dass sie von Zeit zu Zeit ersetzt werden mussten. Pastor Stolberg (jun.) hielt dies im Dramfelder Corpus bonorum von 1776 fest: Die alte Kirchen Agenda von 1569 in Schweinleder; sebr alt und abgenutzet. Eine alte Lüneburgische Bibel von 1660 in Groß 8; neu eingebunden 1766 in schwarz Leder. Eine alte zerrißene Hallische Bibel obne Titelblad in der Schule zu gebrauchen. Stat dieser eine neue Altorfer Bibel von 1751. in schwartz Leder gebunden. ${ }^{92}$

Im Laufe der Jahrzehnte wurden für den Pastor und den Lehrer zusätzlich Evangelienbücher und Erbauungsbücher angeschafft, die ausgewählte Texte aus dem Alten und dem Neuen Testament enthielten wie Schubberts kleine Evangelien Postilla, 4 to Halle 1771. Deßelben Epistel Postilla 4 to Halle 1769. Beyde in schwartz Leder gebunden; bebuef der Vorlesungen des Schulmeisters angeschaffet ${ }^{93}$. Dr: Gesenii Biblische Historien, in Pergament von 1656. Johann Hübeners Biblische Historien. In braun Leder gebunden 1734. Zeben Stück Veränderte Evangelien Bücher 8 In braun Papier gebunden; Hannover 1772.

In den Inventaren finden sich weiterhin das sogenannte Noth- und Hülfsbüchlein und die Sitten-Regeln; schließlich sind nicht nur ein Metbodenbuch bzw. eine Instruction für den Lehrer sondern auch der Rochowische Kinderfreund und Volksliederbücher mit Text und Melodien inventarisiert worden. ${ }^{94}$

Manche Bücher - wie das Methodenbuch - wurden auf Anordnung des Konsistoriums angeschafft ${ }^{95}$, andere auf Empfehlung des Superintendenten. ${ }^{96}$

90 Hammann, Göttingen Bd. 2, S. 527, 528.

91 Krumwiede, S. 187.

92 KiKrAGött, P.A.Dramfeld K. R. III. 1 Belege, 16. Januar 1773

93 KiKrAGött, P. A. Dramfeld K. R. III, Belege 1734-1877, hier 1772. Die Witwe Vandenhoek quittierte den Kauf von Schuberts kurzen Predigten über die Evangelia und Episteln 2. Theile für zwei Reichstaler in bar am 19. Dezember 1772. Vgl. KiKrAGött, P.A. Dramfeld K.R.I.a. 4, Kirchenrechnung von 1772.

94 KiKrAGött, P. A. Dramfeld K. R.I.a. 7 1805-1819.

95 Pfarrchronik [173, 173v].

96 KiKrAGött, P. A. Dramfeld K. R. I.a. 51786. 
Das Dramfelder Corpus bonorum von 1776 vermerkt noch Drey Hannoversche Gesang-Bücher 8 mit grober Schrift. ${ }^{97}$ Diese Gesangbücher, in großer Schrift, waren von Pastor Stolberg (jun.) 1774 für Erwachsene, nämlich für arme alte Leute angeschafft worden, um ihnen das Lesen zu erleichtern und sie für das Lesen zu interessieren. Er legte das Geld für diese Buchanschaffung aus und konnte sich den Betrag aus der Kirchenkasse zurückzahlen lassen, nachdem der Superintendent dem Kauf zugestimmt hatte. ${ }^{98}$

Offensichtlich gab es auch Schulstunden, in denen vor allem das Schreiben geübt wurde, denn in den Kirchenrechnungen werden regelmäßig Geschenke an Papier und Tinte für arme Schreibschüler verzeichnet (Hervorhebung D. Kl.)

Wie wenig die Technik des Schreibens in der Berichtszeit verbreitet war, zeigt sich verschiedentlich in den Kirchenrechnungen: Kirchenvorsteher unterschrieben mit ungelenken Buchstaben, Handwerker mit sehr krakeligen Buchstaben oder gar nicht. Pastor Stolberg (jun.) entgegnete 1767 auf die Forderung des Konsistoriums, sich Auszahlungen durch Quittungen belegen zu lassen: So viel der Arbeitsleute schreiben gekont haben, so viel sind auch bey gebracht, und termino Visitationis produciret worden. ${ }^{99}$

$\mathrm{Ob}$ und wieweit Pastor und Lehrer in Obernjesa und Dramfeld sich den Unterricht geteilt haben, wird in der Chronik nur ein einziges Mal deutlich: Magister Stollberg wies 1749 in seiner Auseinandersetzung mit dem Dramfelder Bauermeister darauf hin, dass es in Dramfeld niemabls im Gebrauch gewesen [sei], daß der Prediger hier Kinder Lehre gehalten. ${ }^{100}$ Allerdings hat er später (1753) dann doch selber Catechismus Lebre erteilt. ${ }^{101}$

Ein großer Teil der Eintragungen betrifft die Armut der Dorfbewohner, die ihre Kinder nicht in die Schule schicken konnten oder wollten, weil sie sie zu Hause bei der Arbeit brauchten bzw. das Schulgeld nicht aufbringen konnten. Folgerichtig belegen die Kirchenrechnungen über Jahre hinweg, dass Schulgeld für mehrere arme Kinder aus der Armenkasse und aus der Stiftung einer Pastorenfrau bezahlt worden ist. ${ }^{102}$ Pastor Stolberg (jun.) wies 1775 daraufhin, wie schwer es sei, finanzielle Unterstützung für die Armen der Gemeinde zu erhalten, und was er in dieser Absicht - allerdings erfolglos - unternommen hätte: Die Hindernißen daß der Armen ibre Kinder

97 Pfarrregistratur Obernjesa, Corpus bonorum 1776, pag. 46ff

98 KiKrAGött, P. A. Dramfeld K. R. III, Belege 1734-1788, hier Beleg No. 20.

99 KiKrAGött, P. A. Dramfeld K. R. I.a.4, Kirchenrechnung 1766/1767.

100 Pfarrchronik [125v].

101 A.a.O. [133].

102 Zum Beispiel KiKrAGött, P. A. Dramfeld K. R. I.a. 2, Kirchenrechnung 1737. 
und die Arme überhaubt nicht weiter unterstützet werden können besteben darin; weil die Armen Casse weiter keinen Zufluß als aus dem Armen Kasten hat; die StraffGelder aus dem Gerichte, Licent-Ordnungen, Gemeine etc. babe nicht erbalten können. ${ }^{103}$

Man gewinnt den Eindruck, dass das Konsistorium mit der Vielzahl von Verordnungen und Rundschreiben versuchte, einen regelmäßigen Schulbesuch zu erzwingen; immerhin forderte es von den Geistlichen in den sog. Schulberichten Informationen über den Bildungsstand aller Kinder; es erkundigte sich nach der Anzahl der armen Kinder, die dem Unterricht fernblieben, wollte die Gründe dafür wissen und erwartete von den Pastoren Vorschläge, wie man Abhilfe schaffen könne. ${ }^{104}$

Auf die Berichte über den unregelmäßigen Schulbesuch und die damit verbundenen mangelhaften Leistungen der Schüler reagierte das Konsistorium einmal mit der Aufforderung an die Pastoren, die Konfirmation zu verweigern, ein andermal mit der Weisung, die säumigen Eltern und Schüler beim Amt anzuzeigen, und damit ihre Armut bzw. ihre Uneinsichtigkeit öffentlich zu machen. ${ }^{105}$ Eine solche Maßnahme scheint jedoch nicht allzu oft angewendet worden zu sein; entsprechende Vorgänge fanden sich bisher lediglich aus dem Jahr 1788: In den Obernjesaer Pfarrakten ist eine Liste erhalten, in der die Eltern und deren Kinder namentlich aufgeführt, die für die Schulversäumnisse auferlegten Geldstrafen ausgewiesen und vom Leinebergischen Gerichtsschulzen Compé als bezahlt quittiert werden. ${ }^{106}$ In der Dramfelder Kirchenrechnung des selben Jahres heißt es: Die Absenten aus der Schule und aus der Catechismus-Lebre, welche der Obrigkeit übergeben worden, sind von derselben bestraft, und das Strafgeld gerichtlich beigetrieben worden. ${ }^{107}$ Ein Jahr später vermerkte Pastor Gräffe: Laut des Verzeichnisses der Schul-Absenten, welches im Jabre 1788 dem Königlichen Amte Friedland übergeben wurde, sind einige Absenten mit Gefängnis, die andern aber nach Verbältnis der versäumten Schultage mit Gelde bestrafet worden, dessen Summe in diesem Jabre mir überreicht worden ... ${ }^{108}$ Schließlich empfahl man eine Staffelung der Gebühren für den Konfirmandenunterricht nach dem Vermögensstand der Eltern. ${ }^{109}$ Als die Ergebnisse

103 Pfarrchronik [164].

104 A.a.O. [162, 163].

105 A.a.O. $[175,175 \mathrm{v}]$.

106 KiKrAGött, P.A.Obernjesa A. 333., 6. November 1788.

107 KiKrAGött, P.A.Dramfeld K. R. I.a. 5, Kirchenrechnung 1788.

108 A.a.O., Kirchen-Register von Dramfeld de 1787. Unbeständige Einnahme Geld wegen übertretener Schulordnung und versäumter Catechismus-Lehre.

109 Pfarrchronik [113]. 
des Unterrichts immer noch nicht den Erwartungen des Konsistoriums entsprachen, regte es an, den mittellosen aber fleißigen Schülern kostenlosen Nachhilfeunterricht erteilen zu lassen bzw. die Schulbücher zu schenken. Schließlich muss noch erwähnt werden, dass man daran dachte, den Schülern das Zuhören, Verstehen und Behalten insgesamt zu erleichtern und ihnen zu gestatten, sitzend am Unterricht teilzunehmen. ${ }^{110}$

Am Ende der Konfirmandenzeit erwartete man, dass die Schüler die Antworten im Katechismus so auswendig gelernt hatten, daß sie selbige von selbst anzufangen wißen, obne daß es nöthig sey sie ibnen den ersten Worten nach vorzusagen ${ }^{111}$; sie sollten im Katechismus und im Gesangbuch fertig lesen können ${ }^{112}$ und den Katechismus mit Verstand beten ${ }^{113}$ Von den Fertigkeiten, die im Schulunterricht erworben wurden, liest man verständlicherweise nichts.

\section{Kollekten}

Die Vielzahl der verordneten Kollekten, die in der Pfarrchronik erwähnt werden, ist ein weiterer Beleg dafür, dass in der Berichtszeit große Teile der Bevölkerung des Kurfürstentums bzw. des Königreichs verarmt waren. In der Chronik selber werden lediglich die vom Konsistorium genehmigten Sammlungen verzeichnet; daneben aber gab es noch die landesherrlichen Kollekten für wohltätige Zwecke. In der Literatur wird darauf hingewiesen, dass die Sammlungen so häufig waren, dass die Bevölkerung sie mehr oder weniger als zusätzliche Steuern betrachtete ${ }^{114}$; denn, so heißt es, mit der gnädigen Gewährung der Kollekten' anerkennt die landesherrliche Regierung, dass die betroffenen Gemeinden - im Fall von Feuerschäden ihre Häuser nicht aus eigener Kraft würden wieder aufbauen können; im Fall von Reparaturen oder Kirchenneubauten nicht in der Lage wären, gottesdienstliche Räume bereit zu stellen bzw. zu unterbalten. ${ }^{115}$ Wenn man dieser Argumentation folgt, ist durchaus zu verstehen, dass die Dramfelder Kirchenvorsteher 1749 eine Spende von 50 Talern für den Bau der Stockhäuser Kirche ablehnten. ${ }^{116}$

\footnotetext{
110 A.a. O. $[175 v, 176]$.

111 A.a.O. $[173 v]$.

112 A.a.O. [175].

113 Kruckenberg, S. 31.

114 Titz-Matuszak, S. 185.

115 A.a.O., S. 189.

116 Pfarrchronik [124v].
} 
Die Hilfe für Brandgeschädigte wurde in Form von sog. Hauskollekten eingesammelt, bei denen der Sammler von Haus zu Haus ging und durch die persönlich vorgetragene Bitte moralischen Druck auf die potentiellen Spender ausübte. Diese Hauskollekten für Brandgeschädigte sollen nur bis in die ersten 1750er Jahre gestattet worden sein; danach musste die 1750 gegründete Feuerversicherung in Anspruch genommen werden. ${ }^{117}$ Bei besonders schweren Schäden wurden auch später noch Kollekten für die Brandopfer angeordnet, wie zum Beispiel nach dem Feuer 1751 in Wernigerode ${ }^{118}$ oder für den Cantor Woltmann in Hiddestorf $1800^{119}$; noch fünfzig Jahre nach der Gründung der Feuerversicherung, 1802, wurde die höhere Geistlichkeit aufgefordert, einem Kollegen in der Inspektion Pattensen zu helfen, der in einer Feuersbrunst einen Schaden von 391 1/2 Th erlitten hatte ${ }^{120}$, während die niedere Geistlichkeit den 1802 abgebrannten Schullehrer Burgtorf im Kirchspiel Wunstorf unterstützen sollte. ${ }^{121}$

Für den Bau und die Reparaturen von Kirchen und Pfarrhäusern schrieb das Konsistorium Becken- und Kirchenvorratskollekten aus, die ebenso wie landesherrliche Verordnungen von der Kanzel verkündet wurden. Die Beckenkollekte, bei der eine Schüssel an der Kirchentür stand, war die unpersönlichste Form einer Sammlung und der Erfolg entsprechend gering. Bei einer Kirchenvorratskollekte musste die Gemeinde ihrer Vermögenslage entsprechend einen bestimmten Betrag aus ihrem Vorrat, ihrer finanziellen Rücklage spenden, die sie hatte anlegen müssen, um anfallende Bau- und Reparaturmaßnahmen finanzieren zu können. Die Gemeinden, die selber noch Reparaturen oder Baumaßnahmen zu finanzieren hatten, spendeten allerdings nicht. Für die Obernjesaer und die ziemlich reparaturanfällige Dramfelder Kirche ist relativ selten eine Kirchenvorratskollekte genehmigt worden. ${ }^{122}$

In diesem Zusammenhang wird in der Literatur noch einmal betont, dass Landesherr und Konsistorium die kollektive Unterstützung vor allem für ihre ordnungs- und finanzpolitischen Ziele eingesetzt hätten; zum einen, um die Steuerfähigkeit und Wirtschaftlichkeit der Kommunen wiederherzustellen, und zum andern, um die ordnungsgemäße Abhaltung der Gottes-

117 Titz-Matuszak, S. 191.

118 Pfarrchronik [129v].

119 A.a.O. [180].

120 A.a.O. [188].

121 A.a.O. [188].

122 Schreiben der Kirchen Kommissarien vom 26. Febr. 1830 an die Gemeinde Dramfeld, dass eine Kollekte nicht bewilligt werden kann, da andere bedürftige Gemeinden auch abschlägig beschieden werden; darüberhinaus würden Vorraths-Collecten zu Thurmbaukosten in der Regel nicht bewilligt (KiKrAGött, P.A.Dramfeld Dr.A.512, aus den Extrakten Blauel). 
dienste zu gewäbrleisten, d.h., die staatserbaltende Funktion der Kirche als Stütze des gesellschaftlichen Systems zu erhalten. ${ }^{123}$

Tatsächlich werden in den Jahrzehnten nach 1750 fast keine Kollekten mehr für die Opfer anderer als der Feuerschäden erwähnt. Eine Ausnahme bildete das verheerende Unwetter im Jahr 1800, das allerdings auf einige Dörfer und Städte (des heutigen) Südniedersachsens begrenzt war und in der Nachbarschaft Obernjesas vor allem Rosdorf, Mariengarten und Teile Dramfelds betroffen hatte. Der Obernjesaer Pastor ermahnte in seiner Predigt diejenigen, die verschont geblieben waren, den Geschädigten selbstlos zu helfen. Er schlug [den beiden Gemeinden Obernjesa und Dramfeld] eine öffentliche Beckenkollekte vor; aus Gründen, die er nicht weiter nennt - einerseits war die Kollekte nicht beantragt worden; vielleicht ging er aber auch davon aus, dass sich der Einzelne stärker angesprochen fühlen würde - wandelte er die Sammlung in eine Privatcolleckte um. Sie erbrachte jedoch keinen einzigen Mariengroschen. ${ }^{124}$

\section{Wetternachrichten}

Beobachtungen des Wetters haben nur Magister Stollberg und Pastor Proffen niedergeschrieben. Magister Stollberg begann damit erst zehn Jahre nach seinem Amtsantritt in Obernjesa und führte sie bis in den Beginn des 7jährigen Krieges fort. Allerdings nahm er keine kontinuierlichen Aufzeichnungen vor, sondern notierte nur besonders auffällige Wettererscheinungen - starke Kälte und späten Schnee, ungewöhnlich späten Frühjahrsbeginn bzw. frühe Wintereinbrüche; verregnete kalte Sommer, starke Regenfälle und heftigen Wind - alles Erscheinungen, die beträchtliche Schäden hinterlassen hatten. ${ }^{125}$ Seine Eintragungen sind immer kurz gehalten; allerdings beschrieb er einen besonders schönen Sternenhimmel im April 1752 vergleichsweise detailliert - unter Darlegung seiner wissenschaftlichen Ansicht - und fügte ergriffen ein lateinisches Dankgebet hinzu: Ens entium omnipotens mise-

123 Titz-Matuszak, S. 202.

124 Pfarrchronik [181].

125 Die immer wiederkehrenden Überschwemmungen zwischen Dramme und Leine, die einen Gang nach Göttingen unmöglich machten, scheinen wohl auch im 18. Jahrhundert zum normalen Wettergeschehen gezählt und infolgedessen nicht besonders erwähnt worden zu sein. Von den Auswirkungen einer solchen Überschwemmung erfährt man z. B. nur aus einer Bemerkung in der Specification was die Kirche zu Dramfeld Anno 1744 vor Oblaten und Wein hat außgegeben unter dem Einkauf im März 1744: NB: Dieser Wein ist von H. Flüggen zu LütgenSchneen geholet, Weilen wegen des großen Waßers Niemand nach Göttingen kommen konnte (KiKrAGött, P. A. Dramfeld K. R. III. 1 Belege. 23. Januar 1745). 
rere nostri, Tibi soli semper sit honor et gloria in secula Amen! $!^{126}$ Dass er ein Erdbeben erwähnte, das man zwar nicht in Obernjesa oder Dramfeld, wohl aber in Göttingen und an anderen Orten gespürt haben will, sollte man nicht als Hinweis auf ein naturwissenschaftliches Interesse und einen Zugang zu entsprechenden Zeitschriften deuten. ${ }^{127}$

Pastor Proffen berichtete - abgesehen von einem Wetterleuchten ${ }^{128}$ ebenfalls nur von extremen Wetterverhältnissen; er notierte mehrfach starke Fröste, durch die das Gemüse erfror, und berichtete von dem heftigen Unwetter 1800, das Schäden in den Dörfern Settmarshausen, Olenhusen, Lemshausen, Mengershausen, Sieboldshausen, Volkerode, Mariengarten, Dramfeld, Jühnde und Barlissen anrichtete. ${ }^{129}$ Schließlich beschrieb er ausführlich einen Unglücksfall im Winter 1805, der heute nur noch schwer nachzuvollziehen ist, da sich die Verläufe von Gräben, Bächen und Flüssen im Bereich Göttingens stark verändert haben. Am 5. Februar machten Treibeis auf der Leine, Schneeschmelze und Regen sowie die unglückliche Regulierung des Wehrs an der Walkemühle die Beileine unpassierbar, so dass ein Fuhrwerk bei dem Versuch hindurchzufahren umschlug, und zwei Menschen und zwei Pferde elendig ertranken. ${ }^{130}$

\section{Krieg und Frieden}

Da die Dragoner, die Kavallerie des hannoverschen Heeres, in Friedenszeiten auf die Dörfer verteilt und dort für längere Zeit einquartiert wurden, heirateten einige von ihnen in örtliche Familien ein und gehörten damit zur Einwohnerschaft. Aber auch ohne einen Familienanschluss hatten sie das Recht auf reservierte Sitzplätze in der Kirche. ${ }^{131}$

Die Eintragungen des Magisters Stollberg lassen erkennen, dass einzelne von ihnen durch ihr gewalttätiges Auftreten wiederholt den Dorffrieden störten. Nachdem er beinahe vom Dragoner Heine, der eine Tochter des

126 Allmächtiger Gott erbarme Dich unser, Dir allein sei Ehre und Rubm in Ewigkeit, Amen! Pfarrchronik [130] 1752.

127 Pfarrchronik [137v] 1756. Für Düren ist zwar im gleichen Jahr ein Erdbeben nachgewiesen, für Göttingen allerdings nicht. (LEYDEcker, Erdbebenkatalog für Deutschland, Stuttgart 2011).

128 A.a.O. [179] 1799.

129 Der Göttinger Professor Meiners besichtigte die geschädigten Dörfer einige Tage nach dem Unwetter und veröffentlichte seine Eindrücke $1801 \mathrm{im}$ Verlag Haude und Spener in Berlin und im Neuen Hannoverschen Magazin. Diese Veröffentlichung ist die Quelle mehrerer Heimatschriftsteller geworden.

130 Pfarrchronik [195], [195v].

131 In Obernjesa waren es bis zu sieben Plätze (KiKrAGött, P.A. Obernjesa A.513.20 und B 4 Fasz. 2.), in Dramfeld vermutlich nur zwei bis vier. 
Valentin Zimmermann [in Obernjesa] geheiratet hatte, geschlagen worden wäre, schrieb er in die Chronik: Ich klagte es bey dem Hn. Obristleutenant (..), aber es ist ihm nichts widerfahren. Und wer that ihm was, als er am 20 Sept. dem Dragoner Becker fast die Hand abhieb? Wer that ihm was, als er Conrad Ferensen schlug, und mit dem Kopffe ins Wasser stürtzte? Wer that ihm was? Als er Conrad Kramern auf freyer Strasse blutrünstig und den Kopf entzwey schlug, daß er darauf närrisch im Kopfe geworden. Wer hat ihm was gethan, als er Deppe bald todt schlug? Solche Soldaten sind den Officiren angenehm, sie haben Courage. Also ist ein Prediger übel daran. ${ }^{132}$

Mit dem Beginn des Siebenjährigen Krieges beendete Magister Stollberg seine Eintragungen in die Chronik - wie sein Sohn später erklärte, waren die Zeiten unsicher geworden, und jedes geschriebene Wort konnte leicht zu Verdächtigungen führen. Sein Sohn und Nachfolger im Amt erlebte den Krieg hautnah und trug die eigenen schmerzhaften Erfahrungen und das, was er aus den Nachbardörfern und aus Göttingen gehört hatte, in die Chronik ein. Das unvorstellbare Ausmaß an Grausamkeiten in diesem Krieg wird von Zeitgenossen und späteren Autoren gleichermaßen bestätigt. ${ }^{133}$ Die Aussage, dass sich das französische Heer an gewisse Regeln gehalten und keine Exzesse zugelassen habe ${ }^{134}$, muss angesichts der Beschreibungen Pastor Stolbergs (jun.) bezweifelt werden. Da im übrigen detaillierte Literatur zum und über den Siebenjährigen Krieg ausreichend zur Verfügung steht ${ }^{135}$, scheint eine weitergehende Darstellung der Zeit hier nicht angebracht.

Die Amtszeit des Pastors Proffen lag in den Jahrzehnten zwischen dem Siebenjährigen Krieg und der Besetzung Hannovers durch Frankreich; und so erfährt der Leser der Chronik detailliert von den neuen Steuern im Land und den wechselnden Einquartierungen französischer und preuBischer Besatzungstruppen. Man liest von der Kriegssteuer von 1798, die mit einem veränderten Berechnungsmodus eingeführt worden war ${ }^{136}$; von

132 Pfarrchronik [128].

133 Vgl. u. a. das Kriegstagebuch eines an den Fouragierungen beteiligten Militärs (St. A. Gött Dep. 114); die Erinnerungen des Pastors Johann Andreas Urban (KiKrAGött, P. A. Barterode 202); das Tagebuch des Professors Rudolf Wedekind: Tagregister von dem gegenwärtigen Kriege...; Andreas Georg Wähner, Tagebuch aus dem Siebenjährigen Krieg (Dahmen, Göttingen 2012); Celle im Siebenjährigen Krieg. Das Tagebuch des Garnisonsauditeurs Johann Philipp Schowart (MastnaK, Celle 2010); Eintragungen im Kirchenbuch von Bovenden (Busch, Kriegs- und Alltagsleben in Bovenden). Weitere vergleichbare Angaben finden sich für den Mündener Bereich bei LoTZE, S. 138ff.

134 Mastnak, J. und TänZer, M.A., S. 28; die hierfür herangezogenen Nachweise bei Ewa AnKLam S. 23 und S. 94 erscheinen überinterpretiert.

135 Vgl. Füssel, 1987, und die dort zitierte Literatur.

136 Pfarrchronik [177]. 
einer extraordinairen Kriegssteuer, die nach der Besetzung Hannovers am 4. Juni $1803^{137}$ zusätzlich zur Landesdefensionssteuer zur Unterhaltung der französischen Besatzungsarmee erhoben wurde; darüber hinaus von einer Hülfsbeisteuer, die von den Einwohnern der Fürstentümer Göttingen und Grubenhagen gefordert wurde, die bisher von den französischen Einquartierungen verschont geblieben waren. Mit den Erträgen sollten diejenigen Landesbewohner entschädigt werden, die unter Einquartierungen gelitten hatten. ${ }^{138}$

Schließlich verzeichnete Pastor Proffen noch die Fouragegelder, die jedes Vierteljahr zur Verpflegung der französischen und später der preuBischen Truppen aufgebracht werden mussten; diese Notizen waren begründet, denn zu allen der genannten Steuern und Abgaben wurden auch Kirche und Pfarre herangezogen. ${ }^{139}$

Neben den Steuern und Fouragegeldern belasteten ständig wechselnde Einquartierungen das Dorf Obernjesa ${ }^{140}$; allerdings scheint das für Pastor Proffen anfangs noch eine Abwechslung im täglichen Einerlei gewesen zu sein. ${ }^{141}$ Als nach der Auflösung der hannoverschen Armee 1803 französische und preußische Truppenverbände durchs Land zogen und tageweise auch in Obernjesa einquartiert wurden, waren bei Pastor Proffen regelmäßig nur die Kommandeure einzelner Verbände untergebracht bzw. bei ihm zu Tisch. Er hat sich offenbar gerne informieren lassen, vermerkte die politischen Hintergründe einzelner Truppenbewegungen; seit dem Frühherbst 1805 bis September 1806 notierte er die Namen der Offiziere, ihren Rang, teilweise ihre Herkunft. Als am 4. Dezember 1805 preußische Soldaten ${ }^{142}$ in Obernjesa einrückten, blieben die Unterkünfte beim Pastor jedoch unbesetzt, da die Offiziere beim Lehrer, beim Zimmermeister Salzmann und bei den größeren Bauern Georg Zimmermann, Heinrich Harriehausen und

137 am 5. Juni 1803, so bei Vierhaus (1979), S. 177.

138 Pfarrchronik [193].

139 Die entsprechenden Angaben finden sich in der Pfarrchronik [193] bis [194v].

140 Für Dramfeld fanden sich bisher keine Hinweise auf Einquartierungen.

141 KiKrAGött, P. A. Obernjesa, A. 112: Immerhin teilte er zur Lage der Gemeinde im Kirchen- und Schulbericht von Ostern 1803 bis Michaelis 1803 auf der Beilage zu Frage $\mathrm{X}$ mit: Der häusliche Zustand derselben [der Gemeinde] ist im Ganzen genommen ziemlich wohlhabend; wenigstens haben sie keine Gassenbettler aufzuweisen. Wenige Jahre später führte Pastor Proffen auf der entsprechenden Beilage im Kirchen- und Schulbericht für Ostern 1806 bis Michaelis 1806 aus: Was den häuslichen Zustand (der Gemeinde) betrift: so hat derselbe durch die heufigen Durchmärsche und starcken Einquartirungen abermabls eine beftige Erschütterung erlitten. Dennoch aber hat er noch nicht Stehlen und Betteln zur Folge gehabt.

142 Pfarrchronik [196v]. 
Christof Harriehausen Erben untergebracht wurden. Dafür musste Pastor Proffen die Offiziere in seinem Haus bewirten, was ihm offenbar erfolgreich gelang: ... weil (aber) des Schulmeisters Mündemann Magd das von der Gemeine zum Mittagsessen angeschafte Fleisch und die Mablzeit überall nicht anständig bereiten konnte, so übernahm es meine Frau; und die 4 ersten Herren, wurden also in meinem Hause zu ibrer grösten Zufriedenheit gespeiset. ${ }^{143}$

\section{Geld, Preise, Kaufkraft}

Die Preise von Getreide und anderen Lebensmitteln sowie von Kleidung, von Viehfutter, von Löhnen, Abgaben und Gebühren - soweit diese nicht in Naturalien fällig waren - werden in der Pfarrchronik in Talern, Guten Groschen, Mariengroschen und Pfennigen angegeben.

Obwohl Preissteigerungen und Währungsverschlechterungen den Alltag der Gemeindemitglieder - je nach Vermögenslage mehr oder weniger stark - beeinträchtigt haben müssen, finden sich in der Chronik hierzu vergleichsweise wenige Eintragungen. Die Pastoren notierten steigende Preise, die durch die Kriegsverläufe oder durch Schädlingsfraß verursacht wurden, offenbar erst dann, wenn sich die Lebenshaltungskosten existenzbedrohend erhöhten.

Ebenso wenig erfährt man aus der Chronik, wie die Bevölkerung mit den Wertverlusten der umlaufenden Münzen umging. Obwohl sich in den erhaltenen Rechnungsunterlagen der Gemeinden Obernjesa und Dramfeld wiederholt Beispiele für die Münzverschlechterungen finden, belegt nur eine einzige Eintragung in der Pfarrchronik - die Erwähnung des Münzediktes vom 15. April $1740^{144}$ - dass und auf welche Weise die Landesregierung dieser Entwicklung entgegen zu wirken versuchte.

Es ist bekannt, dass die hannoversche Währung während der Kriegszeiten immer mehr an Wert verloren hatte, so dass die Regierung versuchte, ihre Währung zu schützen und wiederholt Münzedikte erließ. In diesen Verordnungen wurde bekannt gemacht, welche Münzen noch galten, also gangbare oder unverrufene Münzen waren, und welche schlecht waren, im Geschäftsleben nicht mehr verwendet werden durften und als verrufene Münzen bezeichnet wurden.

Mit dem Erlass eines Münzediktes hatten all diejenigen, die Geld zurückgelegt hatten, teilweise altes Geld in der Hand, das nur mit Abschlägen

143 Pfarrchronik [197]; die offenbar in der feineren Küche erfahrene Pastorenfrau war eine Tochter des Pastors in Landolfshausen und führte diesen Haushalt bereits seit 20 Jahren (Bielefeld 1957, 60).

144 A.a.O. [114] 
umgetauscht werden konnte, und erlitten infolgedessen mehr oder weniger hohe Verluste. Pastor Stolberg (jun.) versuchte beispielsweise, einem größeren Verlust in der Kirchenkasse zuvorzukommen, indem er Holz für eine bevorstehende Kirchenreparatur einkaufte. In der Kirchenrechnung für das Rechnungsjahr 1767-1768 vermerkte er:

Da die alten 1/12 St. [3mg Stücke] laut Verordnung weggeschaffet werden sollten, die Kirche aber an solcher Müntze 36r. Vorraht hatte, und da derselben eine höchst nöhtige Reparation bevorstehet, so habe nach getahner Vorstellung erhaltener Mündl. Concession des Herrn Amtmanns Voigt Laut Rechnung und Quitung 40St. Futter Dielen u. 30 Stück gemeine Dielen $z u$ Northeim in solcher Müntze erhandelt um und für 25rth. Noch zu eben solcher Zeit 5 St. Futter Dielen bezablet laut eben der Quitung mit 1r. 6g. Da diese Dielen abgeholet worden ist für dieselben an Zoll ausgegeben .... $14 .{ }^{145}$ Die Preisangaben in der Pfarrchronik belegen zwar die steigenden Preise, mit denen die Bevölkerung fertig werden musste, erwähnen jedoch mit keinem Wort die Schwierigkeiten, die der alltägliche Umgang mit Geld bereitete allein schon dadurch, dass viele hannoversche Münzen mit unterschiedlichen Nennwerten im Umlauf waren. Rechnungsgrundlage war zwar wie bereits erwähnt der Taler zu 36 Mariengroschen à 8 Pfennige. Geprägt aber wurden keine ganzen Taler sondern nur Bruchteile eines Talers:

Als größte Münze das sog. Zweidrittelstück, das 24mg entsprach. Dann folgte ein EINDRITTELSTÜCK, das 12mg entsprach. Weiter waren im Umlauf Kasseneinsechstel, die $6 \mathrm{mg}$ entsprachen,

Kasseneinneuntel, die $4 \mathrm{mg}$ entsprachen,

EINZWÖLFTELSTÜCKE, die $3 \mathrm{mg}$ entsprachen und

1MARIENGROSCHEN-STÜCKE SOWie

verschiedene Pfennigwerte wie

SeChSPfennigstüCKe, die Gößgen

VieRPfEnNigstüCKe, die sogenannten Matthier und

Dreipfennigstücke, die Dreier.

Gute Groschen fanden sich seltener, weil sie - aufgrund der Talerteilung (24gg à 12d) - nur in einigen Landesteilen zugelassen waren.

Eine Vielzahl von Nachweisen der im Umlauf befindlichen Münzen findet sich dafür in den kirchlichen Abrechnungen. So zum Beispiel die Auszählung einer Beckenkollekte, die in der Dramfelder Kirche eingesammelt und

145 KiKrAGött, P. A. Dramfeld K. R. I.a. 4, Rechnung über Einnahme und Ausgabe am Gelde bey der Kirche zu Dramfeld...vom 1tn Januarii 1767 bis 1tn Januarii 1768. 
am 5. März 1767 abgeliefert worden war. Sie setzte sich aus den folgenden 21 Münzen im Nennwert von 14g. 1d. zusammen: ${ }^{146}$
An $1 / 18$ rth $\quad 1$ St. $=2 g$ :
Ein Zweigroschen Stück,
an $1 / 36$ rth. $\quad 4$ St. $=4 g$ :
Vier Eingroschen Stücke,
an $1 / 48$ rth. 1 St. $=6$ d:
Ein Sechspfennigstück, ein sog. Gößgen,
an $1 / 72$ rth. 14 St. $=7 \mathrm{~g}$ :
Vierzehn Vierpfennigstücke, die sog. Matthier,
an $1 / 96$ rth.
1 St. $=3 d$ :
Ein Dreipfennigstück, ein Dreier.

Um Ordnung in die Abrechnungen zu bringen, mussten sog. Sortenzettel ausgefüllt werden. ${ }^{147,148}$ In diesen Sortenlisten zeigt sich, dass in Dramfeld und Obernjesa vor allem kleine Münzen im Umlauf waren; große hochwertige Münzen wurden relativ selten vermerkt. Als Pastor Bornträger 1795 seinen liquiden Kirchenvorrat abliefern musste, trug er Cassenmäßige Silbermünze als $24 \mathrm{~g}$. $6 \mathrm{~g}$. 4g. [Zweidrittelstücke, Kasseneinsechstel, Kasseneinneuntel], Mariengroschen, gute Groschen, kleine Silbermünze und Conventions-Geld ein. Pistolen zu 7 Gulden, Ducaten zu 4 Gulden oder Goldgulden $z u 2$ Rthl., die der Sortenzettel auch vorsah, konnte er nicht nach Hannover schicken. ${ }^{149}$ Derartig hochwertige Münzen fanden sich höchstens bei Kreditgeschäften zwischen der Kirche, der (weltlichen) Gemeinde oder den Einwohnern, da die Kredite in bestimmten Münzsorten ausgezahlt und in den gleichen oder gleichwertigen Münzsorten zurückgezahlt werden mussten. Die Rückzahlung wurde dann folgendermaßen quittiert: Christoph Diekman hat sein in Golde empfangenes Capital von 10rth. 24g. um Johanni der Kirchen wieder bezahlet in 2 LuisD'or und 24mg. Kassenmäßig verbucht 10rth. ${ }^{150}$

Da es keine Währungsgrenzen gab, waren auch ausländische Münzen im Umlauf, die zum Teil sogar einem Pastor, der die Kirchenrechnung führte, unbekannt waren. Das zeigt sich am Beispiel des Münzhortes, den der Kirchenvorsteher Hofmeister nicht in die Kirchenkasse gelegt, sondern längere Zeit zu Hause für die Kirchenkasse aufbewahrt hatte. Der Kirchenvor-

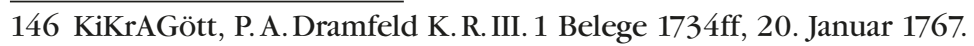

147 z.B. in KiKrAGött, P. A. Dramfeld K. R. III. 1 Belege 1734ff.

148 Pfarrchronik [172], Ausschreiben des Königl. Konsistoriums vom 7. März 1795, das die Pfarren aufforderte, alle entbehrlichen Barmittel - sicherheitshalber - nach Hannover zu schicken und den Sortenzettel vorgab, der die seinerzeit anerkannten Münzsorten aufführte.

149 A.a.O. [172]

150 KiKrAGött, P.A.Dramfeld K.R.I.a. 4, Zusammenstellung der zurückgezahlten Kredite 1766. Der Louisd'Or war eine Goldmünze im Rechnungswert von 5 Taler Gold Conventionsmünze. 
steher übergab die Münzen 1762 dem jungen Pastor Stolberg, der ,ausländische' Brandenburger Münzen und Frankfurter Batzen identifizierte, sowie alte und neue Geldstücke, und die gehorteten Münzen mit insgesamt gut zehn Talern bewertete: ${ }^{151}$

Es fanden sich ein Brandenburger 6 Groschen Stück von 1752,

zwei Brandenburger 3 Groschen Stücke von 1752 und 1754, eine nicht feststellbare Anzahl an alten Mariengroschen,

ein Kasseneinsechstel, alte Sechspfennigstücke,

neue Sechspfennigstücke,

Weißpfennige (Albusstücke),

die sog. Matthiers,

ein Gutergroschen,

diverse kleine Münzen und diverse unbekannte Münzen.

Um diese Münzen umrechnen zu können, waren besondere Kenntnisse vonnöten, von denen man annehmen kann, dass jeder, der ein Geschäft abschließen wollte, sie wohl besaß. Im Fall von Münzverwerfungen (denen die sog. Reduktionen folgten) scheint es eher zweifelhaft, dass jedermann begriff, welche Folgen die Umrechnungen haben würden. Jedenfalls finden sich mehrfach Belege über Auseinandersetzungen zwischen kirchlicher und weltlicher Gemeinde, in denen über ein angemessenes Agio bei Umwechselungen gestritten wurde. ${ }^{152}$

Dass die Umwechselungen den Alltag belasteten, wird auch dadurch deutlich, dass die Wechselkurse der Nachwelt mitgeteilt wurden. In den Archivalien für Dramfeld findet sich ein Blatt mit Angaben von 1796/1797, das zu den Dokumenten in die Kirchturmskugel gelegt wurde: Das jetzige Verbältniß der Münzsorten gegen einander ist folgendes 1) Gold verbält sich gegen Cassen-Münze wie 15 gegen 14, so daß also 15r. in Golde 14 Cassen Münze ausmachen 2) Conventions Münze verbält sich gegen Cassen-Mün-

151 KiKrAGött, P. A. Dramfeld K. R. III. 1 Belege, Sortenzettel vom 21. Oktober 1762: Sortenzettel der am $218 \mathrm{br} 1762$ vorgefundenen Müntzen. welche aus der privat Verwabrung des Kirchen Vorstehers Hofmeisters genommen dato gezählet und in die Kirchenlade verschloßen geleget von Pastore Henr. Ph. Stolberg. Interims Administratore. Die brandenburgischen Münzen enthielten weniger Silber und sind deshalb als geringer zu bewerten. Der Frankfurter Batzen ist der 15te Teil eines dortigen Guldens; die Unterscheidung des Pastors in alte und neue Münzen läßt sich bisher nicht genau klären; es könnten Münzen von vor als auch nach der Währungsreform von 1690 (Währungsunion von Leipzig) gemeint sein (Freundliche Mitteilung von Hans-Jürgen Gerhard).

152 Vgl. KiKrAGött, Sup. Spez. Obernjesa I. 2. b.: Unvorgreifliche Data zur Beantwortung des Rescripti Consistorii d.d. 15t. Dec. 1774 und deßen 8 Postscripten. 
ze wie 8 gegen 7 so daß also 8 r. Conv. Münze $7 r$. Cassen Münze betragen, und 3 gute Groschen C.M. als Agio erforderlich sind um 1r. Conv. Münze einem r. Cassen-Münze gleich zu machen. ${ }^{153}$

Ein Schuldner, der seinen Kredit (in Taler Kassengeld erhalten) zurückzahlen wollte, musste also in dem ihm zur Verfügung stehenden Konventionsgeld 3gg pro Taler mehr zahlen, um den Kreditvertrag zu erfüllen.

In diesem Zusammenhang ist noch zu beachten, dass sich die in der Chronik und in anderen Rechnungen angegebenen Preise nicht einfach in unsere heutige Währung umrechnen lassen. Wollte man eine einigermaßen gültige Vorstellung von der damaligen Kaufkraft der Währung gewinnen, müsste man u. a. herausfinden, wie lange für bestimmte Lebensmittel oder Kleidung gearbeitet werden musste, welchen Anteil die Ausgaben für bestimmte Lebensmittel oder Kleidung an den gesamten Ausgaben hatten und darüber hinaus berücksichtigen, welchen Wert sie für den einzelnen Käufer darstellten.

Da die Probleme der Kaufkraftermittlung indessen eingehend von Hans Jürgen Gerhard bearbeitet und dargestellt worden sind, müssen sie hier nicht weiter vorgetragen werden.

\section{Zur Transkription}

Um dem Leser einen Eindruck der individuellen Schreibeigenarten der Geistlichen zu geben, wurden sowohl die originale Interpunktion als auch die zeitgenössische Rechtschreibung des Chroniktextes zeichen- und buchstabengetreu in die Transkription übernommen. Da die einzelnen Schreiber jedoch von einander abweichende Besonderheiten zeigen, wurde versucht, die Absicht der Schreiber in die Transkription zu übernehmen.

Die Seitenzählung im Original ist verschiedentlich unterbrochen und dann neu begonnen worden; in der Transkription finden sich die gestempelte Seitenzählung des Landeskirchenarchivs [in eckigen Klammern] sowie die Paginierung der Chronisten.

153 KiKrAGött Sup. Spez. Obernjesa Dr. I. 2. a. Hans-Jürgen Gerhard erklärt den Begriff des Kassengeldes folgendermaßen: So wurde etwa die Zahlungsverpflichtung der Bürger einer Stadt oder eines Staates festgelegt in der offiziellen Landeswährung, im Kurfürstentum Hannover direkt als „Cassengeld“ bezeichnet. Da diese besonderen Münzen demjenigen, der Steuern oder Abgaben zu entrichten hatte, oft nicht zur Verfügung standen oder gar nicht (mehr) im Umlauf waren, wurden die Zablungen in andere Münzsorten umgerechnet und in diesen geleistet"(GERHARD, 2006, S. 165). 
a. Im Text:

wurde folgendermaßen verfahren:

lateinische Buchstaben werden grundsätzlich kursiv wiedergegeben;

aufgelöst wurden der Überstrich zur Verdoppelung der Konsonanten, die Abkürzungen der Silben am Ende eines Wortes,

die Abkürzung für des, das, daß,

die Abkürzung für non = nicht.

Magister Stollberg und Pastor Stolberg jun.:

Bei relativ willkürlichen Groß- und Kleinschreibungen von Wörtern wurden auffällig groß geschriebene kleine Buchstaben nicht übernommen; die auffällige Zergliederung der Wörter (Pastor Stolberg jun.) wurde übernommen.

Pastor Bornträgers Abkürzungen bestehen in schwungvollen Schlenkern nach oben oder unten; diese Abkürzungen werden mit einem Punkt angedeutet. Seine Datumsangaben werden nicht kursiv geschrieben, da sie bei ihm nicht besonders betont werden.

Ein a oder o mit hochgestelltem e wird als ä bzw. ö geschrieben.

Pastor Proffen: variierende Abkürzungen oder auffällige Abkürzungen wie d.d.d. werden übernommen.

Hinweise der Bearbeiterin finden sich in eckigen Klammern.

b. In den Anmerkungen gilt:

bei Bibelversen: nur der Anfang des ersten Verses;

Übersetzungen der lateinischen Zitate kursiv;

Zitate aus der Literatur kursiv. 


\section{Abkürzungen ${ }^{154}$}

KiKrAGött

UAG

SUB

HStAH

StadtAGött

GöJb

Mrlt.

Hb., Hbt., Htm., Hten

$\mathscr{B}$

fl.

r., Rth., Rthl.

g., mg.

gg.

d

M

Vl.

$7 b r$.

8br.

9br.

Xbr.
Kirchenkreisarchiv Göttingen

Universitätsarchiv Göttingen

Niedersächsische Staats- und

Universitätsbibliothek Göttingen

Hauptstaatsarchiv Hannover

Stadtarchiv Göttingen

Göttinger Jahrbuch

Malter

Himbten

Pfund

Florin, Gulden

(Reichs)Taler

(Marien)Groschen

GuteGroschen

Pfennig

Morgen

Vorling, Forling $=1 / 2$ Morgen

Quadrat

Septembris

Octobris

Novembris

Dezembris

154 Detaillierte Angaben zu Maßen, Gewichten und Währungseinheiten finden sich bei GERHARD 2006, gegebenenfalls auch bei Hemeling und bei KrancKe. 
$+\ldots+$

a.c.

a.p.

a.p.

Act., Actor.

ao.

Cons.

Cons. Rescr.

d.d.

dH., d.Hn.

Dom.

ej.

e.a.

Fer.

heil.

Hl.

i.f.

Ill.

K. Gr.C.

Br.L.W.

Geh.R.u Z.Con. verordnete Praes.

a.C.u K.R.

K. Chf. Consistor.

1.c.

Mag.

Mh.

non

noie

p.p.

p.
Einfügung

anni currentis, anno currente,

des laufenden Jahres

anno praesente, im gegenwärtigen Jahr

anni praeteriti, des vorigen Jahres

Acta Apostolorum, Apostelgeschichte

Anno, im Jahre

Consistorium, Konsistorium

Konsistorialreskript

de dato, vom soundsovielten

der Herr, des Herrn

Dominica, Sonntag

ejusdem, desselben

eodem anno, im selben Jahr

Feria, Tag

heilig

das Heilige, das heilige Abendmahl

in fidem, zur Beglaubigung

Illustrissimus, der berühmte

Königlich Großbritannisch und Churfürstlich

Braunschweig Lüneburgischer Würklicher

Geheimer Rath und zum Consistorium

verordnete Praesident

auch Consistorial- und Kirchen Raht

Königlich Churfürstliches Consistorium

loco citato, am angegebenen Ort (a.a.O.)

Magister

mH., mHn., mein Herr, meine Herren

nicht

im Namen

perge perge, praemissis praemittendis, u.s.w.

per, durch, mittels 
rsp.

respective, bzw.

Suppl.

Supplementum, Nachtrag

vid. p.

vide pagina, siehe Seite 
Abb. 1 Das Rechnungsbuch, das die Pfarrchronik enthält Quelle: KiKrAGött, P. A. Obernjesa K.R.I.a. 1 


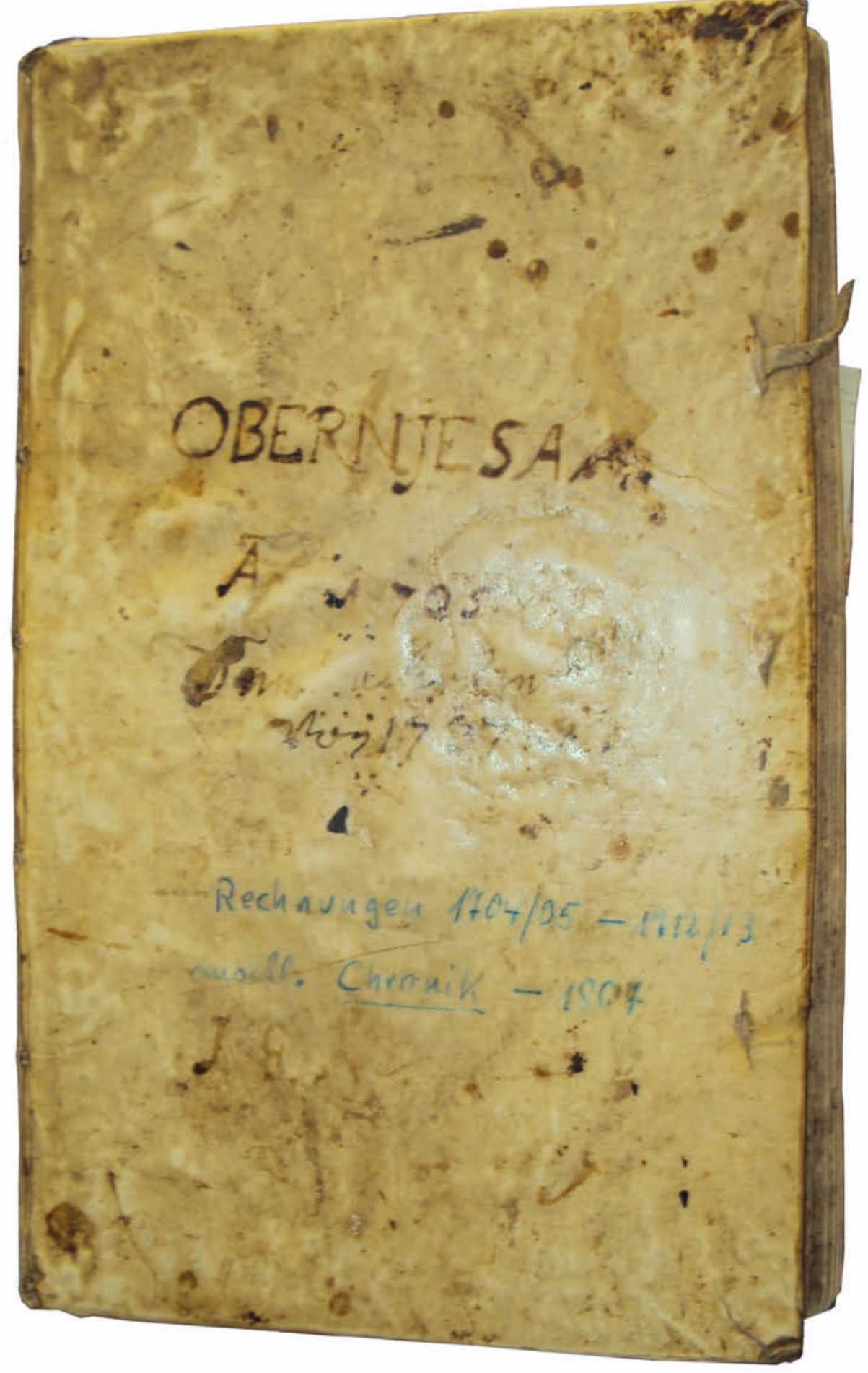




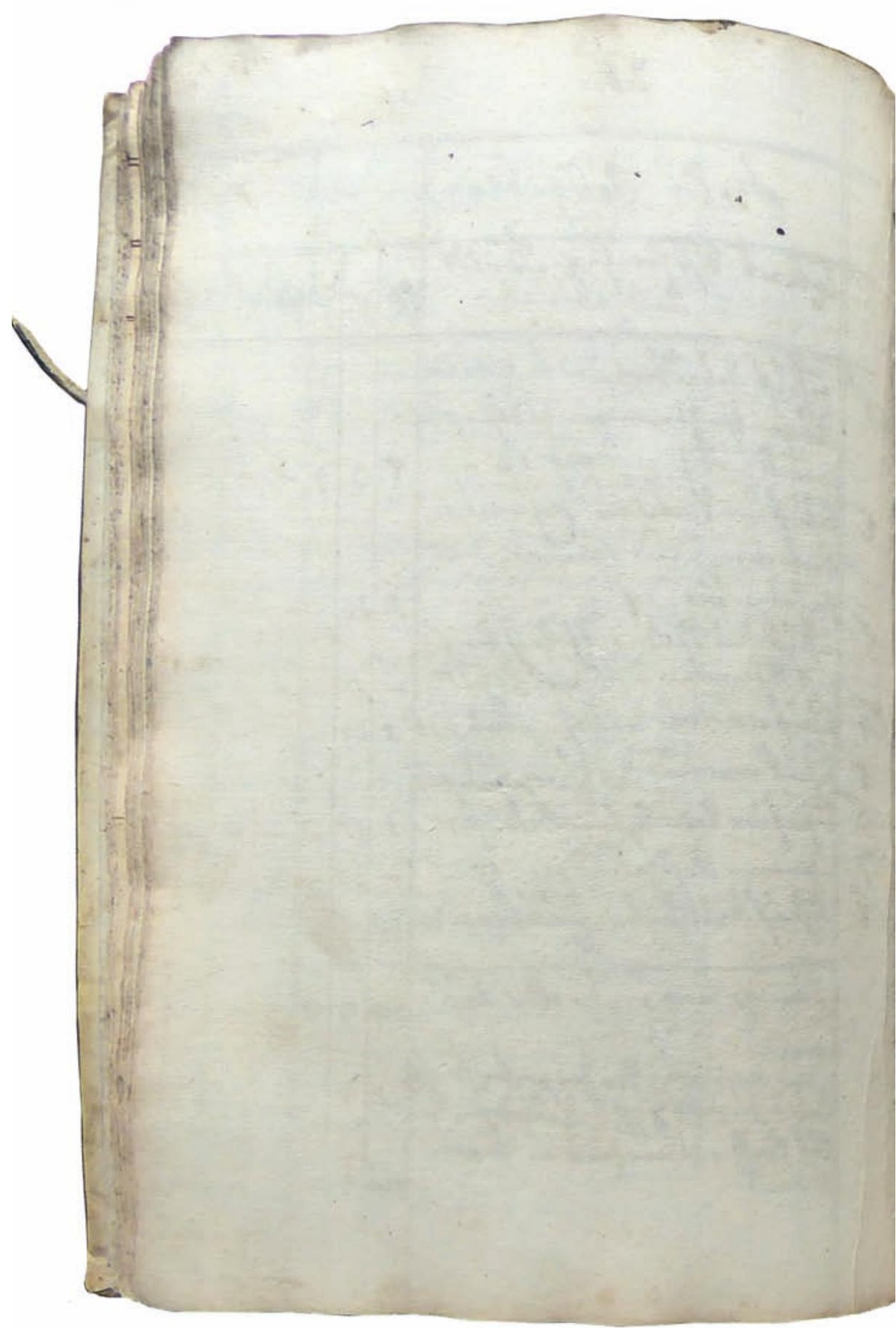




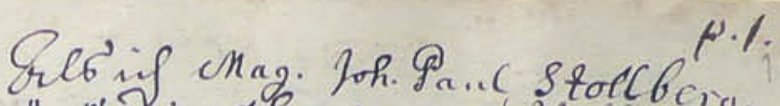

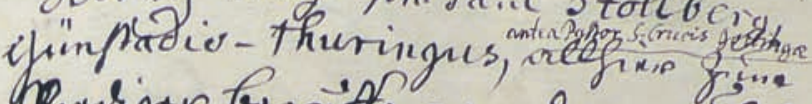

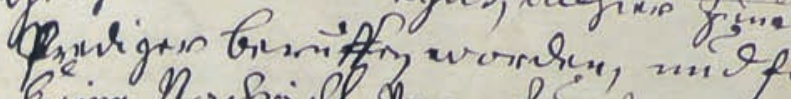

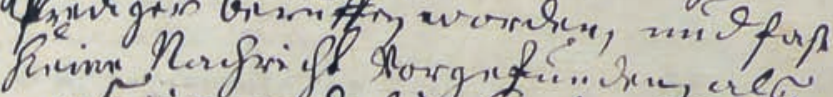

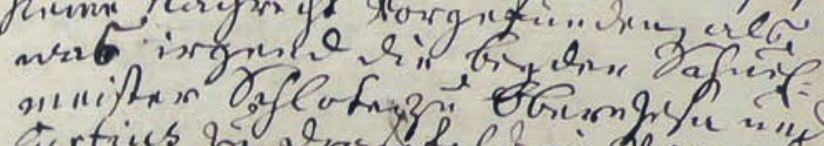

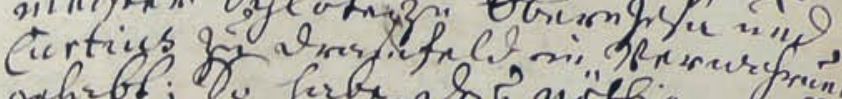

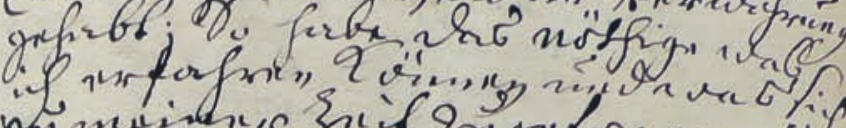

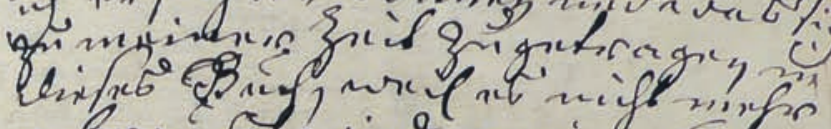

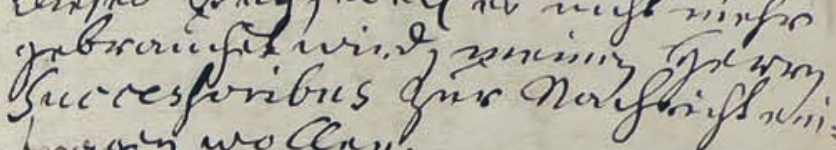
Prargy wo Can,

Oix sperification axr Pnifus

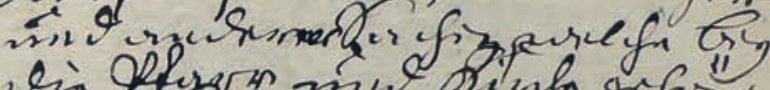

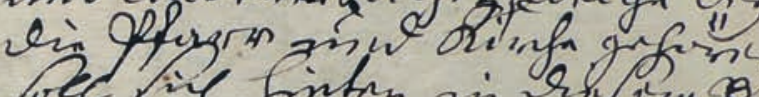

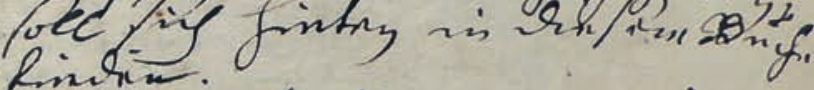

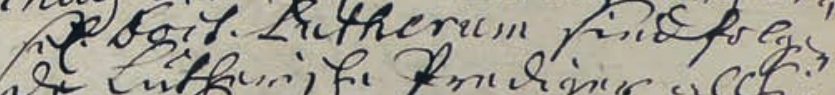

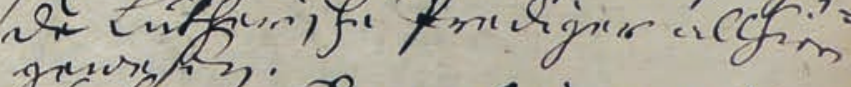
1 Jaconces Dorn, gimmenfis crxo, mmisfus 1550.

2. Girnous Eflutur 1000 .

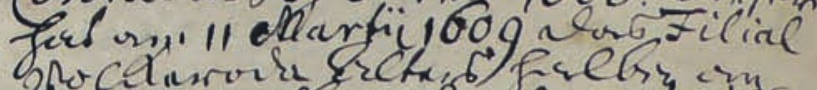

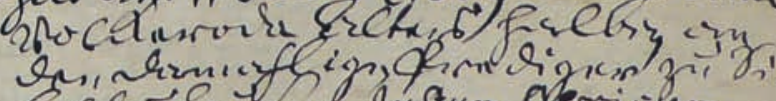

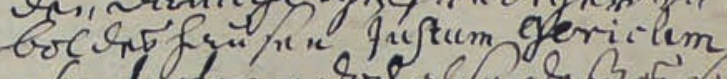

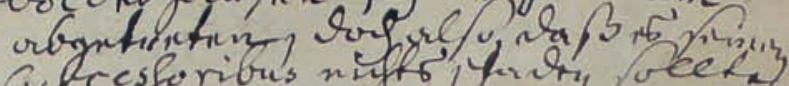

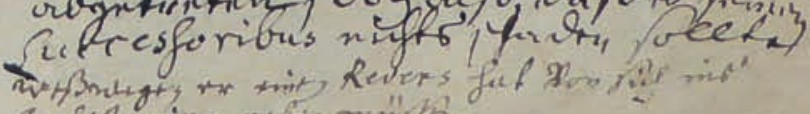

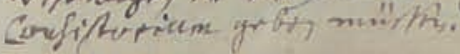

Abb. 2 Der Beginn der Eintragungen durch Magister Stollberg 1737 Quelle: KiKrAGött, P. A. Obernjesa K. R. I.a. 1 [108] 



\section{Transkription}

[108]

p. 1.

Als ich Mag. Joh. Paul Stollberg,

Günstadio-Thuringus ${ }^{1},+$ antea Pastor S. Crucis Gottingae $+^{2}$ allhier zum

Prediger beruffen worden, und fast

keine Nachricht vorgefunden, als

was irgend die beyden Schuel-

meister Schloten zu Obernjesa und

Curtius zu Dramfeld in Verwahrung

gehabt; So habe das nöthige was

ich erfahren können und was sich

zu meiner Zeit zugetragen, in

dieses Buch, weil es nicht mehr

gebrauchet wird, meinen Herrn

Successoribus ${ }^{3}$ zur Nachricht ein-

tragen wollen.

Die Specification ${ }^{4}$ der Bücher

und anderer Sachen, welche bey

die Pfarr und Kirche gehören,

soll sich hinten in diesem Buche finden.

Nach der Reformation durch den

sel. Doct. Lutherum sind folgen-

de Lutherische Prediger allhier

gewesen. ${ }^{5}$

1. Salomon Born, Grimmensis

Saxo ${ }^{6}$, immissus 1556.

1 Günstedt in Thüringen.

2 Vorber Pastor an der Heilig Kreuz Kirche zu Göttingen.

3 Meinen Herren Nachfolgern.

4 Detaillierte Auflistung.

5 Die Amtszeiten der nachfolgend genannten Geistlichen in Obernjesa/Dramfeld nach BIELEFELD 1957, S. $56 \mathrm{ff}$.

6 Salomon Born, 1556-1595. Aus Grimma in Sachsen. 
2. Conradus Schlüter ${ }^{7}$ 1600. Dieser

hat am 11 Martii 1609 das Filial

Volckeroda Alters halber an

den damahligen Prediger zu Si-

boldeshausen Justum Gericum

abgetreten, doch also, daß es seinen

Successoribus nichts schaden sollte.

[andere Tinte:] weßwegen er einen Revers hat von sich ins

Consistorium $^{8}$ geben müssen.

\section{[108v]}

p. 2 .

3. Matthaeus Schwartz 1611.

4. Mag. Andreas Sieburg. ${ }^{10} 1626$.

5. Mag. Joachimus Christophorus Jani ${ }^{11}$

Hannoveranus 1668. Dieser ist noch

an die Jacobs Kirche nach Göttingen

gekommen, hat aber nicht lange daselbß

gelebet. 1669 ist unter ihm die eine

Hälffte vom Pfarrhause allhier, nach

dem Brunnen $\mathrm{zu}$, gebauet worden.

6. Johann Georg Armbrecht ${ }^{12}$ Einbeccensis

1684. mortuus 1713.

7. Joh. Julius Lotzius ${ }^{13}$ aus Holtensen bey

Nordheim gebürtig. 1714. Antea Pastor

Castrensis $^{14}$. Mortuus 1737 den 6 Martii

im 73 Jahre seines Alters.

7 Conrad Schlüter, 1595-1611.

8 Der Revers sowie die Mitteilung an Pastor Stolberg (jun.) vom 10. April 1783, dass Volkerode bei Sieboldshausen bleibt, sind erhalten geblieben (KiKrAGött, P. A. Obernjesa A. 102).

9 Matthäus Schwartz, 1611-1625.

10 Andreas Sieburg, 1626-1668.

11 Joachim Christoph Jani, 1668-1684.

12 Johann Georg Armbrecht, 1684-713.

13 Johann Julius Lotze, 1714-1737.

14 Vorher Feldprediger. 
8. Mag.Joh. Paul Stollberg, ${ }^{15}$ Günstadio-

Thuringus, den 9 Dec. 1737 bin ich einge-

führet. 1735 am 25 Martii bin ich als

Prediger zum heil. Creutze in Göttingen

von dem Hn. Superintendenten Praetorio

eingeführet. 1734 circa festum Paschatos ${ }^{16}$

habe das Sub-Con-Rectorat der Stadt und

RathsSchule zu Göttingen angenommen, als

das Gymnasium aufgehoben wurde, und

die Universität ihren Anfang nahm,

welche erst am 17 Sept. 1737 eingeweyhet

wurde. 1728, 3 Wochen vor Weynachten,

bin ich von Hardegsen aus, zu dem schönen

Cantorat bey dem Gymnasio und der

gantzen Stadt Göttingen beruffen und eingeführet worden.

Den 2 Aprilis 1727 bin ich in meinem

26 Jahre meines Alters Rector an der

Stadt Schule zu Hardegsen geworden

[die folgenden 6 Zeilen in anderer Tinte:]

Und anno 1736 Magister geworden. ${ }^{17}$ Ich habe

in consessu ${ }^{18}$ der Hn. Professorum Philos. den aufge-

gebenen Satz lateinisch vertheidiget da gefraget

wurde: Virum atheismus, an superstitio verae religi-

oni et Reipublicae magis noceat? Atheismum

magis nocere defendi et affirmavi. ${ }^{19}$

15 Johann Paul Stollberg 1737-1761.

16 Um Ostern.

17 Vielleicht ist die Gratulation, die 1739 in Das jetzlebende Göttingen, S. 65, gedruckt wurde, als Glückwunsch zum Wechsel vom Schuldienst in ein Kirchenamt zu deuten: Gratulatoriae. 1736. d. 12. Aprilis. D. Christoph August Heumann, de Transitu per scholam in ecclesiam, ad M. Io. Paul. Stollberg (12. April 1736, Doktor Christoph August Heumann wegen des Überganges von der Schule zur Kirche an Magister Johann Paulus Stollberg).

18 Mit Erlaubnis.

19 Ob der Atheismus oder der Aberglaube der Menschen dem wabren Glauben und dem Staate mehr schade? Ich verteidigte und bestätigte dass der Atheismus mehr schade. 


\section{[109]}

\section{p. 3.}

Am 17 Sept. 1737 hat die Inauguration ${ }^{20}$

der Universität in der Stadt Göttingen

ihren Anfang genommen bey recht schönem

Wetter und Sonnenschein. Der erstere

Gesandte Sr. Königl. Großbrit. Majestaet Geor-

gii II und Churfürstl. Durchl. unsers

Allergnädigsten Herrn waren Seine Hoch-

freyherrl. Excellentz der Herr Geheimte

Rath von Münchhausen ${ }^{21}$, von Straußfurth

bürtig bey Weissensee, welcher in einer

sechsspännigen Staats-Carosse fuhr mit vor-

tretenden 4 Marschällen, welche waren:

H. von Ußlar, H. von dem Busch, $H$. von

Behr, und $H$. von Platen. Der zweyte

Gesandte war Seine Wohlgebohrne Magni-

ficentz Herr Johann Peter Tappe ${ }^{22}$, Con-

sistorial-Director, ein sehr gelehrter Mann,

hielt auf dem mit goldener Tresse bebrämt-

ten Catbeder auf dem Chore, wo jetzt der

Altar stehet, eine vortreffliche Lateinische

Rede, und verrichtete alle ubrige

Actus in eben derselben Lateinischen

Sprache, und setzte den Hn. Doctor

und General-Superintendent Feuerlein ${ }^{23}$

zum ersten Pro-Rectore ein.

20 Einweihung (vgl. Hunger, in: Göttingen Bd. 2, S. 150).

21 Gerlach Adolph von Münchhausen (1688-1770), der Kurator der Universität, d.h. der hannoversche Minister, der die Einrichtung der Universität betrieb (vgl. Hunger, in: Göttingen Bd. 2, S. 143) .

22 Johann Peter Tappe (1678-1754), Jurist, war zeitweise Bürgermeister in Hannover; während seiner Amtszeit verfasste er u. a. eine neue Schulordnung für die hannoversche Stadtschule. Nach seiner Zeit als Bürgermeister wechselte er ins Konsistorium und erhielt von der hannoverschen Regierung als Königlicher Kommissar den Auftrag, dafür zu sorgen, dass in Göttingen die äußeren Voraussetzungen wie Wohnungen und Infrastruktur geschaffen wurden, die eine funktionsfähige Universität brauchte (SAATHOFF, T. 2, S. 15, Mlynek, S. 357 und Hunger, in: Göttingen Bd. 2, S. 147ff).

23 Jacob Wilhelm Feuerlein (1689-1766), Theologieprofessor. Er kam 1737 nach Göttingen als Professor theol. primarius und Generalsuperintendent, wurde 1746 Konsistorialrat, erhielt 1760 das Scholarchat der Göttinger Stadtschule (Wähner, Tagebuch, Anm. 199, S. 33). 
Den 1 Decembris 1737 ist Ihro Majestät

die Königin Carolina ${ }^{24}$, Gemahlin Sr. Königl.

Maj. von Großbrit. Georg des II zu

London sel. verschieden.

Am 9tn. Dec. 1737 wurde von den Hn.

Kirchen Commissarien, Hn. Sup. Hagemann ${ }^{25}$

und Hn. Drosten von Hanstein ${ }^{26}$ mir,

als ich eben aus der Kirche kam, und ein-

geführet worden, ein Königl. Consistorial-

Rescript unterm 5 Sept. 1737 eingehändiget

darinnen mir kund gethan wurde; daß

von hiesiger Pfarr-Länderey sechs

Morgen sollten genommen und bey hiesiges

Pfarr-Wittwenthum geleget werden. Doch solcher

\section{[109v]}

p. 4 .

gestalt, wenn keine Witwe vorhanden

der Prediger solches Land wieder

in Gebrauch haben solle. Und ob ich



Unsere....

Wir unverhalten euch hiemit, was massen

auf Ansuchen der Pfarr-Wittwe Lotzius

zu Obernjesa resolvire ${ }^{27}$ worden; daß

von der dortigen Pfarr-Länderey eini-

ge Morgen bey das dasige Pfarr-Witt-

wenthum, nemlich in jedem Felde ${ }^{28}$ zwey

Morgen geleget werden sollen, und zwar

solcher Gestalt, daß in dem Fall, wenn

keine Pfarr-Witwe vorhanden, so dann

24 Wilhelmine Caroline geb. Markgräfin von Ansbach (1683-1737).

25 Theophilus Andreas Hagemann (Familiendatenbank Dr. Walter Fredebold, N $0125+$ N 0127; N 0303 [15.11.2015]).

26 Carl Friedrich von Hanstein, Drost zu Münden, 1700-1775 (Niedersächsische Fayencen, S. 43).

27 Beschlossen, entschieden.

28 Vom Sommer- und vom Winterfeld sowie von der Brache. 
der jedesmahlige Prediger den Genuß davon haben möge.

Ihr habt demnach das Fernere nöthige deßhalben zu verfügen, mithin von dem

Inhalt dieses Rescripti so wohl dem neu antretenden Pastori, Ehrn ${ }^{29}$ Stolberg als der Pfarr-Witwen Lotzius Nachricht zu ertheilen. Und wir,... Hannover den 5tn. Sept. 1737. K. Grbrt. z. C. B. L. Cons. ver. D. C. u. Kirchen-Räthe ${ }^{30}$ Joh. P. Tappen.

Hierwider habe protestiret und unterm 6 Jan. 1738 folgender Maassen an das Königl. Consistorii zu Hannover supplicire ${ }^{31}$ :

Königl. Großbrt. zum Churfürstl. B.L.Consi-

storio

Hochverordneter H. Consistorial-Director, Hochverordnete Herren Consistorial- u. Kirchen Räthe, Hochwürdige, Hochwohlgebohrne, Hochgebietende u. gnädige Herren!

\section{[110]}

p. 5.

Ew. Hochwürden u. Hochwohlgebr. Befehl gemäß übersende hiebey mit gebührendem Respect meine vor dem Hochlöblichen Consistorio gehaltene kleine Lateinische Rede; und wie mir den 7 Dec. a. p. ein unterm 5 Sept. im Königl. Consistorio abgefaßtes Decret insinuiret ${ }^{2}$ worden, vermöge dessen ich angewiesen werden wolle, der Prediger Wittwe Lotzius zu ObernJesa von dasigen Pfarrländereyen aus jedem Felde 2 Morgen und also ins-

29 Das Prädikat „Ehrn“ bzw. „Ehrwürden“ kennzeichnete die angesehene Stellung eines Geistlichen (Косн, S. 42).

30 Königlich Großbritannisch zum Churfürstl. Braunschweig-Lüneburgischen Consistorio verordnete Director, Consistorial und Kirchenräte.

31 Beantragt, nachgesucht.

32 Übergeben. 
gesammt 6 Morgen zu ihrem Witwenthum einzuräumen; So werden Ew. Hochwürden u. Hochwohlgebr. gnädig geruhen, sich in Unterthänigk. von mir vortragen zu lassen: Wie

1.) Die jetzige Pfarr nach genauer Erkundigung so beschaffen ist, daß ich durch die Translocation ${ }^{33}$ keinen Vortheil dabey gewonnen habe, welches um so viel mehr zu sagen ist, da ich

2.) Keine Erkenntniß vom Ackerbau habe, mithin in den ersten Jahren, durch mercklichen Schaden erst davon Information erlangen muß, wozu denn

3.) kommt, daß durch die besondere Haushaltung meines seligen Antecessoris ${ }^{34}$, nach einhelliger Aussage meiner eingepfarrten Ackersleute, die Pfarr Ländereyen auf solche Art ausgemergelt sind, daß ich bey vielen Unkosten dieselbigen in vielen Jahren erst in solchen Stand wiederum setzen werde, den davon zu hoffenden Nutzen zu ziehen und zu geniessen. Wenn nun aber bey den angebrachten wahrhafftigen Umständen mir noch darzu von meinen pro Salario angegebenen Pfarr-Ländereyen 6 Morgen Landes sollten entrissen werden; So würde mich ausser Stand gesetzet sehen, ohne zu machende unvermeidliche Schulden meinen Haushalt zu führen, Besonders da mein sel. Antecessor, bey denen im guten Stande gewesenen völligen Pfarr Länderey sich ohne Schulden nicht erhalten können. ${ }^{35}$ Uber dem so ieh muß ich

4.) jährl. an das Königl. Amt zu Münden 10r. 30mg. ${ }^{36}$ und an das Kloster Weende jährl. 1r. ${ }^{37}$ wie auch

\footnotetext{
33 Versetzung.

34 Vorgänger.

35 Pastor Lotze hinterlies nicht nur Schulden bei der Kirche, sondern offensichtlich auch eine höchst unübersichtliche Kirchenbuchführung (KiKrAGött, P. A. Dramfeld K. R. I.a. 4, siehe die Antworten auf die Monita zur Kirchenrechnung von 1754/1755).

36 Dienstgeld für die Pfarrländerei (BIELEfEld 1957, S. 51.)

37 Das ist die Gebühr pro recognitione juris patronatus, für das Recht, den Pastor einzusetzen, das erst 1922 abgelöst wurde (BIELEFELD 1957, S. 49).
} 
an hiesigen Schuelmeister 4 Hbt. Rocken jährlich

für sothane Pfarr-Länderey auszahlen, sollten

mir nun annoch 6 Morgen decourtiret ${ }^{38}$ werden, so würde sich ein gedoppeltes damnum emergens ${ }^{39}$

bey mir ereignen und ich

5.) Bey meinen Successoribus in den größten Miscredit

gesetzet werden, daß ich zu erst unter allen Pre-

digern eine solche alienationem vel quasi $\mathrm{zu}$ ihrer

größten Praejuditz., ohne die geringste unterthänigste

Vorstellung deßfalst zu thun, eingestanden hätte. ${ }^{40}$

Ja wenn Ew. Hochwürden und Hochwohlgebr. mir

\section{[110v]}

p. 6 .

gnädigst zu erwegen geruhen werden; daß oben erwehntes gnädigstes Rescript mir allererst den 9 Dec. a. p. insinuiret worden, mithin zu meiner Notitz zu einer solchen Zeit gelanget ist, da ich bereits die Vocation $^{41}$, u. allergnädigste ausgefertigte Königl. Confirmation deßfalß erhalten hatte; So wird sich gar leicht finden, daß ich an solchen PfarrLändereyen bereits ein jus quaesitum erhalten, mithin dieselbigen absque omni diminutione mir gelassen werden müssen; dum enim in plurimis locis salaria non adeo magna constituta sunt, injuria fieret parochis, si diminuerentur qvovis modo. Ill. Boebmerus in jure Parochiali Sect. 7. Cap. 1. \$.28. ${ }^{42}$ Ja es erweiset dieser ge-

38 Abgenommen.

39 Resultierender Schaden.

40 Heißt so viel wie: ...sollten mir noch 6 Morgen genommen werden, hätte ich davon doppelten Schaden und käme bei meinen Nachfolgern in den größten Miscredit, weil ich, als erster in der Reihe der Prediger, zum Beispiel eine solche Abtretung zu ibrem größten Nachteil akzeptiert hätte, ohne deswegen im geringsten vorstellig geworden zu sein.

41 Berufung.

42 Er weist darauf hin, dass wäbrend nämlich in mehreren Orten nicht so große [hohe] Gehalte bestünden, gereichte es den Gemeinden zum Schaden, wenn sie in irgendeiner Weise vermindert würden. [So] der berühmte Dr. Boebmer in Kirchenrecht Sektion 7. Cap. 1. §.28. Magister Stollberg zitiert hier den Juristen Georg Ludwig Böhmer (1715 
lehrte Juriste $l$. $c$. höchst gegründet: daß ein

Prediger nicht einmahl angehalten werden könne, das pactum zu halten, wenn er bey der Vocation versprochen, sich etwas von seinem Salario decourtiren zu lassen; sondern wenn er auch gleich einmahl das geschmälerte Salarium sollte gehoben haben, dennoch ohngeachtet integrum Salarium und dazu den Nachschuß des ihm einmahl decourtirten Salarii fordern könne, quum pactorum, quae contra bonos mores sunt, nulla sit obligatio L. 7. $\$ .7$ D. de pactis. ${ }^{43}$ Wie vielmehr kan ich im gegenwärtigen Falle aus solchen Gründen schliessen, daß mir, da ich kein solches pactum errichtet habe, mein jus quaesitum nicht genommen und meines Lebensunterhalt sine gravi praeiudicio nicht entsetzet werden könne. Notum enim est, quod ea ratione cum ex Salario exiguo et diminuto parochus vivere haud possit, parochus inducatur ed varia media se extribendi excogitanda, unde saepe onerosus esse parochianis cogitur Doct. Boebmerus. l. c. ${ }^{44}$

Ich mag aber so wenig mein Gewissen, als mein Amt durch eine solche unanständige Sorge der Nahrung beflecken und bitte daher Ew. Hochwürden wie auch Hochwohlgebr. unterthänigst mir von meinem Salario, welches ohne dem ad necessitatem nur eingerichtet ist, nichts zu entziehen,

\section{[111]}

p. 7.

sondern der noch sehr jungen Wittwe Lotzius auf andere Art, als mit meinem positiven Schaden gnä-

(1717?)-797), der seit 1740 in Göttingen lehrte und Syndikus der Göttinger Universität war (Wëhner, Tagebuch, Anm. 297, S. 45 und S. 234; Katalog der Bildnisse, Nr. 19).

43 Denn: weil Verträge, die gegen die guten Sitten sind, nicht bindend sind; L.7. \$.7 D. über Verträge.

44 Es ist nämlich bekannt, dass sich der Pfarrer, weil er von dem knappen und geschmälerten Gehalt nicht leben kann, veranlasst sieht, sich die Beschaffung von allerlei Mitteln auszudenken, so dass er von den Pfarrkindern oft als lästig empfunden wird. Dr. Boehmer a.a. O. 
digst hülffliche Hand zu bieten. Es haben die Kirchen zu Obernjesa und Dramfeld ziemliche Revenuen, ich stelle ich [!] es Dero tiefen Einsicht anheim, ob es nicht thunlicher wäre, selbiger davon etwas zu ihrer Sustentation ${ }^{45}$ jährl. zu assigniren. Mit wenigem muß noch in tiefster Submission eröffnen: daß die Witwe Lotzius nicht eher das ihrem sel. Manne übergebene Pfarr-Inventarium auslieffern will, bis ich ihr die ihrem GutDüncken nach angegebene Melioramenten bezahlet habe; ${ }^{46} \mathrm{da}$ ich doch bey meiner Introduction ${ }^{47}$ mich dahin erkläret, daß ich ihr so viel bezahlen wollte, als sie erweißlich machen wird. Ew. Hochwürden und Hochwohlgebr. flehe ich hiedurch gnälig an unterthänigst an, obgedachter Wittwe nicht allein gnädigst und nachdrücklichst anzubefehlen, daß mir die Specification aller zur Pfarr gehörigen Sachen ausgeliefert, sondern auch mein ohne dem geringes Salarium ohne allen Abbruch und Verschmälerung gnädigst gelassen werde. Ich getröste mich gnädigster Erhörung und verharre mit aller Ehrfurcht in tiefster Submission Ew. Hochwürden und Hochwohlgebr. Meiner insonders Hochgebietenden und Gnädigsten Herren unterthäniger Diener M. Joh. Paul Stollberg. Suppl. Obernjesa am Gten Jan. 1738.

Hierauf erhielt ich am 31 Jan. 1738 nachfolgendes, wofür ich $10 \mathrm{gg}$. und $8 \mathrm{~d}$ ohne das Postgeld zahlen mußte. Aufschrifft: Dem Würdigen Wollge-

\footnotetext{
45 Unterstützung.

46 Eine Verordnung, die den Melioramentenvergleich regelte, wurde erst ein Jahr nach Amtsantritt Magister Stollbergs erlassen (ScheuermanN, in: GöJb 61, 2013, S. 188. Vgl. [113v].

47 Einführung.
} 
lahrten [!], Unserm günstigen guten Freun-

de, Ehrn Mag. Jobann Paul Stollberg,

Pastori zu ObernJesa.

Unsere freundliche Dienste zuvor, wür-

diger Wollgelahrter günstiger guter

Freund!

Es ist gelieffert, was ihr wegen der

\section{[111v]}

p. 8 .

auf Ansuchen Weyland eures Antecessoris Ehrn

Lotzii nachgelassene Wittwen bey das dasige Pfarr-

Wittwenthum gelegter 6 Morgen Pfarrlandes

anhero gelangen lassen, und dabey vorgestellet

habt.

Als nun daß solches geschehen solle, von hiesiger

Königl. Regierung im Anfang des Augusti vo-

rigen Jahres bereits resolviret ${ }^{48}$ und festgestellet

ist; So habt ihr dabey $\mathrm{zu}$ acquiesciren ${ }^{49} \mathrm{um}$

desto mehr Uhrsache, als vielleicht dermahleins

eure Witwe, wenn ihr nach Gottes Willen

eine hinterlassen solltet, da von einigen Nutzen

haben kan; Uber dem auch, wenn keine Wittwe

vorhanden ist, das Land an die Pfarr wie-

der zurückfällt:

Was die Pfarr- Melioramenten ${ }^{50}$ betrifft, derenthalben habt ihr bey denen Kirchen Visi-

tatoribus Anforderung zu thun, daß sie sel-

bige untersuchen und liquid machen, es ist aber

dannach die Ausliefferung des Pfarr Inventarii

und Registratur mit aller Zubehör nicht auf-

zu halten: Wie denn solcher halben an besagte

$\overline{48 \text { Entschieden, beschlossen. }}$

49 Sich beruhigen, zufrieden sein.

50 Melioramente sind Neuerungen und Verbesserungen der Ländereien und des Wirtschaftshofes der Pfarre durch den Amtsinhaber, die sich der abgehende Geistliche oder dessen Witwe von seinem Nachfolger zu einem bestimmten Teil bezahlen läßt; die Problematik dieser Vergleiche wird anschaulich bei Scheuermann, in: GöJb 61, 2013 , S. 183-212, dargestellt. 
Visitatores hierbey Rescriptum ergehet. Und wir sind euch zu freundlichen Diensten geneigt.

Hannover den 10 Jan. 1738.

Königl. Großbrt. zum Churfürstl. Br.

Lüneb. Consistorio verordnete Director

Consistorial- und Kirchen- Räthe

Joh. P. Tappen

Tram.

Wegen des Pfarr Inventarii hat sich die Frau

Witwe Lotzius entschuldiget, sie hätte keins.

Und als der Sohn meines sel. Praeantecessoris ${ }^{51}$

Armbrechts bekräfftigte, daß sie ihrem sel. Manne

viele Schrifften ausgelieffert hätten, sammt

dem gantzen Pfarr- und Kirchen-Inventarii wie

auch einen Melioraments Vergleich, habe ich

\section{[112]}

9.

M. Stollberg die Frau Wittwe selbst darum angesprochen; da sie folgende Worte gegen mich ausstieß: Ich sollte hingehen zu ihrem Manne, der lege in der Kirche begraben, den sollt ich fragen, sie wüsste von nichts.

Ich habe auch von ihr nichts erhalten, sondern was ich habe von alten Nachrichten, das haben die Schuelmeisters mir ausgelieffert.

Das Pfarr-Land, welches zum Wittwenthum ist gegeben und wider meinen Willen ausgesuchet worden, von dem Amtsschultzen Pleicken auf Befehl des Herrn Oberhauptmanns von Hanstein ${ }^{52}$ Ist I. Im Dramfelde.

51 Vorvorgänger.

52 Obernjesa gehörte damals zum Amt Münden. 
3 Vorlinge auf die Strüllen schiessend zwischen des Klosters Hilwartshausen und Hn. von Wissels Lande.

1 Vorling am Stockhäuser Wege

II. Im Siboldeshäusischen Felde.

1 Morgen zwischen Kogels Lande.

1 Morgen am Jäger Wege.

III. Im Niederjesischen oder Horl. Felde.

1 Vorling bey dem weissen Steine zur Lincken über den Göttingischen Weg. Dieses Vorling ist von einem 3 Morgen Acker abgenommen.

1 Vorl. beym Nesselbusche zwischen Hilwarthausischen u. Bühren Lande. 1 Morgen am Schaastalle [!], zwischen Dranßfelder u. And. Fischers Lande.

Diese 6 Morgen sind Zehnt- aber nicht Dienstfrey. ${ }^{53}$ [Mit anderer Tinte]: Und trägt die Frau Witwe zu ihrem Theile jährlich zu:

19g. u. 4d. Und der Pastor giebt: 10r. 10g. 4d.

\section{[112v]}

p. 10.

Die beyden Dörffer an der Leine Obernund NiedernJesa haben in alten Zeiten zu den Gütern der Edlen Herrn von Jese gehöret. Von welchen Hn. man heut zu Tage keine Spur mehr findet. Daher kommt der Jeser Berg, ein Kleines Holtz welches nach ObernJesa gehöret, und nicht der Jägerberg, wie es jetzund ausgesprochen wird. $\mathrm{Zu}$ der Pfarr ObernJesa haben bey der 1588 gehaltenen Landesherrlichen

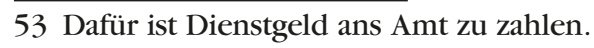


General-Kirchen Visitation ${ }^{54}$ gehöret

die beyden Filial Dörffer und Gemein-

den Dramfeld und Volckeroda.

Pfarrgüter sind damahls angegeben:

1.) Vor Obernjesa 3 Hufen Land. Viel-

leicht sollens Fuldische Hufen seyn.

2.) Von Dramfeld 2 Malter Rocken

6 fl. Geld 1 Hbt Rübesaamen

und 1 Hbt Erbsen. ${ }^{55}$

[mit anderer Tinte und kleinerer Schrift nachgetragen:]

Dieses haben die Dramfelder ohne Zweifel im 30 Jährig. Kriege abgebracht. ${ }^{56}$

\section{3.) Von Volckeroda 6 1/2 Malter Roggen \\ 6 Gulden Geld 1 Hbt Rübesaamen.}

4.) Ein Umgang und Vierzeiten Opffer. ${ }^{57}$

5.) Vom Kloster Marien-Garten

[Angaben mit anderer Tinte am unteren Seitenrand nachgetragen:]

5 Malter Roggen, 2 Mrlt. Gersten, 2 Hbt

Weitzen, 2 Hbt Erbsen, 3r.12g. Geld, 1 Hbt Lein

zusäen und $1 \mathrm{Hbt}$. Rübesaamen, welche letztern

beyde Hbt. mit 2 r. vergütet und bezahlet werden.

541588 wurde eine Generalkirchenvisitation durchgeführt, für Calenberg und Göttingen zwei Generalsuperintendenturen eingerichtet, die damals dem Konsistorium in Wolfenbüttel (Fst. Braunschweig-Wolfenbüttel unter dem evangelischen Herzog Julius) unterstellt wurden (KRUmwiede, Bd. 1, S. 137).

55 Von Dramfeld 2 Malter Roggen, 6 Gulden Bargeld und 1 Himbten Rübesamen (Rübsen, Brassica rapa L., eine dem Raps verwandte Brassica-Art) und 1 Himbten Erbsen.

56 Im Sinne von: Dies haben die Dramfelder ohne Zweifel im 30jährigen Krieg in Vergessenheit geraten lassen.

57 Siehe Schlegel, 3. Teil, S. 146: ...geht zurück auf die ältesten Kirchen-Gebräuche, und hat seinen Ursprung von den freywilligen Opferungen bey der Communion, welche gewöhnlich viermal im Jahre, als an den drey hohen Festen [Weihnachten, Ostern, Pfingsten] und zu Michael gehalten ward. Auf S. 147 heißt es, dass dieses Opfer seiner ersten Einrichtung nach (...) durch einen Umgang um den Altar dargebracht (wird)...Und S. 150 mit Bezug auf die Calenbergische Kirchenordnung: Das Opfer wurde in der Kirche selbst auf dem Altar dargebracht. BIELEFELD gibt im Abschnitt „Die Pfarrbesoldung“ an, dass die Kirchenkasse dem Pastor ein Vierzeitgeld zahlt, darüber hinaus jede Person, die das Abendmabl nimmt, einen geringen Betrag zahlen muss; nicht angegeben ist, wie hoch dieser Teil des Gehaltes war (BIELEFELD, 1957, S. 53). 
Die besten Nachrichten von hiesiger Gegend müssen sich in Wolffenbütel finden, dahin alle Schrifften im Anfange des 30 Jährigen Krieges haben müssen eingelieffert werden.

\section{[113]}

11.

Wegen des pretii der Catechumenorum. ${ }^{58}$

Am 30Jan. 1738 wurde praesentiret. Auf erhaltenem Befehl des Königl. und Churfürstl. Hochlöbl. Consistorii sub dato - Hannover den 21 Junii 1737 beliebet denen sämmtlichen Pastoribus Mündischer Inspection hiedurch ohnverhalten: was massen pro informatione Catechumenorum folgendes reguliret: daß von denen wohlbemittelten $18 \mathrm{mg}$. von denen, die mitlern Standes sind $12 \mathrm{mg}$. und von denen Geringern 9mg. Von den Unvermögenden aber nichts bezahlet werden solle. Es werden also dieselben in Bezahlung für die Information eines jeden Catechumeni Obiges zur Richtschnur führhin dienen lassen. Münden, den 21 tn. Octobr. 1737.

Verordnete Kirchen Commissarii

AF Hagemann. S. Eh.von Hanstein. ${ }^{59}$

Den 1 Dec. 1737 Ist die Allerdurchlauchtigste Großmächtigste Königin u. Frau, Frau Carolina, Königin von Großbrit. Franckreich

58 Gebühr, die die Katechismusschüler zu zahlen hatten.

59 Offensichtlich ließ sich die Frage, wer wieviel für den Konfirmandenunterricht zahlte, nicht auf freiwilliger Basis lösen, so dass das Konsistorium gezwungen war, Richtsätze vorzugeben (vgl. SChlegel, 5. Teil, S. 129). 
u. Irrland, Churfürstin von Braunschweig

u. Luneburg, gebohrne Marck-Gräfin zu

Brandenburg aus dieser Welt abge-

schieden. Praesentatum ObernJesa den 18 Dec.

1737.

Den 1 Februarii 1738 Ist ein Königl. Consi-

storial-Befehl unterm 16Jan. 1738 publiciret

wegen Praenumeration ${ }^{60}$ des ersten Theils der

Landes Constitutionum, welcher Ecclesiasti-

$c a^{61}$ betrifft, mit 1r. u. 16gg. wie auch $1 \mathrm{mg}$.

von den Hn. Superintendenten zu Bestreitung

der Unkosten. Imgleichen Sub eodem dato ${ }^{62}$

\section{$[113 v]$}

12 .

noch ein Königl. Consistorial Befehl, daß die Con-

stitutiones Ecclesiasticae dem neuen Prediger

von der Witwe oder des verstorbenen Pasto-

ris Erben jedesmahl vor Bezahlung der

Melioraments-Gelder sollen extradiret werden.

[Die folgenden drei Zeilen sind mit anderer Tinte eingefügt]:

Anno 1738 ist das Witwen Haus auf dem Klimpe

gebauet worden. ${ }^{63}$ Die Dramfelder haben den dritten Theil

und des Holtzes so wohl als der Kosten hergeben müssen.

Praes. den 5tn. Maji Königl. Consistorial-

Befehl, daß das Trauer Geläute wegen

Absterben Höchst seliger Königin Majestaet

cessiren solle, unterm 25 April 1738.

60 Vorausbestellung.

61 Kirchliche Angelegenheiten.

62 Unter dem gleichen Datum.

63 Sobald der Pastor gestorben war, musste seine Witwe das Pfarrhaus räumen, um dem Nachfolger und dessen Familie Platz zu machen. In Obernjesa wurde das letzte Witwenhaus am nordwestlichen Rand des Dorfes erbaut, oberhalb der dort ursprünglich vorhandenen Lehmkuhle (vgl. BIELEFELD 1957, S. 66). 
Den 11 Maji 1739 ist unterm 17 Junii 1738

Eine Königl. Consistorial-Verordnung publi-

ciret das denen Superintendenten- und

Prediger-Wittwen und Erben, zukommen-

de respective gantze und halbe Gna-

den Jahr betreffend. ${ }^{64}$

Eodem unterm 15tn. Julii 1738 ist die Königl. Consisto-

rial- Verordnung, die Pfarr Meliora-

mente betreffend publiciret.

Den 10tn. Aug. 1738 Ist unterm 29tn Junii

1738 Eine Verordnung ergangen, daß

der Scheffel Schatz selle ver auf die Halb-

scheid $^{65}$ solle erlassen seyn.

Den 15 Julii 1739 unterm 6Julii 1739

Ist eine Haus Collecte für die Abgebrandten

in Harpstädt publiciret. ${ }^{66}$

Den 23Jan. 1740 Ist ein Circular ergangen

unterm 16Jan. 1740, wegen der auf dem

Wildenmann abgebrandten in der Nacht von

21 bis 22 Julii 1739, 64 Häuser daß

eine Haus Collecte sollte verstattet seyn. ${ }^{67}$

Den 10 April 1740 ist unterm 22tn. Martii 1740

der Cattun und Sitz (! ${ }^{68}$ bey schwerer Straffe verboten

64 Die Witwe eines Superintendenten erhielt nach dem Tod ihres Ehemannes noch ein ganzes Jahr lang die Bezüge des Verstorbenen, die Witwe eines Pastors nur noch ein halbes Jahr lang.

65 Die Abgabe auf jeden Scheffel Getreide wurde zur Hälfte erlassen.

66 Harpstedt, Landkreis Oldenburg. Laut Titz-MatuszaK, S. 188, war dies ein besonders grosses Feuer, bei dem 69 Häuser und 45 Nebengebäude abbrannten; um eine ausreichend hohe Spendensumme zu erzielen, wurde eine Hauskollekte genehmigt; die Stadt Göttingen überwies seinerzeit $57 \mathrm{r} .23 \mathrm{mg} .7 \mathrm{~d}$.

67 Einen Schaden in dieser Höhe erwähnt auch Titz-Matuszak, S. 188; die Spendensumme der Stadt Göttingen belief sich seinerzeit nur noch (im Vergleich zu Harpstedt) auf 41r.24mg.6d.

68 Eine landesherrliche Verfügung Georgs II., die die eigenen Textilprodukte schützen sollte. 
worden. [mit anderer Tinte]: Ist 1743 mit dem Anfange des Jahr wieder los gegeben, und das Befehl aufgehoben. ${ }^{69}$

\section{[114]}

13.

Den 1 Martii 1739 sind gegen Abend auf den Sonntag $\mathrm{Oculi}^{70}$ in HeiligenStadt bey die 700 Häuser ohne Ställe und Scheuren abgebrandt. Man konnte das Feuer hier zu Obernjesa sehen.

Den 9tn. Martii 1739 gegen Abend um 9 Uhr sind in Bovenden 7 Häuser abgebrandt. ${ }^{71}$

Den 7 Augusti 1740 Ist das Müntz Edict unterm 15 April hier publiciret worden. ${ }^{72}$

Den 10tn. April 1740 Ist eine Becken Collecte zur Erbauung einer neuen Kirche zu Duingen im Amte Lauenstein unterm 18 Sept. 1739 verwilliget worden.

Anno 1740 ist

Den 30tn. Aug. 1740 Ist eine Verordnung ergangen, unterm 29Julii 1740 wegen des Pietismi und Separatismi. ${ }^{73}$

69 Laut gedruckter Verordnung wurde dieses Edikt bereits am 7. Dezember 1742 wieder aufgehoben, weil man festgestellt hatte, daß der dabey intendirte Nutzen in der Maaße, wie man es gewünschet, nicht erreichet worden (SUB Göttingen VD 18 90216741).

70 Der dritte Sonntag der Passionszeit.

71 Das Bovender Kirchenbuch verzeichnet in dieser Zeit mehrere Brände, die jeweils auf Brandstiftung zurückgegangen sein sollen (BuscH, Kriegs- und Alltagsleben in Bovenden, S. 83).

72 Das hier erwähnte Münzedikt vom 15. April 1740 ist eine der zahlreichen Verordnungen, die regelmäßig erlassen worden sind, um das gute eigene Geld zu schützen (vgl. GERHARD 2001, S. 415); sie gaben die verrufenen, d. h. ungültigen Münzsorten bekannt.

73 Die hannoversche Regierung erließ im Laufe der ersten Hälfte des 18. Jahrhunderts wiederholt Verordnungen gegen und wegen der Pietisten und der Herrnhuter und Mähri- 
Den 12 Novembris Ist abermahls

eine Verordnung unterm 12 Octobr.

1740 wegen des Pietismi ergangen.

Den 20tn. Octobris 1740 Ist der bisher

Römische Kaiser Carl der VI zu ${ }^{74}$

Wien verstorben. Man sagt, daß

Er mit Gifft vergeben sey.

Den 17 Dec. 1740 Ist abermahl eine

Verordnung unterm 31 Oct. 1740 er-

gangen, wegen der Pietisten, Indifferen-

tisten $^{75}$ und ander Teuffels Geschmeiß

Darinnen etliche Kennzeichen ihrer

irrigen Lehre angegeben worden.

Den 16 Martii 1741 Ist ein Circular einge-

lauffen wegen des allgemeinen BußTages

welcher auf den 12 April 1741 im hiesigen

gantzen Lande solle gefeyret werden.

Der Text Jer. 6, 8 vormittages ${ }^{76}$

nachmittages $\psi .79,9:^{77}$

Den 11 Aug. 1741 hat die hiesige Oberjesische

Gemeine, die eine Hälffte von der Schule bauen

schen Brüder (vgl. Willich, Bd. 2, S. 901: 20. Febr. 1703; S. 902 und 903: 15. März 1703; S. 904: 15. May 1711; S. 905, 906: 8. Jun. 1734; S. 906: 12. Oct. 1740; S. 907, 908: 22. Nov. 1748; Oberschelp Bd. 2, S. 262, Krumwiede Bd. 1, S. 230), da die Anhänger dieser Vereinigungen keine gehorsamen Untertanen zu sein schienen: Sie wehrten sich gegen das vom Staat autorisierte konfessionelle Kirchentum, [gegen] die protestantische Staatsund Volkskirche; sie verteidigten ein elementares Bedürfnis, das Leben in Familie und Beruf nicht auf den von Staat und Kirche vorgezeichneten Wegen zu fübren (KRUMWIEDE Bd. 1, S. 225ff).

74 Dieser Kaiser hatte das Privileg für die Göttinger Universität erteilt (vgl. Hunger: Die Georg-August-Universität als Landesherrliche Gründung, in: Elmar Mittler (Hg.): „Eine Welt allein ist nicht genug“. Großbritannien, Hannover und Göttingen 1714-1837. Katalog, Göttingen 2005, S. 105).

75 Hier ist die Gruppe derjenigen gemeint, die gegenüber Religion und Moral gleichgültig waren.

76 Altes Testament, Der Prophet Jeremia, 6. Kapitel, Vers 8: Bessere dich, Jerusalem, ehe sich mein Herz von dir wende...

77 Psalm 79 Vers 9: Hilf du uns Gott, unser Helfer, um deines Namens Ebre willen; .. 
und aufrichten lassen, welches die Dehl

und Scheune in sich begreiffet.

\section{[114v]}

14.

Den 1 Martii 1742 Ist bekannt gemacht

worden daß am 24 Januarii 1742

der Churfürste zu Bayern Carl

Albrecht zum Römischen Kaiser

durch die hohen Churfürstl. Wahl-

Stimmen in Franckfurth am

Main erwählet orden und

Carolus der VII genannt worden.

Den 12 Jan. 1742 Ist ein Patent, daß denen

Deserteurs, welche sich binnen 2

Monathen bey ihren Fahnen wieder

einfinden, Pardon angedegen soll ergangen. ${ }^{78}$

Den 23 Martii 1742 Ist eine Prolongation

unterm 7 Martii, der unterm 12 Jan. 1742

ausgelassenen Pardon Brieffes wegen

der Deserteurs publiciret.

Königl. Consistorial-Rescript wegen

def armen Priester Wittwen unterm

9tn. Martii 1742, ergangen.

Mit dem Anfange dieses Jahrs 1742 Sind

der Herr Pastor Appubn ${ }^{79}$ zu Göttingen

und der H. Mag. Hartel Pastor zu

Siboldeshausen über die Mündische In-

78 Im Österreichischen Erbfolgekrieg war das Kurfürstentum Hannover auf Seiten Österreichs an verschiedenen Feldzügen beteiligt und brauchte infolgedessen ständig Soldaten (vgl. SicharT Bd. 2, S. 377ff); Verordnungen, die eine straffreie Rückkehr des Deserteurs zu den Truppen ermöglichten, wurden wiederholt erlassen, auch nach dem Siebenjährigen Krieg 1762 und 1764 erneuert und erweitert (vgl. Oberschelp, Niedersachen I, S. 333).

79 Johann Ernst Appuhn, damals Pastor von St. Albani in Göttingen, und der Sieboldshäuser Pastor Mag. Franz Konrad Hartel teilten sich den Sprengel Münden II (MeYer, Pastoren II, S. 372). 
spection Superintendenten geworden.

Der H. Sup. Appubn hat die Leine-

Dörffer ${ }^{80}$ sammt der Stadt Dranßfeld

bekommen, und der H. Mag. Sup. Har-

tel die ubrigen Dörffer, weil der

H. Superintendens Hagemann zu Mün-

den sehr alt und schwach ist. ObernJesa

ist auf eine Zeitlang anstatt Siboldeshausen

dem Hn. Sup. Doct. Riebow ${ }^{81}$ gegeben und

dem Hn. Sup. Appubn für ObernJesa Bühren vor

\section{[115]}

15 .

der Walde gegeben worden, bis der Herr Pastor und Senior Mengershausen zu Hedemünden, nach Gottes willen verstirbet, als denn ziehet der H. Sup. M. Hartel nach Hedemünden, Siboldeshausen kommet wieder an den Hn. Sup. Doct. Riebow ObernJesa wieder an den Hn. Sup. Appubn, und Bühren wieder an den Hn. Sup. M. Hartell [!].

Den 9tn. April 1742 Ist der Herr

Superintendens Hagemann in einem

hohen Alter zu Münden selig eingeschlaffen. Ist fast 42 Jahr Superintendens gewesen.

Den 24tn. Junii ist ein Circular wegen der HausCollecte für die 113 abgebrandte

80 Die Dörfer, die zum Gericht Leineberg gehörten: Rosdorf, Grone, Holtensen, Groß Ellershausen.

81 Georg Heinrich Riebow (auch Ribovius oder Ribov) kam 1736 als Superintendent und Prediger nach Göttingen, wurde 1739 ord. Professor der Philosophie, 1742 a. o. Professor der Theologie, [und] 1745 ord. Professor der Theologie; er war von 1758 bis 1759 Prorektor; er ging 1759 als Konsistorialrat nach Hannover (WäHnER, Tagebuch, Anm. 219, S. 35). 
zu Eldagsen, welcher am 18tn. Maji

1742 in $2 \frac{1}{2}$ Stunden geschehen, ergangen.

Des Nachts um 2 Uhr zwischen den 3ten

und 4 ten Julii ist der H. Superinten-

dens M. Hartel zu Siboldeshausen an

einem hitzigen Brust Fieber selig ein-

geschlaffen.

Den 13 Sept. 1742 ist das hiesige Krieges

Volck und Adelipsche Dragoner Regiment

nach Braband ${ }^{82}$, wider den Frantzosen

aufgebrochen, Gott gebe ihnen Glück

wider die Frantzosen.

Den 4 Nov. 1742 Ist der H. Pastor Schaar ${ }^{83}$

zu Diemarden eingeführet.

Den 27 Nov. 1742 Ist der H. Past. Mag.

Muhlert zu grossen Längen selig eingeschlaffen.

Den 25 Nov. am 27 Trinitatis $^{84}$ hat der Herr

Pastor Hüpeden ${ }^{85}$ zu Lütgen Schneen seine Ab-

zugs Predigt gehalten, und ziehet nach

Schauen 3 Meile von Goßlar und 3

Meile von Halberstadt.

\section{[115v]}

16.

Den 23 Dec. als auf den 4 tn. Advents Sonn-

tag ist Johann Lucas Engel aus Minnige-

roda von Eißfelde gebürtig, der bisher

82 Georg II. hatte am 24. 6.1741 zugesagt, die pragmatische Sanktion verteidigen zu wollen: In Folge dieses Beschlusses ließ Georg II. den größten Theil seiner hannoverschen Truppen im October 1742 nach Brabant aufbrechen (vgl. SicHART Bd. 2, S. 84).

83 Clemens Caspar Schaar (Meyer, Pastoren, S. 193 und S. 221).

84 Am 27. Sonntag nach Trinitatis (1. Sonntag nach Pfingsten).

85 Ludolf Wilhelm Hüpeden (Meyer, Pastoren, S. 30). 
Römisch-Catbolisch gewesen, nach dem ich

ihn etliche Wochen informiret, Evan-

gelisch Lutherisch geworden, und hat in

der Dramfeldischen Kirche zum erstenmahl

das Heil. Abendmahl unter beyderley

Gestalt genossen. Gott erhalte ihn

in diesem seligmachenden Glauben und

in einem Heiligen Leben! Mag. Stollberg. ${ }^{86}$

Den 13Jan. 1743, war der erste Sonntag

nach Epiphanias, Ist der neue Herr

Pastor, Henrich Hermann Flügge, zu

Lütgen Schneen, eingeführet worden, von dem Hrn. Sup. Doct. Riebow

dabey ich Mag. Stollberg die Pre-

digt gehalten und assistiret habe.

Den 29Jan. ist endlich der alte u. listige Car-

dinal Fleury des Mittages gestorben. ${ }^{87}$

Den 20tn. Febr. 1743 hat sich Johann Ernst Briecke

von Marien Elisabeth Hentzig Hurkinde

vor Menschen zu Münden losgeschworen. ${ }^{88}$

Den 11tn. Maji 1743 ist die neue KirchenLade

aus Göttingen hier ankommen. ${ }^{89}$ Der Tischer [!]

hat bekommen 5 r. u. der Kleinschmidt

.... 9r. laut Quitungen.

86 Offenbar hat Lucas Engel in Dramfeld nicht das große Glück gefunden. Die Familie gehört in späteren Jahren zu den armen Einwohnern, die u. a. nicht das Schulgeld für ihre Kinder aufbringen konnten (vgl. KiKrAGött, P. A. Dramfeld K. R. III. 1, Belege 1734-1788).

87 André-Hercule de Fleury (1653-1743), französischer Kardinal und Staatsmann, u. a. auch Erzieher Ludwig V. Unterstützte nach dem Tode Carls VI. nicht mehr die Thronfolge von dessen Tochter Maria Theresia (Goyau, Georges: André-Hercule de Fleury. The Catholic Encyclopedia. Vol. 6., Robert Appleton Company, New York 1909).

88 Hurkind: Kind einer Prostituierten bzw. unehelich geborenes Kind (vgl. Brüdermann, S. 400, Anm. 144). Marie Elisabeth Hentzig hatte Johann Ernst Briecke als Vater ihres Kindes genannt. Obernjesa gehörte zwar ab 1743 zum Gericht Leineberg, die hier erwähnte Untersuchung der Vaterschaft Johann Ernst Brieckens, die derselbe ablehnte, hat aber noch vor dem Amt Münden stattgefunden.

89 Der Schrank, in dem die Kirchendokumente, die Kasse und andere kirchliche Wertgegenstände aufbewahrt wurden. 
Das Eichene Holtz ist noch sehr frisch

u. ich sorge, daß sie noch sehr zusam-

men trocknen werde.

[116]

17.

1743

Den 8tn. Junii 1743 sind hier über Obern-

Jesa etliche Tausend grosse Heuschrecken doch

eben nicht weit über der Erde geflogen.

Nachdem man etliche gefangen, hat man

gesehen daß sie Angesichter wie Menschen ${ }^{90}$

u. 4 Flügel gehabt.

Den 1tn. Julii 1743 bin ich M. Stollberg bey

dem Hn. Consistorial-Rath von Hugo

zu Grossen Schneen gewesen, und habe um

eine Collecte von hiesiger Kirche ${ }^{91}$

oder Beysteur zum vorhabenden

Pfarrhausbau für hiesige Gemeinde

zu ObernJesa angehalten. Es hat sich

dieser Herr sehr gnädig dieserwegen

erkläret.

Den 20 Julii hat die Dramfeldische Gemeine hier im Baumgarten eine neue Pforte setzen

lassen. Die Thür hat die ObernJesische Gemeine

machen lassen.

Den 18tn. Aug. ist der H. Sup. Schwachheim

von Sr. Hochwürden dem Hn. Doct. et Prof.

wie auch General-Sup. Feuerlin zu

Siboldeshausen eingeführet worden.

Den 28tn. Aug. sind die neuen Fenster

unten in der grossen Stuben eingesetzet.

90 Vgl. Neues Testament, Offenbarung des Johannes 9.7. Fraßschäden erwähnt er nicht.

91 Magister Stollberg bittet darum, dass das Konsistorium eine Kollekte genehmigt, mit deren Hilfe der Pfarrhausbau finanziert werden sollte. 
Den 1 Sept. 1743. Ist die neue Kirche zu Geißmar von dem Hn. Sup. D. Riebow eingeweihet worden. Er hat die Predigt über Haggai 1, $V 8$ gehalten. ${ }^{92}$ Und soll 12 r. für solche Predigt von dem Hn. von Haremberge ${ }^{93}$ bekommen haben.

\section{[116v]}

18.

\section{1744.}

Den $7 t n$. Dec. ist ein Königl. Consistorial- Rescript unterm 25tn. Oct. ergangen, darinnen verboten wird, Leute, so an der rothen- Ruhr ${ }^{94}$, oder andern ansteckenden Seuchen sterben, öffentl. zu begraben. Und sollen solchen Persohnen, so lange die Contagion dauret, keine LeichenPredigten gehalten werden. Nichts desto weniger solle dem Prediger das Gebühr gereichet werden, welches die Leute sonst hätten geben müssen.

Es sind hier aber, Gott sey Danck, keine

Leute an dergleichen Kranckheiten gestorben.

Den 11 Dec. ist ein Circular ergangen, daß wir Gott dancken u. das Te Deum Laudamus absingen sollen für den am 25tn. Nov. 1743 gebohrnen Jungen Printzen in London. ${ }^{95}$

92 Altes Testament. Der Prophet Haggai. Kapitel 1, Vers 8: Gehet hin auf das Gebirge und bolet Holz und bauet das Haus. .

93 Die von Hardenberg hatten das Patronat über Geismar (vgl. Tütken, H., Geschichte des Dorfes und Patrimonialgerichtes Geismar bis zur Gerichtsauflösung im Jahre 1839, Göttingen 1967). Senior der Familie war seinerzeit Friedrich Karl von Hardenberg (16961763), der in Hannover das Amt eines Oberhofbau- und Gartendirektors bekleidete (van den Heuvel: Aspekte einer adligen Karriere, S. 15).

94 Die Ruhr ist eine Durchfallserkrankung; bei der hier erwähnten roten Ruhr zeigen sich Blutbeimengungen im Stuhl (Mетzке, Krankheitsbezeichnungen, S. 103).

95 Gemeint ist William Henry (25. November 1743/14. November AS - 25. August 1805), der dritte Sohn des Prince of Wales Friedrich Ludwig von Hannover und Enkel Georgs II. (Cokayne, Peerage, Bd. 5, S. 744-745). 
Den 24tn. Dec. hat Johann Jürgen Fischer, Ackermann und Einwohner allhier das 4eckichte Tafel-Gestell, darauf die Num. der Gesänge geschrieben werden in die Kirche geschencket.

1744.

Den 22tn. Martii 1744 ist der H. Pastor und Senior Mengershausen ${ }^{96} \mathrm{zu}$ Hedemünden selig eingeschlaffen.

Den 30tn. Martii, als am andern heil. Oster-Tage, ist der H. Pastor Matthaei, welcher bisher Pastor zu Suershausen gewesen, in grossen Längden von dem Hn. Sup. D. Riebow eingeführet. ${ }^{97}$

Den 29Junii haben die beyden Gemeinden die Oberste Stube u. Kammer tünchen u. schnenen lassen. Die 6 Fenster sind in neue Rahmen gelegt.

[117]

19.

1744

Den 24tn. Aug. ist hier zu OberJesa Kirchen Visitation von dem Hn. Sup. u. Doct. Riebow und Hn. Gerichtsschultzen Iden ${ }^{98}$ gehalten worden. Der mir aufgegebene Text zur Predigt war: Matth. 7, 13.14. ${ }^{99}$

96 Johann Heinrich Mengershausen (Meyer, Pastoren, S. 106 und 476).

97 Johann Friedrich Matthäi(us), (Meyer, Pastoren, Bd. 2, S. 420).

98 Christian Just Iden, (WÄHNER, Tagebuch, S. 96).

99 Gehet ein durch die enge Pforte. Denn die Pforte ist weit, und der Weg ist breit, der zur Verdammnis abführet... 
Den 15tn. 7bris haben die beyden Gemeinden einen gedoppelten eissern Ofen unten in die grosse Stube für 16r. gekauft und setzen lassen.

Den 6tn. Oct. ist ein Königl. ConsistorialRescript unterm 10tn. 7bris ergangen, daß kein Prediger einen fremden, er sey wes Standes oder Würden er wolle, in seiner Kirche solle predigen lassen.

Zwischen den 10 u. 11 Oct. in der Nacht auf den Sonntag zu, ist hier durch Gottes Verhängniß bey der armen Witwe Utermöhlen Feuer ausgekommen, und ist ihr Haus sammt der Scheune bis auf den Grund abgebrannt. Man meinet es sey angeleget gewesen. Dem Barmhertzigen Gott sey tausendmahl gedanckt, daß es nur bey dem einen Hause geblieben, da doch Johann Jürgen Fischers Stall u. Haus gantz nahe darbey stund, und die Flamme immer über dessen Haus her ja gar bis nach der Kirche zu schlug. Die Witwe, da sie schon im Bette mit ihrer Tochter gelegen, hat gantz nichts von ihrem Zeuge gerettet.

[117v]

20.

1744. 1745.

Den 21tn. Octobris hat Mstr. Backhaus die Treppe und Thür zum FutterBoden an der alten Scheune angesetzet.

Den 15tn. 9bris war der 25te Sonntag nach Trinit. hat der H. Sup. Schwachheim zu Siboldeshausen seine Abzugs-Predigt gehalten, u. ist darauf nach Hedemünden 
gezogen. Nun bekommt der H. Sup. Appuhn zu Göttingen dieses Dorf ObernJesa wieder unter seine Inspection, und der H. Sup. D. Riebow bekommt Siboldeshausen wieder. vid. p. 14 in hoc libro. ${ }^{100}$

1745.

Den 20tn. Jan. ist der Römische Kaiser Carl der VII des Abends um 8 Uhr zu München verstorben.

Den 6tn. Febr. Ist ein Consistorial-Rescript unter 14tn. Jan. ergangen, daß kein Prediger ein Freymäurer werden solle. ${ }^{101}$

Und eodem unterm 19tn. Nov. ${ }^{102}$ daß die Extracte aus den Kirchen Registern sollen gemacht und eingeschickt werden

Den 29tn. Martii ist der Pastor H. Nicolaus Hampe zu Lengelern im 96 Jahre seines Alters sel. verstorben. Anno $1649 \mathrm{im}$ Sept. war er zu Göttingen gebohren und 1676 ins Predigt-Amt gekommen. Daß er alß bald 70 Jahr daselbst Prediger gewesen.

\section{[118]}

21.

1745. 1746 .

Den 25tn. April hat der Stadt Musicant aus

Göttingen Herr Seyffert war der Sonntag Quasimodogeniti mit seinen Gesellen eine Kirchen-

Music gemacht. ${ }^{103}$

100 Siehe Seite 14 in diesem Buch.

101 Vgl. Willich, Anhang im Band Supplement, S. 8.

102 Unter dem gleichen Datum ein Konsistorial Reskript, das bereits am 19. November des vorhergehenden Jahres herausgegeben worden war.

103 Erster Sonntag nach Ostern. Mit dem Stadtmusikus Adam Wolfgang Seyffert (auch Seiffart, Seyfart) hatte Magister Stollberg während seiner Zeit als Figuralkantor in Göttingen 
Den 2 Maii 1745 ist auf den Sonntag Misericordias ${ }^{104}$

ist der H. Pastor Glieme ${ }^{105} \mathrm{zu}$ Siboldeshausen

eingeführet worden von Hn. Sup. D. Riebow

Er war vorher 5 Jahr Prediger zu Volpri-

hausen.

Den 11 Julii Abends um 8 Uhr ist die Frau Pastorin

Gliemen geb. Kraul zu Siboldeshausen

in 6 Wochen selig verschieden.

Den 25tn. Oct. ist sind des Nachmittages Heddenhausens

Haus, Scheune und Ställe zu Niedern

Jesa abgebrandt.

1746.

Den 2 et 3 Jan. ist sind die Dramfeldische Kirchen-

Rechnungen zu NiedernJesa von dem

Hn. Doct. et Sup. Riebow und von dem

Hn. Amtmann Hartmann ${ }^{106}$ mit

abgenommen worden.

Den 31tn. Jan. sind die beyden Hn. Kirchen-

Commissarii H. Sup. Appubn, u. H.

Gerichtsschultze Iden hier gewesen wegen

des vorhabenden Pfarrbaues und haben

zugleich die Kirchen-Rechnungen nach

gesehen.

Den 10tn. Febr. ist der H. Pastor Stutzbach ${ }^{107}$

zu Settmarshausen selig verstorben.

Den 18tn. Febr. Nachmittages um 4 Uhr ist die

Frau Amtmannin Hartmann zu

Friedland in Wochen selig eingeschlaffen.

zusammengearbeitet; die Stadtmusiker stellten die Instrumentalisten für die Kirchenmusik (Bielefeld, Jacobi-Kantorei, S. 16, 17). Der Beruf des Stadtmusikers war ein Lehrberuf (vgl. FährmanN, in Göttingen Bd. 2, 909ff). Vgl. [127v].

104 Zweiter Sonntag nach Ostern.

105 Christian Erich Glieme (Meyer, Pastoren, S. 372).

106 Der bürgerliche Leiter des Amtes Friedland.

107 Johann Friedrich Stutzbach. 
Den 10tn. Febr. Ist der H. Doctor Bernhardt

Walther Marperger, Königl. und

Churfürstl.-Sächsischer OberHof-Prediger,

wie auch Kirchen- u. OberConsistorial-Rath

im 64 Jahre seines Alters zu Dreßden

verstorben. ${ }^{108}$

\section{[118v]}

22.

1746.

Den 28tn. Febr. ist der H. Prof. Hermann

von der Hardt im 86 Jahre seines

Alters zu Helmstädt verstorben.

Der H. Consist. R. Götten, welcher ehedem Pre-

diger in Hildesheim, darauf in Zelle und endl.

Sup. zu Lünebrurg gewesen, hat als neuer

Hof-Prediger zu Hannover am 9ten

Trinitatis, war der 7te Aug. über das

ordentl. Evangelium seine Anzugs-

Predigt gehalten. ${ }^{109}$

Den 29tn. 7bris ist unterm 26 Aug. 1746 vom

Königl. u. Churfürstl. Consistorio der Befehl

ergangen, daß dem Studioso Theologiae Jo-

hann Dietrich Cramer aus Nordheim

bürtig die Kantzel sollte verboten seyn

theils weil er Tages vorher im Tenta-

mine $^{110}$ schlecht bestanden, theils weil er

auch per rasuram verfälschte attestata

Academica produciret habe. ${ }^{111}$

108 Bernhard Walther Marperger (1682-1746), war Schüler von August Hermann Francke in Halle und Anhänger des Pietismus (vgl. FlÜGEL, Wolfgang: Marperger, in: Sächsische Biografie, http://www.isgv.de/saebi/23.7.2013).

109 Gabriel Wilhelm Goetten (s. Bodemann: Goetten, Gabriel Wilhelm, in: Allgemeine Deutsche Biographie 9 (1879), S. 449-450 (http://www.deutsche-biographie.de/pnd 116733462.html?anchor=adb (26.11.2015).

110 Erstes Examen vor dem Konsistorium (Tütken, J., Privatdozenten, Göttingen 2005, S. 577).

111 Er hatte radiert. 
Den 14tn. Oct. haben die beyden Gemeinden

ObernJesa u. Dramfeld den Schoppen

an der neuen Scheune wieder ver-

bessert, und aufgerichtet.

Den 26tn. 9bris ist ein Königl. Consistorial-

Rescript unterm 21tn Octobris 1746 prae-

sentiret: daß es hinkünftig wegen der

Kirchen-Sachen bey dem Alten bleiben solle.

Und könnten hinkünftig wieder

Capitalia ausgeliehen werden.

[119]

23.

1747

Den 2 Jan. hat die hiesige Gemeinde den Abriß, den Anschlag u. ein Rescript unterm 16tn.

Dec. 1746 erhalten von Hannover wieder zurück er-

halten nebst der Verwilligung der

200r. vom hiesigen Kirchen-Vorrath

durch den Hn. Sup. Appubn zum neuen

Pfarrhause.

Den 14 et 15tn. Jan. ist wieder eine grosse

Kälte gewesen.

Den $24 \mathrm{tn}$. Febr. ist Kirchen-Visitation ge-

wesen zu Ballhausen den 25tn. ejusd.

zu Grossen Schneen u. den 26tn.

ejusd. zu Lütgenschneen.

Unterm 16 Jan. ist ein Circular ergangen, daß für die Stockhäusische Kirche eine

Becken-Collecte sollte gesammlet

werden. Es ist geschehen $u$. ist hie-

selbst am Sonntage Oculi ${ }^{112}$ einkommen

1r.2g. u. 4 d.

112 Dritter Sonntag der Passionszeit. 
Auf Königl. Cons. Befehl sind auch

aus dem Kirchen-Vorrath in ObernJesa ge-

steuret $18 \mathrm{~g}$. für gemeldete Kirche.

Den 10tn. Martii ist unterm 3 Febr. 1747

ein Consistorial-Rescript ergangen;

daß die Aufgebote 2 Sonntage

hinter einanderher geschehen sollte

u. also allzeit eine Woche zwischen

dem ersten und dem 2 der Aufge-

bot seyn solle. Wenn gleich ein

Fest-Tag in der Wochen einfallen sollte

so soll das Aufgeboth doch daran

nicht geschehen.

\section{[119v]}

24.

1747.

Es ist auch $\mathrm{um}$ im Monath Martio Ein

Königl. Consistorial- Rescript ergangen:

daß kein Prediger bey Strafe der

Remotion ${ }^{113}$ einen Göttingischen Studiosum

copuliren solle, er möchte auch vor-

geben was er wollte; Es wäre denn

daß er ein Testimonium ${ }^{114}$ und Erlaub-

niß von der gantzen Universitaet

erst bey brächte. Zu diesem Befehl

hat ein gleiches Verfahren des Hn.

Pastoris Reinholds zu Weende Ge-

legenheit gegeben, da er im vorigen

Jahre einen jungen Studiosum Juris

aus Ungarn mit einer Doct. Tochter

copuliret hat. ${ }^{115}$

113 Entlassung.

114 Bescheinigung.

115 Reinbolt in Weende hatte die Tochter des praktischen Arztes Heintzmann mit dem ungarischen Studenten Johann Gottlieb Bel aus Ungarn verheiratet. Der Pastor war offensichtlich mit einem gefälschten Brief getäuscht worden und wurde dennoch vom Konsistorium zu 12 Talern Strafe verurteilt (BrüDermanN, S. 413). 
Den 14, 15 et 16 Martii ist noch ein tiefer

Schnee gefallen, und darauf sehr

kalt geworden.

Den 16tn. Martii ist unterm 2 buius ${ }^{116}$

ein Königl. Cosistorial Rescript

ergangen, daß der Studiosus

Theologiae, Johann Dieterich Cra-

mer wieder predigen möge und

dürfe. Am 26tn. Aug. a.p. war

ihm solches untersaget worden.

Den 20tn. April 1747 sind durch den Hn. Sup.

Appubn 2 Consistorial Rescripte ergangen:

daß eine Kirchen- u. Becken Collecte für

die neu zu erbauende Kirche zu Elligerode

Amts und Inspection Hardegsen, sollte gesammlet

und eingesandt werden.

[120]

25.

1747.

Den 25 Maji 1747 bin ich aus dem alten

Pfarrhause aus und so lange in die Schule

gezogen. Den $26 \mathrm{Maji}$ haben sie angefangen

das alte abzubrechen.

Den 6Junii - hat der H. Richter Dann-

hauer mit der jüngsten Jungfer Hannsemanii

Hochzeit gehalten. Er ist nicht lange darnach

Rathsherr u. Calands Verwalter ${ }^{117}$ zu Göttingen

geworden.

116 Des laufenden Monats.

117 Richter Dannhauer starb 1756, er wurde nur 47 Jahre alt; vgl. [137v]. Kalande waren Vereinigungen von Geistlichen und Laien, die an den Kalenden, den ersten Tagen des Monats, ihre Zusammenkünfte abhielten; sie waren im 13. Jahrhundert entstanden, hatten sich ausgebreitet, wurden dann im Zuge der Reformation untersagt; ihr Vermögen ging daraufhin teilweise in städtischen Besitz über; der Kalandsverwalter war seit Dezember 1720 Mitglied des Göttinger Rates (vgl. Gerhard, in: Göttingen Bd. 2, S. 269 und SAATHOFF, Kirchengeschichte, S. 39). 
Den 17 Julii haben die Zimmerleute neml.

Mst. Rammenschweig aus Friedland mit seinen

Söhnen und Gesellen, angefangen das Pfarr-

haus zu richten. Ich M. Stolberg, habe

den ersten Nagel eingeschlagen.

Bauermeister war zu der Zeit allhier:

Christian Bornemann, welcher nachher

fort in alle Welt gegangen. Man meinet

er sey im Wasser umgekommen.

Andreas Hentze war Vorsteher, welcher

sichs mit Wegen und Stegen dabey sehr sauer werden lassen.

Matthias Bode hergegen danckte aus

eben der Ursache $\mathrm{ab}$, vult pius esse, sed est hypocrita et avarus, et semper

avidus ad rem. ${ }^{118}$ Als das Haus gerichtet

war, so hat er in der freyen Strasse das

Gebäude angesehen, die Mütze unter den Arm

genommen, die Hände zusammen geschlagen und

gesagt: Mein Gott! welche ein Pallast! Wäre

es seiner Meinung nach gegangen, so hätte er das

Pfarrhaus wie ein gemein Kuh hirtens Haus

gebauet und das alles, aus vorgegebener

Gottesfurcht. Man kan es an den Witwenhause

sehen, welches unter seiner Direction des Jahrs

vorher einige Jahr vorher 1739 gebauet, u. vorn

schon als jetzt 1755 [!] über $1 / 4$ Elle herüber

gesuncken.

[120v]

26.

1747.

Der andere Vorsteher war: Johann Zimmermann.

Der Dritte: Lorentz Dehne. Zu Dramfeld war

Schultze: Henne, Vorsteher waren: Christian

Utermöhlen, welcher auch Vieles zum Baue

118 ..., er will fromm sein, aber er ist ein Heuchler und habgierig und immer gierig nach der Sache". 
zugetragen. Die Dramfeldische Gemeine hat $\mathrm{zu}$ allem den 3 d. gegeben. ${ }^{119}$ Wenn ich das Eichene Holtz, Dannen Holtz Hand und Spann-Dienste rechne so kommt es über 1300r. ${ }^{120}$

Ich habe über die Thür durch den Tischer Backhaus einhauen lassen: In Dei gloriam ades bas

Pastoribus habitandas exstrui curarunt, Obernjesani et Dramfeldenses, Pastore Mag. Joh.

Paulo Stolbergio 1747, mense junis. ${ }^{121}$

Den 9 Sept. haben beyde Gemeinen um eine

Kirchen Collecte zur Fortsetzung des Pfarrhaus

Baues angehalten, aber nichts erhalten.

Unterm 31 Aug. ist am 28 Sept. Cons. Rescript ergangen, daß sowohl eine Becken- als Kirchen Vorraths Collecte für die neu zu erbauende Kirche zu Eldagsen sollte eingesandt werden.

Den 11 Octobris ist der H. Abt von Mosheim als Cantzler zu Göttingen angekommen. ${ }^{122}$ Er soll 2000r. jährl. bekommen als ein Salarium. ${ }^{123}$

Den 20tn. 8br. hat die Roßdorffer Gemeine etliche Steine bey dem Horl vor meine 7 Morgen her auf der Wiesen fahren lassen, auf Befehl des Hn.

119 Den dritten Teil gegeben.

120 Matthias Bode hatte nicht ganz unrecht: Die vom Pastor angegebenen Kosten lassen auf ein repräsentatives Haus schließen, was auch heute noch zu erkennen ist (vgl. OBERSCHELP Bd. 2, S. 43 und 50, 51).

121 Zum Rubme Gottes tragen die Obernjesaer und Dramfelder Sorge, diese Gebäude den Pastoren zur Wohnung zu errichten, zur Zeit des Pastors Magister Johann Paul Stolberg, 1747, im Monate Juni.

122 Johann Lorentz v. Mosheim, 1693-1755, war ein berühmter Helmstedter Theologe und Kirchenhistoriker sowie Abt von Mariental und Michaelstein; er musste 1737 den Ruf an die Universität Göttingen ablehnen, wurde aber 1747 erneut berufen und erbielt als einziger in der Geschichte der Göttinger Universität - die Würde eines ,Kanzlers' (S AATHOFF, Kirchengeschichte, S. 196). Er gilt als der wohl berühmteste und bedeutendste Kanzelredner in der ersten Hälfte des 18. Jabrbunderts... (HammanN, in: Göttingen Bd. 2, S. 538, Anm. 51) Schon bald nach seinem Tod wurde ibm der Ehrentitel , Vater der neueren Kirchengeschichte' zugelegt (MoELLeR, Göttinger Gelehrte, S. 10).

123 Die Einkünfte der Obernjesaer Pastorenstelle wurden 1735 mit 200r. bewertet (MeYer, Pastoren, S. 215). 
Gerichtsschultzen Iden, Und als sie mir zu nahe kamen, habe dawider protestiret. Es hat aber nichts geholfen. Das Königl. Cons. stehet auch in solchen Fällen den Pastoribus nicht bey. Es soll ein Stein in alten Zeiten dagestanden haben. Welchen aber das Wasser mag verschlammet $u$. zugedeckt haben. Ich habe dadurch vielen Schaden gelitten.

\section{[121]}

27.

1747.

Wie denn dem Pfarr Lande hin und wieder vieles abgepflüget worden. Ich habe zwar um einen Beystand von den Kirchen Gütern zur Mess u. Versteinigung angehalten, aber nichts erhalten. Ich sollte es vorschiessen, u. mein Successor sollte es den meinigen wieder erstatten. Ich habe inzwischen ein und das andere unterdem vorigen Hrn. Gerichtsschultzen Doct. Neubaur ${ }^{124}$ messen lassen und vieles $\mathrm{zt}$ wieder bekommen, Allein bey der Kleinen Breite à 4 Morgen nach dem Niederjesischen Braucke zu, habe ein gantz Vorl. zu bekommen.

Ich ließ auch die 2 Morgen beym Bieflote oder Beyflusse ${ }^{125}$ messen, Als aber dieser jetzige $\mathrm{H}$. Gerichtsschultze unter dessen herkam, ließ er mir die Steine, welche der vorige $\mathrm{H}$. Gerichts Schultze D. Neubaur setzen lassen, wieder heraus-

124 Friedrich Christoph Neubour (1682-1744), Jurist. Seit 1720 Schulze des Gerichts Leineberg und Mitglied der Policey-Commission [auch als Speciale Commission bezeichnet], die Göttingen für die neue Universität vorbereiten sollte. Herausgeber moralisch-literarischer Journale und Hauptautor der Göttinger Zeit- und Geschichtbeschreibung. 1740 musste er wegen Krankheit sein Amt aufgeben. Er starb 1744 in großer Armut. In der Literatur wird er als anerkannter Gelehrter gewürdigt (vgl. u. a. GIERL, 1988, S. 46, 47 oder Gerhard, in: Göttingen, Bd. 2, S. 275).

125 Später als Koppelhude zwischen Obernjesa und Niedernjesa bezeichnet (Wolter, Amt Friedland, S. 65). 
schmeissen, unter dem nichtigen Vorgeben:

Ich sollte beweisen; wie viel Ruthen

Fuß u. Zoll ich hätte, da ich doch

nicht mehr verlangte, als was die

lage mit sich brächte, und meine alte

Specifion [!] 1613 auswiese. Jetzt sind

meine 2 Morgen, 2 Vorl. worden. Und

da ich nicht aufweisen kan, wie viel Ruthen,

Fuße ein jedes Stück habe, als welches

die alten nicht angemercket, wie auch mein

seliger Antecessor Lotzius kein Wort aufgeschrieben,

so habe das Messen u. Versteinigen müssen

anstehn lassen.

[121v]

28.

1747.

Für Mein Kutschen Schoppen, Bühren

Macherlohn, Holtz, Stroh kostet insgesammt

7r. u. 18g. Das TaubenHaus, welches

ich auch bezahlen müssen, kostet 4r. 34g.

Den 13 Nov. ist ein Königl. Circular ergangen

daß für die abgebrandte Stadt Moringen

eine Haus Collecte sollte gesammlet werden.

In Obernjesa sind eingekommen 3r.4g.3d

In Dramfeld - - 1 r.30g.1d. ${ }^{126}$

Den 2 Dec. gegen Abend war ein solcher

Windsturm, daß viele Ziegeln von meinem

Pfarrhause u. Scheune herunter stürtzten

126 In diesem Fall wurde von der Landesregierung eine Hauskollekte ausgeschrieben, die ein hohes Spendenaufkommen erwarten ließ, was auch dringend benötigt wurde. Denn Moringen war bereits 1734 einmal abgebrannt; die Schäden wurden seinerzeit mit über 30 Verletzte[n], einige obne Hoffnung auf Genesung, 110 Wobnhäuser[n] , 159 Nebengebäude[n], Ratskeller und andere[n] öffentliche[n] Gebäude[n] angegeben, jetzt verlor es noch einmal 19 Häuser, 14 Scheunen und 18 Ställe. Die Stadt Göttingen lieferte 1734 eine Kollekte von 120r.11mg.16d, dieses Mal (1747) eine Kollekte von 100r.18mg.4d. ab (Titz-Matuszak, S. 188, 189). 
und den 12 Dec. wiederum Abends um $8 \mathrm{Uhr}$ nebst erschröcklichem Donnersschlage.

Eodem ist ein Junge in der Alten Leine zu Göttingen

Als sein Vater aus Ohen [?] Hausgeräthe für die

Frau Witwe Lotziussen hergebracht ersoffen.

Den 22tn. Dec. hat Deppe, ein Gottloser Kerl, damahls Krüger in Dramfeld sehr auf mich

u. das heil. Abendm. gescholten in Gegenwart des Hn. Amtmanns Lühern ${ }^{127}$ u. des Haus-

Schlächters Bühren.

Den 29 Dec. ließ hir Matthias Bode im Namen des

Hn. geheimten Raths von Steinberg ${ }^{128}$, durch den Nota-

rium Meyer aus Göttingen Possession von seiner

Lehn länderey nehmen. Und kam endlich auch

auf den Kirchhoff, u. nahm da Possession von

einem Stücke 30 Fuß lang und 20 Fuß breit, welches auf meine alte Scheune stößt vor dem Kirch-

hofe. Seine vorgegebene Gottesfurcht, wollte

\section{[122]}

29.

1747.

auch gar von dem Platze, welches jetzund

gegenüber der Schulmeister Schlote zum Küchen-

garten hat, Possession nehmen, unter dem

albern Vorgeben: Es müßte noch 1 Stücke

LehnWerck seyn, weil in seinem Lehn-

Brieffe stünden 2 Stellen fürs Vieh.

Als ich aber weiß, daß daselbst in

alten Zeiten das Pfarr Witwenhaus

daselbst gestanden $\mathrm{u}$. zu meiner Zeit

noch Grund-Steine sind heraus gegraben

worden, habe ich dawider protestiret.

127 Vom Amt Friedland.

128 Hier wird wahrscheinlich Georg Friedrich von Steinberg gemeint sein (vgl. WäHNER, S. 186 und 283). 
Mit dem Stücke von Kirchhofe aber ist es so zu gegangen, welches mir alte Leute erzählet. Im 30 Jährigen Kriege haben die hiesigen Einwohner ein Jeder für sein nöthiges Vieh u. Geräthe etwas von dem Kirchhofe zur Salve Garde ${ }^{129}$ oder freyn Platz bekommen, darauf sie ihr Vieh sicher haben halten können. Nach dem 30 Jährigen

Kriege haben die Vorfahren Matthias Boden es sich zu geignet [!] u. mit in Lehn Brief schreiben lassen, als wenn es den Hn. von Steinberg gehörte. Eben so ist es mit dem so genannten Zappen Wöcke ergangen. Nun eignet es sich Mattbias Bode gantz mit Unrecht $\mathrm{zu}$, u. saget: er hätte einen Eyd darüber geschworen. Es hat mein sel. Präantecessor Armbrecht mit Matthias Boden Vater darüber Streit gehabt u. hat ihn etl. Jahr von heil. Abendmahl abgewiesen, in welchen Bann er auch gestorben ist. Nun macht es Mattbias Bode nicht anders.

\section{[122v]}

30 .

1748.

Unterm 11 Jan habe am 21 Jan. ein Königl. Cons. Rescr. wegen des hiesigen Pfarrhaus Baues, daß ich es so groß gemacht, erhalten. Ein Spitzbube u. Privater

Feind hat es ohne Zweiffel angegeben.

Noch im alten Jahr 1747 ist ein Atbeiste zu Jena verstorben, der sich alle Vermahnung ungeacht sieh dennoch nicht bekehret, u. wegen seiner Familie hat er ein ehrliches Begräbniß bekommen. Doch ist dessen Aaß auf

129 Zum Schutz, als geschützter Platz (vgl. Zedler, Bd. 33, S. 637). 
Fürstl. Befehl hernach, nach 3 Tagen wieder ausgegraben $u$. auf den SchindAnger begraben eingescharret worden

Den 12 Febr. 1748 ist der H. Pastor Mylius, mein Landsmann, zu Hannover an der Aegidien Kirche verstorben. ${ }^{130}$

Den 19 Febr. an Hn. Secret. Arenhold ${ }^{131}$ ein Päckgen Grütze ${ }^{132}$ à $27 £$ wegen Dramfeld, franco gesandt. Porto $14 \mathrm{~g}$.

Den $16 \mathrm{Febr}$. ist von Hannover an den Hn. Sup. Appuhn vom Consistorio berichtet, daß wir keine Kirchen Collecte zu hoffen hätten.

Den 12 Martii ist unterm 16 Febr. ein Circular ergangen, daß eine Becken $\mathrm{u}$. Kirchen Vorraths Collecte für die Kirche zu Holtensen im Leinebergischen Gerichte sollte eingeschickt werden.

Imgleichen unterm 16 bujus eine Becken u. Kirchen Vorraths Collecte für die Kirche zu PegesDorf im Amte Polle.

130 Johann Gottfried Mylius (Meyer, Pastoren, S. 418).

131 Hier wird es sich um den Konsistorialsekretär (1707-1775) Gerhard Justus Arenhold handeln, der seit 1735 beim Konsistorium angestellt war und u. a. mit Bauprüfungsaufgaben betraut wurde (Амт: Die Bauverwaltung des Hannoverschen Konsistoriums S. 3.

132 Geschälte und zerkleinerte Getreide- und Buchweizenkörner, die die Grundlage für Brei bilden. Vermutlich handelt es sich hier noch um ein Geschenk, das aber seit 1755 bzw. seit Anfang der 60er Jahre regulär als sog. Douceur in BauKosten dem Sekretär Arenhold in Höhe der Revisionskosten gezahlt werden musste (KiKrAGött, P. A. Dramfeld K.R.III. 1, Belege 1734-88, Quittungsbüchlein über Visitations-Gebühren und Revisions- und Baukosten Gebühren). 


\section{[123]}

31.

1748.

Im gantzen Monath Martii ist es sehr kalt

u. auch nach Marien Tage ${ }^{133}$ hat 3 Fuß hoch Schnee

gelegen.

Den 19tn. Maji als ich nach Holtensen

ritt tempore vacantiae ${ }^{134}$ daselbst $\mathrm{zu}$

predigen, kam des Morgens um 5 Uhr

Feuer in NiedernJesa auf u. brandte

Schmid Faust Stall u. das Nachbar

Haus hinweg.

Unterm 10 Maji ist am 17 tn. ein Consist.

Rescript ergangen; daß kein Schulmeister

um einen Beytrag zu seiner bessern Sub-

sistentz beym Consistorio supplicieren

solle. Doch sind die recht arme Schulmeister

welchen der Pastor ein Lateinisches Testimo-

nium von ihrem Verhalten u. ihrem Ein-

kommen ertheilet, u. deren Witwen davon

ausgenommen.

Unterm 14 Aug. am 28 Maji ist ein Circular

eingelauffen, daß den Candidaten solle

erlaubet seyn zu catechisiren, in Gegend-

wart Pastoris loci, wie auch die Delinquenten

mit zum Tode zu bereiten, u. sich in

Amts Sachen zu üben.

Unterm 21 Maji ist verordnet, daß die

Fürbitte für die Trouppen cessieren solle.

133 Er meint wahrscheintlich das Fest der Verkündigung des Herrn am 25. März (JöCKLE, Heiligenlexikon, S. 295).

134 Während der Vakanz; die Pfarrstelle war nicht besetzt. 
Den 1 Aug. haben S. Königl. Majestaet Georg der II Morgens gegen 10 Uhr Ihren Königl. Einzug in die Stadt Göttingen gehalten, mit 8 Pferde vor einer Kostbaren Kutsche. Sie haben in Gegenwart des Hertzogs Neucastle als Staats Secret. von Großbrit. ${ }^{135}$ nebst etlichen Staats Ministern von Hannover

\section{$[123 v]$}

32.

1748.

dem Hn. von Münchhausen Hn. von Steinberg wie auch etlichen StaatsDamen in der Universitaets Kirche etl. Doctores creiren sehen, da denn der H. Cantzler von Mosheim eine Teutsche Rede gehalten. Bey dem Eingange in die Kirche haben Ihro Majest. die Rede des damahligen Herrn Prorectoris $^{136}$ D. et. Prof wie auch Superint. Ribows sehr gnädig beantwortet, darauf die Bibliotbec besehn u. des Mittages auf dem Rathhause gespeiset. Doch sind keine Gestücke dabey gelehset worden. Wie anno 1729 bey der Durchreise Ihr. Majestaet ${ }^{137}$ nach Münden alle Geschütze gelöset $\mathrm{u}$. alle Glocken geläutet wurden. Welches sehr rührend war daß den Meisten die Freudens Thränen in den Augen stunden, da sie vivat Georg der II. riefen.

Unterm 12 Julii den 6 Sept. ist ein Circular ergangen, daß die Prediger eine Specification von legaten der Kirche u. Schulbedienten zum besten, solle eingesandt werden.

135 Secretary of State Thomas Pelham-Holles, Duke of Newcastle (Hölscher: Zwischen Legitimation und Lustbarkeit, in: GöJb 59, 2011, S. 59).

136 Rektor war Georg II. selber.

137 Georg II. 
Den 7 Sept. hat Mst. Frede die Stuben-

und Kammer-Schlösser angeschlagen nebst

Hespen und Haken im Pfarrhause. Ich

habe ihm für den Haupt-Schlüssel 1r. aus dem

meinigen geben müssen. Welchen, wenn mein

künftiger Successor ihn haben will, meinen

Erben auch bezahlen muß.

Unterm 9 Aug. ist am 16 Sept. ein Circular

ergangen, daß kein Prediger mehr einen

Schulmeister praesentiren solle.

Den 27tn. Sept. 1748 bin ich ins neue Pfarr-

haus gezogen. ${ }^{138}$

[124]

33.

1748.

Den 5tn. Oct. hatte dem Hn. Superint. Appubn

geantwortet; daß sonst kein legatum vorhanden

wäre, als das Sieburgische à 20r. von dessen

Zinsen jährl. 2 arme Kinder in die Schule ge-

halten würden, wie aus den KirchenRegistern

zu ersehen.

Die Unkosten der am 22tn Oct. abgehaltenen

KirchenVisitation sind auf 29r.6g. und

$7 \mathrm{~d}$ gekommen.

Den 2 Dec. sind die Dragoner aus dem

Brabantischen Kriege wieder zurück u. 6 all-

hir ins Quartier gekommen. ${ }^{139}$

138 Der Bau des neuen Pfarrhauses hat 14 Monate gedauert: am 26. Mai 1747 hatte man mit dem Abbruch des alten Hauses vgl. [120], am 17. Juli 1747 bereits mit dem Richten begonnen vgl. [120]; der Ausbau des Fachwerkhauses hat dann die meiste Zeit in Anspruch genommen.

139 Nachdem am 18. Oktober 1748 der Friede von Aachen geschlossen worden war (vgl. SICHART Bd. 2, S. 476). 
Unterm 14tn. Novembris ist am 1 Dec. ein Circu-

lar ergangen: daß eine Haus Collecte für

das abgebrannte Dorf Börje Amts Grohnde

solle gesammlet werden. ${ }^{140}$

Unterm 22tn. 9bris habe am 5 Dec. Auf An-

klage der Hn. Kirchen Commissarien Appuhns

und Idens, daß ich den Auszug de 1747,

aus dem KirchenRegister noch nicht einge-

sandt hätte, $12 \mathrm{~g}$. aus meinen Mitteln für

das Consist-Rescript zahlen müssen. Da es

doch noch wenige Prediger es eingeschickt

hatten, wie ich mich deßwegen sehr erkundiget habe.

Unterm 22 Nov. ist am 21 Dec. ein Rescript von

der Geheimten RathStube von Hannover wegen

des Hernhuthianismi ${ }^{141}$ ergangen, daß solche

Leute nicht sollen gedultet werden.

Den 29tn. Dec. ist die Dancksagung

wegen des Friedens abgelesen.

\section{[124v]}

34.

1749.

Den 25tn.Jan. 1749 ist der H. Superinten-

dens Bode zu Hardegsen ${ }^{142}$ verstorben. Er mochte

wohl ein hei[m]licher Sucnianer ${ }^{143}$ seyn, denn er hat

140 Titz-Matuszak, S. 189, listet Brandschäden von 42 Wohnhäusern, 6 Speichern, 27 Scheunen und Ställen auf; die Stadt Göttingen sammelte 66rth. 6mg.4d. Vermutlich ist dies das Ergebnis der landesherrlichen Verordnung vom 30. Oktober 1748, wodurch eine Haus-Collecte für die Einwohner des abgebrannten Dorfes Börrie Amts Grobnde angeordnet, zugleich auch vorgeschrieben worden, wie es künftig mit dergl. Haus-Collecten gehalten werden soll (WILLICH, Anhang im Supplementband, S. 10).

141 Pietistische Glaubensbewegung, die auf die Herrnhuter Gemeinde des Grafen Zinzendorf zurückgeht.

142 Superintendent Johann Friedrich Bode stammte aus einer alten Pastorenfamilie; er war der Schwiegervater des Göttinger Tuchfabrikanten Grätzel und wurde als eigenwilliger, streitsüchtiger Mann bezeichnet (Косн, S. 104).

143 Er meint vermutlich einen Socinianer, einen Gegner der Dreieinigkeitslehre. 
vom heil. Abendmahl nicht viel gehalten, Auch von

seiner Gottheit nicht recht gelehret. Einmahl

hat er gar Unsern Herrn Jesum den Zim-

mermanns Sohn öffentl. genennet, Was denn

der wollte! Ein nunmehr seliger Bürger u.

Uhrmacher, Genry, hat es mir mit Thränen ge-

klaget.

Den 20tn. Febr. als auf Königl. Consist. Befehl die

Dramfeldische Kirche zu Erbauung der Kirche

zu Stockhausen 50r. geben mußte; So haben sich

die beyden Altaristen ${ }^{144}$ Hofmeister u. Mst. Lüdicke

mir widersetzet, auch sonst allerhand böse Reden

geführet, u. als ich solches dem Hn. Sup. D. Ribow

mündlich meldete, sagte er sonst nichts als ich

sollte davon Nachricht haben, wie ich mich gegen

sie verhalten sollte. Die Nachricht aber ist aus-

geblieben.

Unterm 7tn. Febr. ist am 22 ejusd. ein Circular ergangen, daß für die Kirche zu Rehburg Amts Rehburg eine Becken u. Kirchen Vorraths Collecte sollte eingesandt werden.

Den 6 Martii ist der Licent Einnehmer Ebers-

mann zu Gross.Schneen verstorben. Er war ein

Feind der Prediger, gab auf ihr Essen u. Trincken

achten, u. schrieb alles Hannover, die Geheimt.

Rath Stube hätte auf sein falsches Angeben uns bald

um die Licent-Freyheit gebracht. ${ }^{145}$

144 Kirchenvorsteher; sie sollten rechtschaffene, bekannte und bemittelte Männer sein (SChlegel, 2. Teil, S. 416-422).

145 Die Geistlichen waren von der Lizentsteuer, einer Steuer auf Lebensmittel, befreit; damit waren Lebensmittel für diese Berufsgruppe preiswerter (vgl. W InNIGE, in: Göttingen Bd. 2, S. 354). Im Inventar der Obernjesaer Pfarr-Registratur, das Pastor Gräffe 1787 angelegt hat, findet sich unter den Verordnungen zum Licent eine - undatierte - Vertheidigung des M. Stolberg gegen die Beschuldigung, als habe er die Licent-Freibeit gemißbraucht, und Tagelöhner für Arbeit gespeiset (KiKrAGött, P. A. Obernjesa A. 120). 
Von 22 Martii an ist es sehr Kalt gewesen u. hat geschneyet bis auf den 31 Martii.

Am 20 April ist die Dancksagung für die am 19 Marti

gebr. Kron Prinzessin von Wallis ${ }^{146}$ Gott abgestattet worden.

\section{[125]}

35 .

1749.

Cons. Rc

Unterm 7 Martii ist am 21 April ein Circular eingelauffen; daß ein Jeder Prediger die Copulirte Persohnen, die getauften und die Begrabenen selbst in das Kirchenbuch ordentlich eintragen solln. ${ }^{147}$

Unterm 17 April ist am 29tn April ein Cons. Resc. ergangen, daß eine Becken und Kirchen Vorraths Collecte für die neu zu erbauende Kirche zu Elbingerode Amts Hertzberg sollte eingesandt werden. Es war ein Brief von dem Herrn Sup. Appubn und ein Brief von dem Hn. Oberamtmann Nannen ${ }^{148}$ zum Hertzberge dabey, in welchen Sie uns zur reichlichen Beysteuer ermahnten.

Den 22 Maji war hier des Mittags ein solch starck Gewitter, daß das Wasser bey 6 minuten armsdick von den Dächern fleß schoß.

146 Die dritte Tochter des Prince of Wales, Friedrich Ludwigs von Hannover, Louisa Anne, eine Enkelin Georgs II.

147 Hier handelte es sich um eine königliche Verordnung, welche die Art und Weise, wie diese Bücher mit geböriger Sorgfalt zu fübren sind, genau vorschreibt; und zwar soll die Einschreibung in diese Bücher nicht durch die Cantoren, Küster und Schulmeister, sondern durch die Prediger selbst geschehen (vgl. SCHLEGEL, 2. Teil, S. 398).

148 Leiter des Amtes Herzberg am Harz. 
Den 23 Maji hat das Gewitter in Bremcke

u. Reinhausen dergestalt nieder gelassen, daß einige Menschen ersoffen und Häuser weggeflossen sind. Von Friedland bis nach Göttingen sind alle Wiesen verschlemmet. Das Gewitter hielt 5 Tage an.

Am 29 Maji war Kirchen Visitation zu Dramfeld in Loco, die Ausrichtung der Mahlzeit war in des Hn. Försters Bussens Hause, und kam über 19r. ${ }^{149}$ Als wir aus der Kirche kamen fragte der H. Superintendens Doct. Ribow in Gegenwart des Hn. Oberamtmanns Hartmanns $^{150}$ die Gemeine; ob sie was wegen des Gottesdienstes und der Schule zu erinnern hätten? So antwortete der Schultze Henne: Ich, der Pastor käme zu spät, ich liesse die Kirche erst nach 10 Uhr angehen,

\section{[125v]}

36.

1749.

Und hielte daselbst keine Kinder Lehre, wie an andern Orten gebräuchlich. Ich war mir eine solche Anklage nicht vermuthen, und antwortete:

Was gebt ihr Dramfelder denn eurem Pastor daß ihr ihm die Zeit des Gottesdienstes vorschreiben wollet? Ich kan zu Obernjesa die Kirche vor Tage nicht angehen lassen. Denn wer will die Lichter darzu austhun? Ich gehe bald $3 / 4$ Stunde auf dem Wege. Die ObernJeser wollen auch ihren ordentlichen GottesDienst haben. Es ist genung, daß ich alle Sonntage,

149 KiKrAGött P.A.Dramfeld K. R. III. 1. enthält eine Liste der verbrauchten Lebensmittel und Gewürze sowie der Kosten für Köchin und Hausfrau (siehe Einführung, Abschnitt 3: Die weltliche Verwaltung).

150 Leiter des Amtes Friedland. 
Festtage, Fasten- und BußPredigten 2 mahl predigen muß und mich selbst überbringen muß, da ihr mir nichts dafür gebet. Auch wenn bey schlimmen Wege, ich ein Pferd nehme;

so hats ja hier nicht einmahl Stallung, und muß es ins Wirthshaus bringen und etwas dafür geben. Da doch ehemahls ein Stall bey der Schule dazu gewesen. Und was die Catechismus Lehre betrift; So ists niemahls im Gebrauch gewesen, daß der Prediger hier Kinder Lehre gehalten. Uberdem habe ichs mich erboten, daß ich ehemahls wie allhier vor Schloten in einem halben Jahre kein Schulmeister war, zu weilen Catechismus Lehre halten wollte, wenn die Gemeine mir des Mittages wollte zu essen, da antwortete mir aber der alte Schultze Hartung, das wäre was neues, das wären sie nicht schuldig, darauf ich erwiederte, so ist das auch was neues, daß ich euch Catechismus Lehre halten solle. Auf meine Frage: Was sie dem Pastori gäben, antwortete der Schultze; wir geben unsern 3tn Theil zum Pfarr-Bau. Ich sagte: Davon kann ich nicht leben etc.

[126]

37.

1749.

Ich dencke öffters: Wie ungleich gehets doch in der Welt zu, wenn ich auf dem Wege nach Dramfeld höre, daß in GrossenSchneen kaum ausgeläutet wird, du hast schon einmahl geprediget, und jener läßt erst zur Kirche läuten, der doch noch einmahl so viel Einkünfte, und weniger Arbeit hat.

Unterm 16 Maji ist ein Circular am 13Junii ergangen, daß eine Kirchen Collecte für die 
Kirche zu Landrihausen Amts Calenberg ${ }^{151}$ solle eingesandt werden.

Den 28Junii haben die beyden Gemeinen die Schweinställe hinter der Scheune abbrechen u. neue machen lassen, weil s alles Holtz daran faul war.

Von Pfingsten bis auf den 5 post Trinitatis hat es beständig geregnet $u$. war so kalt daß man einheitzen mußte.

Den 23Julii Morgens ist der reiche Edelmann von Bodenhausen zu Nieder Gandern verstorben.

Unterm 11tn. 7bris hat der H. Sup. Appubn ein Circular ergehen lassen, daß die Kirchen Extracte und das Witwen Geld sollten eingesandt werden.

Den 22 Sept. abends zwischen 7 u. 8 Uhr war ein starckes Nordlicht. Von hier anzurechnen nam es über Diemarden seinen Anfang und drehete sich über Göttingen bis nach Volckeroda herum. Unten war es schwartz u. weiß. Uber uns Blutroth, so daß die weissen Strahlen wie Dampf in die Höhe führen. Es dauerte fast 25 Minuten. Es war sehr fürchterl. anzusehen.

Den 21tn. Sept. ist die Frau Sup. Heidelmannin, gebr. Steinhausen, zu Joinsen ${ }^{152}$ in Wochen und im 42 Jahre ihres Alters selig eingeschlaffen.

151 Landringhausen, heute Ortsteil von Barsinghausen (vgl. Meyer, Pastoren II, S. 45).

152 Jeinsen bei Eldagsen, heute Ortsteil von Springe. Vgl. Büsıng, Beschreibung der Stadt Eldagsen, in Büsching, Magazin... Bd. 7, S. 533. 


\section{[126v]}

38.

1749.

Den 30tn. $7 b r$. hat Bornemann fast $70 \mathrm{Jahr}$ alt einen Schuster, Gruben, todt geschossen.

Unterm 19 Sept. kam ein Circular an, daß eine

Becken u. KirchenVorraths Collecte für die gantz neu zu erbauende Kirche vor dem Aegidien Thore zu Hannover solle gesammlet u. eingesandt werden.

Den 23tn. Oct. habe durch Ludolph Biermann über 12 Stämme in Garten versetzen lassen.

Den 13, 9bris ist der hiesige Bauermeister Bornemann weg gegangen, man sagt daß er im Wasser umgekommen sey. War sonst ein guter Mann, nur daß er auf die Weissagung des flüchtigen Paters so viel hielte, von welchem er sagte: Wenn 1748 der jüngste Tag nicht käme, wie der Pater aus der Offenbahrung Johannis erwiesen hätte, so wollte er nichts mehr glauben. Matthias Bode hat ihm immer fanatische Bücher zugesteckt, aus vorgegebener Frömmigkeit. Scilicet! !53 $^{13}$

Unterm 13 9bris ist am 26 9br. ein lang und kurtz Gebet wegen der Viehseuchen ${ }^{154}$ ergangen, per

Circulares vom Hn. Sup. D. Ribow.

153 [Ironisch]: selbstverständlich.

154 Da die Ursachen der Rinderpest seinerzeit noch unbekannt waren, gab es zwar eine Reihe von Rezepten für sogenannte Vorbauungsmittel aber keine wirkungsvollen Gegenmittel; darüber hinaus betrachtete man auch in aufgeklärten Kreisen die Seuchen als göttlichen Eingriff, allerdings nicht unbedingt als eine Strafe (vgl. HüNEMÖrder: Zwischen abergläubischem Abwehrzauber, S. 26). 
Den 9tn. Dec. kam der H. Sup. Schilling ${ }^{155}$ aus

Hohnstädt hier auf meinen Hof gefahren, in Mei-

nung dieses Dorf wäre Siboldeshausen, wo er wegen der Pfarr Gebäude mit dem Hn. Ober-

Amtmann zu Fredland eine Commission

hatte.

Den 31 Dec. ist unterm 12 Dec. ein Circular ergangen daß zu der neuzuerbauenden Kirche im Oberdorfe zu GrossenSchneen eine Becken als Kirchen Vorraths Collecte sollte gesammlet und eingesandt werden.

[127]

39.

1750 .

Unterm 16Jan. ist ein C. $R$. ergangen daß die hiesige Kirche 10r. behuf der Grossen Schneeischen Oberkirche einsenden sollte, welches auch am 27 Jan. geschehen.

Den 12 Febr. ist die Frau Waase ${ }^{156}$ Frau Doct. u. Prof. Theol. Heumannin ${ }^{157}$, nachdem sie über 25 Jahr Lahm gewesen, im 50 Jahre ihres Alters selig eingeschlaffen.

155 Christian Heinrich Schilling (Meyer, Pastoren, S. 529).

156 Anderer Begriff für Base (vgl. Grimm, Spalte 2272).

157 Die Frau des Professors Christoph August Heumann; dieser war bis zur Gründung der Georgia Augusta Leiter des Pädagogiums, also ein Kollege von Magister Stollberg (als Figuralkantor) gewesen, ab 1734 Professor, ab 1745 Ordinarius an der Universität. Die Verwendung des Begriffs Waase (Base) belegt, dass die Familie Stollberg der Familie Heumann mehr als kollegial verbunden gewesen ist; in Göttingen waren sie in der Gotmarstraße Nachbarn (vgl. Wellenreuther, 1988, S. 470). 1755 disputierte Magister Stollbergs Sohn Heinrich Philipp vor Professor Heumann (vgl. [136v]). Im Juli 1757 schickte Magister Stollberg sicherheitshalber seine besseren Sachen zu Professor Heumann zur Aufbewahrung nach Göttingen; einen Monat vorher hatte ihn dieser, gemeinsam mit Professor Feuerlein, noch im Gottesdienst in Obernjesa besucht (vgl. [140v]). Als der ehemalige Kollege in Ehren emeritiert wurde, nahm Magister Stollberg schon keine Eintragungen in die Chronik mehr vor (vgl. Hunger, in: Göttingen Bd. 2, S. 142 und Krumwiede, Bd. 1, S. 248). 
Am 8tn. Martii als am Sonntage Laetare ${ }^{158}$

haben die Göttingischen Chor Schüler ${ }^{159}$ die Passion

in hiesiger Kirche abgesungen. Ich habe ihnen

des Mittages was zu essen gegeben. ${ }^{160}$

Den 10 Martii habe durch Saltzmann

18 wilde Birn- und Aepfel Stämme in den

Knickhofe pflantzen lassen. Kosten $24 \mathrm{~g}$.

Den 19 Martii habe dem Hn. Amtmann

in Friedland die Dramfeldischen Kirchen

Restanten zugesandt.

Den 3tn. April ist ein Cons. $R$. ergangen

daß 2 armen alhir solten 2 neue

Gesang Bücher ${ }^{161}$ solten geschencket werden.

Das Buchbinder Lohn u. Porto hat die

hiesige Kirche müssen ausgeben.

Zwischen den 14 u. 15 April war hier ein

solcher Wind, daß er viele Bäume dar-

nieder gerissen $u$. beschädiget.

Von 2 Febr bis ultimum Martii ist es hier immer

schön Wetter u. Sonnenschein gewesen, von

Anfang des Aprils aber bis auf den 18tn.

ist es kalt, regnitzt u. schlimm Wetter gewesen.

Den 19 April ist in Lütgen Schneen Kirchen

Visitation gewesen. Ich habe mit adsisti-

ret [!].

158 Der vierte Sonntag der Passionszeit.

159 Hier muss der Chor des Gymnasiums gemeint sein; offensichtlich hatte Magister Stollberg gute Beziehungen zu seinem Nachfolger Johann Friedrich Schweinitz (vgl. GARBE und Wiechert, GöJb 37, 1989, S. 80).

160 Ebenso wie Gehälter zum Teil in Naturalien gezahlt wurden, galten Mahlzeiten als Honorar (vgl. GARBE und WIECHERT, GöJb 37, 1989, S. 75 und 79).

161 Man benutzte das Hannoversche Gesangbuch von 1657, das von einem Theologen und einem Juristen (Justus Gesenius und David Denecke) gemeinsam herausgegeben worden war (HammanN, in: Göttingen Bd. 2, S. 528). 


\section{$[127 \mathrm{v}]$}

40.

1750.

Unterm 13 April sind am 27tn. bujus zur Erbauung

der Hottenroder Kirche von mir, als von der

hiesigen Kirche eingesandt $5 r$.

Unterm 24 April ist am 6 May ein Circular

ergangen, daß die Fürbitte wegen der Vieh-

seuche cessiren solle.

Den 12 Maji ist der H. Pastor Ströver ${ }^{162}$

zu Ballnhausen selig eingeschlaffen.

Unterm 1 Maji ist am 16 bujus ein Circular

ergangen, daß eine Becken- $\mathrm{u}$. KirchenVorraths

Collecte für die Kirche zu Barbis solle eingesandt werden.

Den 18tn. Maji als am Pfingstmontage führten

sich die Dragoners Heidmann u. Vogel

und Wedemeyer sehr gottlos unter der

Predigt auf. Sie stoßten einander mit der

dicken Faust, lachten und schlugen die

Jungens auf die Köpfe.

Den 24 Maji ist dem Printzen von Wallis

ein Printz gebohren. ${ }^{163}$

Den 11 Aug. ist der Zeugmacher Bornemann

der für etl. Monathen seinen Nachbar Gruben in

Göttingen erschossen, decollotiret zu Grohnda. ${ }^{164}$

Den 16 Aug. hat H. Seyffert Stadt Musicus

aus Göttingen eine vocal und instrumental

Music in hiesiger Kirche gemacht.

162 Joachim Ströver (MEYER, Pastoren, S. 52).

163 Der fünfte Sohn Friedrich Ludwigs, Prince of Wales, Friedrich Wilhelm.

$164 \mathrm{Zu}$ Grone hingerichtet. 
Den 30tn. Aug. kam des Nachmittages der

Dragoner Heine, welcher Valentins Zimmermanns

Tochter hir zu Frauen hat, zu mir auf die Pfarr

und fragte trotzig: Warum ich sein Kind nicht

\section{[128]}

41.

1750.

taufen wollte? Ich antwortete: ich habe ja nicht gesaget, daß ich ein Kind nicht taufen wolle, sondern habe nur einen Schein von euer Frauen Schwester gefordert u. diesen muß ich haben weil sie an einem andern Orte wohnet, vermöge der Consist-Verordnung. Er fragte mich aber nochmahls: Ich sollte ihm sagen, ob ich sein Kind taufen wollte und hielt dabey aus, als wenn er mich schlagen wollte. Ich antwortete: Ja, wenn ich den Schein bekomme, er wüßte von dem Befehl nichts das schöre ihn nichts, u. hatte allerhand lose Worte. Ich klagte es bey dem Hn. Obristleutenant von Scölln ${ }^{165}$ aber es ist ihm nichts widerfahren. Und wer that ihm was, als er am 20 Sept. dem Dragoner Becker fast die Hand abhieb?

Wer that ihm was, als er Conrad Ferensen schlug, und mit dem Kopffe ins Wasser stürtzte? Wer that ihm was? Als er Conrad Kramern auf freyer Strasse blutrünstig u. den Kopf entzwey schlug, daß er darauf närrisch im Kopfe geworden. Wer hat ihm was gethan, als er Deppe, bald todt schlug? Solche Soldaten sind den Officiren

165 Wahrscheinlich Capitain von Sckölln, vom Dragonerregiment von Wendt (5.C. R. Drag.). (SicharT Bd. 2, S. 89). 
angenehm, sie haben courage. Also ist

ein Prediger übel daran. ${ }^{166}$

Den 20 u. 21 post Trinit. haben die hiesigen

Ackerleute Wand ${ }^{167}$ von Hn. Grätzels Walcke-

mühle ${ }^{168}$ wegfahren müssen, also sind 2

Sonntage nicht geheiliget worden.

\section{$[128 \mathrm{v}]$}

42.

1750.

Im Monathe Augusto ist Johann Zimmermann Bauermeister geworden.

In diesem Monath Octob. ist die Stockhäuser

Kirche neu gebauet und gerichtet.

Den 28tn. Oct. haben beyde Gemeinen meinen Born

reingemacht. Mst. Deppe ist hineingestiegen, und hat

1r. bekommen.

Den 15tn. Novembris Mittages ist der H. Pastor

Hampe ${ }^{169} \mathrm{zu}$ Deiderode, alt 54 Jahr, verstorben.

Den 17 Dec. des Sonnabends Abend hat der

H. Pastor Matthaei ${ }^{170}$ zu Grossen Lengden im

Finstern von der Treppe herunter den Halß

abgestürtzt, u. ist gl. todt geblieben.

166 Der Articuls-Brieff des Kurfürsten Georg Ludwig stellte diese Gewalttätigkeiten unter schwere Strafen, wenn sie denn von den Vorgesetzten verfolgt wurden (vgl. SicHART Bd. 2, S. 125ff).

167 Leinwand.

168 Johann Heinrich Grätzel (1691 -1770) war der bedeutendste Tuchfabrikant Göttingens (BEER: Nachbleibsel der Sündfluth, in: GöJb 56, 2008, S. 173). Wenn man den Ausführungen Diether Kochs glauben kann, war Grätzel auch einer der risikofreudigsten, ehrgeizigsten und rücksichtslosesten Unternehmer seiner Zeit, so dass die hier angeprangerte Sonntagsarbeit durchaus glaubhaft erscheint. Hier handelt es sich wohl um die Grätzelsche Walkemühle an der Grone, die er aufgrund der Unterstützung durch die hannoversche Regierung 1727 errichten durfte (КосH, S. 104).

169 Caspar Heinrich Hampe (Meyer, Pastoren I 189).

170 Johann Friedrich Matthaei (Meyer, Pastoren I 369, II 419, 420). 
Den 30 Nov. Morgens um $4 \mathrm{Uhr}$ ist der Marchal von Sachsen zu Chambord in einem Alter von 54 Jahren als Lutherisch verstorben und darnach zu Straßburg öffentl. begraben. ${ }^{171}$ Der König von Franckreich hatte ihm $30 \mathrm{Jahr}$ Bedenckzeit zur Annehmung der Catholischen Religion gegeben, weil er, vermöge der Grundgesetze, sonst kein General FeldMarchal von Franckreich werde können.

Barbara Catharina Keil aus Grossen Sömmern bey Erfurth kam hir her Betteln auf 2 Krücken in Manns Kleidern. Weil ihr wegen des Kalten Brandes beyde Beine abgenommen waren. Ein erbärmlich Spectacul.

Im Monath Octob. 1751 ist ein Nasehorn zu Göttingen gewesen. Es sollte über 500 Centner schwer seyn. War ein gewaltiges Thier. Es hatte Schuppen wie ein Finger dick u. eine Hand groß. ${ }^{172}$

[Die Seiten 43 und 44 fehlen, sind offensichtlich herausgetrennt worden.]

\section{[129]}

45.

1751.

bey gesagt: Wer von Musicanten lachen würde, oder sonst Jemand, dem wollte er den Degen um im Leibe umwenden. Piepers Tochter, u. des jungen [das folgende Wort ist unkenntlich gemacht] Frau, des hiesigen [die folgenden beiden Wörter sind ebenfalls unkenntlich gemacht] Tochter ist vielmahls des Nachts

171 Hermann Moritz Graf von Sachsen, gen. Marschall von Sachsen, ein illegitimer Sohn des Kurfürsten August I. von Sachsen.

172 Es könnte sich um das Nashorn Clara handeln, das 1751 von dem holländischen Kapitän Douwe Mout van der Meer in Verona, Venedig, Wien, Prag und Frankfurt zur Schau gestellt wurde und den Weg zur Verschiffung nach London vielleicht über Göttingen genommen hat (FAUST, Zoologische Einblattdrucke, Stuttgart 2003, S. 58). 
bey ihm gewesen. Endlich wie er sich an

den jetzigen Adsessor Insinger ${ }^{173}$ durch

eine Pasquille ${ }^{174}$ vergriffen, da ihm

ein Grüner Thor für seine Haus-

hälterin ein Paar unverlicente

Handschuh weggenommen ist worden, ist er

ohne Gnaden Geld cassiret worden.

Jetzt hält er sich zu Dassel auf der Papir-

mühle auf, und seine Mutter schickt ihm

noch immer Geld. Sein Vater, der

Obersten, will ihn nicht mehr für seinen

Sohn erkennen. ${ }^{175}$ Er konnte seinen Namen

kaum schreiben, und war doch Lieutenant.

[Die folgende Zeile mit kleineren Buchstaben eingefügt]:

Er hat noch andere garstige Streiche mehr verübet.

Den 26Julii war ein sehr heisser Tag.

Den 8 Aug. 1751 als am 9 post Trinitatis ist der

bisherige Rector zu Elbingerode H. Johann

Just Schmidt ${ }^{176}$, als Pastor zum Garten Hof,

Deiderode und Elckshausen ${ }^{177}$ in der Kirche

zum Kloster MarienGarten von dem

Hn. Sup. D. Ribow eingeführet. Ich habe

mit adsistiret [!].

Den 22 Julii ist die verwitwete Printzessin

von Wallis mit einer Printzessin nieder-

gekommen. ${ }^{178}$

173 Vermutlich ist die Rede vom 1736 zum dirigierenden Bürgermeister in Göttingen ernannten Hofgerichtsassessor Insinger, der die Aufgabe hatte, die beiden anderen Bürgermeister zu kontrollieren. (WellenReuther 1988, 28ff).

174 Schmähschrift.

175 Vermutlich handelt es sich um Leutnant Bothe (s.u.). SiCHART verzeichnet einen Oberst Bothe als Kommandeur des 4. Kavallerieregiments Adelebsen im Verzeichnis der StabsOfficiere und Kompagnie-Chefs vom Jahre 1755 (SICHART Bd. 2, S. 98 und 105).

176 Johann Justus Schmidt (Meyer, Pastoren I 189).

177 Elkershausen.

178 Caroline Mathilde; ihr Vater Friedrich Ludwig von Hannover, Prince of Wales, war bereits am 20. März A.S./31. März 1751 gestorben; sie wurde mit Christian VII., König von Dänemark und Norwegen verheiratet (KImber, Peerage, S. XIX). 
Den 25tn. Aug. ist das alte Back- und

Brau-haus abgebrochen von beyden Gemeinen, und am 6 Sept. wieder neu aufgerichtet.

\section{[129v]}

46.

1751. 1752.

Den 29 Aug. 1751 war der 12 post Trinit. von Got ist der H. Pastor Thielo ${ }^{179}$ von Gotha

her von dem Hn. Sup. D. Ribow zu Ballenhausen eingeführet.

Unterm 13 Aug. ist Befehl u. am 5 Sept. für die am 30tn. Junii abgebrandte Stadt Wernigerode eine Haus Collecte gesammlet worden. 2r. 4 g. 1d.

Den 11 Sept. war ein sehr starcker Wind.

Den 21 Sept. ist der H. Sup. Prof. wie auch Pastor an der Jacobi zu Göttingen D. Christian Korthold selig eingeschlaffen.

Den 8tn. Octobris habe vom Hn. Consist. u. General Sup. Pratjen Antwort erhalten; daß er meine Abhandlung über Jacobi II in die Bremische Bibliotbec mit einrücken wollte. ${ }^{180}$

Den 25 bis auf den 29tn. Oct. war es sehr helle, und frohr daß auch die Fenster frohren.

179 Johann Franz Friedrich Thielo (Meyer, Pastoren I 52, II 44).

180 Johann Hinrich Pratje war seit 1749 Generalsuperintendent der Herzogtümer Bremen und Verden. Das Verzeichnis seiner Schriften zeigt ihn als Autor einer Vielzahl von theologischen und historischen Artikeln (vgl. OTTE, Milde Aufklärung). Die von Magister Stollberg erwähnte Abhandlung M. Joh. Paul Stolbergs Pastoris zu Obernjesa bey Göttingen Versuch durch eine nicht ungegründete Muthmassung die Zweifel etlicher Stellen des Briefes Jacobi zu beben ist gut 25 Seiten lang und erschien 1754 in der Bremund Verdische Bibliothek, worinn zur Aufnabme der Wissenschaften, insonderheit der theologischen, philologischen und bistorischen, allerley brauchbare Abbandlungen und Anmerkungen mitgetheilet werden, bey Christian Wilbelm Brandt, Hamburg. 
Unterm 14 Oct. ist ein Circular ergangen, daß das grosse u. kleine Gebet von 1749, wegen der wieder überhand genommenen Vieh-Seuche solle verlesen werden.

Den $8 t n$. 9bris hat es zum erstenmahl geschneyet in diesem Herbste.

Den 17tn. 9bris von 6 bis 9 Uhr Morgens sind in Roßdorf 2 Häuser 1 Scheure u. 1 Stall abgebrandt.

Den 26tn. Nov. ist der ViceSyndicus D. Joh. Andreas Hannesen $^{181}$ auf dem Amte Niedeck bey seinem Schwager verstorben, und nach Grossen Lengden begraben.

Unterm 4tn. Jan. 1752 ist am 4tn. Febr. ein C. Resc. ergangen daß für die Kirche zu Helstorf Amts Neustadt am Rübenberge eine Becken- und Kirchen-Vorraths Collecte sollte eingesandt werden.

Den 17tn. Febr. hat sich der H. Pastor Thielo zu Ballenhausen mit der jungen Frau Witwe Zähn aus Gotha vom Herrn Pastor Schaar in der Kirche zu Ballenhausen copuliren lassen.

\section{[130]}

47.

1752.

In der Nacht zwischen den 6 u. 7 tn. April war die Luft am Himmel so rein gegen Morgen, daß ich damahls viel tausend Sterne mehr als sonsten gesehen habe.

181 Johann Andreas Hannesens Beyder Rechten Doktors und Vice-Syndicus der Stadt Göttingen. Magister Stollberg wird ihn geschätzt haben, denn Doktor Hannesen veröffentlichte nicht nur in deutscher Sprache (Verschiedene kleine teutsche Schriften, Göttingen 1748), sondern verfaßte auch lateinische Grußadressen. 
Es stund einer bey dem andern u. war auch nicht einmahl eine Handbreit Raum darzwischen. Weil ich nun glaube, daß ein jeder FixStern eine Sonne sey, und andere Planeten bey sich habe; Rief ich aus Ehrfürcht für den Ewigen Gott aus. Ens entium omnipotens miserere nostri, Tibi soli semper sit honor et gloria in secula Amen! 182

Den 12 April sollen die Catechumeni nach Göttingen zum Hn. Sup. Appubn kommen.

Unterm 24 Martii 1752 ist am 23 Aprilis ein gedoppeltes Cons. Resc. eingelauffen, neml. es sollte für die Kirche zu Landrihausen Amts Calenberg eine Becken und für die Kirche zu Lippoldeshausen eine Amts Brackenberg eine Kirchen Vorraths Collecte eingesandt werden.

Unterm 10 April ist den 24tn. bujus ein Konigl. Cons.R. ergangen, daß Gott wegen der gesteurten ViehSeuche eine Dancksagung sollte abgestattet, und die Vorbitten für solche nachgelassen werden.

Unterm 24 Martii ist am 26 Maji. Cons. Rescr. eingelauffen, daß für die Kirche zu Hoyershausen Amts Lauenstein eine Becken u. Vorraths Coll. solle eingesandt werden.

182 Allmächtiger Gott erbarme Dich unser, Dir allein sei Ehre und Rubm in Ewigkeit, Amen. 


\section{[130v]}

48.

1752.

Unterm 19 May ist am 7 Junii ein C. Resc.

ergangen, daß Nachricht an den Hn. Sup. solle

eingesandt werden: Wie viel Uberschuß von

den Behuf des Bauwesens in 6 Jahren

als von 1740 bis 1746 zurückgelegten

annoch vorhanden sey?

Den 8. Junii haben meine Knechte eine

Ehrenfuhr an die grossen Schneeische Ober-

Kirche gethan, und haben ein 8 Spännig

Stück Tannen Holtz von Witzenhausen

nach grossen Schneen gefahren. Die Knechte

haben was zu trincken bekommen.

Unterm 6 April ist am 14tn. Junii von der

Geheimter Rath Stube ${ }^{183}$ eine Verordnung

wegen des Kirchengeldes ergangen.

Den 15tn. Junii haben die beyden Gemeinen

auf meinen Fruchtboden den Eßtrich

giessen lassen. Auch ist der Rauch-

boden begossen. Sind 30 Malter zu

gegangen.

Von 19 bis 23 ist der Giebel nach dem Brunn $\mathrm{zu}$ von Mst. Münschern ${ }^{184}$ beworffen worden.

12 Malter Gips u. 10 Malter Scheffel Leder Kalck ${ }^{185}$

sind zugegangen.

Den 30 u. 31 Julii ist die Leine und

Dramme ausgegangen $u$. hat alles verschlemmt.

183 Gemeint ist die Gruppe der Geheimen Räte, d.h. die Minister, die in Hannover die Regierungsgeschäfte für den abwesenden König führten.

184 Vgl. [131v] und [156v].

185 Luftsaurer, ungelöschter Kalk. 
Den 4 Aug. ist auf dem Reinshofe ein Knabe von 2 Jahren in der Garte und am 7 Aug. ein Knabe, Bielefeld, von 9 Jahren in der Leine ertruncken.

Den 22 Aug. 1752 ist der H. Pastor Schaar zu Diemarden des Morgens selig eingeschlaffen.

\section{[131]}

49.

1752. 1753.

Von 2 Julii an bis auf $31 \mathrm{Aug}$. Hat es beständig geregnet.

Den 19 Sept. hat sich der Herr Sup. Appubn $\boldsymbol{z} u$ Gott mit des sel. Hn. AmtsVerwalters Müllers nachgelassener Witwe, gebohrne Saalfeldin, von Hardenberge wiederum verheyrathet.

Den $5 t n$. Oct. wurde ich des Abends nach Reinhausen gehohlet dem Hn. Amtmann Hinüber ${ }^{186}$ in seiner Todes Noth bey zustehen, weil der Prediger in Diemarden H. Schaar u. Reinhausen verstorben war. Nach langen Ermahnen und Beten kam er endlich zur Erkenntnis seiner Sünden und bezeigte ein Verlangen zum heil. Abendmahl, das er bisher immer verachtet hatte, welches ich M. Stolberg, ihm um 2 Uhr des Nachts reichete, bis er endl. am 8 Oct. verstorben.

Den 7 Dec. hat sich der H. Pastor Schmidt zu Deiderode wiederum verheyrathet, u. auf der Rasemühle Hochzeit gehalten. ${ }^{187}$

186 Laut Staatskalender muss es sich hier um Christian Erich Hinüber handeln (Sieben-facher Königl. Groß-Britannisch- und Chur-Fürstl... auf 1750, S. 105). An anderer Stelle wird der Amtmann von Reinhausen als Carl Ernst Hinüber genannt, der vermögend gewesen sei und Geld an Göttinger Bürger verliehen habe (vgl. Wellenreuther 1988, 286).

187 Die Gastwirtschaft Rasemühle scheint nach der Gründung der Universität eingerichtet worden zu sein und war wohl bis in die zweite Hälfte des 19. Jahrhunderts in Betrieb (Freundliche Auskunft von Frau Heidrun Dolezel MA). 
Zwischen den 14 und 15 Dec. war es in der Nacth[!] insonderheit um 10 Uhr ein solcher Sturmwind daß mein Bette erschütterte, Hin und wieder hat es Dächer ab- und Bäume niedergerissen.

1753.

Den 28tn. Febr. 1753 ein Trostschreiben an

den Hn. Amtsschreiber Blumen ${ }^{188}$ nach

Brackenberg gesandt, das seine Frau

Liebste in Wochen verstorben.

Den 12 Martii hat Mst. Köhler den Knopf

von dem Dramfelder Thurm abgenommen. ${ }^{189}$

Den 25tn. ist der H. Pastor Fuchs zu

Diemarden eingeführet. Er war vorher $S u b$ -

Conrector zu Ilefeld gewesen. ${ }^{190}$

[131v]

50.

1753.

Den 25 April ist ein Circular von Hn. Sup.

Appubn ergangen, daß ein jeder Prediger seine Catechumena selbst coram facie Ecclesiae ${ }^{191}$ confirmiren könne, weil der H. Sup. kranck wäre.

Unterm 11 May ist am 9tn. Junii kam ein C. Rescr. an, daß für die Kirche zu Kirchwehren Amts Blume-

188 Johann Friederich Blum. Der Amtschreiber hat die Funktion eines Vertreters des Amtmannes, ist also der zweite Beamte im Amt (Böhme, Scholz und Wehner, Dorf und Kloster Weende, S. 123).

189 Vgl. KiKrAGött. P. A. Dramfeld Dr.A. 512.

190 Johann Nicolaus Fuchs. Die Klosterschule Ilfeld, auch als Pädagogium Ilfeld bezeichnet (heute im thüringischen Landkreis Nordhausen), und das Stift wurden mit der Gründung der Universität Göttingen der Aufsicht der Göttinger Professoren [Johann] Matthias Gesner und nach ihm Christian Gottlob Heyne unterstellt. Sie wird als Vorbereitungsanstalt für die Göttinger Universität bezeichnet (FucHs, Bücher aus der Bibliothek G.W. Leibniz', S. 244).

191 Im Angesicht (vor) der Gemeinde. 
nau eine Becken- und KirchenVorrathsCollecte solle eingeschicket werden.

Den 9 Junii hat der Thurmdecker Mst. Köhler den Knopf auf den Dramfelder Thurm nachdem er ihn verguldet, wieder aufgesetzet. Es war keine Jahrzahl dran, und war von Zinn gegossen. Es stund aber der Name, Lorentz Utermöhlen, daran. Demnach mußte dieser Knopf ohngefähr über $140 \mathrm{Jahr}$ alt seyn, da dieser Mann zu Dramfeld gelebet.

Den $3 J u l i i$ ist des Schultzen Mengershausen Sohn, als er sich bey dem Were baden wollen, in der Leine ersoffen.

Den 14tn. Julii ist der Steinweg vor meinen Fenstern hernach dem Pferdestall zu gemachet. und den Kirchenfußsteig auch.

Den $16 J u l i i$ haben die Dramfelder 2 Malter Lederkalck gebracht.

Unterm 26Julii ist am 31 ein Cons. $R$. ergangen I. Ob die Sommerschule gehalten werde. II. An welchen Tagen? III. Wie viele Kinder? IV. Ob deßwegen den Aedituis à part was gegeben werde? V. Wie viel Schulgeld der Schulmeister jährlich von einem jeden Kinde bekomme?

Im Aug. ist der Vorder Theil des Hauses mit Kalcke von Mst. Münschern beworfen. Das Taubenhaus nach Mittag zu machen lassen kostet mir mit Essen und Trincken deshalb ... [unleserlich] uber $7 \mathrm{r} .{ }^{192}$

192 Vgl. Seite [144av]. 
[132]

51.

1753. 1754 .

In der Nacht zwischen 4 und 4 [!] Sept. ist der H.

Doctor und Professor Theologiae Operin selig

eingeschlaffen. Vir erat orthodoxus et pius. ${ }^{193}$

Den 2 Oct. ist der H. Leonhard Scholae

Gottingensis Director gestorben. ${ }^{194}$

Den 6 Dec. habe durch den Herrn Prof. Wedekind ${ }^{195}$

in Göttingen nebst $4 \mathrm{mg}$. Porto an den Herrn

Sup. Ratblef zu Nienburg zwo Abhandelungen

eingeschickt: Die erste handelt certitudine

resurrectionis, ${ }^{196}$ die andere hält in sich eine

Erläuterung des Stücks 1 Cor. 6, 1.2.197

welches er mit in seinen Theologen ein-

rücken will. ${ }^{198}$

Den 12 Dec. ist H. Mentzer ${ }^{199}$ Pastor zu

Hattorf verstorben.

193 Er war ein strenggläubiger und frommer Mann. Professor Joachim Oporin starb am 5. September 1753 (Carstens, in: ADB Bd. 24, 1886, S. 381).

194 Johann Christoph Leonhard, vormals Professor der alten Sprachen (MiCHAEL, Die Göttinger Schulen, in: Göttingen Bd. 2, S. 667).

195 Professor Rudolf Wedekind ist als Kollege von Magister Stollberg zu betrachten: Er war seit 1741 Konrektor an der neu eingerichteten Stadtschule (nachdem das Pädagogium 1734 zugunsten der Universitätsgründung aufgehoben worden war [108v]). 1748 wurde er zum außerplanmäßigen Professor der Philosopie an die Göttinger Universität berufen; man sagt allerdings, dass er als apl. Professor nicht vom engeren Kern der Professorenschaft anerkannt wurde (vgl. GIERL, 1988, S. 83); 1754 Leiter der Stadtschule; später Pastor an St. Albani. Herausgeber eines moralisch-literarischen Journals. Während des Siebenjährigen Krieges führte er ein bekannt gewordenes Tagebuch (PANnENBORG, Rudolf Wedekind: Tagregister von dem gegenwärtigen Kriege, Göttingen 1896).

196 Über die Gewissheit von der Auferstehung.

197 Wie darf jemand unter euch, so er einen Handel hat mit einem andern, hadern vor den Ungerechten..

198 Ernst Ludwig Rathlef wird als eifriger Seelsorger, guter Geschäftsmann und als ordnungsbewußter Pfarrer bezeichnet, war seit 1752 Superintendent in Nienburg und gab in den Jahren 1754 bis 1756 eine Wochenschrift Der Theologe heraus (vgl. MeuseL, Lexikon der vom Jahr 1750 bis 1800 verstorbenen teutschen Schriftsteller, Bd. XI, Hildesheim 1968, S. 54-57).

199 Balthasar Mentzer (Meyer, Pastoren, 472). 
Von 13 bis 18 Dec. hat es beständig geregnet, ist warm gewesen bis auf den 29tn.

Dec. u. ist groß Wasser gewesen.

Den 23 Dec. war der 4te Advent ist der Adjunctus Pastor Julius Gustav Albertinus Hannover in Grossen Schneen eingeführet zu Grossen Schneen.

1754.

Den 4tn. Jan. des Morgens um $5 \mathrm{Uhr}$ ist der Pastor Hannsemann ${ }^{200}$ zu Grossen Schneen im 72 Jahre selig eingeschlaffen, und den 15tn. öffentl. begraben. 12 Schulmeister trugen u. 8 Pastors sind ihm gefolget.

Der H. Sup. D. Ribow hielt ihm die LeichenPredigt über Rom. 8, 18. ${ }^{201}$ Thema Einige Mittel wider die Bitterkeit des Todes. Exord: Also muß man des Todes Bitterkeit vertreiben.

\section{[132v]}

52.

1754 .

Unterm 22 Martii ist ein C. R. ergangen, daß wir berichten sollten: Was es eigentlich mit dem Beweinkauffen der Kirchen Stände ${ }^{202}$ für eine Beschaffenheit habe?

Den 2 Maji hat die hiesige Gemeine die KirchHofes Pfosten setzen lassen.

200 Eberhard Heinrich Hansemann (Meyer, Pastoren, 373).

201 Denn ich halte es dafür, daß dieser Zeit Leiden der Herrlichkeit nicht wert sei, die an uns soll offenbart werden...

202 Nach dem Tod eines Kirchstuhlinhabers sollte dieser von seinem Erben erneut gekauft werden. 
Den 21 May ist der Lieutenant Bothe ${ }^{203}$, wegen seiner garstigen $\mathrm{u}$. üblen Streiche abgedancket.

Des Nachts zwischen den 29 u. 30 May und zwischen

11 u. $12 \mathrm{Uhr}$, da der Mond 8 Tage alt und

$1 \frac{1 / 2}{2}$ Stunde vorher untergegangen war, stund

ein Regen Bogen gegen Osten am Himmel

welches hir mit mir viele Leute gesehen.

Zeit meines Lebens ist das erstemahl daß ich

solches des Nachts observiret.

Unterm 31 Maji ist ein C. $R$. ergangen, daß

für die Kirche zu Brokum Amts Lemför [!]

eine Kirchen-Vorraths Collecte solle ein-

gesandt werden.

Den 27 Junii sahe ich gegend Abend um $8 \mathrm{Uhr}$ einen grossen funckelnden Stern bey der Sonne.

Es was ausserordliches [!] er ging aber mit der

Sonne unter.

Den 17 Julii ist der bisherige Hofrichter

Herr von Haacke als Consistorial

Praesident ${ }^{204} \mathrm{zu}$ Hannover introdeci-

ret worden. Er ist nicht lange darnach

auch wircklicher Geheimer Rath

geworden.

Den 19Julii sind die vergülteten Zeige-

blätter von der Uhr an den Thurm

wiederum aufgehencket $u$. feste gemacht worden.

Den 26Julii der Advocatus Herr Wellner

Registrator zu Hannover beym Consistorio

geworden.

203 Vgl. [129]; vermutlich handelt es sich um den Leutnant Bothe, der 1752 in Ellershausen einquartiert war und dort den Studenten die Bekanntschaft mit liederlichen Frauenspersonen vermittelte; die Universitätsverwaltung bat daraufhin die Vorgesetzten des Leutnants um dessen Versetzung in ein anderes Dorf (UAG, 635.1, f 27).

204 Levin Adolph von Hake, von 1754 bis 1771 Präsident des Konsistoriums (Амт, Die Bauverwaltung des Hann. Konsistoriums, S. 1). 
[133]

53.

1754.

Christoph Pieper ein Soldat unter des

Hn. Generals von Hugo Regiment ${ }^{205}$, gehet

mit dem abgesetzten Lieutenant Bothen in

allen Krügen herum u. treibt Boßheit.

Als ich einstmahl in der Catechismus

Lehre die Hurerey bestraffet ohne Jemand

zu nennen, hat ihn der Lieutenant hie-

her aus dem Kruge schicken wollen, mich

zur Rede zu setzen und zu schlagen ich bin

aber eben nicht zu Hause gewesen.

Da hat der Bothe gefraget: bist du hin

gewesen nach dem schwartzen Mann? u.

Pieper hat gesagt: Der Donner und

das Wetter soll dem Papen in den schwartzen

Kragen schlagen, wenn ich ihn antreffe.

Den 10 Sept. ist ein Papistischer Drago-

ner Wolf in Christoph Zimmermanns

Hause verstorben. Ein Catbolischer Pater

ist ohne mein Wissen $u$. Willen in seiner

Kranckh. bey ihm gewesen. Da wir Lutherische

Prediger aufs Eißfeld einem Krancken das

heil. Abendmahl zu reichen, nicht kommen

dürfen. Warum leidets denn die Obrgk.

daß Catbolische hier ins Land kommen

dürfen. ${ }^{206}$ Ich habe es dem Herrn Sup. $A p$ -

pubn gemeldet, es ist aber keine Antwort

darauf kommen.

205 SiCHART erwähnt das Regiment des Oberst von Hugo (4. I. R. B) in einer Logierliste von 1748, die zeigt, dass das Regiment seinerzeit weitab von Göttingen in mehreren Orten einquartiert war (in Stolzenau, Liebenau und Steyerberg, in Diepholz und Lemförde, in Sulingen und in Bruchhausen und Vilsen, sowie in Wildeshausen). Vgl. SICHART Bd. 2, S. 95; Nachweis des Regiments 1755 siehe S. 101.

206 Zwar hatte Georg II. mit dem Reskript vom 9. April 1746 die ständige Anwesenheit und Wirksamkeit von katholischen Geistlichen in der Stadt Göttingen erlaubt (WEHKING, in: Göttingen Bd 2, S. 587), was jedoch nicht hieß, dass die beiden Konfessionen in der Praxis gut miteinander auskamen. 
Den 5tn. Oct. das Vest ${ }^{207}$ auf meinem

Kutschen Schoppen machen u. stopffen lassen

bringet 1r. u. $4 \mathrm{~g}$. Die Jungens aus

Dramfeld haben es gemacht.

\section{[133v]}

54.

1754. 1755.

Am 3tn. Nov. Abends um 6 Uhr ist der

H. Senior, Pastor Henning Flügge an der MarckKirche [!]

selig eingeschlaffen. War ein gewaltiger

Orator et vir pius. ${ }^{208}$

Des Nachts von 24 bis den 25 Novemb. hat der

Rath alle Kühe, welche auch noch gesund

gewesen, aus der Nicolai und St.Johannis

Pfarr mit Gewalt vors Thor treiben und

todt schiessen lassen, damit die bis anhero

wütende Viehseuche nicht weiter um sich

greiffen möge. ${ }^{209}$

Den 30 Dec. nachmittages um 4 Uhr ist der

Herr Kloster Verwalter, oder Amtmann

Oppermann wie sie ihn nannten, unvermuthet gestorben. ${ }^{210}$

1755 .

Von dem 6Jan. 1755 an bis den 12 Febr. ist ein

solcher grosser Schnee gefallen, daß man von

einem Dorfe fast nicht zum andern kommen

können ${ }^{211}$, auch sind Hinmid wieder Menschen.

verfrohren, wie denn der Constabler Mayer

207 Der First des Schuppens.

208 War ein gewaltiger Redner und frommer Mann (vgl. Meusel, Band 3, S. 405).

209 In der Literatur heisst es, dass dies eine zeitgenössische Praxis gewesen sei (HÜNEMÖRDER, in: ENGELKen et al. (Hg.) S. 22).

210 Der Name wurde vermutlich später nachgetragen. Justus Friedrich Oppermann war von 1745 bis 1755 als Verwalter auf Mariengarten (vON BOETTICHER, S. 157).

211 Auch aus anderen Orten gibt es Berichte über eine unglaubliche Menge Schnee im Winter 1755 (Busch, Kriegs- und Alltagsleben in Bovenden, S. 84). 
aus Göttingen, hinter dem Garten Hofe $\mathrm{H}^{212}$ auch todt gefrohren ist.

Des Nachts von 10 und 11 Martii ist der H. Professor Köhler $^{213}$, ein grosser Historicus selig eingeschlaffen.

Den 11 Martii Abends um 6 Uhr ist der Herr Pastor Zwinckmann ${ }^{214}$ zu NiedernJesa sel. eingeschlaffen, nach dem er an der gelben sucht 5 Wochen kranck gewesen.

Den 18 bujus ist er nach Stockhausen in die Kirche begraben worden. Weil ich kranck wurde; so hat der H. Pastor Flügge die Abdanckung gehalten. Alt $61 \mathrm{Jahr}$.

Den 13tn. April ist der Pastor zu Grossen Schneen Aberti zum Diacono an der Michaelis Kirche zu Hamburg erwählet worden. Er hatte daselbst am Sonntage Laetare über die Epistel die Probe Predigt gehalten. Ein sogenannter Oldermann ${ }^{215}$ hat ihm am 26 April die Vocation überbracht.

\section{[134]}

55.

\section{5.}

Den 9tn. May ist der H. Pastor Sothe des Morgens an der Lieben Frauen Kirche zu Göttingen verstorben. Der Göttingische Magistrat hatte ihm die Pfarr anno 1734 gegeben. Er war ein geitziger Mann, und hat viel Geld seines verstorbenen Bruders Doct. Sothen Kindern nach gelassen. Weil er nicht wollte

\footnotetext{
212 Hinter dem Kloster Mariengarten.

213 Johann David Köhler (WäHner, Tagebuch, S. 261).

214 Heinrich Lorenz Zwinck[g]mann (Meyer, Pastoren, 193).

215 Ein Vertreter der Hamburger St. Michaelisgemeinde.
} 
daß ihr Lehn nicht sollte getheilet werden, entschloß er sich unverheyrathet zu bleiben, und hielt mit einer Magd Haus und ließ seinen Bruder freyen. Alles aus Geitz. $^{216}$

Den 16 May Abends um 5 Uhr bekam meine Frau, Hedewig Elisabeth gebr. Henckeln ${ }^{217}$, den Schwindel im Garten und wurde darauf vom Schlage auf der rechten Seite des gantzen Cörpers gerühret, und als wir bey ihr in der Kammer beteten, weil sie verscheiden wollte, wurde uns unterdessen um 11 Uhr ohngefähr des Nachts unser Brau Kessel von 24 Eymer, welcher mir 18r. gegolten, gestohlen. Wir haben den Dieb nicht eigentlich ausforschen können.

Den 17 May habe den Herrn Doctor Papen ${ }^{218}$ in meiner Kutschen zu meiner Frauen heraus hohlen lassen.

Den 2 Junii ist Kirchen Visitation zu

Lütgenschneen gehalten worden, und ich habe ratione der Kirche zu Dramfeld die beyden

216 Pastor Justus He[i]nrich Sothen war einer der wenigen Geistlichen, die Kredite vergaben (Wellenreuther 1988, S .278).

217 Dieses ist einer der wenigen Hinweise auf die privaten Verhältnisse der Pastoren. Immerhin war Magister Stollberg mit der Tochter eines Göttinger Ratsherrn verheiratet und hatte auf diese Weise Verbindung zu den Kreisen der Göttinger Honoratioren. Das gleiche gilt für seinen Sohn und Nachfolger im Amt Heinrich Philipp Stolberg, der mit der Tochter Maria Sophia des Göttinger Ratsherrn Heinrich Joachim Winiker verheiratet war (vgl. Bielefeld 1957, S. 58 und 59, sowie Косн, S. 56, Anm. 37).

218 Stadt- und Landphysikus (Amtsarzt) Doktor Christoph Henricus Papen (1709-1758). Magister Stollberg hätte auch einen anderen Arzt kommen lassen können; aber er kannte Dr. Pape sicherlich bereits aus seiner Göttinger Zeit, und er kannte den guten Ruf Papes als Arzt. Schließlich hatten sie einen gemeinsamen Bekannten, den Professor Heumann. Sein bisheriger Arzt H. Gudewill in Groß Schneen war vermutlich älter (und/oder gebrechlich?), denn er starb im folgenden Jahr (21.5.1756 (vgl. [138]). Frau Stollberg aber starb erst sieben Jahre später (vgl. Bielefeld 1957, S. 59 und BEER, in: Museumsbrief Nr. 16 des Chemischen Museums der Universität Göttingen, S. 2-10). 
Hn. Kirchen Commissariis D. et Sup. Ribow

u. Hn. Ober Amtmann Hartmann

gezahlet 23r.12g. von 7 Jahren.

\section{[134v]}

56.

1755.

Den 15tn. Junii ist des Schulmeisters Schloten

Sohn, Johann Friedrich, durch den Hn. Sup.

D. Ribow zum Schulmeisters adjuncto

eingeführet. Weil der Vater vorgab, er

bekäme öfters die Colic, ob er gleich noch

keine $50 \mathrm{Jahr}$ alt ist, und setzte sich unter

dem Singen nieder, u. schiene als wenn

er keine Luft kriegen könnte. Weil nun

ein Fremder von der Hälfte nicht hätte

leben können; So ist ihm sein Sohn, welcher

noch nicht 22 Jahr alt ist adjungiret.

Der Schulmeister gab dem Hn. Sup. eine

Mahlzeit, und die Gemeine hatte den Hn.

Superint. gehohlet $\mathrm{u}$. brachte ihn auch wie-

der zurück. ${ }^{219}$

Den 29 Junii ist der H. Pastor Schierholtz ${ }^{220}$ zu Grossen Schneen eingeführet worden. Er war vorher Pastor gewesen zu Bühren vor dem Walde.

Den 5 Julii ist ein $C$. $R$. ergangen, daß dem

Herrn Secretario Ahrendhold jährlich auch

so viel haben sollte von jeder Kirche

als der H. Revisor bekäme. ${ }^{221}$ Ich habe

219 Das heisst, dass die weltliche Gemeinde - nicht die Kirche - die Kosten für den Transport des Superintendenten übernommen hatte.

220 Johann Ludwig Schierholz (Meyer, Pastoren I 373).

221 Der Konsistorialsekretär Gerhard Justus Arenhold (1707-1775) war seit 1735 als „Secretarius supernumeranus", also obne festes Gehalt, beim Konsistorium angestellt (...). 1755 übertrug man ihm (...) die „Expedition der Bausachen“. Für diese Arbeit, (...) bekam er aus dem „Bau-Expeditions-Fond“, der 1755 geschaffen worden war und aus einer Abgabe der Gemeindevermögen finanziert wurde, ein Gehalt von 200 Reichstalern (Амт, Die Bauverwaltung, S. 3). 
es dem Altaristen wissen lassen. Weil ich nichts mehr mit der hiesigen Kirchen-

Rechnung zu thun habe. ${ }^{222}$

Von 23 Julii an bis den 1 Aug. war es so kalt daß man einheitzen u. Handschuh anziehen mußte.

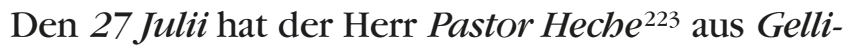

bausen seine IntroductionsPredigt in Göttingen

zu unser Lieben Frauen gehalten. Darauf ist der H. Sup. D. Ribow vor den Altar getreten und hat durch die Altaristen der Gemeine Vocation verlanget, weil aber unterdessen auf eines gewissen Mannes Anstiften die Gemeine weg u. aus der Kirche gegangen, so hat der H. Sup. gesagt: In Ermangelung der Vocation wollte er die Introduction bis auf eine bequemere Gelegenheit aufschieben.

\section{[135]}

57.

1755

Und damit ist der Gottes Dienst ausgewesen.

Es ist nachher ein Leipziger Mag. Gautsch ${ }^{224}$ dazu gekommen.

Von Marien Tage an hat es bis auf den $11 \mathrm{Aug}$. beständig geregnet, also daß fast alles Korn auch auf dem Halme ausgewachsen ist.

Unterm 2 Aug. ist Cons. $R$. ergangen dem Abgebrandten Prediger Mensching zu Seeltze eine milde Beysteuer ein zuschicken Ein Jeder Prediger hat es aus dem Seinigen thun müssen. Ich habe $18 \mathrm{~g}$. gegeben.

222 Die Rechnungsführung war dem Lehrer Hardeland in Rosdorf übertragen worden.

223 Vermutlich Pastor Johann Conrad Heise (Meyer, Pastoren, 308).

224 Friedrich Benjamin Gautsch (vgl. SAATHoff 1929, Tabelle: Die evangelischen Pfarrer Göttingens in vier Jahrhunderten). 
Unterm 21 Aug. ist ein C.R. eingelauffen daß so se wohl eine Becken- als KirchenVorraths Collecte für die Kirche zu Lauenstein solle eingesandt werden.

Den 9tn. Sept. Morgens um $4 \mathrm{Uhr}$ ist der Herr Cantzler von Moßheim in Göttingen verstorben. ${ }^{225}$

Unterm 14 Sept. ist ein C.R. ergangen, daß auf den 20 post Trinit. wird seyn der 12te Oct. da Gott für den Religions Frieden solle gedancket werden, welcher nun mehr $200 \mathrm{Jahr}$ gedauret wider alles Wüten und Toben des Teuffels. ${ }^{226}$ Der vorgeschriebene Text war: Actor. 9, 31. So hatte nun die Gemeine Friede - - Geistes. [vom Schreiber gewollte Auslassung]. ${ }^{227}$

Damit Mhn. Successores wissen mögen, wie ich zu der Zeit geprediget habe; So will meine kurtze Disposition aufschreiben. Vot. ${ }^{228}$ Erhalt uns Herr bey deinem Wort, und steur des Pabst und Türcken Mord die Jesum Christum Deinen Sohn, stürtzen wollen von seinem Thron. Amen. verte

[135v]

58.

1755.

Exord. $\psi$ 118, 15.16. ${ }^{229}$ Man singet - . - - Sieg.

225 Vgl. [120v].

226 Gemeint ist der Augsburger Reichs- und Religionsfrieden vom 25. September 1555.

227 Apostelgeschichte 9, 31: So hatte nun die Gemeinde Frieden durch ganz Judäa und Galiläa und Samarien...

228 Votum, Gebet.

229 Exordium, Einleitung, Psalm 118, 15.16: Man singt mit Freuden vom Sieg in den Hütten der Gerechten... 
a Wie klinget der Jubelgesang?

$\beta$ Worüber freuen sich die Gerechten?

$\gamma$. Wo wird dieser Jubelgesang gesungen?

$A p p l .^{230}$ Vor 200 Jahren sungen unsere

Vorfahren, da sie noch wenig Kirchen

hatten, in ihren Hütten auch einen Jubelgesang;

Wie die ersten Christen in den 300 Jahren

nach Christi Geburth. Hier singen die ersten

Christen f und dancken Gott für den erhalte-

nen Kirchen-Frieden. Tex Act. 9, 31.

Thema das freudige Singen, in den Hütten

der Gerechten

Präloq. ${ }^{231}$ Enthielt die Ursachen, warum

wir dieses Fest feyern,

1. Gott, dem allerhöchsten zu dancken für den erhaltenen Religions Frieden

2. Gott, daß Er unserm Allergnädigsten König und Hn. Georg II. fürstl. Gedancken eingegeben.

3. Gott für das theure Leben U.A.K.

und $\mathrm{Hn}$. zu bitten...232

Thema Das freudige Singen in den Hütten der Gerechten. Sie bringen Gott Ehre u. Preiß

I. Für den erhaltenen Kirchen Frieden; So hatte nun die Gemeine Friede durch gantz Judaea, und Galilaea und Samaria.

II. Für die Bekräftigung der Gnade Gottes durch einen heil. Wandel. Nach dem Gr. Text III. Für den An- und Zuwachs der Christlichen Kirche. Durch den Trost des heil. Geistes wurden sie an der Anzahl immer stärcker etc...

230 Applicatio, Anfügung.

231 Präloquium, Vorspruch, Einleitung.

232 Unseres allergnädigsten Königs und Herrn. 
Des Nachmittages 2 Cor. 13, 11. ${ }^{233}$ Darüber habe einen kurtzen Sermon gehalten.

\section{[136]}

59.

Damit meine Herren auch wissen mögen, wie es mit dem allgemeinen Bußtage gehalten sey, als der Frantzose in unser Land fallen wollte 1741. vide den 16 Martii 1741 in boc libro pag. 13. ${ }^{234}$ Worüber dazu mahl im gantzen Lande geprediget worden, und was ich für ein Thema gehabt; So will davon auch eine Disposition wieder hersetzen:

Prael. Esaiae 58, $1 .^{235}$

Exord. Act 3, 19.236 Petrus schreyet den Juden Busse und Gnade zu.

Applicatio...237

Text Jeremiae 6, $8 .^{238}$

Thema: Die ermunternde Buß- und

Gnaden Stimme Gottes durch Jeremiam.

I. Wie er allen Verstockten und unbuß

färtigen Sündern in die Ohren und

Hertz schreyet: +Busse+ Thun. Busse und

bessere Dich Jerusalem.

II. Wie Gott ihnen auch zuruffe

Gnade! Ehe sich mein Hertz von

Dir wendet, ehe ich Dich zum wüsten

Lande mache...

Jus war: Lehre... Vermahnung,

Warnung u. Trost.

233 Zuletzt, liebe Brüder, freuet euch...

234 Siehe den 16. März 1741 in diesem Buch Seite 13.

235 Prälusio, Vorspiel: Jesaja 58, 1: Rufe getrost, schone nicht,

236 Exordium, (Einleitung), Apostelgeschichte 3, 19: So tut nun Buße und bekehret euch, daß eure Sünden vertilgt werden.

237 Anschluss, Anfügung.

238 Jeremias 6, 8: Bessere dich, Jerusalem, ehe sich mein Herz von dir wende... 
Weil jetzt der Frantzose wieder mit uns nichts Gutes im Sinne hat, wäre wohl ein Bußtag wieder nöthig. Denn es leidets die Ehre Franckreichs nicht einen theuer zugesagten $u$. im Namen der heil. 3 Einigkeit gemachten, ewigen Frieden zu halten.

\section{[136v]}

60.

\section{5.}

Den 30 Sept. hat mein Sohn, Henrich Philip Stolberg unterm Vorsitz Sr. Hochwürden des Herrn Doct. Heumanns ${ }^{239}$ disputiret:

De Supplementis historiae literariae Gottingensis.

Den 19 Octobr. ist der H. Pastor Kelterborn zu Reckshausen Morgens zwischen 3 u. 4 Uhr an einem Stickflusse im 70 Jahre seines Alters verstorben. ${ }^{240}$

Den 27tn. Octobris haben die beyden Gemeinen meine alte Scheune auf der Seite nach dem Hofe durch die Jungens von Dramfeld decken lassen. Sind 2 Schock und 10 Bund verbraucht. ${ }^{241}$

Den 27tn. Oct. ist Knokens Scheune voll Frucht in Volckeroda abgebrandt.

Den 6 Nov. kam Singräfe Reformirter und Allbrecht Catholischer Religion, beyde Drago-

239 Christoph August Heumann, 1681-1764, Inspektor des Göttinger Pädagogiums; später Professor für Philosopie und Theologie in Göttingen; von 1739-1740 und 1746 für sechs Monate Prorektor www.uni-goettingen.de/de/heumann-christoph-august/103169.html (3.9.2015).

240 Pastor Kelterborn starb an einem Lungenödem, einer Flüssigkeitsansammlung in der Lunge infolge von Herzversagen (MeTZKe, S. 112).

241 Verbrauch an Stroh. 
ners, einer lag zu Stockhausen u. einer lag bey der Johann Zimmermäneschen auf dem Hofe, des Mittages um 12 Uhr und setzten mich mit Ungestüm zur Rede, warum ich am Sonntage vom Glauben geprediget hätte. Was wollt ihr davon haben? Antwortete ich, ihr seyd ja meine Schaafe nicht, soll ich meinen Glauben nicht vertheidigen? Nach der Zeit habe gehöret, daß die Johann Zimmermannin Rel. Ihnen Branntewein gegeben und sie darzu animiret weil sie ihre andere Tochter dem Catholischen Allbrecht zur Ehe geben wollte. ${ }^{242}$ Ich habe es dem Hn. Fahndrich Berg gemeldet, es ist aber nichts daraus worden. ${ }^{243}$

Den 7 Dec. ist der H. Pastor Mengerhausen ${ }^{244} \mathrm{zu}$

NiedernJesa eingeführet, und Stockhausen ist für eine Consistorial-Kirche erkläret.

242 Die Frage, was einen Soldaten, gar einen Katholiken, für eine Witwe als Schwiegersohn attraktiv machte, ist nicht eindeutig zu beantworten. Das bunte Tuch allein (JÜNEMANN, GöJb 27, 1979, 101) kann es nicht gewesen sein. Schließlich mussten die Höfe Abgaben für die Unterhaltung der Armee zahlen und die Unterkunft unentgeltlich stellen; dagegen war die Altersversorgung aus der Invaliden-Casse für einen einfachen Soldaten überaus gering; eine Hinterbliebenenversorgung gab es erst seit 1793 (ОвеRsChelp I, S. 330-332). Es ist denkbar, dass die Witwe Zimmermann wieder einen Mann auf dem Hof haben wollte, der Kraft und ausreichend Zeit für die anfallenden Arbeiten hatte. Wie oft und wohin die Obernjesaer Dragoner in Friedenszeiten zum Exerzieren ausrükken mussten, ließ sich bisher nicht klären.

243 In der Praxis dürfte so mancher Absatz des Articuls-Brieff des Kurfürsten Georg Ludwig, der die Disziplin der Armee regeln sollte, nicht eingehalten worden sein. Immerhin heißt es in Abschnitt 18 Jeder Soldat zu Roß und zu Fuß, vom böchsten bis zum niedrigsten, sollte gegen den Magistrat und Einwohner jeden Orts, da er logirte, insonderheit gegen den Wirth, dessen Frau, Kinder und Gesinde sich bescheidentlich, züchtig und freundlich erweisen, denselben keinen Despect, Unehere, Gewalt und Unrecht antbun; zum Gegenfall sollte sowohl und fürnemlich gegen den commandirenden Officier, wenn demselben solches geklagt, aber von ihm nicht gestraft oder abgestellt worden, als auch gegen den Verbrecher selbst ernstlich nach Befindung des Excesses, mit gebührender harter Strafe unnachläßig verfahren werden (SICHART Bd. 2, S.129).

244 Ludolph Heinrich Mengershausen (Meyer, Pastoren II, 193). 
[137]

61.

1755. 1756.

Den 8 Dec. hat Hanß Bühre vom

Altaristen Amte altershalber

abgedanckt. 1720 hatte ers angetreten, und will bis an sein Ende in den

Stuhl treten ${ }^{245}$, welches ich ihm auch zugesagt.

Unterm 4tn. 9bris ist ein C.R. ergangen

daß der Clerus minor, als Rectores,

Cantores, Küster, Organisten, und Schul-

meister, dem abgebrandten Küster Orga-

nisten und Schulmeister, Johann Christian

Lütkemüller zu Seeltze Amts Blume-

nau eine milde Beysteuer senden möchten. ${ }^{246}$

Den 24 Dec. sind endlich die 3 Fenster

Laden in der Eckstube fertig geworden

und angeschlagen.

1756.

Am neuen Jahrs Tage hat der H. Pastor

Flügge zu Lütgenschneen seine Abzugs Rede

gehalten, und ist am 11 Jan. war der erste

Sonntag post Epiphan. zu Osterode eingeführet.

Unterm 3 Nov. 1755 ist am 8Jan. 1756 eine Instruction von der Geheimten Rathsstube ergangen u. 2 Bogen Tabellen vom Consistorii A.B. Darein vom Pastore die Gebohrnen, Verstorbenen u. Copulirten Persohnen sollen auf A. Und auf B die jetzt lebenden Persohnen sellen aufgezeichnet und eingeschickt werden. Die Anzahl der jetzt lebend. Persohnen zu Obernjesa waren: 310. Und die zu Dramfeld, 298.

245 Er wollte seinen Kirchenvorsteherplatz in der Kirche behalten.

246 Die genannten Funktionsträger unterstanden alle dem jeweiligen Pastor. 


\section{$[137 v]$}

62.

1756.

Den 12Jan. Abends um 5 Uhr ist der Herr Pastor

Glieme zu Siboldeshausen an einem Stick-

fluß selig eingeschlaffen im 53 Jahr seines

Alters, und am $15 \mathrm{tn}$. Abends stille beygesetzt. ${ }^{247}$

War auch Einbeck bürtig, sein sel. Vater

war daselbst Rector. Und war vorher Pastor

zu Volprihausen 5 Jahr gewesen, ehe er nach

Siboldeshausen kam.

Den 27 Jan. hat sich der H. Pastor Mengers-

hausen zu NiedernJesa von dem Hn. Pastor

Schierholtz ${ }^{248}$ copuliren lassen.

Den 18 Febr. Morgens gegen 9 Uhr ist ein Erd-

beben zu Göttingen und an andern Orten

herum gespühret worden. ${ }^{249}$ Wir aber haben

hier in Obernjesa und Dramfeld nichts

gespühret, es hat aber beständig denselben

Tag geregnet.

247 Die Beerdigung erfolgte ohne Gesang der Gemeinde und ohne Predigt eines Kollegen.

248 Vom Pastor in Groß Schneen.

249 Der spätere Kurfürst Wilhelm I. von Kassel erwähnt die recht kräftigen Stöße eines Erdbebens, die er als 13jähriger Schüler in Göttingen beim Frühstück mit seiner Mutter erlebte, in seinen Memoiren (von Hessen, S. 18). Und der Göttinger Professor der Astronomie Tobias Mayer, der um seine Instrumente gefürchtet hatte, veröffentlichte einen Monat später den Versuch einer Erklärung des Erdbebens in den hannoverschen Nützlichen Sammlungen (19. Stück (1756), S. 289). Im Kirchenbuch von Bovenden findet sich eine ähnliche Eintragung: Anno 1756. Wird in der Nachbarschaft zu Gottingen, Angerstein, Harste und andern Orten d $17 t$ Febr. vormittags zwischen $6 u .7 u .9 u .10$ Uhr ein leichtes Erdbeben Verspühret so aber keinen Schaden that (BuscH, Kriegs- und Alltagsleben in Bovenden, S. 85). Andere Orte: lediglich für Düren ist im gleichen Jahr ein Erdbeben nachgewiesen, für Göttingen dagegen nicht (LEYDECKER, Erdbebenkata$\log$ für Deutschland, Stuttgart 2011, S. 62). Weitere leichte Erderschütterungen im Januar und im April 1767, die zwar im Bovender Kirchenbuch vermerkt wurden, finden sich in der Pfarrchronik von Obernjesa nicht (Busch, Kriegs- und Alltagsleben in Bovenden, S. 91). Auch nicht das Erdbeben knapp dreißig Jahre später, das in den Gemeinderechnungen erkennbar wird, weil die Gemeinde Dramfeld an Arme die große Noth wegen Erdbebens gelitten 6 Groschen spendete (HStA Hannover, Hann. 74 Reinhausen Nr. 1531, Rechnung über Einnahme und Ausgabe Geld derer Gemeinde Revenuen bey der Gemeinde Dramfeld Amtes Friedland Vom 1ten May 1784 biß dahin 1785). 
Den 25 Febr. ist ein Cons. Rescr. ergangen nebst

Zwo Tabellen, darauf die gebohrnen, gestorbenen

und copulirte Persohnen von 1727 an bis

1754 sollen specificiret $\mathrm{u}$. eingesandt werden.

Knäblein sind geboren 122. Und Mägdlein 119.

Gestorben MannsPersohnen 82. Und Weibl. 92.

Copuliret sind 55 Paar. zu Obernjesa.

Zu Dramfeld gebohren Knäblein 96. Und Mägdlein

88. Gestorben 63 Manns- und 75 FrauensPers.

Copuliret 59 Paar. ${ }^{250}$

Den 16 Martii sind mir von Hn. Doct. Götten

Hof Prediger und Consist.- Rathe zu Hannover

2 Exemplaria von seinen gesammleten

Liedern für Prediger zur Haus-An-

dacht franco zugesandt worden. Dieses

hatten nur einige Prediger bekommen.

Den 18 Martii Morgend um $8 \mathrm{Uhr}$ ist H. Dann-

hauer Calands Verwalter u. RathsHerr

zu Göttingen verstorben aetatis 47.

\section{[138]}

63.

1756.

Den 4 und 5 April sind die Hessischen

Soldaten hierdurch nach Engeland ge-

gangen. ${ }^{551}$

Den 11 April ist der H. Pastor Schmidt ${ }^{252}$

ein Bruder des Hn. Pastoris zu Deiderode

eingeführet zu Lütgen Schneen eingeführet.

Am 14 April ist ein C.R. ergangen, daß

zum Pfarrhause Negenborn eine

250 Vgl. Pfarrchronik [137].

251 Die Landgrafschaft Hessen-Kassel vermietete seit Ende des 17. Jahrhunderts seine Soldaten vornehmlich an England.

252 Johann Christoph Schmid, war auch Hospes im Kloster Loccum gewesen und danach Stiftsprediger in Loccum (Meyer, Pastoren, 30). 
KirchenVorraths Collecte solle einsendet [!] werden.

Den 25 April ist des Nachmittages um $1 \mathrm{Uhr}$ in dem Buschwercke, welches nach Siboldes hausen gehöret, beym Wege von Dramfeld nach Siboldeshausen Feuer ausgekommen, doch hat es dem Obernjesischen Holtze keinen Schaden gethan. Es war eben ein starcker Wind $u$. hat über 4 Stunden gebrandt.

Den 22 May ist ein C.R. ergangen daß für die Haupt Reparation des Hamelischen MünsterThurms eine Becken Collecte solle eingesandt werden. War hier 12g. 3d.

Den 21tn. May ist mein bisheriger Medicus und Chirurgus H. Gudewill zu Grossen Schneen selig eingeschlaffen. Ich bin mit zu seiner Leiche gewesen am 25 May.

Den 8Junii des Nachmittages hat es hier gehagelt $u$. hat dasjenige Korn jenseit der Dramme und uber unter der Mühle über die Halbscheid verdorben. Es war der Dritte Pfingst Tag.

Den 8Junii ist der H. Pastor Gersting 253 zu Reckershausen eingeführet.

Den 25 Julii ist der H. Pastor Engelbrecht ${ }^{254}$ zu Siboldeshausen eingeführet, er ist vorhin Pastor zu Bartolfelde u. noch vorher Pastor zu Bühren gewesen. 


\section{[138v]}

64.

1756.

Den 8 Aug. hat sich der H. Pastor Schmidt

zu Lütgen Schneen mit des sel. Hn.

Amtmanns Hupeden jüngster Tochter

als einer StiefSchwester des Hn. Amtmanns

zu Jühnde zu Jühnde copuliren lassen.

Den 20 Aug. sind hier 11 Junge Burschen

zu Soldaten ausgenommen worden.

2 sind wiedergekommen.

Den 12 Sept. Abends um $10 \mathrm{Uhr}$ ist der H.

Pastor Schmidt zu Deiderode an

einem Stickfluß selig eingeschlaffen,

er hat eine junge schwangere Frau

hinterlassen und ist am 15 bujus in der

Stille mit Leuthen beygesetzet. ${ }^{255}$

Den 15tn. Sept. hat mir H. Busse der

Förster zu Dramfeld einen Haasen

geschickt. er schenckt mir alle

3 Jahre - ohngefähr - Haasen, da er mir doch

sonst nichts gibt als das Beichtgeld

da ihm doch erlaubet ist von Hanno-

ver seinem BeichtVater öffters einen

zu geben, wie er auch berechnen soll.

Den 21 Sept. hat der H. Sup. Appubn

ein Circular herum gesendet daß das

Witwen Geld und Revisions-Gebühr

solle eingesendet werden. ${ }^{256}$

255 Ohne Gesang und Predigt aber unter Glockengeläut.

256 Hier handelt es sich wohl um die Einsetzungs- Gebühr (pro recognitione juris patronatus) ans Kloster Weende, die zu Michaelis (29. September) fällig war (vgl. BIELEFELD 1957, S. 49). 
Den 9tn. Oct. hat die Frau Witwe Schmidt zu Deiderode einen Sohn nach ihres sel. Manns Tode gebohren.

\section{[139]}

65.

1756.

Den 1 Octob. hat der König in

Preussen bey Prag mit 35000

Mann über 70000 Mann Ostereicher geschlagen. ${ }^{257}$

Den 20tn. Oct. 1756 ist endlich mein Thorweg nach dem Kirchhofe zu gesetzet worden von Mst. Dehnen.

In der Nacht von 6tn. Nov bis auf den $7 t n$. war ein grosser Windsturm.

Den 27tn. Nov. des Morgens ist dem Hn.

Past. Engelbrecht zu Siboldeshausen ein junger Sohn gebohren, und Johann Georg genannt.

Den 2 Dec. habe bey der Geheimten Rath stube um Erlassung des hiesigen Dienstgeldes von der Pfarr angehalten. ${ }^{258}$

Den 17 Dec. ist ein Cons. Rescript unterm 16 Nov. ergangen, daß die Pastores die getauften, gestorbenen und copulirten Persohnen sollten einschicken. In Obernjesa lebten damahls 310 Persohnen. Es waren gebohren 9 Persohnen, 15 gestorben

257 Schlacht bei Lobositz zwischen Preußen und Österreichern; beide Seiten nahmen den Sieg für sich in Anspruch (MAstnaK, Celle im Siebenjährigen Krieg, S. 196). 258 Die Pfarre Obernjesa war dem Gericht Leineberg dienstgeldpflichtig. 
u. 1 Paar copuliret.

In Dramfeld lebten dazumahl 298

Persohnen, gebohren waren in diesem

1756 Jahre 7 Persohnen, 5 gestorben

u. 1 Paar copuliret. ${ }^{259}$

[139v]

66.

1757.

Den 7 tn. Jan. Nachmittages ist dem Herrn

Pastor Mengershausen zu NiedernJesa

ein junger Sohn gebohren, und den 22tn.

Jan. wieder verstorben.

Den 5tn. Febr. ist ein Cons. Rescript

unterm 13Jan. ergangen, daß eine

Kirchen Vorraths Collecte zu einer

Haupt Reparation der Kirche zu

Erichhagen Amts Wölpe sollte

eingesandt werden.

Den 9 Febr. ist unterm 17 Jan. ein Circu-

lar ergangen daß dem Hn. Sup. u. Pastori

Primario Berckelmann zur Neustadt

am Rübenberge eine Beysteuer sollte

eingesandt werden, weil auf seiner

Studier Stube Feuer ausgekommen

und vieles verbrandt wäre.

Ich habe ihm 12g. gesteuret.

Den 13 Febr. als am Sonntage Sexagesimae ${ }^{260}$

mein Sohn zu Barderoda für Hn. Pastor

Schwartzkopf geprediget.

Die Kayserl. Königl. Armee wider den

König in Preussen soll 180000 Mann

259 Vgl. [137] und [137v].

260 Der zweite Sonntag der Vorpassionszeit. 
starck seyn. Diese will Ketzer Blut ver-

giessen, und s uns ausrotten. Gott stehe

uns und der Preussischen Armee bey.

Den 6tn. May aber hat der König in Preussen

die grosse Kayserl. Königl. Armee

geschlagen. ${ }^{261}$

Den 22, 23 und 24 Martii ist Tag und Nacht grosser

Sturmwind gewesen.

Den 31tn. Martii Morgens um $6 \mathrm{Uhr}$ ist H. Wissel

zu Göttingen verstorben.

[140]

67.

1757.

Den 3 April ist der H. Pastor zu Deiderode

zum Garten Hofe vom Hn. Sup. D. Ribow

eingeführet.

Den 6tn. April meine Wellen à 100 von

Dramfeld hohlen lassen. Habe müssen

Jungen tnd für Hauen und Binder-

lohn $24 \mathrm{~g}$. bezahlen.

Den 8tn. April ist H. Hofrath Schmauß

Prof. Juris publici zu Göttingen ver-

storben. Er war ein öffentlicher Athe-

iste oder Naturaliste und ging weder

zur Kirche noch zum Abendmahl, und hat viele Studenten mit seinem

unChristl. Leben u. Reden verführet

oder doch geärgert. ${ }^{262}$

261 Am 6. Mai 1757 fand die Schlacht bei Prag zwischen Preußen und Österreichern statt; der preußische Sieg diente zur Sicherung des Nachschubs (Mastnak, S. 85 und 196).

262 Johann Jacob Schmauß war seit 1734 Professor an der Göttinger Universität, und zwar einer der ersten Mitglieder der juristischen Fakultät. Seine Quelleneditionen waren bekannt und wurden geschätzt. Magister Stollberg kommentiert hier das merkwürdige 
Den 18 April sind endlich unsere Dragoner

nach Hameln den Frantzosen entgegen

gezogen. ${ }^{263}$

Den 28tn. April ist der H. Mag. Köhler ${ }^{264}$

zu Lengelern verstorben. War

noch ein junger Mann.

Den 2 May sind eine Compagnie Hessen

Reutter hier ins Quartier gerückt, und

am 3tn. May hier einen Rasttag gehabt.

Den 3tn. May ein Gebeth für die KriegsVölcker

hier praesentiret. Gott hat uns

aber nicht erhöret, denn kurtz darauf

wurde der Herrtzog [!] von Cumberland

mit aller seiner Armee bey Hastebeck

nicht weit von Hameln geschlagen. ${ }^{265}$

Mit dem Anfang dieses Monaths Majo ist ein

$\mathrm{Hb}$. Rocken á 1r. und 15g. gestiegen.

berufliche Pflichtbewusstsein des Professors, das den Kurator der Universität, A. G. von Münchhausen veranlasste, ihm wohlwollend ins Gewissen zu reden, er möge fortan für Harmonie mit den Collegen sorgen, den cultum divinum externum nicht verabsäumen, und diejenigen durch die That widerlegen, welche an seinem Christenthum grundlos zweifelten, auch nichts in Collegiis und Discursen einfließen lassen, was zum Nachtheil der Religion ausgebeutet werden könnte. 1754 veröffentlichte Schmauß ein Buch über Naturrecht, das in einer Streitschrift als kirchliche Irrlehre bezeichnet wurde; dadurch wurden schließlich das Konsistorium und der Kanzler der Universität aufmerksam, die fürchteten, dass dem Ruf der Göttinger Universität geschadet und die Jugend verführt werden könnte. In der Memoria, die ihm [Professor] Gesner hielt, wurde auf Grund der Mittheilungen des Superintendenten Appubn seines christlichen Abscheidens ausdrücklich gedacht (Frensdorff, ADB Bd. 31 (1890), S. 628-631).

263 Im Frühjahr 1757 drang ein französisches Heer von 100.000 Mann unter dem Marschall d'Etrées durch Westfalen vor und überschritt die Weser (ОвеRSCHELP Bd. I, S.13). Wenn die Obernjesaer Dragoner zur Garnison in Göttingen gezählt haben sollten, gehörten sie zum Regiment Block, das im April 1757 kriegsbedingt die Stadt verließ (PRÖvE, in: Göttingen Bd. 2, S. 482).

264 Jakob David Köhler (Meyer, Pastoren II, 73).

265 William Augustus, Duke of Cumberland, der zweite Sohn Georgs II., war 1757 Oberbefehlshaber der alliierten Truppen (Wähner, Tagebuch, Anm. 23, S. 5); gemeint ist die Schlacht bei Hastenbeck am 26. Juli 1757, die zunächst für die Verbündeten siegreich zu sein schien, dann aber durch den Mangel an Entschlossenheit des Herzogs sich in eine schwere Niederlage verwandelte (SАATHOFF, T.2, S. 48). 
Unterm 26tn. April ist am 13 May ein Circu-

lar eingelauffen, daß auf künftigen Buß

tag über Joel 2, 12. 13.14 etc. ${ }^{266}$ sollte geprediget

und des Nachmittages über den $\psi .81,14.15$ etc. ${ }^{267}$

ein Sermon etc. gehalten werden.

[140v]

68.

1757.

Den 30 May ist der H. Cons. Rath Doct. Pleßke und General Sup. in Zelle verstorben. ${ }^{268}$

Den 12 Junii haben mich der H. Doct. et Prof. Primarius Consistorial-Rath Feurlin nebst

dem Hn. Doct. Heumann besuchet, und sind in der Kirche in meiner Predigt

gewesen, am 2 Trinitatis. ${ }^{269}$

$\mathrm{Zu}$ dieser Zeit ist ein $\mathrm{Hb}$. Haber auf $1 \mathrm{r}$.

und $12 \mathrm{~g}$. gekommen.

Den 3 tn. Julii sind 4 Wagen von Obernjesa

und 4 Wagen aus Dramfeld nach

Hameln aufgebrochen. Alle Adeliche

Amtleute und Pastores welche Pferde

haben, haben müssen an Spannen. um den

königl. Schatz à 30 Millionen nach Stade ${ }^{270}$ zu bringen

266 Altes Testament. Der Prophet Joel Kapitel 2, Verse 12, 13, 14, usw. Doch spricht auch jetzt der Herr: Bekehret euch zu mir von ganzem Herzen mit Fasten, mit Weinen, mit Klagen!...

267 Psalm 81, 14.15. etc. Wollte mein Volk mir gehorsam sein und Israel auf meinem Wege gehen, so wollte ich ihre Feinde bald dämpfen und meine Hand über ihre Widersacher wenden,...

268 Meinhard Pleßken (http://d-nb.info/gnd/116209771 (23.8.2015)).

269 Professor Wedekind bestätigt in seinem Tagregister von dem gegenwärtigen Kriege das relativ friedliche erste halbe Jahr 1757 und schreibt für die Monate Julius und Augustus: „Da im ganzen ersten halben Jahre nichts erbebliches und anzeichnungswürdiges vorgefallen, so will ich hier ein kleines Tagregister von dem gegenwärtigen Kriege, welcher sich leider schon über den grösten Teil Deutschlands erstrecket, in so weit selbiger insonderbeit unsere Stadt mit betroffen und ferner betreffen wird, einrücken..." (PANNENBORG, S. 7).

270 Stade war ebenso wie Hameln als Festung ausgebaut und infolgedessen zu diesem Zeitpunkt ein sichererer Ort für die Kriegskasse. 
Den 10tn. Juli2 ${ }^{21}$ habe laut Specification

meine beste Sachen im schwartzen

Kuffer nach Göttingen zur Verwahrung dem Hn. Doct. Heumann geschicket ${ }^{272}$, in dem die Frantzosen schon Münden und Hedemünden sollten eingenommen haben. Wie sie denn auch den 16tn. Julii Göttingen einnahmen, doch haben sie Niemanden ein Leid gethan. Nur haben alle Städte viele Brandschatzung ${ }^{273}$ geben müssen. Göttingen sammt der Universitaet haben allein über 150 tausend thaler baar schaffen müssen. Andere Städte haben alle vieltausend geben müssen. Die Dörffer mußten Haber, Heu und Stroh auch viele Kühe liefern, unserm Dorfe, ObernJesa, trug es über 80 Malter Haber 3 Fuder Stroh, 3 Fuder Heu und 2 Kühe. Da sahen meine Zuhö rer am ersten was Krieg wäre.

\section{[141]}

69.

1757.

Von 1756 ist etwas nachgehohlet.

Den 14tn. Julii sind 4 Wagen mit Heu von

hier aus nach dem Frantzösischen Lager gefahren nach Münden, welche Stadt ihnen bereits 4000r.

271 Lt. Lotze, S. 139, 140, zogen die französischen Truppen am 10. Juli 1757 abends 8 Uhr in Münden ein.

272 Vermutlich erschien Magister Stollberg die befestigte Stadt Göttingen erheblich sicherer als das Dorf Obernjesa; vielleicht hatte er auch von dem beruhigenden Schreiben des Ministers von Münchhausen an die Universität gehört, dass dieser nichts passieren würde (vgl. SAATHOFF, T. 2, S. 45 und SснӧNE, 1887, S. 50). Magister Stollberg war vermutlich nicht der einzige, der versuchte, seinen Besitz vor den französischen Truppen in Sicherheit zu bringen; am 18. und 19. Juni waren z. B. hannoversche Honoratioren geflüchtet und am 19. und 21. Juni gingen die letzte Königliche Pferde, Kutschen und Rüstwagen nebst allen Bedienten hierdurch [durch Celle] von nach der Görde, welches ein betrübtes Schauspiel war" (MASTNAK, S. 86).

273 Ausgleichszahlungen an die Truppen, um Plünderungen und Feuerlegen zu verhindern. 
Brandschatzung geben müssen. Sind den 15 Julii Nachmittages wieder gekommen.

Den 16Julii Nachmittages sind die Frantzosen

in Göttingen eingezogen. 4 Cavalerie

Regimenter sollen auf dem Masche liegen

u. 4 Infanterie sollen in der Stadt

liegen. ${ }^{274}$ Dieses ist der Erfolg als Nachwehen

von der unglücklichen $u$. verlohrnen Schlacht

bey Hameln von dem Hertzog von Cum-

berland, unsers Königes Georg des II

Printzen für welchen wir täglich bitten

mußten. Er soll beständig etliche Da-

mes von Frantzosen in Hameln und

etliche vornehme Frantzösische Officiers

bey sich gehabt haben. [Spätere Unterstreichung? Tinte in der Farbe der folgenden Notiz]

[Fünf Zeilen Marginalnotiz neben der Unterstreichung]:

Ist eine/ Bauren Sage/ gewesen. Denn/

d. Herz. v. Cum/berland hat sich/

nachher genug/ legitimiret / wegen der

verlohrnen Schlacht/ H. Phil. Stol./

berg. Pastor/ antecess. filio.

Die Frantzosen

sollen schon in der Flucht gewesen seyn.

Er hat nur noch 4 Regimenter sollen

anrücken lassen, welches er aber nicht

thun wollen, sondern gesagt: Reteriret

euch ins Teuffels Namen. Das muß

was bedeuten. Darauf verbreiteten [sie] sich

durch gantze Hannoverische Land. Dazu

274 Professor Rudolf Wedekind berichtet in seinem Tagregister, dass Vormittages um 11 Uhr fünf französische Regimenter, drei zu Pferde und zwei zu Fusse, vor die Stadt (rükketen). (...). Nachmittages um 4 Uhr rücketen also die Truppen ein; ein Regiment nebst einer Compagnie Husaren in die Stadt, und die übrigen ins Campement auf die Masch. Die Masch war damals eine große Wiese zwischen der alten Leine und dem Leinekanal unmittelbar unterhalb der Stadt (PANNENBORG, S. 8). 
mahl mußten wir noch 3 Fuder Stroh

und 3 Fuder Heu lieffern u. 2 Kühe. ${ }^{275}$

Von 1756 ist nachzuhohlen. Am 20 8br

ist endlich mein Thorweg gesetzet worden.

Mit Matthias Boden hatte wegen seines Stückgens

Gartens hinter meiner alten Scheune einen

Streit. Im 30 jährigen Kriege haben die

[141v]

60.70 .

1756.

die hiesigen Einwohner eine Salva Gardia ${ }^{276}$ auf

hiesigen Kirchhof eingenommen und ihre beste

Sachen auf den Kirchhof gebracht, da ein

Jeder so viel Raum auf dem Kirchhof be-

kommen, als wo 2 Stücke Kühe haben stehen

können. ${ }^{277}$ Nach dem 30 Jährigen Kriege habens

die Boden es sich von Herrn von Steinberge

zu Lehen schreiben lassen, weil sie Lehn von

demselben haben. Mein sel. Praeantecessor ${ }^{278}$

$P$. Armbrecht hat dieser Wegen Matthias

Boden Vater bey die 10 Jahr vom heil.

Abendmahl abf abweisen müssen. In

welcher Boßheit derselbe auch gestorben

seyn soll. Dieser Matthias Bode, der

bypocrita et eximie malus, qui inter pietistas

vult numerari et ideo attentus est ad rem ${ }^{279}$,

275 Die täglichen Fourage- und Lebensmittellieferungen sowie die Truppendurchzüge 1757 bestätigt Professor Wähner ausführlich in seinem Tagebuch (vgl. PAnnenborg, S. 9). Professor Wedekind, der Direktor der Stadtschule und später Pastor an St. Marien, seufzte im November des Jahres: Ach! Es vergeht einem jetzt alle Lust und Munterkeit. Ich werde daher von allen diesen betrübten Kriegsgeschichten nichts weiter anzeichnen, als was etwa die Schule und Schulsachen davon angeht (PANNENBORG, S. 11).

276 Geschützter Bezirk aufgrund eines Schutzbriefes für das Kirchhofsgelände.

277 Diese Darstellung wird durch archäologische Untersuchungen bestätigt (vgl. SCHRÖDER, in: GöJb 38, 1990, S. $25 \mathrm{ff}$.

278 Vorvorgänger.

279 Dieser Matthias Bode, Heuchler und ausserordentlich böse Mensch, der unter die Pietisten gezählt werden will und daher die Sache aufnimmt, protestierte.. 
protestirte, als ich die ThorPföste wollte

gleich setzen lassen, daß sie ungefähr nach

meiner Scheune unter meine Tachtrauffe und

etwas an sein Stück Land gekommen wären.

Und sagte platteutsch ${ }^{280}$ : Dat gebe ich nich tau, nich einen halben Faut, eck hebbe einen

chieren Eyd oberschwören möten (: wer

hats ihm geheisen über unrecht mässige

Güter, die er sich gottloß zugeeignet und

der Kirche gehören, einen falschen Eyd

zu schweren. Sed hic faciunt pietistae,

ut omnia aliena, si possent, sibi arrogarent. ${ }^{281}$

Ich habe nach der Zeit so from er thut, auch aus

andern Stücken ihn besser kennen lernen.

Hier heißts recht: Si vis pius esse, nesi pietista.:282

1756 sind allhier die Kleinen Brechen ${ }^{283}$ mit Eisen inwendig aufgekommen.

\section{[142], [143], [144] eingelegte Briefe}

[Die Briefe gehören in die Zeit der Aufzeichnungen des Pastors Proffen, siehe [189]ff.]

\section{[144a, 144b]}

[Eingeheftetes Blatt handschriftlich paginiert]

\section{Specification}

Was von einigen Stücken, als welche die Gemeine hätte anschaffen müssen, alle meine gehöret.

Als im Kuhstalle die 1. Kuhkrippen, welche ich mit hieher gebracht. 2. Steinewege hören der Kirche

280 Dies ist einer der wenigen Hinweise darauf, dass die Bauern plattdeutsch sprachen, während der Pastor mit lateinischen Zitaten brillieren konnte; in der Literatur wird dazu ausgeführt: Die Sprachbarriere, welche im 18. Jahrhundert die plattdeutsch sprechende Landbevölkerung und die unteren Volksschichten von den hochdeutsch redenden und schreibenden Gebildeten trennte, muß man als eine der grundlegenden Tatsachen des sozialen Lebens ansehen (OBERSCHELP Bd. 2, 159).

281 Sinngemäß: Aber hier tun die Pietisten, dass sie alles Fremde, wenn sie es können, sich aneignen.

282 Sinngemäß]: Wenn du fromm sein willst, sei kein Pietist.

283 Er meint vermutlich Flachsbrechen. 
und zeugsteinere Krippe gehören meine, die ich mit aus Göttingen gebracht und erst beym Born stand, darein Andreas Hinrich Utermöhlen mein gewesener Großknecht ein Loch hinein gemacht, damit eine Kuh Kette konnte hinn [Papier beschädigt] gemacht werden. Die übrigen 2 steinere Krippen hat die Kirche vor alten Zeiten angeschaft, welche sich nunmehr die Gemeine anmasset. Vor alten Zeiten, wie die alten Register lauten, hat die Kirche alle solche Stücke anschaffen müssen und auch die Reparation im PfarrHause, weissen, Pfenster flicken etc. aus welchem Grund solches geschehen, ist eigentlich nicht bekannt, doch erzählte mir des sel. Pastoris Armbrechts jüng ster Sohn, Frantz Ernst Armbrecht: Es wären viele alte Nachrichten bey der Pfarr gewesen, welche nach dem Tode des sel. Lotzii tempore vacantiae verlohren gangen, und mir nicht zu Handen kommen sind, ob ich gleich deßwegen ins Consistorium geschrieben. Insonderheit ein Buch in Folio 2 bis 3 Finger dick darinnen solche alte Nachrichten gestanden. Insonderheit daß noch in Papischtischen [!] Zeiten ein Adelicher der Herr von Geyso, die hiesige Pfarr und Kirche dotiret und Patron gewesen welche Familie schon vor 300 Jahren ausgestorben. Auch erzählte er mir: daß entweder die Kirchen Länderey von der Pfarr wären genommen worden, daher das onus entstanden, oder es wäre bey dotirung, dieses mit aus bedungen worden. [Ende der Seite]

\section{[144a v]}

Im Pferdestalle gehöret der Gemeine alleine die grosse Pferde Krippe, die Hülte aber über der grossen Krippe und die Kleine Krippe gehören meine.

In der Scheune gehöret meine die grosse Leiter, 
wie auch das LukenSeil sammt der Polene ${ }^{284}$, welches ich alles der Frau Witwe Lotzius bezahlen müssen. Auch alle Schleiten ${ }^{285}$ gehören meine.

Im Hause gehören alle beyde Tauben Häuser meine die ich für mein Geld habe müssen machen lassen. Wie auch alle Tauben da ich ein Paar Tauben für $3 \mathrm{mg}$. bezahlet habe. Doch hat der Ilck ${ }^{286}$ die alten Tauben noch im alten Hause alle gefressen, die jetzigen sind mehrentheils jung. Die beyden Tauben Häuser kommen mir über 6r. zustehen. Der Kutschen Schoppen nebst dem Wagen gehöret auch meinen, welchen ich vorm Jahre 1758 wiederung habe decken lassen. Und kommt mir über 9r. zusammen, das Holtz ist von altem Schoppen und Bienenhause. Der so genannte Knickhof ist meine, wie auch die Pfosten, Thür und Eisenwerck und das Höltzerne Schloß. Wer als Pastor hier an kömmt muß für den Garten allein, ohne die Bäume 7r. der Witwe oder Erben wieder geben. Es hat ehemahls der selige Mag. Andreas Sieburg solchen Garten für die Pfarr gekauft von Böilckens Garten, welchen nunmehr Saltzmann hat. Das Haus und Garten ist ein Erben Zinß von der Pfarre und muß der Eiwohner [!] alle Jahr an die Pfarr einen gewissen Canonem $^{287}$, geben, wie auch das sogenannte Klimen Haus wie der Garten worinnen jetzt Jürgen Windwehn wohnet.

284 Ein Flaschenzug: 1. Die Rolle, um welche sich das Windseil in der Scheuer dreht. 2. Die Winde in der Scheuer selbst. (SСНамвасн, Wörterbuch der Niederdeutschen Mundart, S. 157).

285 Auch als ,sleite' gebraucht; das über die Balken der Scheuer gelegte büchene Querholz. Auf die sleiten legt man dann die Garben, das Heu und das Strob (Sснамвасн, S. 194).

286 Mustela putorius, der Iltis (Grimm, Spalte 2060).

287 Geld und Naturalien in einem bestimmten Verhältnis; insgesamt 10g sowie 5 Hähne und 120 Eier (vgl. BieLEFELD 1957, S. 52 und 53). 


\section{[144b]}

Des Kraut-oder Küchen Gartens Pfosten, Thür und Zaun gehöret alles meine es hat solchen der sel. Pastor Lotzius von den 4 Morgen Pfarr Länderey abgenommen und zum KrautGarten gemacht, und den Nachbarn, als dem Müller, Wrüger, und Johann Zimmermann, jedem 3 gute Süßnüsse stehen lassen.

Dieses habe aufgesetzet in ObernJesa den 17tn. May 1759. M. JP. Stolberg. Pastor.

Es gehören auch alle Zäune meine, welche ich muß machen lassen, und die Gemeinen haben mir nichts gegeben sie sagen: dafür bekäme der Pastor in ObernJesa ein Looß Weiden, von Dramfeld bekommt er nichts.

[Ende des eingehefteten Blattes] 


\section{[145]}

61. 71 .

1756. et 1757 .

Ich mußte also von meinem Hofe etwas nehmen, damit der Thorweg konnte gleichwerden, da mein Hof doch schon klein genung ist, und ich kaum mit dem Ackerwagen umwenden kann, und dem Bauren seiner Boßheit nachgeben, denn der $\mathrm{H}$. von Steinberg ist jetzt geheimter Rath in London. ${ }^{288}$ 1757

Noch etwas von Matthias Boden zu gedencken; so kam er 1756 gar mit einem Notario, Meyer mit Namen, und wollte etwas von $+\ldots+$ [Einfügung unleserlich] des Witwen Hauses nehmen, weil wie er sagte, das Stücke vom Kirchhofe für 2 Stellen für 2 Küh wäre gar zu klein wäre-, ich habe aber gewisse Merckmahle, daß in alten Zeiten das Wittwenhaus da müsse gestanden haben weil wir etliche grosse Steine, wo jetzt des Schulmeister Garten ist, nach Zimmermanns Scheune hin, ausgegraben haben, daß ehemahls ein Gebäude daselbst müsse gestanden haben, das wollte dieser Mann auch haben. Ich protestirte aber gleich dar gegen und sagte: daselbst hätte in alten Zeiten das Witwenhaus gestanden, dabey ist es dato daby geblieben. So gehets, wenn sich Pietisten einer hohen Hülfe zu getröst vermogen, da doch der Kirchhof schon kleine genung ist.

288 Vgl. [121v]. 
[Ende der Eintragungen von Magister Johann Paulus Stollberg]

[Beginn der Eintragungen von Pastor Heinrich Philipp Stolberg] 


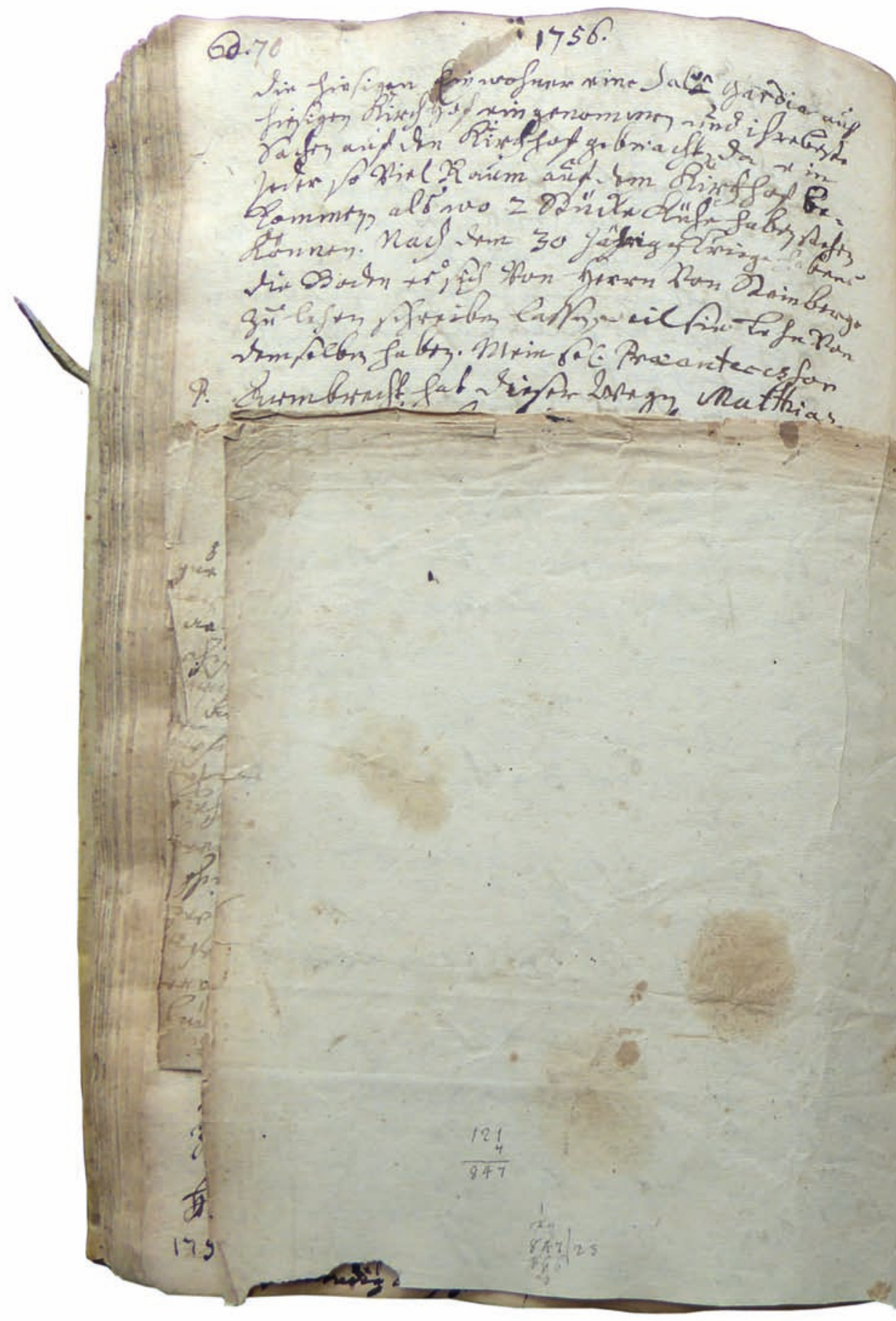


Thming the alfo 170 of 17.7 .

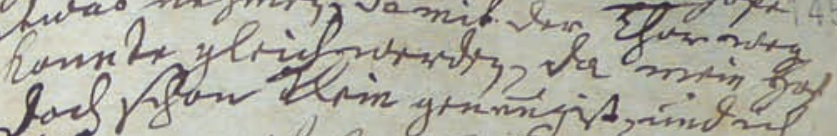

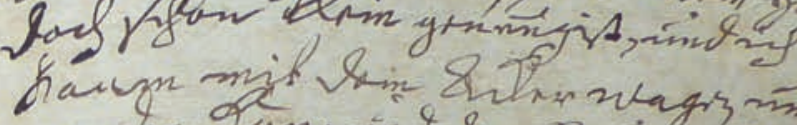

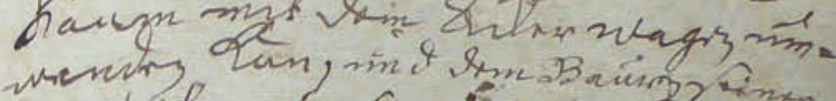

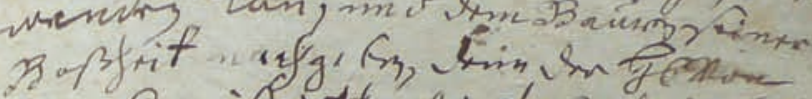

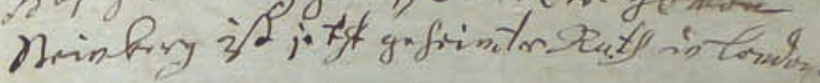

\section{7 .}

Norfatweafelimen Matthias Bork

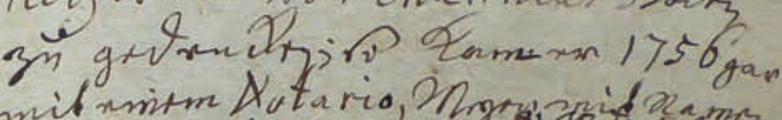

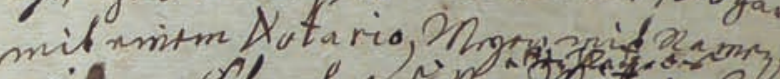

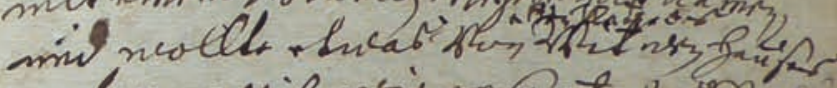

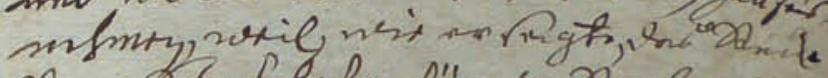

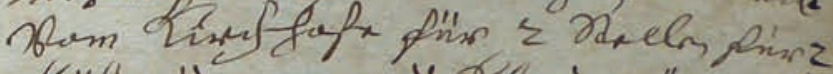

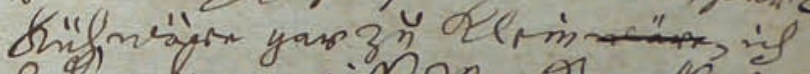

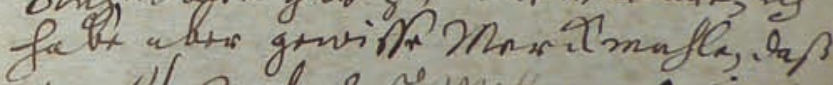

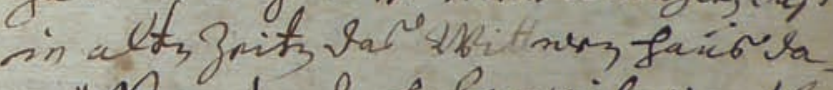
mïf yotamly fa bownilmins thif.

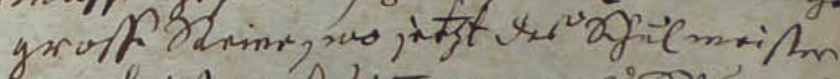

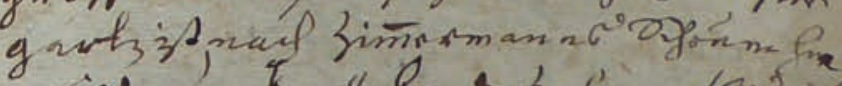

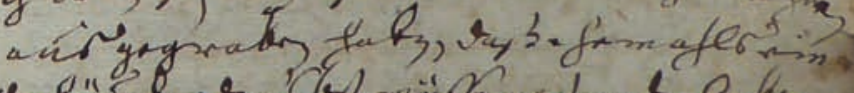

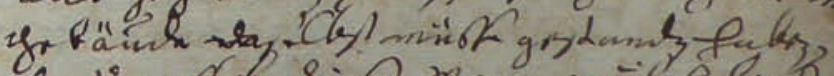

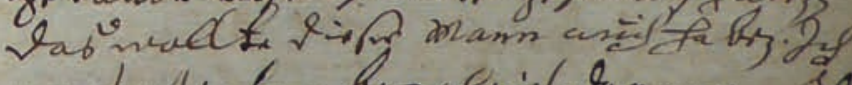
protedict abtrgltid angrgs is

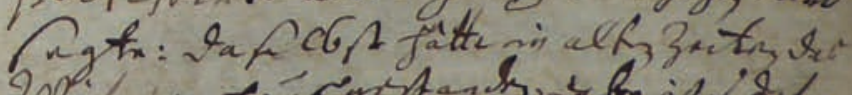

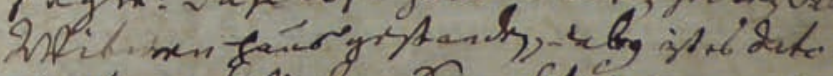

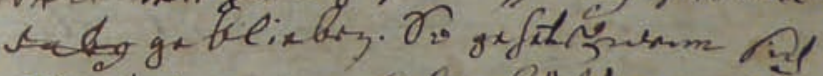

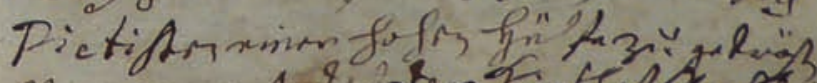

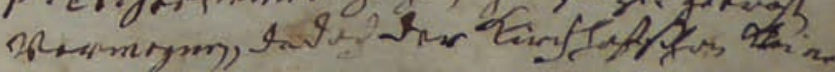
yoiningif.

Abb. 3 Die Schrift des Magisters Stollberg 1756 Quelle: KiKrAGött, P. A. Obernjesa K. R.I.a. 1 [145v] 


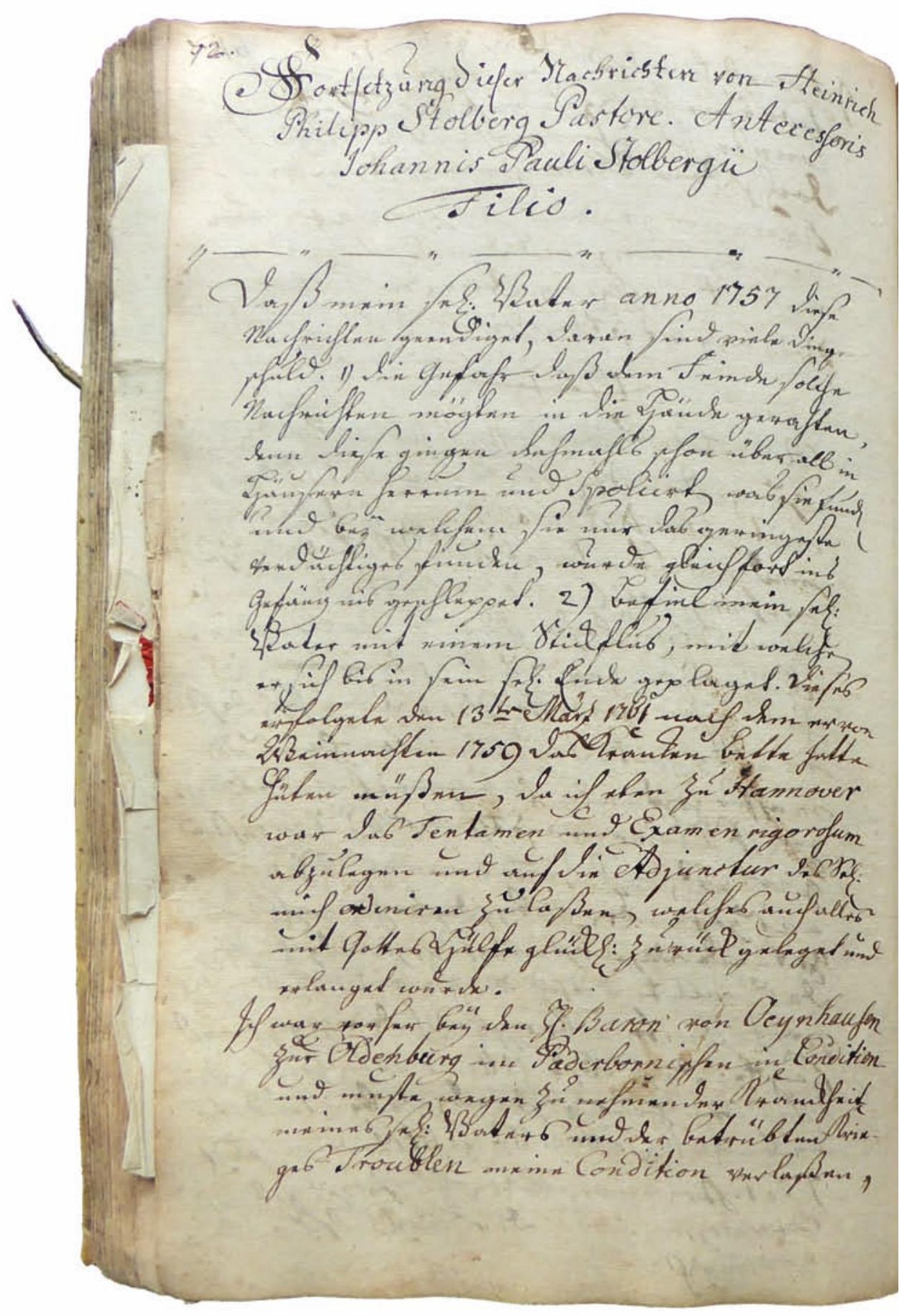




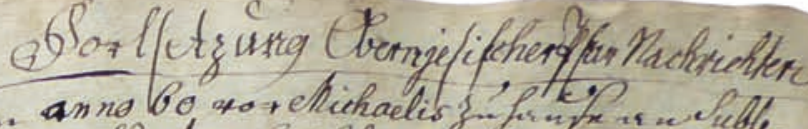

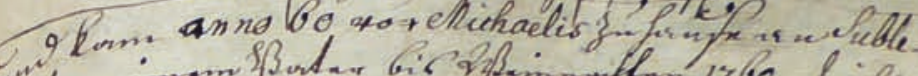

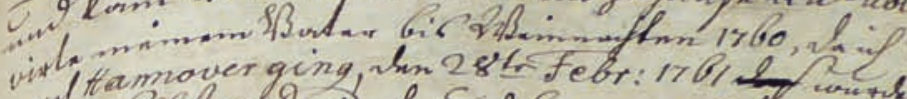

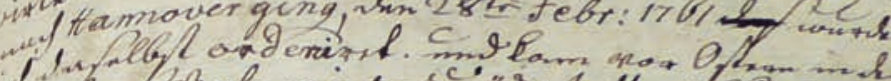

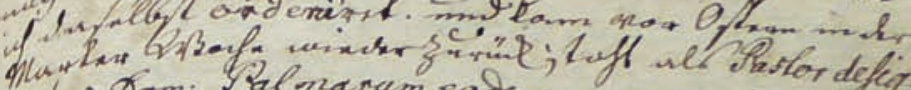

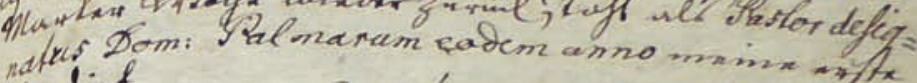

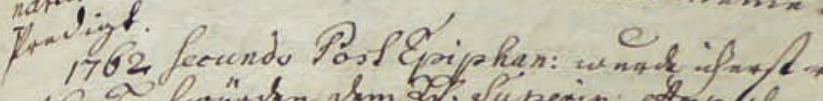

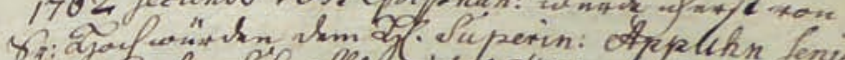

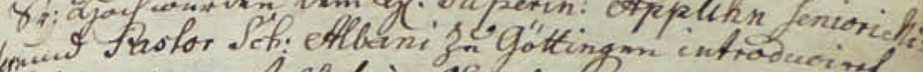

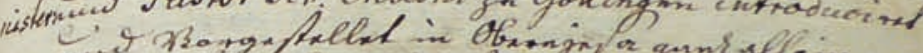

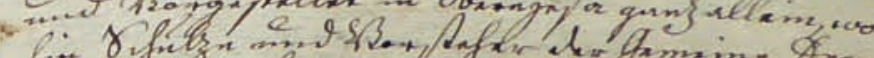

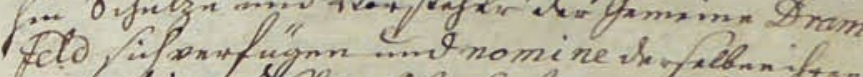

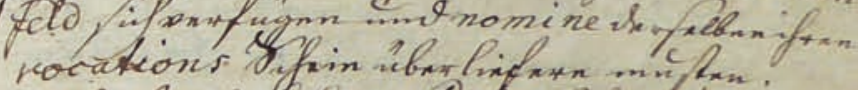

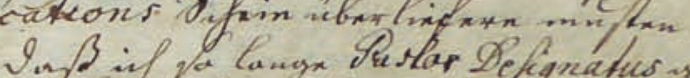

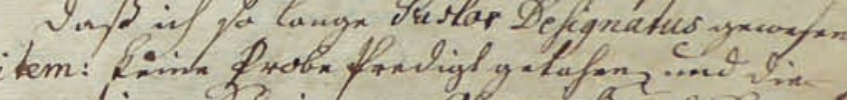

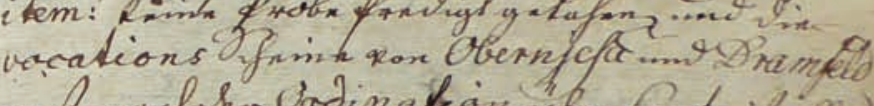

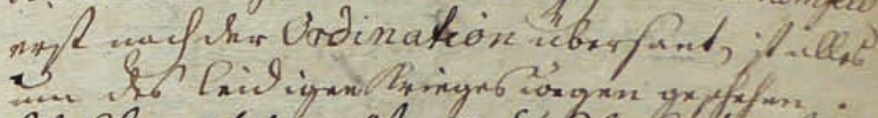

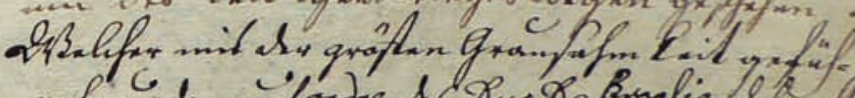

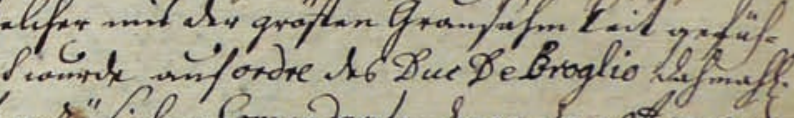

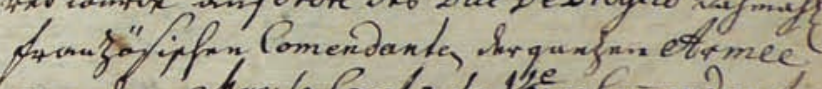

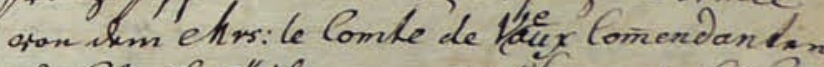

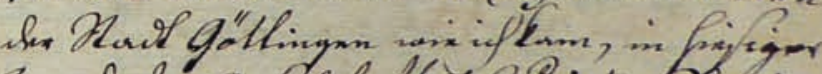

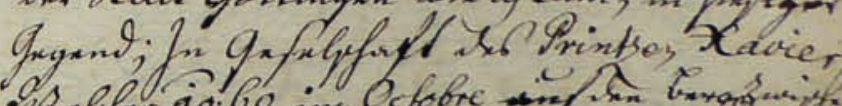

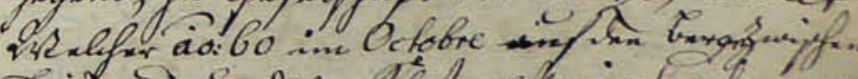
Deiderode .... Ys.m. Th har charien Yarten ...

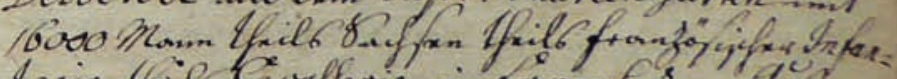

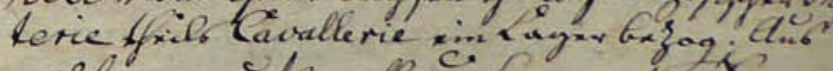

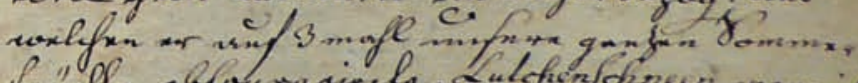

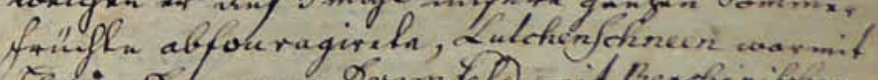

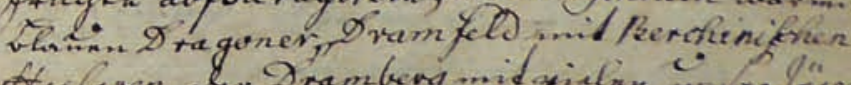

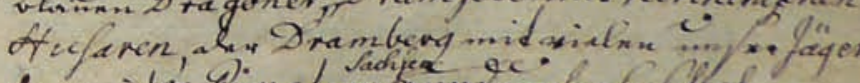

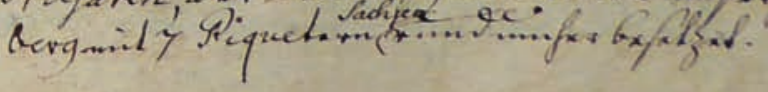

Abb. 4 Fortsetzung der Chronik durch Pastor Stolberg Quelle: KiKrAGött, P.A. Obernjesa K.R.I.a. 1 [145v], [146] 
[145v]

72.

Fortsetzung dieser Nachrichten von Heinrich

Philipp Stolberg Pastore. Antecessoris

Johannis Pauli Stolbergii

Filio.

Daß mein sel. Vater anno 1757 diese

Nachrichten geendiget, daran sind viele Dinge

schuld. 1) Die Gefahr daß dem Feinde solche

Nachrichten mögten in die Hände gerahten, denn diese gingen dahmahls schon über all in Häusern herrum und Spoliirten was sie funden und bey welchem sie nur das geringeste verdächtiges funden, wurde gleichfort ins Gefängnis geschleppet. ${ }^{289}$ 2) Befiel mein sel: Vater mit einem Stickflus, mit welchem er sich bis in sein sel. Ende geplaget. Dieses erfolgete den $13^{\underline{t n}}$ März 1761 nach dem er von Weinnachten [!] 1759 das Kranken Bette hatte hüten müßen, da ich eben zu Hannover war das Tentamen und Examen rigorosum abzulegen und auf die Adjunctur des Sel: mich ordeniren zu laßen, welches auch alles mit Gottes Hülfe glückl: zurück geleget und erlanget wurde.

Ich war vorher bey den Hn. Baron von Oeynhausen zur Oldenburg im Paderbornischen in Condition ${ }^{290}$ und muste wegen zu nehmender Kranckheit meines sel: Vaters und der betrübten Krieges Troublen meine Condition verlassen,

289 Pastor Stolberg ist der einzige der vier Chronisten, der erwähnt, dass schriftliche Aufzeichnungen den Feinden verdächtig vorkamen.

290 Er war Hauslehrer bei der Familie von Oeynhausen. 


\section{$[146]$}

Fortsetzung Obernjesischer Pfarr Nachrichten

und kam anno 60 vor Michaelis ${ }^{291}$ zu hause an. Sublevirte meinem Vater bis Weinnachten 1760, da ich nach Hannover ging, den 28hㅡ Febr: 1761 des wurde ich daselbst ordeniret. und kam vor Ostern in der Marter Woche wieder zurück; taht als Pastor designatus Dom: Palmarum eodem anno meine erste Predigt.

1762 secundo Post Epiphan : ${ }^{292}$ wurde ich erst von Sr: Hochwürden dem Hn. Superin: Appubn seniori Ministeri und Pastor Sct: Albani zu Göttingen introduciret und vorgestellet in Obernjesa ganz allein, wohin Schulze und Vorsteher der Gemeine Dramfeld sich verfügen und nomine derselben ihren vocations Schein überliefern musten.

Daß ich so lange Pastor Designatus gewesen item: keine Probe Predigt getahen, und die vocations Scheine von Obernjesa und Dramfeld erst nach der Ordination übersant, ist alles um des leidigen Krieges wegen geschehen. ${ }^{293}$ Welcher mit der grösten Grausahmkeit geführet wurde auf ordre des Duc De Broglio ${ }^{294}$ dahmahl. französischen Comendanten der ganzen Armee von dem Mrs: Le Comte de Veaux Commendanten der Stadt Göttingen ${ }^{295}$ wie ich kam, in hiesiger

291 Fest des Erzengels Michael am 29. September.

292 Am 2. Sonntag nach Epiphanias (Dreikönigstag oder Erscheinungsfest, 6. Januar).

293 Siehe die Literaturangaben in Hunger, in: Göttingen Bd. 2, S. 166.

294 Victor-Francois Duc de Broglie, französischer Offizier, 1759 französischer Marschall (WäHner Tagebuch, S. 236)

295 Der Befehlshaber der Besatzung der Stadt Göttingen General Noel de Jourda, comte de Vaux, wird von Zeitgenossen ähnlich charakterisiert: Von der Härte und der Grausamkeit des von aller menschlichen Empfindung entferneten Generallieutenant, Graven von Vaux, welcher seit zwei Jahren alhier obne Unterlas commandant gewesen, mag die Historie reden (Pannenborg, S. 18; Wähner, Tagebuch, S. 159). 
Gegend; In Geselschaft [!] des Printzen Xavier ${ }^{296}$

Welcher ao: $60 \mathrm{im}$ Octobre ${ }^{297}$ auf den Bergen zwischen

Deiderode und dem Kloster Marien Garten mit

16000 Mann theils Sachsen theils französischer Infan-

terie theils Cavallerie ein Lager bezog. Aus

welchen er auf 3 mahl unsere ganzen Sommer

Früchte abfouragirete, Lutchen Schneen war mit

Blauen Dragoner ${ }^{298}$, Dramfeld mit Berchinischen

Husaren $^{299}$, der Dramberg mit vielen, unser Jäger-

berg mit 7 Piquetern Sachsen rundumher besetzet.

\section{[146v]}

Continuatio Chron: Obernjesanae

Dis währet unter vielen Drangsahlen der armen Bauren, welchen gröstentheils ihr Horn- Schweine- Schaf und Pferde Vihe hin weggenommen wurde eins nach dem andern.

Unter der Zeit wurde auch gleichfals der Göttingische Wall mit Pallisaden starck besetzet $^{300}$, wozu Obernjesa 6000 Stück Liefern müßen; noch mehr Außenwercke und Demi lünen angeleget; wozu viele 100 Bauren zu Graben gezwungen ureten auch in die Schönsten

296 Prinz Xaver von Sachsen, französischer General (von Poten, in: http://www.deutschebiographie.de/pnd101420153.html?anchor=adb (15.11.2015)).

297 Professor Wähner notierte bereits unter dem 16. September 1760: Das franz. Lager steht noch immer zu Deienrode und unsere Husaren bey... und unter dem 20. September: Gegen Abend zwischen 5-6 Uhr ward die Stadt mit einer starken fr. Einquartierung beleget. Auch haben sie ihr Lager bei Deienrode wieder bezogen, aber in weit grösserer Anzahl... (Pannenborg, S. 15 und 16). Vgl. Lotze, S. 166.

298 Soldaten des Regiments Royal Pologne, das 1747 vom Comte d'Orlyk aufgestellt wurde, aus Deutschen bestand und für Frankreich kämpfte (vgl. WäHner Tagebuch, Anm. 83, S. 14).

299 Französische Soldaten unter dem Befehl des Marschalls László Bercsényi (auch: Ladislas Ignace Graf von Bercheny, 1689-1778 (WähneR, Tagebuch, Anm. 11, S. 2); im September 1757 wurden sie im Gefolge des Herzogs von Richelieu beim Einzug in Celle beobachtet: Husaren von Berchini mit rothen Mützen (MASTNAK, S. 95).

300 Laut SAATHOFF, Bd. 2, S. 56 ff sollte Göttingen damals zu einem starken Stützpunkt für die Franzosen ausgebaut werden. 
Gärtens vor allen Thoren Wall und Graben gemacht wurden. Alles unter dem Commando des Graven von Veaux.

In dieser Zeit wurden auch viele Heu Stroh Korn und Haber Magazine daselbst angeleget dezt da denn in die Sct:Jacobi Kirche Rauzeug ${ }^{301}$ und Heu auch noch in allen Privat Scheuren Heu in die schöne Collegen Kirche ${ }^{302}$ und Auditoria und Sct: Albani Mehl auch in die Sct:Mar: Virgin: ${ }^{303}$ Heu geleget wurde, des Zeughauses Nonnen Klosters und alle übrige publique und privat Boden wurden mit Haber Rocken und Gersten angefüllet. Hier zu Hat Obernjesa sein ganzes Heu alles Stroh, allen Haber Gersten und etwas Rocken der ihm bey dem Cantonirungs quartiren ${ }^{304}$ nachgelaßen war, mit der grösten Gewalt liefern müßen und weil das Rocken Stroh zu dem gesezten quanto nicht hinreichte, so muste Obernjes $a$ von andern Orten es kauffen und liefern. Und weil alle übriggebliebene fourage

\section{[147]}

gleichfals der Foderung nicht gleich kam, so muste Obernj. 1400 r. fourage Gelder bezahlen, Außer diesem aber zahlet dis Dorf Mohnahtlich 200r. [verbessert zu 250] Contribution $^{305} 24$ Traitement $^{306}$ und 18r. Salvegarden ${ }^{307}$ Gelder. und so alle übrige Dörfer und Ämter

301 Dazu zählen Erbsen-, Wicken- und Getreidestroh.

302 Pauliner Kirche.

303 Marienkirche.

304 Vorübergehende Unterbringung von Besatzungssoldaten, im Gegensatz zur längerfristigen Einquartierung.

305 Kriegssteuer, die die Besatzungsmacht erhebt, um die Besatzungstruppen zu unterhalten.

306 Geldabgaben zum Unterhalt der Truppen; belastet wurden Pacht- und Eigenland sowie das Haus des Zahlungspflichtigen; darüber hinaus wurden Beiträge erhoben, um die höheren Offiziere zu schmieren; vgl. OADramfeld XVIII, 3: Gemeine Rechnunge von den Tracktementz Geldern wie fielle der alle Mochnnaht gesamlet Anno 1760.

307 Schutzgelder, vgl. ZedLer, Bd. 33, S. 637. 
um Göttingen theils mehr, theils weniger nach ihrer

Größe.

$\mathrm{Zu}$ ende des Novembr: 1760 fiel schlechte Witte-

rung ein, so daß die Cavallerie nicht gut mehr

draußen stehen konte wegen des Kohtes, dero

wegen kam sie vom Berge herrunter und legte

sich in die Dörfer zum Cantoniren, da denn

in Obernj: 5 Regimenter bis zum Außgang

Decembris lagen.

Um diese Zeit hatte man noch den grösten

Theil der Winterfrucht in den Scheuren, weil das Dreschen bey 50 und mehr StockPrügeln verbohten war; Allein es wärete kaum 24 Stunden, so war in mancher Scheuren wo 30 und mehre Schock Rocken lagen, nicht so viel mehr, außer dem was auf den Mistplätzen und in den Gärtens ausgestreuet, damit man ein Schwein hätte auf ein mahl sat füttern können.

So verwüsteten die Feinde zu der Zeit den Segen Gottes; denn sie bauete Hütten in die Gärtens davon, unter welchen in manchen Garten von ganzen battalliones die Pferde Stunde, ich selbst mein sel: Vater hatte in seinen Garten 4 Companien mit Zeltern u. Pferden ${ }^{308} 9$ Officir mit 18 Maultiren 24 Pferden in Ställen und Scheuren

\section{$[147 v]$}

Continuatio Chronic: Obernjes:

Dis wärete 4 Wochen lang bis Ausgang Decembris 1760 . Und nachdem sie alles Verdorben, was zum Unterhalt der Menschen und des Vihes nöhtig war, so zogen sie endlich hin weg, schickten aber zu vor 10000

308 Laut SicharT, Bd. 2, S. 194, 195, brauchte eine Infanteriekompanie von 114 Mann grundsätzlich insgesamt 22 Zelte; theoretisch hätten dann mindestens 88 Zelte im Garten des Pastors gestanden. 
Mann nach Göttingen zur Besatzung, welche aus lauter Piquetern von allen französischen Regimentern bestund. für diese musten Strohsäcke, Bette, Lackens, Decken, Töpfe, etc: Von den Dörfern und Bürgern geliefert werden.

Den 18hㅡ Decembr: 1760 kamen die Unsrigen unter dem Commando des Hn. Gener: Leut: von Luckner ${ }^{309}$ und Bloquirten Göttingen etwa 8 - 10 Tage, da sie denn unverrichteter Sache aus Mangel der Lebensmittel und fourage auch wegen der schlechten Witterung wieder abzihen musten.

Kaum aber waren diese fort, so fingen die Drangsahle von neuen unter dem Bauren wieder an; denn man erpreßete mit der grösten Gewalt und Unbarmherzigkeit den lezten Halm Stroh von dem Bauren, Auch tägl: 2 Futterschneider und 6 Schanzarbeiters, den ganzen Winter hin durch, dabey hatten die oben angeführten Contribution Traitement $\mathrm{u}$ Salvegarden Gelder beständig ihren Fortgang:

\section{[148]}

Cont: Chron. Obernjes:

Das grausahmste bey dem allen war, daß wenn ein Mann einen Tag hin weg blieb, so kamen des andern Tages sogleich 6 bis 7 Husaren nebst einen Leutenant, welcher zur Straffe Bauermstr: und Vorsteher 50 bis 100 Prügel

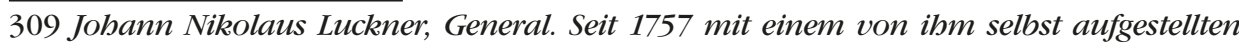
Husarenkorps (Freikorps) in hannoverschen Diensten. Er fübrte mit diesem Husarenkorps überraschende Überfälle auf die französischen Truppen aus (WÄHNER Tagebuch, Anm. 287, S. 44). LOTZE, S. 179, lobt Luckner, der mit seinen kübnen unerschrockenen Husaren stets vorn an war und die schwierigsten Aufträge ausfübrte.... 
auf den Hintersten geben lies, daher diese zu lezt so scheu wurden, daß sobald sich nachher ein Husar sehen lies, so lief alles hin weg, und da nahm man denn den ersten Bauren den man habhaft wurde, zulezt auch Frauens Persohnen und theilet solchen die 50, 60 etc: Prügel aus, wovor dem Executori $12 \mathrm{mg}$ : und quitung, daß und wie viel Prügel er $\grave{a}$ Person gegeben, ausgefertiget und gegeben werden musten.

Anno 1761.

Fing man von unserer Seiten den Feldzug mit einer starken Cannonade vor Cassel an, Allein sie war ohne Folgen, denn sie musten unverrichteter Sache halber wieder ablaßen, der H. Graf von Lippe Bückeburg ${ }^{310}$ commendirte dieselbe.

Der Schauplaz [!] des Krieges war dis Jahr Hessen und Westphalen so: Paderborn- Münstersche etc:

Göttingen blieb immer in französischen Händen durch eine Garnison von 8 - 10000 Mann. Unsere WinterFrucht samleten wir dennoch bey allen Drangsahlen ein; Allein

\section{[148v]}

1761. Contin: Chron: Obernj:

wie es an die Zeit der SommerFrüchete kam, so zog sich ein Corp der Unsrigen über die Dörfer bey Hoexter, und dis nöhtigte die Franzosen über Cassel und Münden ein noch halbmahl so großes Corp herrunter zu schicken, welches sich bey Göttingen auf den Leineberge mit dem rechten Flü-

310 Wilhelm (Friedrich Ernst) Graf von Schaumburg Lippe (WäHnER Tagebuch, S. 39, Anm. 245). 
gel gegen Norden und mit dem Linken gegen

Süden lagerte.

Dieses Corp fouragirte nun im Gronischen

Rostorfschen und endl: auch in unserm Horl

felde $^{311}$ die Sommer Früchte zur Hälfte.

Darauf zog sich es wie es etwa 3 Woche da

gelegen Hinauf nach Esebek, von dar

über Moringen nach Eimbeck, Nortbeim, Gandersheim den ganzen Harz und umliegen

den Gegenden.

Ferdinand $^{12}$ zog sich über Höxter durch den Solling

über Hameln Hannover hinter die Hufe $e^{313}$

und so stund sie eine ganze Zeit, bis die

Franzosen über Goslar sich um die Hufe hin-

umschlichen welches Ferdinant nach Hanno-

ver retirirn hieß, dabey er noch etwas ab

krigte, welches die Franzosen zum andern

mahle das ganze Brauschweigische [!] zu über

schwemmen vergönnete.

Wolfenbuttel wurde erobert und mit Brauns

weig gedachten sie nicht beßer zu machen

[149]

Contin: Chron: Obernjes.

Allein der H. Gener: Leut: v. Luchner [!] beschlich

die Belagerer von hinten und schlug sie un-

vermuhtet aus ein ander da denn die große

311 Die Ackerfläche am Horlgraben (auch Hurrel bezeichnet), der zeitweise die Grenze zwischen den Ämtern Friedland, Gericht Leineberg und Münden kennzeichnete (vgl. Wolter, Amt Friedland, S. 67).

312 Ferdinand, Herzog zu Braunschweig und Lüneburg (Wolfenbüttel), 1721-1792; seit 1740 in preußischen Diensten; wurde im November 1757 mit der Führung der Streitkräfte zur Verteidigung Hannovers betraut und in der Folge Obernkommandierender auf dem westlichen Kriegsschauplatz (WÄHnER Tagebuch, Anm. 137, S. 23).

313 Ein Höhenzug bei Einbeck, der während des Siebenjährigen Krieges mehrmals umkämpft war, u. a. 1761 (Lindner, S. 500-501). 
Ferdinandische Armée zu Hülfe kan und alles wieder zu verlaßen sie zwang.

Unter deßen aber hatten sie schon einige Hunder tausend r. Contribution aus geschrieben aber noch nichts erhalten. Daher führeten sie alles Zug- und Horn Vihe, das sie habhaft werden konten hinweg benebst 12 Predigern und 3 Superintendenten als Geißeln, weil die Beamten und Richter ausgetreten waren. brachten alles nach Göttingen, wo die besten Pferde verauctioniret, die andern aber den Dorfschaften um Göttingen mit Gewalt aufgezwungen wurden. Unser Dorf bekam 4 Wagen mit 4 Pferden bespannet, welche aber schon halb verhungert waren, weil sie in 48 Stunden keine Handvol zu freßen gekrigt, für diese muste unser Dorf geben 800r.

Um eben diese Zeit, galt der Hb. Rocken $4 \mathrm{r}$. Nun wurde aller Orten March Ruhten abgestochen von Göttingen aus eine über Geis mar nach Duderstadt, über Reinhausen nach Heiligenstadt. über Stockhausen Fried Rechshausen $^{314}$ nach Witzenhausen, über Nieder $\mathrm{u}$ Obernjesa nach Witzenh. gerade zwischen meinen beyden Gartens vorbey. Auf allen diesen passirten nun viele Trouppen weil es schon

\section{[149v]}

1761. Contin: Chron: Obernjes:

zieml. in den Herbst hinein kam. Davon wir abermahls vieles leiden musten, denn die mehresten machten hir Nachtlager unter andern hatten wir auf ein mahl 1400 Mann 1200 Pferde im Dorfe. welchen das mehr

314 Reckershausen. 
ste an fourage und Lebensmitteln gereichet werden muste.

Gleich darnach ging die ganze Artillerie und alle Pontons ${ }^{315}$ welcher Zug unzähl bar war hier durch, er daurete aber von des Morgens um 8 Uhr bis nachmittages um 3 Uhr.

Uber Rosdorf, Mengershausen nach Hedemünden, über Gronde nach Munden gingen viele Regimenter Infanterie.

Alles in die Winterquartire an der Werre, an u. über die Fulda.

Wir aber blieben unter der Zuchtruhten der Göttingischen Garnison, welche 1) auf den Zimmer Hofe, 2) in den Universitas Garten eine ungemein große Bekerei, auf der London Schenke ${ }^{316}$ in der Schule und alten Brauhause, an der Leine, Lazeretter angeleget hatte. schon wie die Armée in die Gegend Eimbek kam.

Um diese Zeit galt der Hb. Rocken 4r.18. Der Weizen 5r. Die Gersten 4r. Die Früchte aber würden noch weit mehr gegolten haben, wenn nicht verschiedene unserer Bauren als Andreas

[150]

Contin: Chron: Obernjes: 1761.

Hariehausen und Christop: Zimmermann nach Northausen Mülhausen; endl: in die Gegend Dresden und Leipzig gefahren, und den Rocken daher geholet hätten: denn hier war nichts mehr zu bekommen.

315 Schwimmkörper für Brücken.

316 Heute als Michaelishaus bekannt. 
Unsere Trouppen lagen diesen Winter in Hildesheimischen wo Ferdinands Hauptquartir war, im Paderbörnischen Lippschen und Münsterschen.

In diesen Winter musten wir abermahls vieles ausstehen, theils von der Garnison an Lieferungen Geldes und fourage, Arbeiten an Festung und Magazienen, theils von der über Großen Theurung aller Lebens Mittel. Denn $1 \widetilde{\pi}$ Rindfleisch galt 9mg. da es sonst 3 gegolten. Kalbfleisch 8 g. sonst 10d. Schweine fleisch $6-8 \mathrm{~g}$. sonst $2-3 \mathrm{~g}$. ein Hamel 8r. sonst 1r.18g: 1 to Butter $24-39$ g: 1 Ey 1g.4d. 1 Hb. Rocken 5 r. Weitzen 6r. Gersten 4r. Erbsen 4r.18g: 1 Quartir Fein Franzwein 24g. sonst 7g. 1 Paar MannsSchuhe 3r.18g. FrauensSchuhe 2 r.18g.

Im Mohnat März 1762 fingen die Unsrigen schon an sich in Hildesheimischen zu bewegen und zogen sich theils nach Eimbek theils nach der Weser. Die Franzosen hielten sich noch zur Zeit sehr stille in Göttingen. Allein aus Northausen Mulhausen zogen sie sich an der Werre herrunter ins Hessische.

Um Ostern 1762 rückten die Unsrigen über die Weser ins Padebornische Lippische und Hessische Die Franzosen gingen Cassel näher.

Im Majo kam ein Corps Franzosen von 30000 Mann bey Martzhausen, Hebenshausen u. Niederngandern $\mathrm{zu}$

\section{[150v]}

1762. Continuatio Chroni: Obernjes.

stehen, welches aber den $3^{\text {tn }}$ Tag wieder fortging

Den 1sten Junii 1762. Lagerte sich ein Corps Franzosen auf den Berg hinter Deiderode von etwa 20000 Mann. 
Den 8 fouragirten $^{317}$ diese Trouppen der Dramfelder ihr Win

terfeld und unser zum Drittel dabey ich 15 Morgen

ein Büßete.

Den 15 th fouragirten sie aber mahl an der Dramme

herrunter und vor dem Holze herraus bis an

an meinen KüchenGarten über d. Dorfe her.

Den $16^{\text {th }}$ Ging fast die ganze Caval. nebst Volon-

tairs nach dem Harz und kamen d. 17th wieder

zurück mit 100 000r. Contributions Geldern

und 4 Geißeln in einem Wagen.

d. $18 \underline{t n}$ des Sontages nach Trin: d. $6 \underline{t n}$ als ich

eben Communion halten wolte bekam ich von

einigen officiren die Nachricht, daß sie

um 8 Uhr des Morgens wiederum foura-

giren wolten. Ich lies also um 7 Uhr den

Gottes Dienst angehen, einen Bußgesang

singen, verrichtete ein Gebet vor die Commu-

nicanten nach vorgegangner Anzeige des

Vorhabens der Feinde, und theilete das $\mathrm{Hl}^{318}$

aus und schloß mit: Gott sey gelobet und

Kaum war ich aus der Kirchen, so erthönete

schon die Luft von dem Wiehern der Pferde und

dem Geschrey der Fourageurs, und da ging

der Lezte Theil des Winterfeldes verlohren.

Nachdem Nun aber Herzog Ferdinand nach und

nach den Franzosen an fing die Päße nach

[151]

1762. Continuat: Chron: Obernj:

Frankreich zu besetzen, so brach dis auf

Corps d.

317 Das Plündern der bestellten und noch nicht abgeernteten Felder war die von allen Kriegsparteien geübte Art und Weise, die eigenen Heere im Feindesland zu ernähren.

318 Das Heilige, das heilige Abendmahl. 
den $22 \frac{\text { ten }}{2 u n i i} 1762$ auf und ging über Witzenhausen ${ }^{319}$

Mrs. De Veaux aber blieb noch immer in Gött-

tingen und forderte allein von Obernjesa

tägl: 500 rationen Rocken und 500 rat: Heu. er

bekam sie aber nicht.

Um diese Zeit traf der H. von Wüllen Land-

Syndicq ${ }^{320}$ von Hannover einen accord wegen

Geldforderungen mit ihm, kraft deßen

er bis Novembr: 1762 eine gewiße Summe

Geldes von der Königl: Regirung vor die Stat

und platte Land haben solte. Darauf

ging er endlich plözl. unvermuhtet

den 16 $\frac{\text { tn }}{\text { Julii }} 1762$ aus Göttingen in guter und löbl. Ordnung. nach dem er vor her viele 1000 Säcke Mehl seinen Soldaten zum verkauffen geschenket. Kanonen vernagelt, das Pulver verschüttet die Kugeln ins Waßer geworfen. und eine große Mine unter dem ersten Pulverturme von der Sct: Albani Kirchen nach dem Wehnder Thore in die Luft gesprenget, welches eine solche Breche gab, daß man 15 mann Hoch herraus und herrein passiren konte. Sie gingen aber nicht weiter als bis Friedland da sie des Nachts ordre krigen wieder ein zu rücken.

d. 17 Julii kamen sie also um 6 Uhr des Morgens wieder in Göttingen nahmen alles wieder in Besitz, und weil nun alle Magazins ausgelifert waren durch die Soldaten,

319 Es findet sich kein Wort über den erfolgreichen Angriff des Herzogs Ferdinand auf das französische Lager zwischen Calden, Grebenstein und Hofgeismar am 24. Juni 1762. Immerhin soll es ein kostspieliges Essen für die gefangenen französischen Offiziere im Schloss Wilhelmsthal gegeben haben (vgl. Lotze, S. 172).

320 Albert Christoph von Wüllen (1713-1789), Hofgerichtsassessor und seit 1742 Syndikus des Fürstentums Calenberg; er gründete 1750 gemeinsam mit dem Abt des Klosters Loccum, Georg Wilhelm Ebell, die Landschaftliche Brandkasse (Hannoversches Biographisches Lexikon, S. 396. Vgl. WäHner Tagebuch, S. 45, Anm. 295). 


\section{$[151 v]$}

1762. Contin: Chronic: Obernj:

so wurde ausgeruffen, ein jeder

Bürger solte sein Schrot wieder liefern

weil aber die Mehresten solches den

Soldaten mit 10, 20, 50, 100 und mehrn

r: à Sack von 4 Hb. 1r.24g: 1r. auch 18

auch 12g. bezahlet, und nichts wieder ge-

geben wurde, so hielte man zurück

Darauf wurde bey auf Hencken anbe-

fohlen, in 3 Tagen alles zu liefern. und

bey welchem am 4ten Tage durch eine

genaue Visitation noch was gefunden

würde, der solte aufgehencket werden.

Und so musten also die Bürger ohne

endGeld alles wieder hergeben. Dennoch

aber blieb etwas zurück, welches gefunden

und die Persohn wo bey es gefunden wurde

gefängl. eingezogen, geschloßen, und nach

Cassel geliefert

In dieser Zeit aber segnete Gott die Anschlä-

ge unsers Heerführers Ferdinands, daß

dem Feinde alle Zufuhre an Lebensmitteln

verhindert wurde ${ }^{321}$, Daher wurde der Feind

genöhtiget, eine solche Wendung zu-

machen, mit der Ganzen Armée,

daß er nicht auch von Frankreich ab

schloßen würde, und dieser erforderte

die Göttingische Garnison näher an sich

321 Vgl. die Darstellung bei Lotze, S. 173: Um nun die Franzosen aus ibren festen Lagern bei Cassel zu vertreiben, schnitt ihnen Ferdinand die Kommunikation mit Frankfurt a.M. ab. Der französische General Rochambeau, der diese deckte, wurde angegegriffen und nach einer hartnäckigen Gegenwehr in die Flucht geschlagen. Die ansehnlichsten Magazine bei Rotenburg fielen dadurch in die Hände der Alliierten. Am 23. Juli 1762 kam es zur Schlacht bei Lutterberg, die ausführlich bei Lotze beschrieben wird (S. 173-176), und in der Folge zum Abzug der Franzosen aus Göttingen und Münden am 16. und 17. August 1762. 
[152]

1762. Contin: Chron: Obernjes:

zu zihen. Und hinzu bekam selbige auch

den 15 Aug. ordre solchen Ausmarsch aus der Stad.

den 16 ejusd: vorzunehmen. wie auch geschahe.

Allein alle Pferde wurden 8 tage vorher noch erpreßet, die nur möglich waren, selbst mein Meyer büßete 4 Pferde dabey ein und noch andere 4 aus dem Dorfe. Und so geschahe es rund um Göttingen herum bis Northeim. Endlich kam der Tag und die Stunde des Abmarschirens. welcher war

der 16te Aug. 1762. Des Morgens um 6 Uhr wurde, erst Brod ausgetheilet, darauf die ganze Garnison zu Walle comendiret die Brustwehre von Geismar bis Albaner thore zu rasiren Pallisaden abzuhauen, die Mauren abzu brechen; Andre worfen aus dem Pulver thürmern allen Vorraht an Kugel Pulver Patronen Cartetschen etc. heraus in den Graben und in die Leine: Wobey 124 Mann Sachsen ein sehr jämmerliches Ende genommen, welches mit keiner feder $\mathrm{zu}$ beschreiben. Diese wolten auf Befehl den $2 \underline{\text { tn }}$ Pulver Thurm von der Albaner Kirche nach dem Wehnder Thore hin kurz vor 8 Uhren gleichfals aus lehren, gehen daher vor der Rel. Oppermann ihren Garten unter dem Walle hin in selbigen Thurm, wie die garten Leute aus gesagt, und ein Theil nebst dem Officir bleibt haußen und auf dem Walle stehen. 


\section{[152v]}

pag: 86.

Continuat: Chron: Obernjesan:

Darauf entzündet sich von ohngefehr das Pulver und der große thurm praßelt in die Höhe der Wall berstet und die Menschen werden wunder bahr zer gliedert, so daß man im Post Hofe einzelne Arme und Beine gefunden, einige Steine sind sogar aufs Marckt ans Rahthauß geflohen [!] etc: ${ }^{322}$

Darauf marschiret der Feind aus über Stockhausen Friedland Witzenhausen.

Den 18 th $A u g:$ kamen die Unsrigen, die Franzosen aber gingen bis Warburg mit der ganzen Armée Cassel aber war noch besetz [!]wurde von den Unsrigen belagert 6 Wochen unter deßen rasirten die Un srigen die Göttingischen Festungswercke, eben als Cassel nun überging mit accord kam die frölige Post es ist Friede! und nicht lange nahher wurde es bekräftiget von allen Seiten, und wir feyreten auch nach vor geschriebener Formel vom Könl. Consis: am Heil. 3 Königsfeste $+\underline{1763}+$ solenniter dieses Friedes Fest. ${ }^{323}$

Nach diesem gingen sogleich die großen armeen aus einander und Hauß Hannover danckte alles bis auf 9000 Mann ab da doch der Unsrigen wohl 40.000 Man im Felde gewesen.

322 Über dieses Ereignis ist von mehreren Personen berichtet worden, vgl. Füssel, in: GöJb 60, 2012, S. 155.

323 Die Friedensschlüsse von Paris [10. Februar 1763] zwischen Großbritannien und Frankreich und von Hubertusburg [15. Februar 1763] zwischen Preußen und Österreich im Jahre 1763 beendeten eine siebenjährige Kriegsphase, in der das Kurfürstentum Hannover eine unglückliche Nebenrolle gespielt hatte (VIERHAUs, in: Göttingen Bd. 2, S. 33, 34). 
[153]

p. 87.

Contin: Chron: Obernjes:

Die Königl. Regirung hat darauf von allen u jedem ein Verzeichniß der Krieges Kosten gefordert welches von meiner Gemeine in folgendem bestehet: ${ }^{324}$

$[153 v]=$ leere Seite

\section{[154]}

89.

Cont: Chron: Obernjesan:

Das aller erste was Königl. Regirung zur Wieder aufnahme des Ackermannes ${ }^{325}$ resolviret ist folgendes:

\section{Unsere $\mathrm{pp}$}

Es haben Sr: Königl. Maj: unser allergnädigster H. mit der aller Huldreichsten Bezeugungen zu er kennen gegeben, wie sehr es aller höchst Ihro am Herzen lieget, $d ß d$. d. d. ${ }^{326}$ vorgedaurete schwehre Krieges Zeiten in mancherley Betracht so sehr mitgenom mene Landes Gegenden u. vornehml. diejenigen der Fürsten thümer Göttingen Grubenhagen auch die Grafschaft Sternberg * einige Ämter des Hämelschen Districts, welche vom Anfan [!] bis zu Ende des Krieges, den feindl. Einfällen und verHeerungen fast ohnabläßig ausgesetz gewesen. d. alle nur mögl. Hülfsmittel wieder empor gebracht, und insonderheit, das Wesentliche des Landwirthschaftl: Standes, der Ackerbau und die Vihzucht der Untertahnen, baldmögligst wieder ergenzet $u$. wieder hergestellet werde.

324 Keine Angaben im Text.

325 Gemeint ist das Wiederingangbringen der Landwirtschaft.

326 daß die durch die.. 
In solcher Absicht haben allerhöchst gedachte Ihro Königl. Maj. unter andern untertähnigsten Vor schlägen, zu genehmigen geruhet, wie hie mit bekant gemacht wird:

Daß I) allen und jeden Dero Span Dienstpflichtigen Untertahnen, in vorbewegten Fürstentühmern, welche auf den 1 stn Maj 1764 ihre völlige Bespannung werden wieder angeschaffet da bey zugleich ihr Feld insgesamt werden wieder bestellet haben, ein Dreyjähriger Erlass aller ihrer in die Amts Register abzuführenden Geld u Korn Abgiften angedeyen solle. Auch nach Befinden, auf Pflichtmäßigen Bericht

\section{[154v]}

90.

Contin: Chron: Obernjes:

der Beamten, denjenigen welche ohn erachtet solcher Beyhülfe, keinen Credit zufinden vermögen der Betrag solcher Amts Abgiften auf ein mahl aus den registern vorgeschoßen werde.

Es ist demnach von denjenigen Eingeseßenen Untertahnen, welche sich in den lezt bestimten Falle des Unvermögens u. credit mangels befinden, ein genaues jedoch mögligst einzuschränkendes Verzeichniß, nebst bey zu fügenden Gut achten, auf zu nehmen, u daßelbe gegen Ablauf des nächst ein stehenden Mohnahts Maj, zu Königl. Kammer einzusenden. da mit wegen der Ausgaben Berechnung des daraus erwachsenden von obgesezter Zeit an den Unterthanen zu leistenden Vorschußes das Nöhtige verfüget werden könne.

Gleich wie auch II tens Königl. Kurf. Kammer Sorgfalt darin bereits d. nöhtige Vorkehrung gemacht, $d ß d$. an Brod u. SaatKorn Mangel 
leidenden Einwohnern Obbemelter Gegend die Nohtdurft daran gegen leidliche Preise zu geführet wird; Also wird selbige auch in Alle Wege geneigt seyen, daß zu desto volständigerer und un aufhältl: wieder Bestellung, des gesamten Acker Baues, den Dienstpflichtigen eine ihnen nöhtige Erleichter und Minderung der in Natura an die Amter zu leistenden Hand und Span Dienste zu gute kommen möge, Im maßen es sich von selbst verstehet, daß das von ihnen in d. Register zu bezahlende Dienst Geld mit unter jenem Erlasse begriffen.

III tens $\mathrm{Zu}$ fordersahmster wieder in den

Standsetzung der bey d. KriegesZügen verderbte

[155]

91.

Contin: Cbron: Obernjesanae

Gebäude Gärten und Befriedigungen auch wiederherstellung des Abgängigen Acker und Wagen Gerähtes ist Konigl. Kammer gewillet, und d. d. Befehle Ihro Maj: bemächtiget, daß darzu erforderl. Bau u. Nutzholz, den Bedürftigen Untertahnen, welche sonst auf keinerley Ahrt darzu rahten können noch eigene Hölzung haben aus den Herrschaftl. Forsten ohnentgeldlich ver abrreichen [!] zu laßen.

Wesfals denn auch die darüber zu verfertigende Verzeichniße nachvorgängiger mit den Forst Bedienten gemeinschaftlich vor zu nehmender genauer u. pflichtmäßiger Untersuchung der Bedürfniße zu Königl. Kammer bewillig u. Verfügung zu ordnungsmäßiger Zeit, ein zu senden seyn wird.

Wan aber bey allen obigen es vor allendingen und haupt sachlich darauf ankömt daß vor er- 
wähnte $\mathrm{u}$. andere d. LandesUnterthanen zur

Beförderung ihrer wieder Aufnahme angedey-

ende Beyhülfe u. Wohltaten, nach der Landesvä-

terl. Absicht aller höchst Ihro Königl. Maj. von Ihnen

zu ihren würckl. wahren Besten verwendet, nicht

ob auf Leichtsin $u$. fahrlaßigk. in ihren eigenen

Bemühungen $u$. anzuwendenden Fleiße gezogen

werden möge:

Als ist von Amts wegen, wie dan eines jed.

Diesttreu [!] u redl. Beamten u Dieners eigenen

Pflicht und Gesinnung ihn selbst darzu anleiten wird darüber allein die Sorgfältigste Achtsahmkeit zu

halten, und den Haußhalt eines jeden AmtsUnter-

\section{[155v]}

92.

1763 Contin: Cbron: Obernjes:

thanen von Zeit zu Zeit nachzu sehen $\mathrm{u}$ zu bemerken in Summa wie wir vertrauen, daß ihr es euch ein an genehmes Geschäfte werdet seyn laßen den entkräfteten Zustand der d. d. Krieg beküm merten - eurer Pflege Befohlenen Untertanen wieder empor zu helfen, ihnen über all mit gutem Raht $u$. vernünftiger Anweisung an Hand und zur Seite zu gehen. Wir p.p. Hannover d. 30 $\stackrel{\text { tn }}{\text { März } 1763 .}$

Königl. Großbrittanische zur Churfürstl.

Braunschw. Lüneb. Cammer verordnete Cammer Präsident, Geheimte Rähte Geheime Kammerauch Kammer Räthe

G. A. von Münchhausen.

An den Gerichtsschulzen Conradi ${ }^{327}$ wegen des Leine bergischen Gerichts.

327 Ernst Christian Conradi, Schulze des Leinebergischen Gerichts (Siebenfacher ... Staatskalender auf das Jahr 1763, S. 127). 
Dieses Decret ging als ein Circular zur

Verlesung im Gerichte herum. u

war hieselbst d. 28 $\underline{\text { th }}$ April 1763.

[156] $=3$ leere Seiten

\section{[156v]}

Im Mohnaht 8bris 1764 habe durch Meister Münscher ${ }^{328}$ von Hitzelrode mein Eckstube blau und meine Wohnstube Nußfarbe anstreichen laßen $\mathrm{Zu}$ beyden habe ich, mit unterschriebe ner Prediger, die Farben gekauft nebst $8 \widetilde{m}$ Lein Ohl für 3r.18g: und dem Meister habe für seine Arbeit gezahlet 2 r. den Empfang bescheiniget seine Unterschrift Obernjesa d. 19ํㅗ Nov: 1764 Henrich Phil Stolberg Johann Henrich Münscher WeißBinder

Im Nov: 1764 habe oben um meinen KüchenGarten eine lebendige Heinebüchen Hecke angeleget wo zu 12 Schock Stämme verpflantzet welche von Nienrode ${ }^{329}$ habe herfahren laßen für die Stamme habe bezahlet $1 \mathrm{r}$. 2 Persohnen 2 Tage sie gerotet. $\quad-.24$ 2 Persohnen 2 Tage wiedergeplanzet $\quad-.12$

Auch habe 1760 an den Baumgarten rechter Hand der Pfort eine Dornenn Hecke pflanzen laßen, die Dornen sind hier aus dem Berge gerot von 2 Persohnen $z 1$ Tage 12g. dieselbige zu setzen 1 Tag von 2 Persohnen à $6 \mathrm{~g}$. fac: $12 \mathrm{~g}$. Den Gang im BaumGarten von einer Pforte zur andern habe auch 1760 setzen laßen von 1 Persohn 1 Tag 6g. Henr. Phil. Stolberg.

328 Ein Weisbinder Meister Münscher wird auch noch zwanzig Jahre später bei den Reparaturarbeiten am Pfarrwitwenhaus beschäftigt (KiKrAGött P. A. Obernjesa K. R. I.a. 4 Kirchenrechnung von 1784, Monitum 10).

329 Es könnte sich um das Gut Neuenrode in der heutigen Gemeinde Neu Eichenberg handeln. 
[157]

Berechnung der Kosten meines

Pfarr Schucke Brunnens angelegt

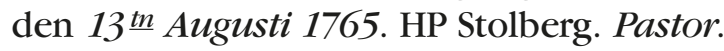

Das Ventil von gegoßenem Metal 3r.

Der eiserne kuferne Stiefel von Mstr. Puschern 3r.

Die Stange 1 r.

Eine große eiserne Büchse über das

Ventil

$18 g$.

Der Hölzerne Stiefel mit 2 eisernen

Bänden u dem Leder

Arbeits Lohn von 7 Tage für

$24 \mathrm{~g}$.

Meister und 2 Gesellen $a 1$

Tag für alle 3 Persohnen $24 \mathrm{mg}$. fac.

4r. $24 \mathrm{~g}$.

Summa

12r. 30g.

Diese Summa von 12r.30g. ist mir Unter

Schriebenen von den Hernn Bastor stolberg

richtig bezahlt

oberJeßa d. 13t. August

1765

[...?] Christoph Lücke brunnen

Meister in göttingen

[in anderer Tinte]:

Hiezu komt noch 28 fuß Ellern Holtz 21g. vid Quit. A

selbige herzufahren

14g. vid Quit: $B$.

Das Oberste Eichen Röhr Stück habe hir aus dem

Holze erhalten.

Dieses Pumpen Werck habe 1767 wieder aufnehmen laßen und Oben in meinen Garten wieder gebraucht zu einer Schucke. 
[zwischen [157v] und [158] ohne Seitenzahl eingehefteter Zettel]:

[Vorderseite des eingehefteten Zettels]:

Nachricht wegen des Pfarr

Schucke Brunnens. 1765.

Im Früh Jahre 1765 besahen die Geschwohrnen

hiesiger Gemeine, der Bauermeister Andr:

Hariehausen, Georg Heine, Joh: Andr. Seufer

als Vorstehern auch Lorentz Debne Junior

als ZimmerMeister meinen Brunnen; erkanten, erstl: daß eine gefährl: Sache für Menschen u.

Vihe auch für die ersten über aus Beschwehrl:

wäre theils weil er als ein Wickel Brunnen

über aus tief auch so offen stünde, resolvirten

dahero auch bey dem Verfall deßelben

Schlinges und Wickelwerck, ein neues

zu verfertigen und zwar nach meiner

Angabe in Form eines Achteckichten Häuß-

chens mit einem Tache. Nach diesem gericht

dieses wieder in ein Strecken Welches von

dem Zimmermeister auf r. [keine Zahlenangabe] geschätzet wurde.

[Rückseite Zettel]

Da nun aber nach diesen sich der Fall eräuserte

daß mein altester Sohn ein Kind von 2 Jahren bald

hinein gestürzet wäre, resolvirte ich zu meiner

Sicherheit bequemlichkeit, und der Gemeine

zum Nutzen aus meinem Brunnen ein Druck

werck machen zu laßen, die Kosten vorerst

aus meinen Mitteln vorzuschießen in der Hof-

nung die Gemeine werde sie mir wenn

sie erst in beßern Umständen wären wieder

erstatten. Im Fall aber solches nicht geschihet

rechne ich solche zu den Melioramenten, und

der Successor wird gehalten, im Fall er sie

behalten will, sie wieder zu erstatten.

Obernjesa den $11^{\text {tn }}$ Aug. 1765

Henrich Philip Stolberg Pastor 


\section{$[158 v]$}

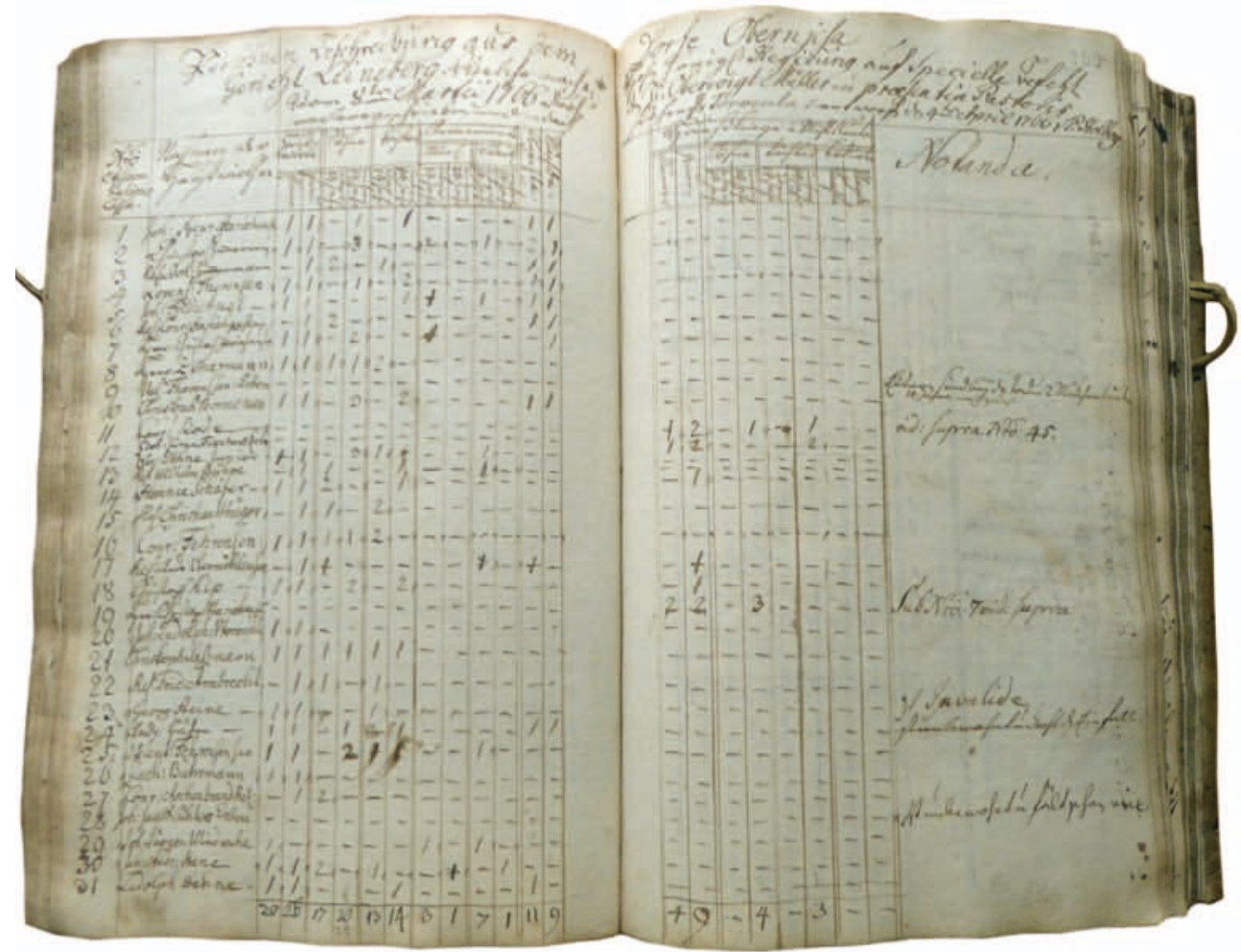

Abb. 5 Tabelle: Persohnen Beschreibung aus dem Dorfe Obernjesa Gericht Leineberg vom 8. März 1766 / Quelle: KiKrAGött, P. A. Obernjesa K. R. I.a. 1 [158v], [159]

\section{[158v]-[160]}

[Linke und rechte Seiten der Tabelle]

\section{Persohnen Beschreibung aus dem Dorfe Obernjesa,}

Gericht Leineberg. Welche nach der Hohen Konigl. Regirung auf SpecielleBefehl vom $8_{\text {tn }}$ Martii 1766 durch den Hn. Obervoigt Müller in praesentia Pastoris nach vorgeschrieben und nach stehende Formulas entworfen den 4tn April 1766 P. Stolberg 


\begin{tabular}{|c|c|c|c|c|c|c|c|c|c|c|c|}
\hline \multirow{3}{*}{ 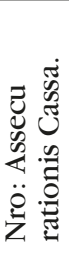 } & \multirow{3}{*}{$\begin{array}{l}\text { Nahmen der } \\
\text { Haußwirthe }\end{array}$} & \multirow{2}{*}{\multicolumn{2}{|c|}{$\begin{array}{l}\text { Hauß } \\
\text { wirte }\end{array}$}} & \multirow{2}{*}{\multicolumn{2}{|c|}{ Söhne }} & \multirow{2}{*}{\multicolumn{2}{|c|}{ Töchter }} & \multicolumn{4}{|c|}{ Anverwante } \\
\hline & & & & & & & & \multicolumn{2}{|c|}{ Mänl. } & \multicolumn{2}{|c|}{ Weibl. } \\
\hline & & 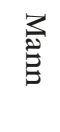 & $\stackrel{T}{\mathfrak{Z}}$ & 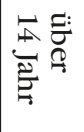 & 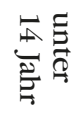 & 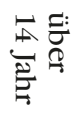 & 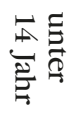 & 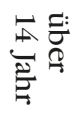 & 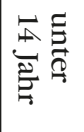 & 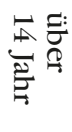 & 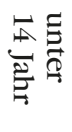 \\
\hline 1 & Joh: Henr: Hariehausen & 1 & 1 & - & 1 & - & 1 & - & - & - & - \\
\hline 2 & Christoph Zimmermann & 1 & 1 & - & 3 & - & - & - & - & 1 & - \\
\hline 3 & Rel. Joh: Zimmermann & - & 1 & 2 & - & 1 & - & - & - & - & - \\
\hline 4 & Lorentz Fherensen (!) & 1 & 1 & - & 1 & - & 2 & - & - & - & - \\
\hline 5 & Joh: Frid: Apel & 1 & 1 & - & - & - & 1 & 1 & - & 1 & - \\
\hline 6 & Rel: Conr: Hariehausen & - & 1 & 2 & - & - & - & - & - & - & - \\
\hline 7 & Henr: Christof Hariehausen & 1 & 1 & - & 2 & - & - & 1 & - & - & - \\
\hline 8 & Henr: Zimmermann & 1 & 1 & 1 & 1 & 2 & - & - & - & - & - \\
\hline 9 & Val. Fherenssen: Erben & - & - & - & - & - & - & - & - & - & - \\
\hline 10 & Cristoph Borneman & 1 & 1 & - & 3 & - & 2 & - & - & - & - \\
\hline 11 & Conr: Boden & - & - & - & - & - & - & - & - & - & - \\
\hline$\{12$ & Joh: Jürgen Fischers Erben & - & - & - & - & - & - & - & - & - & - \\
\hline$\{12$ & Lor: Dehne. Junior & 1 & 1 & - & 3 & 1 & - & - & - & 1 & - \\
\hline 13 & Re. Wilhelm Bühre & - & 1 & 1 & - & - & 1 & - & - & 1 & - \\
\hline 14 & Hennie Schäfer & 1 & 1 & 2 & - & - & 1 & - & - & - & - \\
\hline 15 & Rel. Christian Wrüger & - & 1 & 1 & - & 2 & - & - & - & - & - \\
\hline 16 & Conr: Fehrensen: & 1 & 1 & 1 & 1 & 2 & - & - & - & - & - \\
\hline 17 & Rel. Andr: Utermöhlen sen. & - & 1 & 1 & - & - & - & - & - & - & - \\
\hline 18 & Christoph Kip & 1 & 1 & - & 2 & - & 2 & - & - & - & - \\
\hline 19 & Hnr: Christoph Hariehausen & - & - & - & - & - & - & - & - & - & - \\
\hline 20 & Joh: Ludolph: Utermöhlen & 1 & 1 & - & - & - & - & - & - & - & - \\
\hline 21 & Christoph Salzmann & 1 & 1 & 1 & 1 & 1 & 1 & - & - & - & - \\
\hline 22 & Rel. Frid: Armbrecht & - & 1 & 1 & - & 1 & - & - & - & - & - \\
\hline 23 & Georg Heine & 1 & 1 & - & - & 1 & - & - & - & - & - \\
\hline 24 & Andr: Bühre & 1 & 1 & - & 1 & - & 1 & - & - & - & - \\
\hline 25 & Valent: Fehrensen sen. & 1 & 1 & - & 2 & 1 & 1 & - & - & 1 & - \\
\hline 26 & Zach: Bührmann & 1 & 1 & - & - & - & - & - & - & - & - \\
\hline 27 & Conr: Aschenbrand Rel: & - & 1 & 2 & - & - & - & - & - & - & - \\
\hline 28 & Joh: Jacc Kühters Erben & - & - & - & - & - & - & - & - & - & - \\
\hline 29 & Joh. Jürgen Windwehe & 1 & - & - & - & - & - & 1 & - & 1 & - \\
\hline 30 & Joh: Andr: Hane & 1 & 1 & 2 & - & 1 & - & - & 1 & - & 1 \\
\hline 31 & Ludolph Dehne & 1 & 1 & - & - & - & 1 & - & - & - & - \\
\hline & & 20 & 26 & 17 & $20^{330}$ & 13 & 14 & 3 & 1 & 7 & 1 \\
\hline
\end{tabular}




\begin{tabular}{|c|c|c|c|c|c|c|c|c|c|c|}
\hline \multirow{3}{*}{ 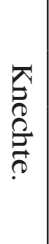 } & \multirow{3}{*}{ 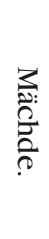 } & \multicolumn{8}{|c|}{ Häußlinge u Mihtsläute } & \multirow[b]{3}{*}{ Notanda. } \\
\hline & & \multirow[b]{2}{*}{ جִ } & \multirow{2}{*}{ 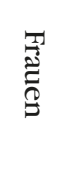 } & \multicolumn{2}{|c|}{ Söhne } & \multicolumn{2}{|c|}{ Töchter } & \multicolumn{2}{|c|}{ Bedinte } & \\
\hline & & & & 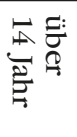 & 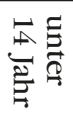 & 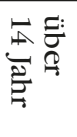 & 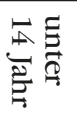 & 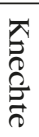 & 离 & \\
\hline 1 & 1 & - & - & - & - & - & - & - & - & \\
\hline 2 & 1 & - & - & - & - & - & - & - & - & \\
\hline 1 & 1 & - & - & - & - & - & - & - & - & \\
\hline 1 & 1 & - & - & - & - & - & - & - & - & \\
\hline 1 & 1 & - & - & - & - & - & - & - & - & \\
\hline 1 & 1 & - & - & - & - & - & - & - & - & \\
\hline- & 1 & - & - & - & - & - & - & - & - & \\
\hline- & - & - & - & - & - & - & - & - & - & \\
\hline- & - & - & - & - & - & - & - & - & - & $\begin{array}{l}\text { Eltern sind beyde tod u } 2 \text { Mädchens unter } 14 \\
\text { Jahren nachgelaß }\end{array}$ \\
\hline 1 & 1 & - & - & - & - & - & - & - & - & \\
\hline- & - & 1 & 2 & - & 1 & - & 1 & - & - & Vid: supra. Nro: 45. \\
\hline- & - & 1 & 2 & - & - & - & 2 & - & - & \\
\hline- & - & - & - & - & - & - & - & - & - & \\
\hline- & - & - & - & - & - & - & - & - & - & \\
\hline- & - & - & - & - & - & - & - & - & - & \\
\hline- & - & - & - & - & - & - & - & - & - & \\
\hline- & - & - & - & - & - & - & - & - & - & \\
\hline 1 & - & - & 1 & - & - & - & - & - & - & \\
\hline- & - & - & 1 & - & - & - & - & - & - & \\
\hline- & - & 2 & 2 & - & 3 & - & - & - & - & Sub Nro:7 vid: supra. \\
\hline- & - & - & - & - & - & - & - & - & - & \\
\hline- & - & - & - & - & - & - & - & - & - & \\
\hline- & - & - & - & - & - & - & - & - & - & ist Invalide \\
\hline- & - & - & - & - & - & - & - & - & - & Ist unbewohnt und droht d. Einfall \\
\hline 1 & 1 & - & - & - & - & - & - & - & - & \\
\hline- & - & - & - & - & - & - & - & - & - & \\
\hline- & - & - & - & - & - & - & - & - & - & \\
\hline- & - & - & - & - & - & - & - & - & - & \\
\hline- & - & - & - & - & - & - & - & - & - & Ist unbewohnt u fält schon ein \\
\hline- & - & - & - & - & - & - & - & - & - & \\
\hline- & - & - & - & - & - & - & - & - & - & \\
\hline 1 & - & - & - & - & - & - & - & - & - & \\
\hline 11 & 9 & 4 & $9(!)$ & - & 4 & - & 3 & - & - & \\
\hline
\end{tabular}




\begin{tabular}{|c|c|c|c|c|c|c|c|c|c|c|c|}
\hline \multirow{3}{*}{ 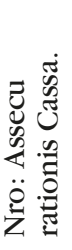 } & \multirow{3}{*}{$\begin{array}{l}\text { Nahmen der } \\
\text { Haußwirthe }\end{array}$} & \multirow{2}{*}{\multicolumn{2}{|c|}{$\begin{array}{l}\text { Hauß } \\
\text { wirte }\end{array}$}} & \multirow{2}{*}{\multicolumn{2}{|c|}{ Söhne }} & \multirow{2}{*}{\multicolumn{2}{|c|}{ Töchter }} & \multicolumn{4}{|c|}{ Anverwante } \\
\hline & & & & & & & & \multicolumn{2}{|c|}{ Mänl. } & \multicolumn{2}{|c|}{ Weibl. } \\
\hline & & $\stackrel{3}{\stackrel{2}{\Xi}}$ & בְּ & 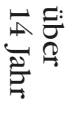 & 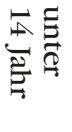 & 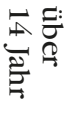 & 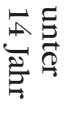 & 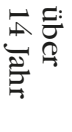 & 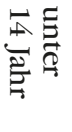 & 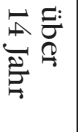 & 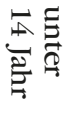 \\
\hline 33 & Joh: Adrian & 1 & 1 & - & 2 & - & 2 & - & - & 1 & - \\
\hline 34 & Joh: Henr: Hentze & 1 & 1 & - & - & - & - & - & - & 1 & - \\
\hline 32 & Andr: Deppe & - & 1 & - & - & - & 1 & - & - & 1 & 2 \\
\hline 35 & Johan: Pieper & 1 & - & - & - & - & - & 1 & 1 & 1 & - \\
\hline 36 & And: Bühren Erben & - & 2 & - & - & - & - & - & - & - & - \\
\hline 37 & $\begin{array}{l}\text { Joh. Christoph } \\
\text { Heddenhausen }\end{array}$ & 1 & 1 & - & 1 & - & - & - & - & 1 & - \\
\hline 38 & Christoph Utermöhlen & 1 & 1 & - & - & 1 & - & - & - & - & - \\
\hline 39 & Joh: Henr: Junge & 1 & 1 & - & - & - & 4 & 1 & - & 1 & - \\
\hline 40 & Lor. Fehrensen Rel: & - & 1 & 1 & - & 3 & - & - & - & - & - \\
\hline 41 & Joh. Christ. Seufer & 1 & - & - & - & - & - & 1 & 1 & 1 & 1 \\
\hline 42 & Lor: Dehne senior & 1 & - & - & - & - & - & 1 & - & - & 1 \\
\hline 43 & Christ. Zimmermann & - & - & - & - & - & - & - & - & - & - \\
\hline 44 & Andr: Henr: Gercke & 1 & 1 & - & 2 & - & - & - & - & 1 & - \\
\hline 45 & Conr: Bode & 1 & 1 & - & 2 & 1 & 1 & - & - & - & - \\
\hline 46 & Christoph Bode & 1 & 1 & - & 3 & - & 1 & - & - & - & - \\
\hline 47 & $\begin{array}{c}\text { Rel. Joh: Andr: } \\
\text { Untermöhlen, Junior }\end{array}$ & - & 1 & 1 & 1 & 1 & - & - & - & - & - \\
\hline 48 & Mattias Hampen Erben & - & - & - & - & - & - & - & - & - & - \\
\hline 49 & Die Pfarre & 1 & 1 & - & 1 & - & 2 & - & - & 1 & - \\
\hline 50 & Witwen Hauß & - & 1 & - & - & 2 & - & - & - & - & - \\
\hline 51 & Die Schule & 2 & 2 & - & 1 & - & 1 & - & - & - & - \\
\hline 52 & Hirtenhauß. & 1 & 1 & - & - & - & - & - & - & - & - \\
\hline & & 14 & 17 & 2 & 13 & 8 & 12 & 4 & 2 & $10(!)$ & 4 \\
\hline
\end{tabular}




\begin{tabular}{|c|c|c|c|c|c|c|c|c|c|c|}
\hline \multirow{3}{*}{ 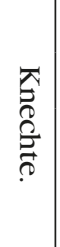 } & \multirow{3}{*}{ 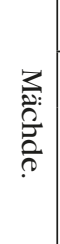 } & \multicolumn{8}{|c|}{ Häußlinge u Mihtsläute } & \multirow[b]{3}{*}{ Notanda. } \\
\hline & & \multirow[b]{2}{*}{$\stackrel{3}{9}$} & \multirow{2}{*}{ 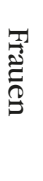 } & \multicolumn{2}{|c|}{ Söhne } & \multicolumn{2}{|c|}{ Töchter } & \multicolumn{2}{|c|}{ Bedinte } & \\
\hline & & & & 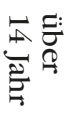 & 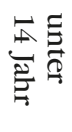 & 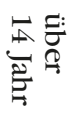 & 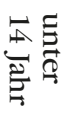 & 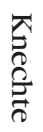 & 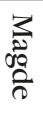 & \\
\hline- & - & - & - & - & - & - & - & - & - & \\
\hline- & - & - & - & - & - & - & - & - & - & \\
\hline- & - & - & - & - & - & - & - & - & - & $\begin{array}{l}\text { Eigenthümer dienet zu Grossen } \\
\text { Schneen Amts Friedland. }\end{array}$ \\
\hline- & - & - & - & - & - & - & - & - & - & \\
\hline- & - & - & - & - & - & - & - & - & - & \\
\hline- & - & - & - & - & - & - & - & - & - & \\
\hline- & - & - & - & - & - & - & - & - & - & \\
\hline- & - & - & - & - & - & - & - & - & - & \\
\hline- & - & - & - & - & - & - & - & - & - & \\
\hline- & 1 & - & - & - & - & - & - & - & - & $\begin{array}{l}\text { sind beyde } \\
\text { Licentschreiber }\end{array}$ \\
\hline- & - & - & - & - & - & - & - & - & - & \\
\hline- & - & 1 & 1 & - & - & 1 & - & - & - & Sub Nro 2. vid: supra. \\
\hline- & - & - & - & - & - & - & - & - & - & \\
\hline 1 & - & - & - & - & - & - & - & - & - & \\
\hline- & - & - & - & - & - & - & - & - & - & \\
\hline- & - & - & - & - & - & - & - & - & - & \\
\hline- & - & 1 & - & - & 1 & 1 & 2 & - & - & Erben sind nicht da sondern dienen. \\
\hline- & 3 & - & - & - & - & - & - & - & - & \\
\hline- & 1 & - & - & - & - & - & - & - & - & \\
\hline- & 1 & - & - & - & - & - & - & - & - & \\
\hline- & - & 1 & 2 & - & 2 & 1 & - & - & - & \\
\hline 1 & 6 & 3 & 3 & - & 3 & 3 & 2 & - & - & $\begin{array}{c}\text { Diese Persohnen BeSchreibung } \\
\text { hat das Mohnahts Fixum zuwege } \\
\text { gebracht nach welchen die Geistl. } \\
\text { à Persohn } 2 \mathrm{~g} .4 \mathrm{~d} \text { die Laien } 4 \mathrm{~g} . \text { geben } \\
\text { müssen. }\end{array}$ \\
\hline
\end{tabular}


$[160 v]$

Continuatio Chronicae Obernjesanae

1766. Im Herbst ist der Giebel an der großen Scheure

Neu gemacht item der Backoffen ganz neu.

Auch sind von Obernjesa 4 u von Dramfeld

2 Steinerne Krippen in den Kuhstall gebracht

worden.

1767 im Frühjahre habe in meinen KüchenGarten den Brunnen angelegt auf meine Kosten er hat mir auszugraben 36 Fuß tief von Johannes Künkler ge kostet an Tagelohn Eßen

$1 \mathrm{r}$.

11 Fuder Steine haben die Obernjesischen Acker Leute mir zugefallen daran gefahren nur Chri-

toph Hariehausen nicht, der Schulze, welcher sehr Grob ist. Vom Đeideröder Stockhäuser Berge wobey ihnen 4 Quartir Brantwein gegeben fac: 1r.9g.

1 Kanne Bier macht

Das Fuder Steine zu brechen 3 bezahlen $6 \mathrm{~g}$. in die Gemeine 1g. 4d à Fuder fac $\log .4 \mathrm{~d}$ Mstr. Valentin Wetter von Gertenbach hat selbigen gemauret u $\grave{a}$ Klafter ihm bezahlet 1r. fac: 6 Klafter $6 r$. Summa Henr. Phil. Stolberg Pred.

Im Früh Jahre 1768 habe ich das aus dem Küchen Brunnen beym Hause herrausgenommene Rohrwerk in diesen Brunnen setzen, und zu einem Schuckoder Zugwerck aptiren laßen durch den Meister und Bürger Daniel Christoph Krüger aus Göttingen, und accordmäßig für solche Veränderung und Aptirung bezahlet 6r. obige 6r. sind mir von den Hn. Pastor Stolberg richt bezahlet Obern Jese d. 16ten Martz 1768 DCKrüger Brunnen und röhren Meister aus Gottingen. 


\section{[161]}

Continuatio Chron: Obernjesanae

[kein Text]

[161v]

[kein Text]

[162]

\section{Contin: Chronicae Obernjesanae}

1775 den $27^{\text {th }}$ Febr: kam ein Zirkularschreiben des In-

halts: daß wir von den armen Kindern berichten u deswegen folgende fragen beantworten sollen.

1. Wird den $\$: 34$ in unsrer Calenb. Arm. Ordnung de 1702 welche in $1 \mathrm{Tom}$. der Landes Gesetze pag. 958

stehet in dero Gemeine völlig nachgelebet? Oder

2. Finden sich dagegen Hinderniße u worin bestehen selbige? und

3. Wie ist denselben nach den Local-Umständen abzuhelfen?

4) Sind auch irgendwo in dero Gemeine arme Kinder vorhanden, für welche weder von den Ihrigen noch aus irgend einem andern Fond, das Schulgeld bezahlet werden kan, und was sind davon für Uhrsachen vorhanden? und wie ist der Nahme solcher verlaßene Kinder 5. Haben dero Schulmeister solchen Kindern für welche schlechter Dinges kein Schulgeld hat bezahlet werden können, das Schulgeld wohl gantz oder zum Theil erlaßen? Und wie ist der Nahme dieser Schulmeister?

Diesem Schreiben dHn. Superin. Luther 331 war das Consistorial Rescript beygeleget de dato Hannover d. 24Jan: 1775. verbis: 
Unsere pp

Ob wohl in d hiesigen Landes-Ordnungen nahmentlich

$\$ 34$ der Calenberg. Armen Ordnung für solche Kinder

deren Eltern ihrer Armuht wegen das Schulgeld für

sie nicht erlegen können, dien sahme Vorsehungen

geschen [!], so ist doch diese Sache von viel zu großer

\section{[162v]}

Contin. Chronicae Obernjesanae 1775.

Wichtigkeit, und der Schaden, welcher aus dem unterbliebenen Schulbesuche entstehet, viel zu schwehr wieder ein zu bringen, als daß mann bestandig in der Ungewißheit bleiben könte: Ob den Landes-Ordnungen in diesem Stücke auch außer der hiesigen Residentz Stadt allenthalben $\mathrm{u}$ vollig gelebet worden, was für Hinderniße wiedrigen falls im Wege stehen u. wie nach den Local Umständen den selben abzuhelfen seyn mögte. Nahmens Sr. Königl. Maj. u Churf. Durchl. unsers aller gnädigsten Herren begehren wir dem nach ihr wollet hier über so gleich von den Pre digern und durch dieselben von den Schulhaltern (doch ohne diesen den Inhalt dieses Ausschreibens näher zu melden:) Pflichtmäsigen Bericht erfordern. In sonderheit auch noch dar über: Ob irgend wo arme Kinder vorhanden sind, für welche weder von den Ihri gen, noch aus irgendeinem andern Fond das Schulgeld bezahlet werden könne mit Anführung der Uhrsachen davon. ${ }^{332}$

2) Aus solchen Berichten habt ihr einen so kurtzen Auszug zu machen als nur ohne Nachtheil der Deutlichkeit möglig ist. und wenn in der euch anvertrauten Inspection, oder Kirchspiel

332 Es ist nicht zu erkennen, wer die Zeilen unterstrichen hat und wann. 
der gleichen Mangel sich nicht findet, mit Uber

gehung weiterer Specialien blos anzuzeigen

[163]

Contin. Chron: Obernjes. 1775.

woher das Schulgeld erfolge, wofern aber irgend wo der gleichen verlaßene Kinder sich finden solten, dieselben Nahmentl. anzuzeigen nach der hier unter befindl. Tabella.

In der Inspection N. finden sich an Kindern Quaestionis

\begin{tabular}{|l|l|l|l|}
\hline Nahme & Im Kirchspiel & Ort der Schule & Uhrsachen davon. \\
\hline
\end{tabular}

3.) Dabey habt ihr die Vorsicht so wohl selbst zu gebrauchen, als a. d. Predigern einzuschärffen daß die Frage überhaupt zwar nicht blos von Waisen, sondern auch von andern armen Kindern sey. In das specielle Verzeichniß aber nach dem Obigen keines weges alle arme Kinder zu bringen seyen, noch auch die für welche das Schul geld, nicht leicht, oder nicht ohne Mühe erhalten und bezahlet werden kan, noch sonst aus neben Absichten auf die Erleichterung der Eltern, Schul halter oder Cassen u.d.m. mehrere auf geführet werden sollen. ${ }^{33}$ als solche für welche schlechter dinges kein Schulgeld bezahlet werden können.

4:) Die Jenigen Schulmeister welche nach dem Zeuchniß der Prediger, das Schulgeld gantz oder zum Theil erlaßen haben, sind nach dem Orte wo sie jetzo stehen, uns bemerklich zu machen, sonderl. diejenigen welche ohne dem die gering sten Einkünfte haben. 
$[163 v]$

Contin. Chron: Obernjes. 1775.

5. Dabey ist auf alle weise zu verhüten, daß Niemand sich zur Erhaltung des Schulgeldes alhier unmittelbahr melde weil solches vergebl. seyn würde. Und zu dem Ende ist diese Nachfrage nicht ruchtbahr zumachen.

6): Als auch bey Einsendung der im Jahre 1769 geforderten Anschläge von dem Ertrage der Schulen nicht aus allen Inspectionen gemeldet worden, ob und an welchen Orten die Schulmeistern einen freyen Tisch haben so ist bey dieser Gelegenheit das Verzeich niß derselben jetzo von euch noch auf einen besondern Bogen beyzufügen fals dergleichen vorhanden sind.

Obgedachte Berichte erwarten wir von euch nebst dem hiebey gelegten Duplicate so von den Predigern mit dem praesentato zu un ter zeichnen, spätestens vor Ablauf des März Mohnahts d. J. Wir sind euch pp Han: d. 24Jan 75 K. Gr. C. Br. L. w. Geh. R. u z. Con. ver ordnete Praes. a. C. u K.R.

Von dem Busche ${ }^{334}$

An alle Superintendenten u Ministerio.

334 Königlich Großbritannisch Churfürstlich Braunschweig Lüneburgischer Würklicher Geheimer Rath und zum Consistorium verordnete Praesident auch Consistorial- und Kirchen Rahte. Von dem Busche. Hier handelt es sich um Christian Dieterich v.d. Busche, der von 1772 bis 1779 als Präsident des Konsistoriums amtierte (Амт, Die Bauverwaltung, S. 1) 
Diesem lag ein Verzeichniß der Praparen

den im Hannoverischen Schul-Seminario um

Neujahr 1775.

Auch ein Formular wie künftig die Confirmanden

einzusenden mit dem Verzeichniß.

[164]

Contin: Chron: Obernjesanae 1775.

Auf Vorstehendes habe unterm 8 März 1775

folgendes berichtet.

ad. 1mo quaestion: Superintendents. Eine Armen-Cassa wie

in der angezogenen hohen Verordnung de 6 Dec: 1702 verordnet

ist hier gar nicht. Ich habe zwar selbige in den Theuren

Jahren zu errichten gesuchet; Allein Ich fand bey allen

garzu viele Wiedersprüche, und für mich un über

windliche Schwierigkeiten, daher ich ermüdet die Sache

wieder liegen laßen. Es kan also dem $\$ 34$ nicht in

allem nachgelebet werden. So weit also die Einahme

des Armen Kastens reichet und die Zinsen von einem

Legato à 20 r. alhier und zu Dramfeld so viel wird

Schulgeld vor arme Kinder bezahlet. Bücher

aber können nicht gereichet werden, weil die Cassa

nicht so viel vermag. Unterdessen habe in Gegen

bey der dißjährigen Öfnung des Armen Kastens in

Gegenwart der Kirchen Vorsteher zu Obernjesa

6r. in ein Papier gefunden worin geschrieben: Von

den Zinsen dieser 6r. sollen jährlich 2 Catechis-

$m i$ für arme fleißige Schulkinder an geschaffet

werden. Dis ist der Wille des Gebers J.C.Z.

$\mathrm{Zu}$ Dramfeld fand der gleichen Papier mit

5r. und eben dieser Vorschrift unter den Buchstaben

J.C.Z. ${ }^{335}$ Ich werde nicht ermangeln diese Legata

335 In der Dramfelder Kirchenrechnung von 1774 heißt es, dass am 1. Weihnachtstag 1774 im Beichtstuhl der Dramfelder Kirche ebenfalls eine Spende von $5 r$. gefunden wurde, die in Papier eingewickelt und mit den Buchstaben M.C.S. gekennzeichnet war; der Pastor kommentierte die verbuchte Einnahme mit den Worten, dass dergleichen seit langen Jahren nicht geschehen sei (KiKrAGött P. A. Dramfeld K. R. I.a. Kirchenrechnung 1774). 
gehörigen Orts im Register in Einnahme zu bringen und davon aufs Jahr, nach vorher ein geholter Concession dHn. Super: Gebrauch zu machen suchen.

2. Die Hindernißen daß der Armen ihre Kinder und die Arme überhaubt nicht weiter unterstützet werden können bestehen darin; weil die ArmenCassa weiter keinen Zufluß als aus dem Armen Kasten hat; die StraffGelder aus dem Gerichte, Licent-Ord nungen, Gemeine etc: habe nicht erhalten können.

\section{[164v]}

Contin: Chron: Obernjesa. 1775.

3. Und weil ich nun schon vor einigen Jahren vor meine Persohn solche Zuflüße nach der Armen-Ordnung verschiedene mahle vergeblich gesuchet, so könte diesem meines Erachtens nicht anders abgeholfen werden als daß von Höherer Hand wegen der Armen-Ordnung ein Monitorium ${ }^{336}$ erginge. 4. Auf die Frage Ew: Hochehrwürden wären noch wohl derselben einige; Allein nach des Con: Decr: nro. 3. sind der gleichen keine hier.

5. Weder hier noch zu Dramfeld hat der Schul meister aus commiseration ${ }^{337}$ das Schulgeld geschenket, wohl aber einigen Armen schenken müßen, weil Nichts davon ohne weltlichen Arm zu erlangen gewesen.

[Am Rand] ist praesent. d. $5^{\text {tn }}$ März 1775.

Anno 1774 in Herbst wurde zu Obernjesa Visitation gehalten und $\mathrm{zu}$

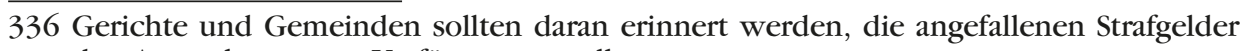
den Armenkassen zur Verfügung zu stellen.

337 Barmherzigkeit, Mitleid. 
gleicher Zeit die Kirchen Länderey aufs neue verpachtet; diese Verpachtung ist vom Königl. Consistorio in folgendem Rescripto ratihabiret. ${ }^{338}$

\section{Copia.}

Unsere pp

Die nach eurem Bericht vom 12 d.M.

in termino Visitation. zu Obernjesa

geschehene ander weite Verpachtung

des der dasigen Kirche zustehenden Landes

und der Wiesen von Petri Cathedra ${ }^{339} 1775$

bis dahin 1781 wird bewanten Umständen

nach von uns hirmit genehmiget. Wir sind pp

Hannover d. 26Jan: 1775.

Königl. pp Präsident auch Consistorial- und Kirchen Rathe

$N B$. war nicht unterschrieben von d. Busche.

\section{[165]}

Contin: Chron: Obernjes. 1775

Wegen schlechter Reisen und oft übler Witte rung auch der Kälte ist es dem Prediger höchst lästig nach Dramfeld zu reisen und so gleich kalt erfroren und naß in die Kirche zu gehen ohne sich erholen erwärmen und abtrocknen zu können, daher habe ich Pastor Henrich Phil. Stolberg Königl. Consistorio den Vorschlag eines Anbaus an die Dramfelder Kirche als eine zu heitzende Sacristey getahn, deßen von mir selbst gemachter Anschlag sich auf 41r. be tragen. Hier auf ist folgendes resolviret.

Unsere Freundl. Dienste und Wilfah-

338 Manchmal wird auch die Form ,ratifizieren' gebraucht (vgl. Mastnak, S. 98).

339 Petri Stuhlfeier; 18. Januar; seit Johannes XXIII. der 22. Februar (https://www.heiligenlexikon.de/BiographienP/Petrus_Fest_Cathedra_Petri.htm (16.8.2015)). 
rung zu vor, Ehrwürdiger, Hochgelahrter, auch Achtbahrer günstiger und gute Freunde. Wir haben erhalten, was auf Veranlaßen des Pastoris zu Obernjesa Ehrn Stolbergs, ihr, wegen Erbauung einer kleinen $\mathrm{Sa}$ cristey bey seiner filial-Kirche zu Dramfeld, an hero berichtet, und dabey mit ein geschicket habet. Ob wir nun wohl bey denen darin an geführten Umständen Uns geneigt finden, diesen vorgeschlagenen Anbau an die Kirche zur Bequemlichkeit des Predigers zu genehmigen so mag doch solches nicht anders, als von dem Uberschuße der Kirche geschehen. Ihr habt daher zu berichten in wie fern der gegen wärtige Vorraht, dar zu hinreichet; oder Pastor

\section{$[165 v]$}

Contin: Chron: Obernjesanae 1775.

das Fehlende vorschießen und die Erstattung nach und nach von den Uberschießenden Geldern der Kirche gewärtigen wil? Imgl. da der Anschlag keines Ofens erwähnet, auf welche Ahrt Pastor die von ihm zu stehende Feuerung beschaffen wil? Und in wie fern weder da durch, noch durch die Durch Brechung der Kirchen-Mauer einige Besorgniß für das Kirchen Gebäude entstehe? Weil endlich bey der Incl. der Sohle nur auf 8 Fuß angenomenen Höhe die Stube zu Niedrig ausfallen; mit hin selbiger nach Beschaffenheit der Lage noch etwas zu zu geben seyn würde, die Schwelle auch über all, wenigstens $1 \frac{1}{2}$ Fuß in die Höhe gebracht und untermauret werden muß, so habt ihr anzuzeigen, wie viel durch bey des der hiebey zurück kommende Anschlag erhöhet werden dörfte. Wornach weitere resolution er folgen 
soll. ${ }^{340}$ Wir sind euch $\mathrm{zu}$ freundl. Diensten

geneigt. Hannover d. 16Jan: 1775.

Königl. Grb. u. Churf. Br. Lüneb. Würklicher

Geheimter Raht u. zum Consistor. verordnete

Praesident auch Consistorial u. Kirchen Rahte

v d Busche

An die Kirchen Comissar.

zu Obernjesa. soll vielleicht

Dramfeld heißen.

[rechts unten der Name des Schreibers:] Unruh

[166]

Contin. Chron: Obernjesan: 1775.

In einem Monito Consistoriali über die

Kirchen Register wundert sich Königl. Consistor:

daß bis hie her vom Witwen Hause in den Re gistern noch keine Miethe berechnet wäre es wird darauf geantwortet, wie das die Witwe noch lebe ${ }^{341}$, und nach deren Ableben die Gemeinen

Obernjesa und Dramfeld sich wägern würden solches zuzulaßen daß die Kirche das Hauß vermiete, und so würden sie ferner Nichts daran repariren. Darauf ist folgendes rescri-

biret:

340 Die Sakristei wurde tatsächlich und zwar im Zuge des gründlichen Umbaus der Dramfelder Kirche in den Jahren 1776 bis 1777 gebaut. Der hier vom Pastor zitierte Brief ist nur eines der vielen Schreiben, die im Vorfeld der sogenannten Hauptreparation der Kirche zwischen Gemeinde, Kirchenkommissarien und Konsistorium - insbesondere über die Frage der Finanzierung - gewechselt worden sind (vgl. Kleineke in: GöJb 63, 2015, S. 48).

341 Hier handelt es sich um die Witwe des Pastors Lotze, die 1775 starb. Die Mutter des Pastors Johann Philipp Stolberg war bereits 1762 gestorben; vgl. BIELEFELD 1957, S. 58, 59. 
Unsere pp ...voller Tittel

Uns ist aus der ad Monitum Consistor: $6 .^{342}$ über

die Rechnung der Kirche zu Obernjesa bey gebrach-

ten Beantwortung referiret: aus welchen

Grunde die dasige Gemeine sich wegert, die

reparations Kosten an dem dasigen Pfarr

Witwen Hause zu übernehmen. Ihr habet nun

die Gemeine zu bedeuten, daß zwar demnächst

die Mieth Gelder von sothanen PfarrWitwenhause

in der Kirchen Rechnung zur Einnahme gebracht,

dabey aber genau bemerket werden solle, wie

viel davon unter den Kirchen Vorrathe begriffen

um davon bey vorfallender Gelegenheit, die

Bau- u Reparations-Kosten, welche behuef

des mehr gedachten Witwen Hauses, nöthig

sind, bestreiten zu können. Und wie solchem

nach die Einwendung der Gemeine, hin durch

wegfält, so bleibet sie auch inso ferne dermahlen un-

ter dem Kirchen Vorrathe keine MietGelder vom Witwen

Hause vorrähtig, zu Bestreitung der gegen wärtigen

erforderlichen Reparations-Kosten verbunden. Wir sind euch pp

Hannover d. $31^{\text {tn }}$ Jan: 1775. K.Gr. C. Br. Lüb. würkl. G. Raht

u. z. Cons. verord. Praes. a. C. u K.R. vdBusche

[Ende der Eintragungen des Pastors Johann Philipp Stolberg]

[Beginn der Eintragungen des Pastors Bornträger]

342 Das Konsistorium hatte mehrere Vorgänge in der Obernjesaer Kirchenrechnung gerügt und eine Erklärung gefordert; hier bezieht man sich auf die Antwort auf Rüge Nr. 6 . 



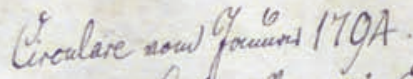

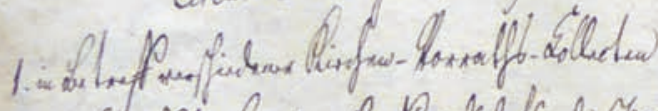

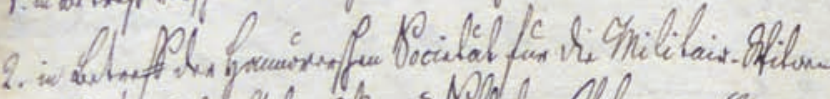

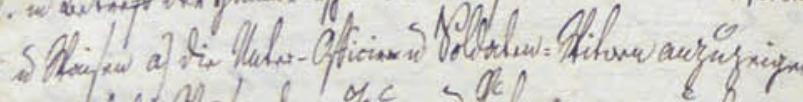

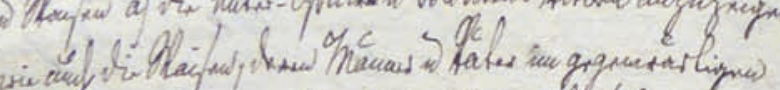

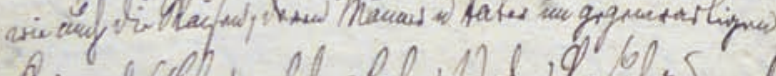

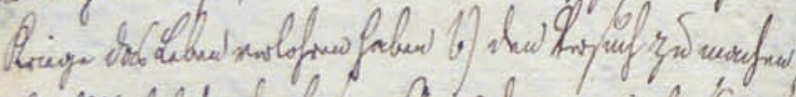

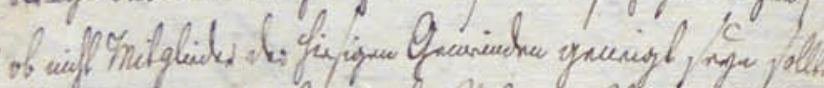

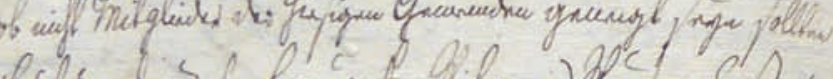

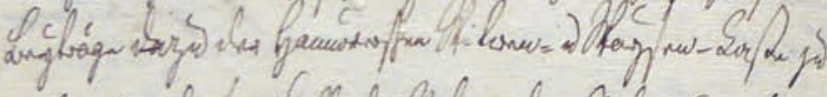

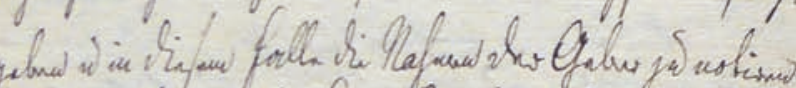

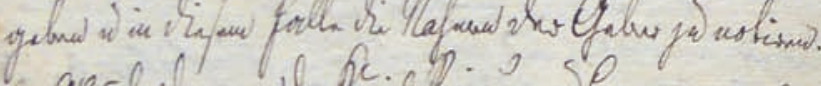

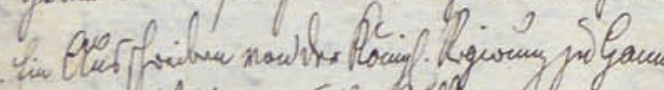

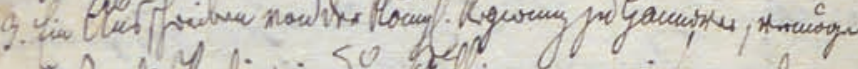

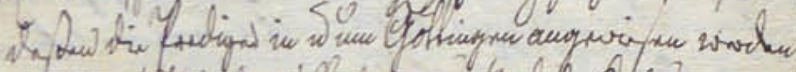

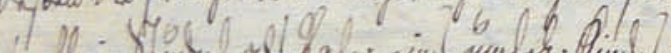

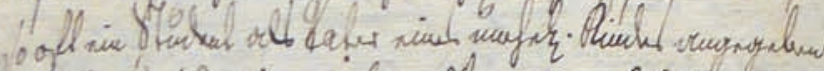

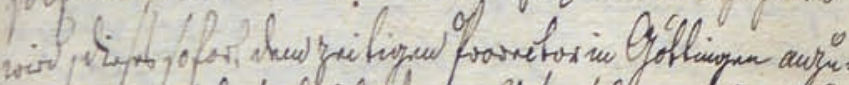

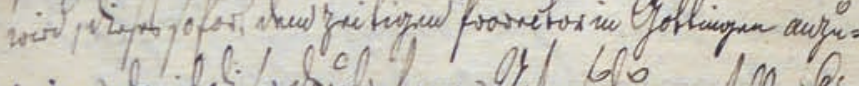

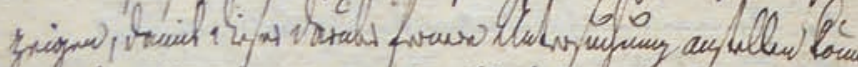

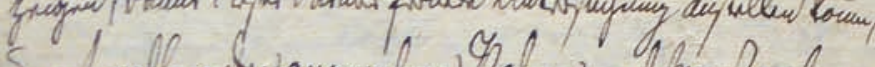

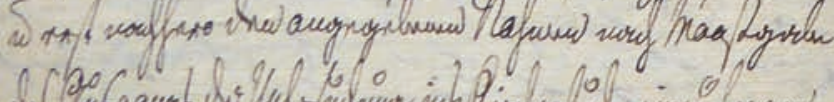

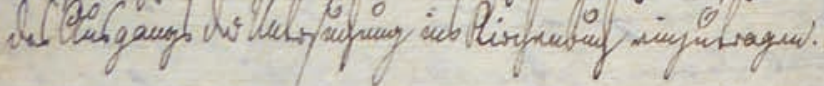




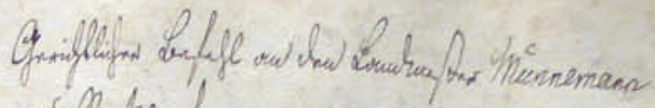

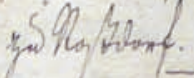

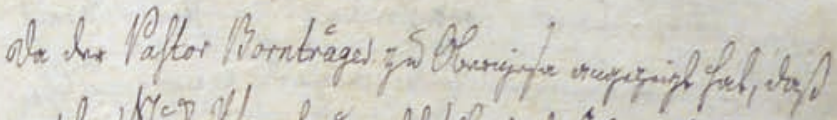

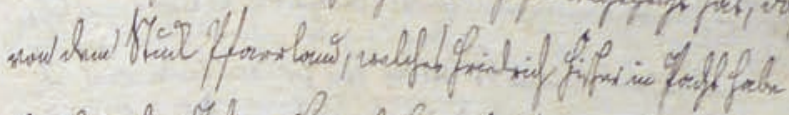

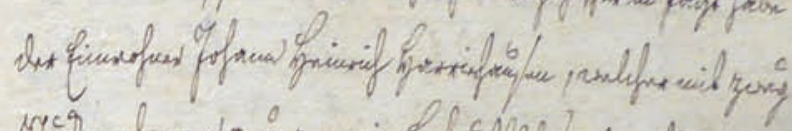

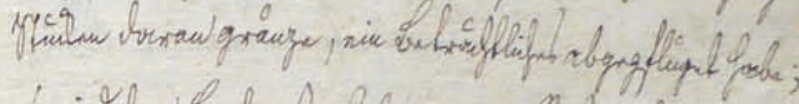

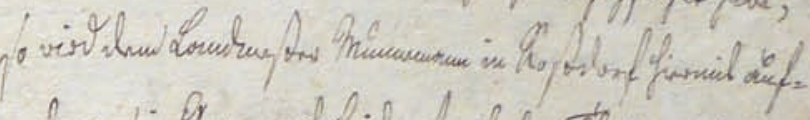

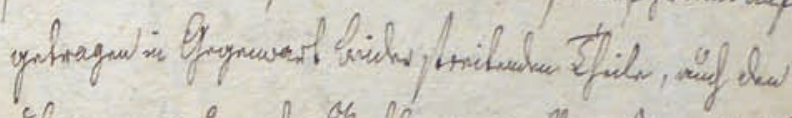

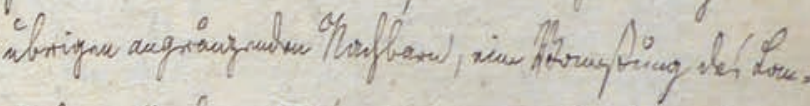

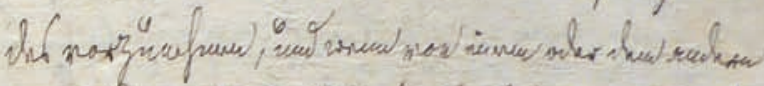

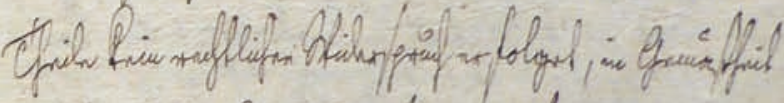

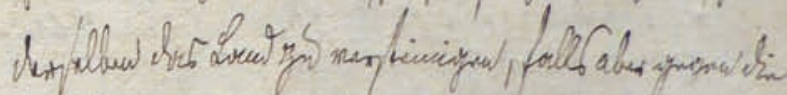

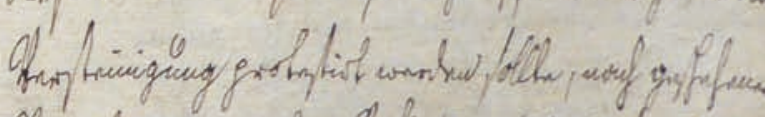
of $A 6$ if $\&$ ic

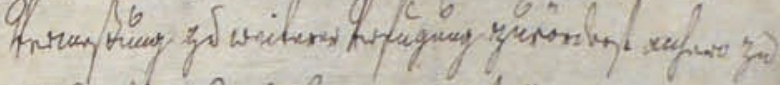

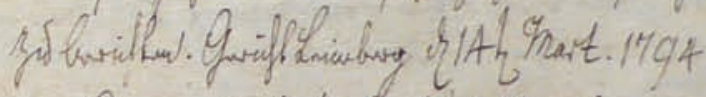

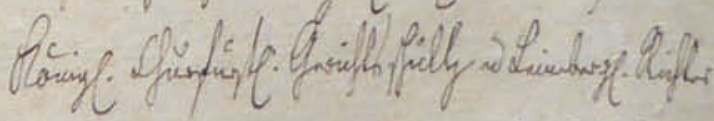

$$
\begin{aligned}
& \text { C.F.L. Pachevia }
\end{aligned}
$$


$[166 v]$

Circulare vom Januar 1794.

1. in Betreff verschiedener Kirchen-Vorraths-Collecten

2. in Betreff der Hannoverschen Societät für die Militair-Witwen

u. Waisen a) die Unter- Officiere u. Soldaten-Witwen anzuzeigen, wie auch die Waisen, deren Männer u. Väter im gegenwärtigen Kriege das Leben verloren haben b) den Versuch zu machen, ob nicht Mitglieder der hiesigen Gemeinden geneigt seyn sollten Beyträge dazu der Hannoverschen Witwen- $u$. Waysen-Caße zu geben $u$. in diesem Falle die Nahmen der Geber zu notiren.

3. Ein Ausschreiben von der Königl. Regierung zu Hannover, vermöge deßen die Prediger in u. um Göttingen angewiesen werden, so oft ein Student oder Vater eines unehel. Kindes angegeben wird, dieses sofort dem zeitigen Prorector in Göttingen anzuzeigen, damit dieser darüber fernere Untersuchung anstellen könne, u. erst nachhero den angegebenen Nahmen nach Maaßgabe des Ausgangs der Untersuchung ins Kirchenbuch einzutragen. ${ }^{343}$

[167]

Gerichtlicher Befehl an den Landmeßer Münnemann zu Roßdorf.

Da der Pastor Bornträger zu Obernjesa angezeigt hat, daß von dem Stück Pfarrland, welches Friedrich Fischer in Pacht habe der Einwohner Johann Heinrich Harriehausen, welcher mit zwey Stücken daran gränze, ein Beträchtliches abgepflüget habe; so wird dem Landmeßer Münnemann in Roßdorf hirmit aufgetragen in Gegenwart beider streitenden Theile, auch den übrigen angränzenden Nachbarn, eine Vermeßung des Landes vorzunehmen, und wenn von einem oder dem andern Theile kein rechtlicher Widerspruch erfolget, in Gemäßheit derselben das Land zu versteinigen, falls aber gegen die Versteinigung protestirt werden sollte, nach geschehener

343 Ein Student unterstand grundsätzlich der Gerichtsbarkeit der Universität. 1793 war eine Verordnung erlassen worden, nach der Alimentations- und Satisfaktionsklagen nur vor dem Universitätsgericht erhoben werden durften. Wenn es in der Literatur heißt, dass in der zweiten Hälfte des Jahrhunderts häufig der Pfarrer die Geburt anzeigte, wenn ein Student als Vater angegeben wurde (BRÜDERMANN, S. 405), liegt das vermutlich daran, dass die Pastoren den Aufforderungen der hannoverschen Regierung nachkamen und diese Väter meldeten. 
Vermeßung zu weiterer Verfügung zuvörderst anhero zu

zu berichten. Gericht Leineberg d. 14tn. Mart. 1794

Königl. Churfürstl. Gerichtsschultze und Leineberg. Richter

C.F.L. Zachariae.

$[167 \mathrm{v}]$

Circulare vom 26ten May 1794

1) auf die richtige Führung der Schulregister, sowie es auf dem Titelblatte derselben vorgeschrieben ist $\mathrm{zu}$ achten $\mathrm{u}$. darauf zu halten, daß diejenigen Kinder, welche die Catechismuslehre versäumen gehörig bemerkt werden und zu dem Ende auch die Schulmeister zu erinnern, daß die bereits confirmirten Kinder in dem Schulregister mit der Ueberschrift: Confirmirte Kinder oben an stehen müßen

2) Die Schulmeister anzugeben, welche die Schulregister nicht gehörig führen und das Schreiben und Kopfrechnen in der Schule hintansetzen.

3) auf die Kinder sorgfältig zu merken, die noch nicht fertig lesen können, damit ihnen in der öffentl. Schule oder privatim könne nachgeholfen werden, sonst sie um Michael. zum Pfarrunterricht unter den Confirmanden nicht anzunehmen 4) Durch die Schulmeister für die Militair-Witwen- u. WaysenSocietät sammeln zu laßen u. für jeden r. 3g. ihnen gut zu thun.

[168]

Pro memoria wegen des an die hiesige Pfarre gehörigen sogenannten Knickgartens. ${ }^{344}$

Diesen Garten habe ich im Jahre 1794 an die Geschwister Salzmann, da der ihnen zugehörige Garten unmittelbar an denselben angränzt, für 1r.27g. Courant. Münze jährliches Pachtgeld vermiethet. Die Veranlaßung, welche mich hierzu bewogen hat, gab die Erfahrung der Unmöglichkeit das Obst des Gartens gegen Dieberey zu schützen, weshalb nämlich der Garten für die Pfarre mehrentheils ohne Nutzen war und nur Verdruß verursachte. Damit indeß, weil ich es den

344 Knick = lebende Hecke als Teil der mittelalterlichen Dorfbefestigung. Das Pfarrgrundstück reicht auch heute noch bis an das Gelände der ehemaligen Dorfbefestigung im Westen der Ortschaft heran (vgl. SCHRÖDER, GöJb. 38, 1990, S. 29). 
Geschwistern Salzmann auf ihre Bitte gestattet habe den Zaun zwischen dem Pfarrgarten und dem ihrigen wegzunehmen, die Pfarre selbst in der Folge durch Verrückung der Gränzen nicht lädirt werden könne: so habe ich am 9tn. 7br. 1794 den Inhalt des Pfarrgartens durch den Landmeßer Mündemann von Roßdorf ausmeßen laßen, wodurch sich dann ergab, daß der Inhalt deßelben 21 Ruthen 16 Fuß betrage. Weil die Geschwister Salzmann der Meynung sind, als habe der Knickgarten einst dem Hofe zugehört, den sie jetzt besitzen, und sey hernach bloß für $7 \mathrm{r}$. an

\section{$[168 \mathrm{v}]$}

an die Pfarre versetzt, so daß es also ihnen frey stehe die Wiedererlangung des eigenthümlichen Besitzes des Gartens gelegentlich zu suchen: so füge ich noch die Bemerkung hin$\mathrm{zu}$, daß sich in der hiesigen Pfarr-Registratur und zwar unter den in einem metallenen Kästchen verwahrten Papieren der gerichtliche förmliche Kauf-Receß wegen dieses Gartens befinde, aus welchem erhellt, daß der Garten nicht versetzt sondern im Jahre 1675 dem damaligen Pastor M. Christoph Jani behuf der Pfarre für 7 r. erb- und eigenthümlich verkauft sey. Obernjesa d. 9tn. 7br. 1794.

J. C. F. Bornträger

[169]

Circulare vom 13ten. Septembr. 1794.

1) am 20tn. oder 23tn. hujus die Michaelis-Gefälle ${ }^{345}$ einzusenden

2) $29 \mathrm{mg}$. als Beytrag zu dem für jede Inspection anzuschaffenden Willichschen Auszüge der Calenbergischen LandesGesetze $^{346}$ nebst 4g. von Dramfeld einzuschicken und sich

345 Abgabe zu Michaelis.

346 Die in alphabetischer Reihenfolge ausgeführte Gesetzes- und Verordnungssammlung umfasst drei Bände, die in den Jahren 1780 bis 1782 erschienen: Churfürstliche Braunschweig-Lüneburgische Landes-Gesetze und Verordnungen Calenbergischen und Grubenhagenschen Theils in einen Auszug nach alphabetischer Ordnung gebracht von Friedrich Christoph Willich (1745-1827) der Rechte Doctor, und Actuarius der GeorgAugust Universität. Der zweite Band kostete immerhin 2r.4ggr. 
deshalb auf das deshalb vom Consistorio eingegangene Rescript vom 1tn. Julii 1794 zu beziehen.

3) anzuzeigen ob die Dächer auf dem Pfarr- und Schulhause reparirt seyn ${ }^{347}$

4) den Schulmeistern aufzugeben die Schulregister vom gegenwärtigen Sommer halben Jahre in den 1sten Tagen des Octobr. einzuliefern und sie sodann bis zum 7 ten 8 br. einzusenden.

[169v]

Nachricht die hiesige Pfarrländerey betreffend. Bey meiner Antretung der hiesigen Pfarre habe ich folgende Einrichtung der Benutzung der Pfarrländerey und folgenden Betrag derselben an Morgenzahl vorgefunden:

1) an Andreas Seuffer sind verpachtet 48 Morgen $1 \frac{1}{2}$ Vorling

2) an einzelne Pächter sind verpachtet

3) an Poppe in Sieboldshausen ist verpachtet

4) an Fr. Pastorin Stolberg ist verpachtet

5) die Pfarre hat in eigner Kultur 45

1
$1 / 2$ " 1 18 " 1

Summa: 114 Morgen

$\mathrm{Zu}$ diesen 114 Morgen gehören noch als eigentliches Pfarrland 6) 6 Morgen Ackerland, welche die verwitwete Fr. Pastorin Stolberg jetzt im Besitz hat und welche nach deren Ableben an die Pfarre zurückfallen vide supra $p .4$.

\section{Notanda}

1) In dem mit Andreas Seuffer von meinem Vorgänger dem Hn. P. Gräffe errichteten Pacht-Contracte fand ich nur 48 Morgen angegeben; bey genauer Erkundigung fanden sich jedoch 1 1/2 Vorl. mehr. 2) Nach den älteren Specificationen als nach a) der von 1619 von Matth. Schwarz b) der von 1664 von Andr. Siburg und c) der von M. Stolberg von 1738, machen 122 M. die Pfarrländerey aus.

347 Bereits während der Amtszeit des Pastors Graeffe war unter dem 16. Februar 1790 ein Ausschreiben des Konsistoriums ergangen, das die Kirchenkommissarien aufforderte, die Kirchen- und Pfarrgebäude öfters zu begutachten und über den Reparaturbedarf zu berichten (vgl. WILLICH, Supplementband, S. 31, 32). 
Nach dem obigen besteht sie jetzt aus 120 M. und, wenn man den Gemüse-Garten, der ehemals Ackerland gewesen ist, dazu rechnet, aus 120 M. 1 1 1/2 Vl., so daß also 1 M. $1 / 2$ Vl. fehlen.

[170]

Circulare vom 5 tn. xbr. 1794.

1. Ausschreiben des Consist., nach welchem die zu confirmirenden Kinder d. 1 tn. May 14 Jahre alt seyn müßen u. nur fahigen u. fleißigen Kindern 3 Monathe erlaßen werden sollen.

2. Die Verzeichnisse der Conf. u. Paroch. Listen in der vollen Woche nach dem $N_{\text {: }}$. einzusenden.

Consistorial-Rescript in Betreff einer Reparation der Uhr und des Jahrgeldes an den Uhrmacher.

Unsere $\mathrm{pp}$

Da in der Kirchen-Rechnung von Obernjesa vom Jahre 1792, pag.

32 ein Jahrgeld für den Uhrmacher von 18mg., welches seit 3 Jahren nicht bezahlt ist, nebst den Kosten einer Haupt-Reparation der Uhr von 1790 mit 5r.16g. 4d ante lineam ${ }^{348}$ gesetzt und darüber vom Rechnungsführer in der Beantwortung ad Mon. Cons. 9 über die Rechnung von 1790 Verhaltungsbefehle erbeten worden: so bewilligen wir für dasmal und ohne Consequenz, daß die gedachte Reparations-Kosten in Ausgabe aufgeführt werden, künftig aber dürfen im Kirchen-Register nur die kleinen Reparaturen berechnet werden, welche die Summe von 5 r. nicht überschreiten, widrigenfalls die Gemeine solche aufzubringen verbunden ist.

verte

170v]

Das dem Uhrmacher ausgesetzte Jahrgeld von 18mg. kann jedoch ferner mit Beziehung auf dieses Rescript pag. 32 in Ausgabe gebracht werden. Wir überlaßen euch demnach

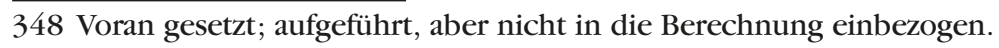


hiervon dem Rechnungsführer Nachricht zu geben und sind pp Hannover d. 25t. September 1794.

Königl., wirkl. Geh. Rath u.s.w.

Circulare vom 14tn. Jan. 1795.

1) Die verlangten Catechismen am $24 t$. huj. abhohlen zu laßen

2) Ankündigung einer Becken-Collecte behuf des neuen

Kirchenbaues zu Hettensen, Inspection Hardegsen.

[171]

Nach der Instruction de 1778 in Betreff der jährlich einzusendenden Parochial-Listen ist bey der Abfaßung derselben folgendes zu merken:

1) wenn $Z$. b. Jemand stirbt der gerade $15 \mathrm{Jahr}$ alt ist, so wird derselbe noch in die Claße derer zwischen 10 und 15 Jahren gesetzt.

2) in die Bemerkungen gehört die Anzeige

a) wegen Zwillings- u. Drillings-Gebuhrten nebst deren Zahl.

b) ob die Todtgebohrnen eheliche oder uneheliche Kinder waren

c) des bestimmten Alters und der Lebens-Umstände eines über 100 Jahre alt gewordenen

d) der Veranlaßung eines Plus der Gestorbenen als der Gebohrnen

e) anderer besonderer merkwürdigen die öffentl. Gesundheit oder den Bevölkerungs Zustand betreffender Notizen.

[171v]

Ausschreiben des Königl. Cons. vom 7 ten März 1795.

Unsere $\mathrm{pp}$

Es ist diensam gefunden, die bey den Kirchen- und andern geistlichen Aerariis vorräthigen Gelder, in so fern sie bey den laufenden Ausgaben zu entbehren stehen, fordersamst anhero einsenden zu laßen, damit sie demnächst erforderlichen Falls, an einem sichern Ort aufbewahrt werden mögen. Ihr habt diesemnach an die Euch untergebenen Rechnungsführer so fort zu verfügen, daß sie auch den bey ihnen, oder auch in der Kirchenlade vorhandenen baaren Geldvorrath, soweit er entbehrlich 
ist, nebst einem genauen Sortenzettel ${ }^{349}$ in Absicht der Münzsorten, nach beyliegenden Modell, gegen eure Interims-Quitung baldthunlichst abliefern: worauf solches nebst einer doppelten Abschrift jenes Sortenzettels, in besonderen für jedes Aerarium zu bezeichnenden Beuteln, in einem gemeinsamen Umschlage, unter der Addresse: Kirchengelder an Königl. Consist. zu Hannover, anhero mit der Post einzusenden ist.

Wir zweifeln nicht an möglichst sorgsamer Beschleunigung dieses Geschäftes, und werden die daher entstehenden

\section{[172]}

Ausgaben auf die Aeraria zu repartiren seyn. Auch gewärtigen wir das Duplicat dieses Ausschreibens, welches von jedem Rechnungsführer, da es ihm zur Notiz kommt, mit Anführung des Tages und seines Nahmens zu unterschreiben ist, ad acta zurück. -

349 Der Sortenzettel enthielt die seinerzeit anerkannten, d.h. die gültigen Münzsorten. 


\section{Sorten-Zettel}

Von der $\{$ Kirche $\}$ zu...

$\{$ Capelle $\} \ldots$

dem Aerar-Register zu...

werden hierbey geliefert

\begin{tabular}{|l|c|c|c|}
\hline & Thaler & Mg. & Pf \\
\hline in Pistolen zu 7 Gulden & - & - & - \\
\hline in Ducaten zu 4 Gulden & - & - & - \\
\hline in Goldgulden zu 2 r. & - & - & - \\
\hline $\begin{array}{l}\text { in Caßenmäßiger Silbermünze als } \\
\text { 24g. 6g. 4g.350 }\end{array}$ & 1 & 28 & - \\
\hline 3 Mariengroschen ${ }^{351}$ & 3 & 18 & - \\
\hline 2 Mariengroschen & 2 & 30 & - \\
\hline guten Groschen & 2 & 18 & - \\
\hline kleiner Silbermünze & 1410 & 1423 & - \\
\hline in gedachter Kupfer Münze & - & - & - - \\
\hline (in Conventions-Geld & 68 & 297 & - \\
\hline für voll gerechnet & 75 & - & \\
\hline \multicolumn{1}{|c|}{ Summa ${ }^{352}$} & & & - \\
\hline
\end{tabular}

\section{$[172 v]$}

Anliegendes Pro memoria des Hn. Sup. Luther. vom 16tn. März 95.

- - 2) daß jeder Rechnungsführer in der künftigen Woche spätestens am Mittwochen oder Donnerstage schriftlich oder mündlich anzeige, wie viel Kirchengeld 1) bey ihm 2) in der Kirchen-Lade 3) bey den Vorstehern in Verwahrung liege

350 In Münzen mit dem Nennwert von 24g., $6 \mathrm{~g}$. und 4g; vermutlich sind die sog. Zweidrittelstücke, Kasseneinsechstel und Kasseneinneutel gemeint (GERHARD, 200 Jahre Sparkasse, S. 416).

351 Ein 3Mariengroschenstück wurde auch als Einzwölftelstück bezeichnet (GERHARD, 200 J. Sparkasse.)

352 Keine Angaben. 
und wieviel nach seiner Meinung davon zu bestimmten Ausgaben, die dabey zu bemerken sind, zurückbleiben müße.

\section{Circulare vom 15tn. May 1795}

4) am Schluße dieses Monaths auf einem besondern Blatte, nach beyliegenden Formularen anzuzeigen

a) was sich für enorme ${ }^{353}$ Absenten theils in der Schule und theils in den öffentlichen Catechismuslehren in dem verfloßenen Monathe gefunden haben, damit bey der weltl. Obrigkeit die nöthige Hülfe besorgt werden könne. - Die dabey bewiesene Accuratesse solle bey jedesmaliger Einsendung der halbjährigen Berichte dem Königl. Consistorio namentl. angezeigt $u$. dadurch bemerklich gemacht werden, wie dem geschärften Monitorio vom Jahre 1737, welches sich Tomo I Const. Calenberg. pag. $924^{354}$ findet, die gehörige Folge geleistet sey.

$\mathrm{Zu}$ den enormen Absenten sind diejenigen Kinder zu rechnen, welche ohne gegründete Ursache, um derentwillen sie Urlaub

\section{[173]}

gesucht haben

1) die Sommerschule eine ganze Woche

2) die sonntägl. Catechismuslehren 2 mal hinter einander versäumet haben, wobey anheim gegeben werde, ob Ew.- es nöthig finden, in der nächsten Predigt oder Catechismuslehre die Eltern nochmals daran zu erinnern, daß sie es dem Schullehrer gehörig anzeigen, wenn sie gegründete Ursache finden, weshalb sie ihre Kinder zuweilen nicht zur Schule oder in die sonntägl. Catechismuslehre schicken können. b) ob sich unter denjenigen Kindern, die jetzo $13 \mathrm{Jahr}$ alt sind u. daher auf Michael. dieses Jahrs dem Pfarr-Unterrichte beywohnen dürften, solche finden, die noch nicht fertig zu lesen im Stande sind u. deren

353 Im Sinne von ungewöhnlich, außergewöhnlich, auffällig; vielleicht auch von ungewöhnlich großer Anzahl.

354 Erster Band der Verordnungen und Gesetzessammlung Chur- und Fürstl. BraunschweigLüneburgische Landes-Constitutiones und Verordnungen in drei Bänden. 
Rel. Erkenntniß noch sehr schwach ist, damit für selbige in Zeiten durch Privatstunden in den Schulen gesorgt werden könne; -n c) ob erwachsene Schulkinder vorhanden sind, die sich in den öffentl. Schulstunden, dem gedruckten Ausschreiben des Königl. Consist. vom 7t. April 1785 gemäß, noch nicht im Schreiben üben - auch die Schullehrer nach $\$ 110$ \& 150 des Methodenbuchs das Corrigiren des Geschriebenen am Rande des Schreibbuches non versäumen.

5) In den Schulen darauf zu halten, daß die Wochen Gesänge nach pag. 47 des Methodenbuchs non hintangesetzt u. den Kindern zugleich erklärt werden - Es würde gut seyn, wenn die Kinder erster Classe mit der Bibel u. dem Gesangbuche besonders mit dem Anfange eine Woche oder einen Tag um den andern bey den Leseübungen abwechselten.

\section{[173v]}

6) bey den BeweisSprüchen, welche die Kinder aus dem Catechismus auswendig gelernt haben, darauf zu achten, daß sie selbige von selbst anzufangen wißen, ohne daß es nöthig sey sie ihnen den ersten Worten nach vorzusagen. - Auch die Wiederhohlung des Auswendiggelernten, wozu sich in der Instruction für Schullehrer in der Mitte von p.3 eine besondere Anweisung wegen der Sommerschule findet, den Schullehrern bestens zu empfehlen.

7) die geübten Kinder dazu anzuhalten das Pred Thema der Predigt nebst deßen Eintheilung aufzuschreiben, damit sie theils den Nutzen des Schreibens dabey anerkennen theils zum Behalten der Predigt angewöhnt werden $u$. in der Schule bey der Wiederhohlung der Fragen Predigt in der Schule, nach \$135 des Methodenbuchs, gehörig antworten können.

8.) es sey durch ein Rescr. Cons. angezeigt, daß die zur Einsendung nach Hannover bestimmten Kirchengelder in hiesiger Gegend bald möglichst zinsbar belegt werden mögten u. auf jede dazu vorfallende Gelegenheit zu achten. - Auch künftig kein Convent. Geld bey Kirchen-Gefällen, da dieses vom Königl. Cons. ausdrückl. untersagt sey, anzunehmen. 


\section{[174]}

\section{Ad Nro 4 a gehörige Formulare}

Die Kinder welche zu Obernjesa und Dramfeld, welche 13 Jahr alt sind und noch nicht fertig lesen können oder schwach in ReligionsErkenntniße sind

\begin{tabular}{|l|c|c|c|}
\hline \multicolumn{1}{|c|}{$\begin{array}{c}\text { Die Nahmen der } \\
\text { Aeltern }\end{array}$} & \multicolumn{2}{|c|}{$\begin{array}{c}\text { Die Nahmen der Kinder } \\
\text { welche schwach sind } \\
\text { im Lesen Rl.Erkenntniße }\end{array}$} & Die Ursache davon \\
\hline $\begin{array}{c}\text { 1) N.N. ein unbe- } \\
\text { mittelter Ackermann } \\
\text { 2) N.N. eine Tage- } \\
\text { löhner Witwe }\end{array}$ & Jo. Heinrich & Anne Cathrine & $\begin{array}{c}\text { Oeftere Versäumniß } \\
\text { der Schule }\end{array}$ \\
\hline 3) N.N. ein Invalide & Jo. Wilh. & Jo. Wilhelm & Schwäche des Verstandes \\
\hline
\end{tabular}

\section{Verzeichniß}

der erwachsenen Kinder in der Schule zu - welche sich im Schreiben üben könnten aber solches bisher versäumet haben

\begin{tabular}{|l|l|l|l|}
\hline Die Nahmen der Aeltern & Die Nahmen der Kinder & Alter & Die Ursache davon \\
\hline $\begin{array}{l}\text { 1) N.N. ein unbemittelter } \\
\text { Tagelöhner }\end{array}$ & Friedr. Wilhelm & 12 Jahr & Mangel an Papier \\
2) N.N. Ein Leineweber & Anne Margarethe & 13 Jahr & Mangel an Fleiß. \\
\hline
\end{tabular}

Verte 


\section{$[174 v]$}

Verzeichnis

der erwachsenen Kinder in der Schute zu -

Enorme Absenten

vom Monathe May 1795

\begin{tabular}{|l|c|c|c|c|}
\hline $\begin{array}{c}\text { Die Nahmen der } \\
\text { Aeltern }\end{array}$ & $\begin{array}{c}\text { Die Nahmen der } \\
\text { Kinder }\end{array}$ & Alter & $\begin{array}{c}\text { In der Schule } \\
\text { gefehlet }\end{array}$ & $\begin{array}{c}\text { In der } \\
\text { Catechismuslehre } \\
\text { ohne Urlaub } \\
\text { gefehlt }\end{array}$ \\
\hline $\begin{array}{c}\text { 1) N.N. ein dürftiger } \\
\text { Tagelöhner }\end{array}$ & $\begin{array}{c}\text { N.N. Confirmirt } \\
1794\end{array}$ & $15 \mathrm{Jahr}$ & - & $3 \mathrm{mal}$ \\
$\begin{array}{l}\text { 2) N.N. eine } \\
\text { Ackermanns } \\
\text { Witwe }\end{array}$ & $\begin{array}{c}\text { N.N. Confirmirt } \\
1795\end{array}$ & $14 \mathrm{Jahr}$ & - & $2 \mathrm{mal}$ \\
3) N.N. ein Invalide & N.N. - & $12 \mathrm{Jahr}$ & $\begin{array}{c}4 \text { mal (NB } \\
\text { dies bedeutet } \\
\text { halbe Tage }\end{array}$ & 3 mal \\
\hline
\end{tabular}

Auszug aus einem Circulare vom 5tn. Jun. 1795. betreffend die zu übernehmende Vicariat-Arbeit zu Rossdorf nach dem Absterben des Hn. P. Eikemeyer. ${ }^{355}$

1. Die Actus ministeriales ${ }^{356}$ abwechselnd von einer Woche zur andern mit Hn. P. Mullert zu Mengershausen ${ }^{357}$ u. Hn. $P$. Mylius $^{358}$ zu Grone zu übernehmen

2. wegen der sonntägl. Arbeiten die Anzeige vom Cantor

355 Gottlieb Karl Eikemeyer (Meyer, Pastoren II 113, II 325).

356 Die dienstlichen Verrichtungen eines Pastors wie Taufen, Trauungen, Konfirmationen und Beerdigungen.

357 Gemeint ist Pastor Muhlert in Mengershausen.

358 Ludwig Eberhard Mylius (Meyer, Pastoren I 352). 
[175]

Fromme 14 Tage zuvor zuerwarten

3. Diejenigen, die sich zur Proclamation ${ }^{359}$ melden, nach Göttingen an dHn. Superint. Lutter zu weisen.

Auszug aus einem Circulare vom 24t. Jun. 1795

1) wegen der 13 jährigen Kinder den Aeltern derselben vorzustellen ob sie ihre Kinder nicht nur in die öffentl. Schulstunden sondern auch in eine vom Schullehrer täglich zu haltende Privatstunde schicken wollen, wofür von jedem Kinde dem Schullehrer wöchentl. 1g. zu geben sey und für arme Kinder aus der Armen-Caße bezahlt werden könne. Nur diejenigen Kinder würden Michael. unter die Confirmanden anzunehmen seyn, welche in diesem gedoppelten Unterrichte so weit gekommen wären, daß sie nicht nur im Catechismo sondern auch im Gesangbuche fertig lesen können. (es solle sich dieses jedoch 2) nur auf gegenwärtigen Sommer erstrecken, von nun an hätten die 12 jährigen Kinder dahin zu trachten, daß selbige durch fleißigen Besuch der Schule u. durch eignen Fleiß im Hause das Lesen gehörig lernten)

2) Diejenigen enormen Absenten, welche es noch im Monath Jul. blieben, sollen der weltl. Obrigkeit zur Bestrafung angezeigt werden $u$. sollen uns bey dem nächsten PfarrUnterrichte als Zuhörer nicht aber als Confirmanden zugelaßen werden. Die auswärts Dienenden sollen von dem Prediger, in deßen Gemeine sie gedinet, eine Bescheinigung

\section{[175v]}

beybringen daß sie die Sommerschule u. die sonntägl. Catechismus lehren besucht hätten

3) auf das Schreiben aller Kinder zu halten wie auch auf die Aufschreibung des Thema der Predigt u. die nachläßigen Kinder herunter zu setzen.

359 Anmeldung zur Konfirmation. 
Auszug aus einem Circulare- Schreiben vom 18tn. Aug. 95. Am 29tn. buj. oder am 5tn. 7br. die Revis. und Douceur-Gelder einzuschicken.

nochmalige Erinnerung an den Inhalt des vorstehenden Circulare Vorschläge zu thun, u. Anschläge einzuschicken, wie dafür gesorgt werden könne, daß die Kinder in der Kirche während der Catechismuslehre und des Pfarrunterrichts zum Sitzen kommen mögten, weil das lange Stehen die Aufmerksamkeit ermüde.

Circulare-Schreiben vom 30tn. 7br. 95

Rescript Königl. Consist. unterm 30tn. Jan. 1795 die Verlängerung der Revisions-Gebühren für die Jahre 1795, 96, 97 betreffend, wornach für 500r. bis 1000r. an Vermögen 18g., 1000 - 1500: 1r., 1500-2000: 1r.18g.

u. s.w. von dem Kirchen-Aerario auszuzahlen sind.

Nota Dieses Rescript ist in den nächsten Kirchen-Rechnungen am gehörigen Orte zu allegiren.

Circulare- Schreiben vom 3t. xbr. 95.

1. In einem Pro memoria auf einem halben Bogen zu bezeugen, an welchem Tage die letzte Kirchen-Visitation gehalten worden, ob dazu ein ganzer Tag oder nur ein Nachmittag genommen sey; imgleichen ob man damit eine Introduction oder eine Verpachtung der Kirchen-Länderey oder ein anders Geschäft verbunden habe. Ferner - ob von Seiten der Prediger Hinderniße in den Weg gelegt oder Entschuldigungen bey-

[176]

gebracht sind warum die Kirchen-Visitation faärlicher [!] Umstände halber oder wegen zu spät abgelieferter Kirchen-Rechnungen im vorigen u. gegenwärtigen Jahre nicht gehalten sey - bis zum 15t. xbr. einzusenden.

2) noch ein anders Pro memoria auf einem halben Bogen beyzufügen,

u. darin zu berichten, ob nun die Kinder während der Catechismus-Lehre

u. während des Pfarr- Unterrichts zum Sitzen kommen können. H de 18t. xbrs. ${ }^{360}$

360 Hannover, den 18. Dezember. 
Circulare vom 7 tn. Mart. 1796.

1. Monita über die Schulberichte de Mich. 1794 bis dahin 1795

„Obernjesa: Aus den wohlgefaßten Berichten ist die Amtstreue des Predigers mit Zufriedenheit ersehen worden“

2. Circulare-Schreiben a) Künftig bey Einsendung der halbjährigen Berichte auf Michaelis jedesmal anzuzeigen, ob sich Candidaten am Orte aufhalten b) nochmals für die Militair-Witwen-Caße durch den Schulmeister Sammlungen anstellen zu laßen und dem Schulmeister dafür von jedem r. $3 \mathrm{mg}$. zu geben.

c) Das 1te Verzeichniß der diesjährigen Confirmanden bis zum 19t. dieses einzusenden $u$. die Schul-Register am 26t. dieses nachzuschicken.

3. Nachricht an das Publicum wegen der Einnahme u. Ausgabe der behuf der Militair-Witwen eingekommenen Gelder. Der Betrag der Einnahme besteht in 1647r.17g.1d., wovon 10000r. bey der Königl. Rentkammer u. 3000r. bey dem Comtoir des Hofagenten Salomon Michael David ${ }^{361} \mathrm{zu} 4$ pro Cent belegt sind. Die Ausgabe für 217 Witwen u. 397 Kinder beträgt 2397r. 18g., wozu hernach noch so viele hinzukommen, daß diese Ausgabe $2484 \mathrm{r}$. 24g. beträgt. - Es ist derselben die Bitte hinzugefügt in den Attestatis künftig den Vermögens-Zustand der um Hülfe nachsuchenden Wittwen u. Waysen genau anzugeben.

361 Salomon Michael David, seinerzeit Bankier des Welfenhauses, u. a. zuständig für die Geld- und Wechselgeschäfte der welfischen Kriegskanzlei, starb 1791 (geb. 1718/24); hier ist die Firma gemeint (vgl. RiEs, Hofjuden als Vorreiter, S. 44). 


\section{[176v]}

Circulare vom 13tn. Jan. 1797

(vom Hn. Generals. Wagemann) ${ }^{362}$

1) darauf zu achten, daß der aus dem Kirchen-Aerario anzuschaffende Versuch der gemeinen Rechte u. Landes-Verordnung u. s.w. in den Schulen gehörig benutzt werde (laut Ausschr. Cons. de 8 xbr 96) 4) den Bericht die Candidaten betreffend vom Jahre 96 einzusenden auch sich einen eigenhändigen Aufsatz ihre Beschäftigung angehend von selbigen geben zu laßen.

5) die Nahmen der Prediger- u. Schulmeister-Witwen anzuzeigen u. diesen aufzugeben die Bittschriften wegen der Beyhülfen aus dem Fisco nächstens einzusenden.

6) für arme Kinder auf Kosten der Kirche 6-9 Exempl. des neuen Gallischen Lehrbuchs abhohlen zu laßen.

[Ende der Eintragungen des Pastors Bornträger]

[Beginn der Eintragungen des Pastors Proffen:

362 Generalsuperintendent Johann Gottfried Wilhelm Wagemann. 


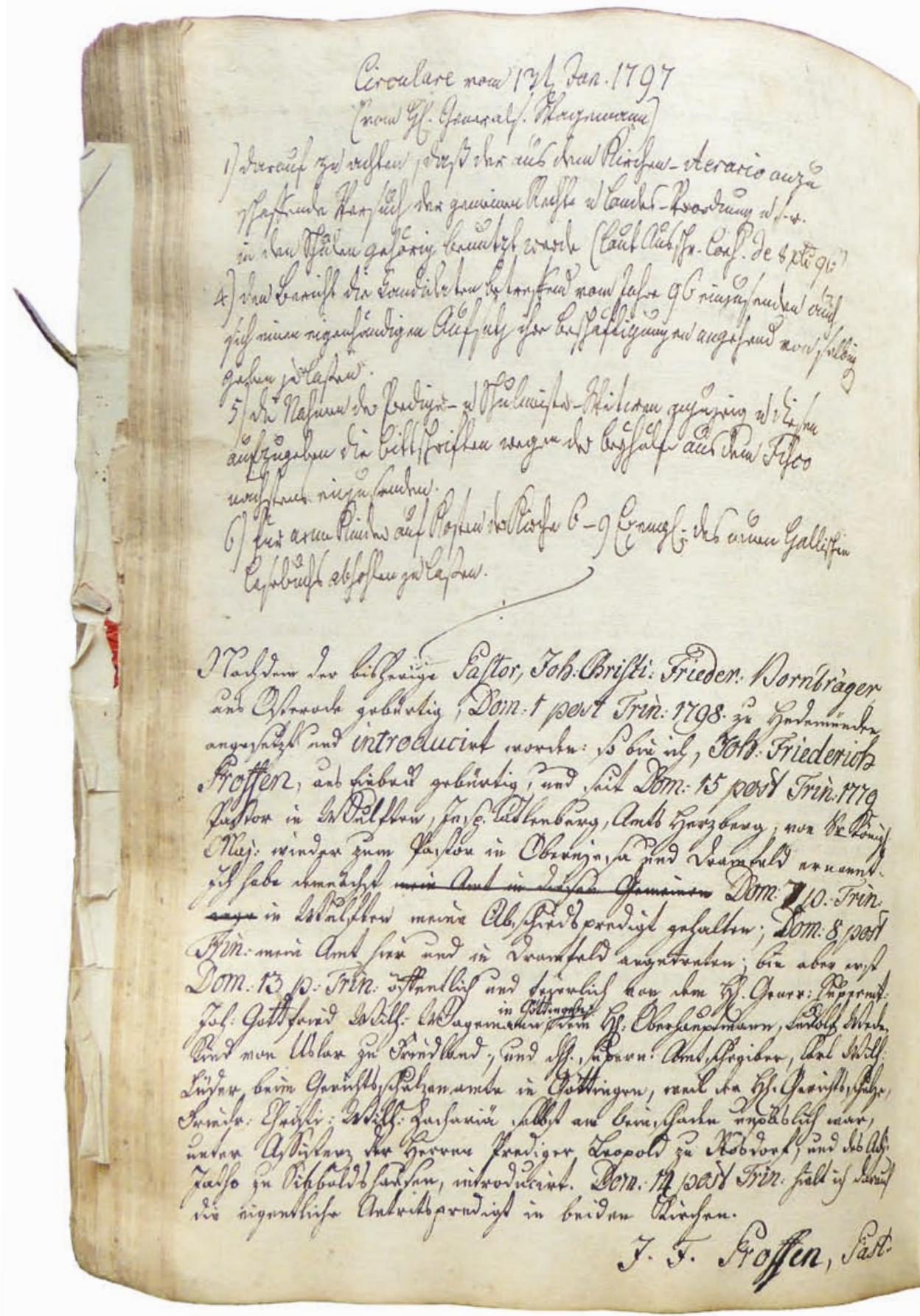




\section{Pisteritati Obernjefanae et Dramfeld:}

\section{Haln 27908}

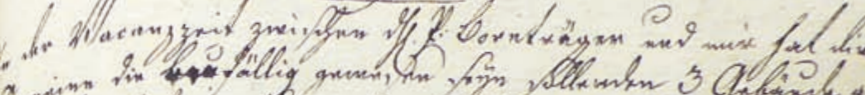

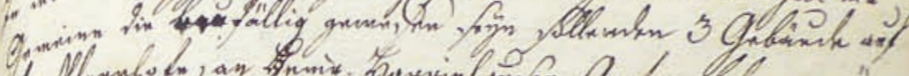

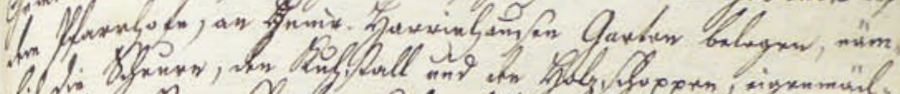

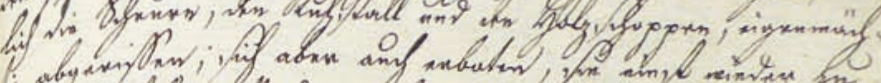

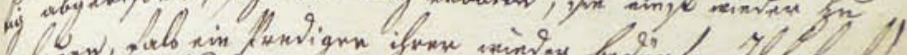

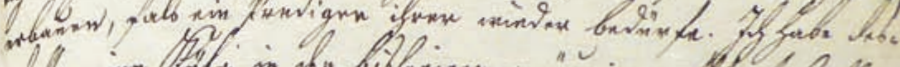

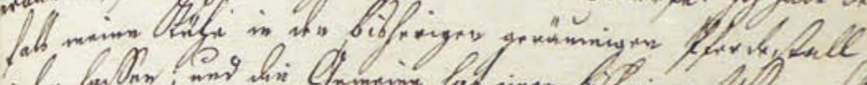

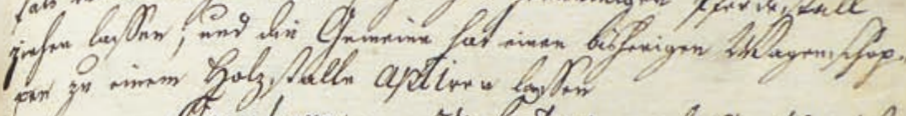

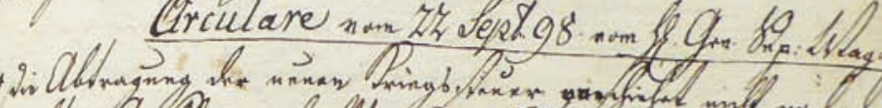

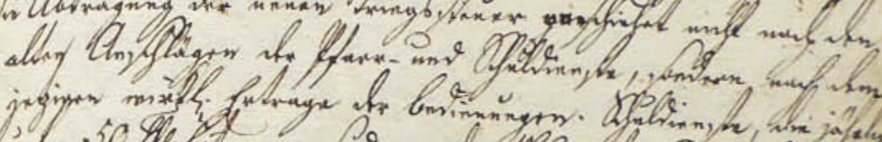

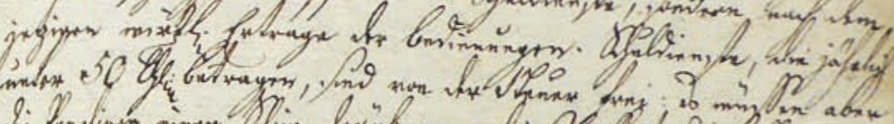

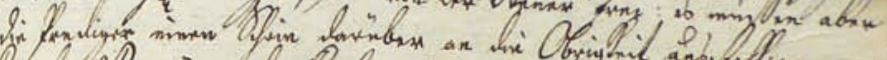

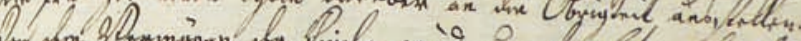

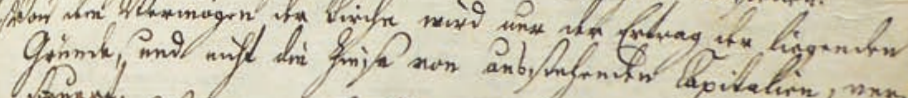

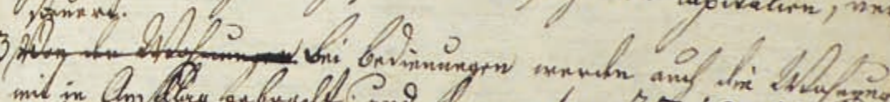

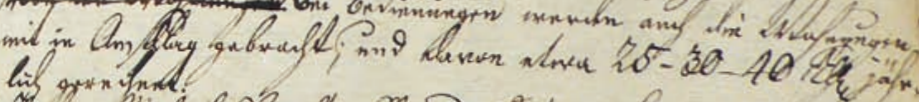

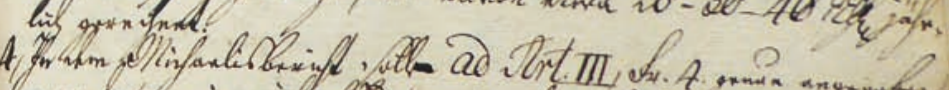

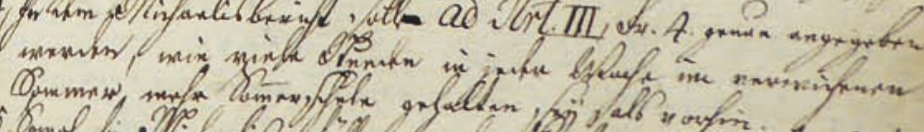

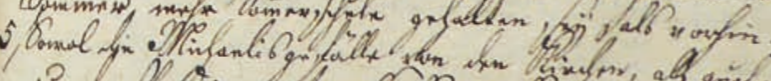

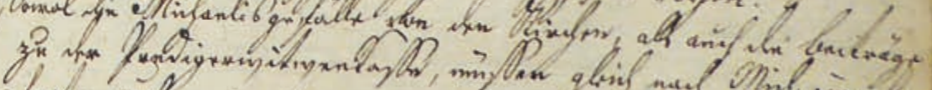

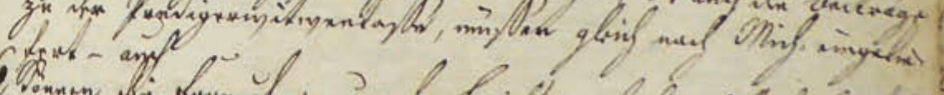

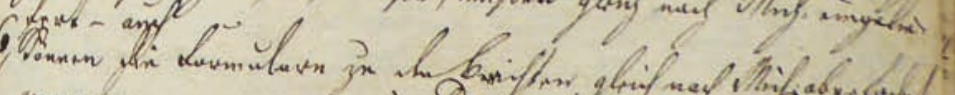
Imanims.

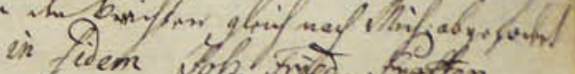
feem wots Tried. Troffer.

Abb. 7 Der letzte Eintrag des Pastors Bornträger und der erste Eintrag des Pastors Proffen Quelle: KiKrAGött, P.A. Obernjesa K.R. I.a. 1 [176v], [177] 
Nachdem der bisherige Pastor, Joh: Christi: Frieder: Bornträger, aus Osterode gebürtig, Dom: 1 post Trin: $1798 .^{363} \mathrm{zu}$ Hedemünden angesetzt und introducirt worden: so bin ich, Job: Friederich Proffen, aus Einbeck gebürtig, und seit Dom: 15 post Trin: 1779 Pastor in Wulften, Insp. Catlenburg, Amts Herzberg, von Sr. Königl. Maj: wieder zum Pastor in Obernjesa und Dramfeld ernannt. Ich habe demnächst mein Amt in diesen Gemeinen Dom: 7 : Trin: in Wulften meine Abschiedspredigt gehalten; Dom: 8 post

Trin: mein Amt hier und in Dramfeld angetreten; bin aber erst Dom: 13 p: Trin: Öffentlich und feierlich von dem Hn. Gener: Superint: Joh: Gottfried Wilh: Wagemann in Göttingen, dem Hn. Oberhauptmann, Ludolf Wedekind von Uslar zu Friedland; und dHn. Supern.Amtschreiber, Carl Wilh: Lüder beim Gerichtsschulzenamte in Göttingen, weil der H. Gerichtsschulze, Friedr: Christi: Wilh: Zachariä selbst am Beinschaden unpäslich war, unter Assistenz der Herren Prediger Leopold ${ }^{364} \mathrm{zu}$ Rosdorf, und des Adj. Jatho $^{365}$ zu Sieboldshausen, introducirt. Dom: 14 post Trin: hielt ich darauf die eigentliche Antritspredigt in beiden Kirchen.

$$
\text { J. F. Proffen, Past. }
$$

[177]

\section{Posteritati Obernjesanae et Dramfeld:}

Anno 1798:

In der Vacanzzeit zwischen dHn. P: Bornträger und mir hat die Gemeine die baufällig gewesen seyn sollenden 3 Gebäude auf dem Pfarrhofe, an Heinr. Harriehausen Garten belegen, nämlich die Scheure, den Kuhstall und den Holzschoppen, eigenmächtig abgerissen; sich aber auch erboten, sie einst wieder zu erbauen, fals ein Prediger ihrer wieder bedürfe. Ich habe desfals meine Kühe in den bisherigen geräumigen Pferdestall ziehen lassen; und die Gemeine hat einen bisherigen Wagenschoppen zu einem Holzstalle aptiren ${ }^{366}$ lassen

363 Erster Sonntag nach Trinitatis.

364 Ernst Heinrich Georg Leopold (Meyer, Pastoren II 325).

365 Johann Jatho (Meyer, Pastoren II 372, I 229).

366 Herrichten. 
Circulare vom 22 Sept 98. vom Hn. Gen. Sup: Wag:

1) Die Abtragung der neuen Kriegssteuer geschiehet nicht nach den alten Anschlägen der Pfarr- und Schuldienste, sondern nach dem jetzigen wirkl. Ertrage der Bedienungen. Schuldienste, die jährlich unter 50 Thl: betragen, sind von der Steuer frey: es müssen aber die Prediger einen Schein darüber an die Obrigkeit ausstellen.

2) Von dem Vermögen der Kirche wird nur der Ertrag der liegenden Gründe, und nicht die Zinse von ausstehenden Capitalien, versteuert.

3) Von den Wohnungen Bei Bedienungen werden auch die Wohnungen mit in Anschlag gebracht; und davon etwa 25-30-40 Thl. jährlich gerechnet.

4) In den Michaelisbericht soll ad Art. III, Fr. 4. genau angegeben werden $^{367}$, wie viele Stunde in jeder Woche im verwichenen Sommer mehr Sommerschule gehalten sey als vorhin.

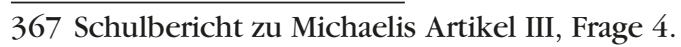


5) Sowol die Michaelisgefälle von den Kirchen, als auch die Beiträge zu der Predigerwitwenkasse, müssen gleich nach Mich: eingeliefert - auch

6) Können die Formulare zu den Berichten gleich nach Mich: abgefodert werden. in fidem Joh. Fried. Proffen.

\section{$[177 \mathrm{v}]$}

Pag: 2. Posteritati, 1798 et 1799

Circulare vom 15 Dec: 1798.

Einem Consistor- Rescr: d.d: 20 Nov. zufolge, ward, in Beziehung

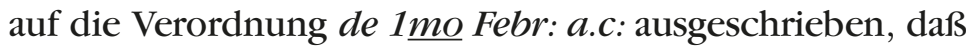
die Prediger Dom. Septuag. ${ }^{368} 1799$ eine Predigt über Matth. 27, 1-8 ${ }^{369}$ halten - demnächst leserlich abschreiben - und sie durch die Superintenden ten dem K: Cons: zuschicken sollten. in fidem J.F. Proffen.

Kurz vor Weihnachten war in der Nacht durch das eine Fenster zu der OstSüdseite, und zwar durch Zernichtung der untersten Scheiben der einen Hälfte des Fensters ein Einbruch in die Kirche geschehn. Vielleicht aber waren die Thäter durch Hundebellen verstöret worden. Denn nur hatten sie vom Altare die beiden weissen Laken, und weiter nichts, mitgenommen. Auf meine Anzeige davon an die Hn. K. Commissarien kam sogleich dH. Amtschreiber Lüder hieher, um visum repertum ${ }^{370}$ von dem Einbruche aufzunehmen. Weil aber der Diebstahl ganz unbeträchtlich war: so wurde auch nicht darauf inquirirt, und der Thäter ist also nicht bekannt geworden.

\section{$\underline{A N N O} 1799$}

$\mathrm{Zu}$ Anfange des Jahrs sind statt der bish 2 Tafeln, worauf die Nr. der Gesänge bisher nur annotirt wurden, 2 andere neue Tafeln, in welche die Zahlen, auf kleinen Brettern angestrichen, hineingeschoben werden;

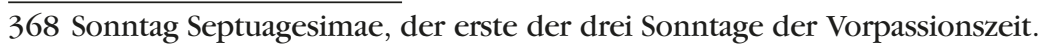

369 Des Morgens aber hielten alle Hohenpriester und die Ältesten des Volks einen Rat über Jesum, daß sie ihn töteten...

370 Untersuchungsbericht. 
Wie auch ein neues Taufpult, auf welchem zugleich ein Pult zum Vorlesen für den Schulmeister angebracht ist;

und auch Barrièren vor dem Altar, die vorhin gar nicht waren, auf Kosten der Kirche

samt einer neuen Hallischen Bibel zum gottesdienstlichen Gebrauch des Predigers, angeschaft worden.

In der Nacht vom 22sten auf den 23sten Febr: zwischen 2-4 Uhr war hier und ein schrecklicher Sturm und in demselben ein so schreckliches Gewitter, daß der gemeine Haufe geglaubt hat: der jüngste Tag sey da. Auch in der Harzgegend hat sich dieser Vorfall eben so schrecklich geäussert. Mit demselben aber hat sich der Winter gebrochen, der allenthalben so schrecklich gewesen ist, daß Menschen in den Häusern, auch Hirsche in der Wildniß, und viel Vieh in den Ställen erfroren ist.

\section{[178]}

\section{Pag: 3. Posteritati de 1799}

Oeffentlichen Blättern zufolge ${ }^{371}$ ist die Kälte am 7 ten Febr: in Hamburg über 10 Grad nach Reaumür; ge am Abend bei Thauwetter 14 Grad unter Null - und am 8ten frühe eine Kälte von 16 1/2 Grad - und folglich nur $1 \frac{1}{2}$ Grad von der am 25 Dec: 1798 verschieden gewesen.

Am 24 sten Febr. ist dH. Hofrath, Georg Christof Lichtenberg in Götgen an der Entkräftung gestorben, und am 28sten d. M. Vormittags solenniter ${ }^{372}$ begraben. Er war ein sehr berühmter Professor Physices et Astronomiae.

Am 5 ten Apr. ist auch der Hofrath, und Prof: Philos. ordin: Joh. Christof Gatterer ${ }^{373}$ in Göttingen, Alters halber gestorben. Er war ein berühmter Professor historiarum.

371 Pastor Proffen hatte offensichtlich Zugang zu Zeitungen und Zeitschriften. Ob und welche er abonniert hatte, war bisher nicht festzustellen (vgl. [191v]).

372 Georg Christoph Lichtenberg, 1742-1799, Professor für Mathematik und Experimentalphysik (Corpus Academicum Gottingense (1737-1928) bearbeitet von Max ARnim, Vandenhoeck \& Ruprecht, Göttingen 1930, S. 174); bei seiner Beerdigung sollen über 500 Studenten dem Sarg gefolgt sein (Promies 1987, S. 151).

373 Johann Christoph Gatterer, 1727-1799 (Corpus Academicum, S. 115). 
In diesem Frühjahre habe ich den Knickgarten, welchen mein Antecessor, H. P. Bornträger, an die Gebrüdern Salzmann für nur, 4 Thl. Conv: M. verpachtet hatte, in eignen Gebrauch genommen. Weil ich aber keinen Wannezaun ${ }^{374}$ zwischen jenem und diesem Garten fand: so habe ich, zumahl Salzmanns ihn nicht machen wollten, für mein eigen Geld durch Hampen und Künckler ${ }^{375}$ machen lassen. Einer von jenen Beiden soll mir jedoch die Kosten dafür erstatten.

Auch habe ich die Hecke am Baumgarten heraus durch Poppen und Löning in Sieboldshausen für 1 Thl. und die Hecke am Knickgarten für 12g. binden lassen, ohne die Zehrungskosten.

Gleichfals habe ich auch durch den Zimmermann Schäfer 2 hohe neue Pfosten von Eichenholze nebst einer Schwelle, wozu mir der Bauermeister, Joh. Christof Zimmermann, altes Bauholz von den vormahligen abgerissenen Pfarrhaushaltsgebäuden hergab, vor den Knickgarten setzen und legen - auch eine neue Gartenthür durch den Tischler, Friedr. Lüdecken in Dramfeld, machen lassen.

Einem K. Ch: Consistorialbefehl zufolge haben alle Prediger unsers Landes einen so genannten Pfarrbericht, welcher von allen Umständen des Predigers und der Pfarre eine genaue Nachricht enthalten soll, einschicken müssen. Ein Exemplar davon, welches mit dem Original, das ins K. Consist: abgeschickt ist, gleichlautend ist, habe ich, weil es von allen Angelegenheiten der Pfarre Nachricht giebt, für meine Herren Successoren sub dato 7 Jun: 1799 in die Registratur zurückgelegt.

\section{[178v]}

Pag. 4. Posteritati de 1799.

Einem Circular vom 1 Jan: zufolge wurde den samt Predigern unserer Inspection sowol die Verordnung Königl. Landesregierung d.d. Hannover d. 14 Jan: 1799, als auch ein Rescript K.Chf. Consist: d.d. Hannover d. 4 May 1799 im Druck communicirt; und im ersten dem Publiko unsers Landes die Lectüre des philosophischen Journals von den beiden Professoren Fichte

374 Ein Zaun, der die Grenze markiert; vgl. Sснамвасн, S. 285, 286.

375 Vgl. Seite [160v]. 
und Niethammer in Jena bei Strafe von 50 Thlrn. verboten; ${ }^{376}$ und im bishern die Prediger und Candidaten unsers Landes zu sorgfältiger Prüfung und vorsichtigem Gebrauch derselben ermahnt; und, zu Widerlegung + ... + der dadurch etwa verbreiteten + dieser Schrift und Ausrottung + schädlichen und gefährlichen Grundsätze, erinnert: Schäffers Abhandlung über des Hn. Prof. Fichte Appellation an das Publikum, Gotha 1799 ${ }^{377}$, und Eberhards ${ }^{378}$ über den Gott dHProf: Fichte, und den Götzen seiner Gegner, Halle 1799; zu benutzen eines Ungenannten Appellation an den gesunden Menschenverstand in einigen Aphorismen 1799; und neues theologisches Journal 1stes Stück 1799 zu benützen.

Bis an die Ernte dieses Jahrs stiegen die Fruchtpreise so hoch, daß der Ht. Weizen auf $15 \%$ bis 2 Thl.

$$
\begin{aligned}
& \text { “ } \text { Roggen auf } 1 \frac{2 / 3}{\text { bis } 13 / 4} \text { “ } \\
& \text { “ } \text { Gersten auf } 1 \frac{1 / 6}{} \\
& \text { Haber auf } 1 \text { Thl. }
\end{aligned}
$$

und das Bund Langstroh auf 1/4 Thl: kamen. Die Fourago ward so theuer, daß Mancher sein Strohdach abgedeckt ${ }^{379}$ - mancher sein Stück Vieh deshalb erstochen hat. Die Roggenernte gieng erst 3 Wochen nach Jacobi ${ }^{380}$ an.

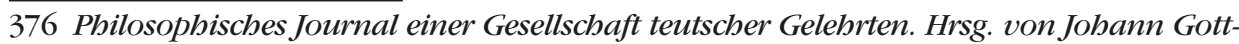
lieb Fichte und Friedrich Immanuel Niethammer. Jena, Leipzig 1795-1800. In der Literatur heißt es dazu, dass - aus Furcht vor Unruhen - mit der Verordnung vom 14. Januar 1799 eine Presse- und Bücherzensur eingeführt wurde, die in dieser Schärfe in Kurhannover bis dabin unbekannt gewesen war (HAASE, Bd. 2, S. 68). Bemerkenswert ist, dass die Regierung der Öffentlichkeit - einschließlich der Studenten - die Lektüre des Philosophischen Journals der Professoren Fichte (1762-1814) und Niethammer (1766-1848) verbot; das Konsistorium ihren Pastoren jedoch eine kritische Lektüre gestattete. Der Kurator der Universität Ernst Brandes scheint diese Einschränkung der universitären Arbeit gebilligt zu haben; aus Briefen geht hervor, dass er die Wirkungen der Schriften eines akademischen Lehrers auf die studierende Jugend so hoch einschätzte, dass er es sicherer fand, wenn ein unrubiger Geist von Professor seines Amtes enthoben würde (HaAse, Bd. 2, S. 68ff).

377 Schaeffer, Friedrich Wilhelm: Über des Herrn Professor Fichte Appellation an das Publikum, die ihm beigemessenen atheistischen Grundsätze betreffend, Gotha 1799.

378 Eberhard, Johann August: Ueber den Gott des Herrn Professor Fichte und den Goetzen seiner Gegner: Eine ruhige Prüfung seiner Appellation an das Publikum in einigen Briefen. Halle 1799.

379 Dies ist ein Hinweis darauf, dass die Dächer mit Roggenstroh und nicht mit Schilf gedeckt waren.

380 25. Juli. 
In der Nacht vom $\mathbf{1 7}$ ten bis $\mathbf{1 8}$ Sept. war ein so starker

Frost, daß der Toback, die Vitsbohnen- und Kartoffelnblätter ${ }^{381}$

erfroren waren.

In diesem Sommer ist das Haus- Scheuren- und Backhausdach umgelegt durch Mstr. Boden aus Hitzelrode; und durch den Maurer zu Lütgenlengden die Mauer um den Aalpfuhl neu gemacht.

In diesem Sommer ist, mit Bewilligung der Herren Kirchencommissarien, für den verstorbenen Altarist Stolten in Dramfeld, der Einwohner und Grobschmid, Joh: Ludewig Lüdecke, dazu wieder von mir angesetzt: aber nicht beeidigt.

\section{[179]}

\section{Pag: 5 Posteritati de 1799 u. 1800}

In der Nacht vom 26sten zum 27sten Sept. fast 2 Uhr wurde man durch so helle und ganz unablässige Blitze am westlichen Horizont, die jedoch den Himmel überall erleuchteten, aufgeweckt, daß Entsetzen und Schrecken uns anwandelte, weil der Himmel immer offen war, und kein Donner gehört wurde. ${ }^{382}$ Nur erst nach und nach, da sich das Gewitter immer mehr gegen Norden zog, hörte man einen entfernten Donner.

Unterm 23Jan: 1800. wurde eine K. Chf: Consistorialverordnung dd. 28 Nov. 1799 per Circulare an alle Pfar ren communicirt, nach welcher bekannt gemacht wurde, daß zwischen unserm und den Fürstl: Braunschweig: Consistoriis eine Uebereinkunft getroffen sey, daß,

381 Offensichtlich war das Kartoffelkraut noch nicht abgestorben, so dass die Kartoffeln später als in anderen Jahren geerntet werden mussten. Im übrigen ist aus einer Verordnung vom 19. September 1799 zu entnehmen, dass das Abweiden der Kartoffelfelder erst Mitte Oktober würde erfolgen dürfen, da die Ernte 1799 später als sonst beginnen würde. Zur Bedeutung der Kartoffel im Göttingischen schrieb Professor Meiners 1801: Die Cartoffeln-Erndte ist unsere Weinlese, und in wenigen Weingegenden wird der Herbst mit so allgemeiner Fröblichkeit gefeiert, als die Cartoffel-Erndte um Göttingen... (Meiners, Kurze Geschichte..., S. 224). Zum unentbehrlichen Volksnahrungsmittel soll die Kartoffel durch die Kornknappheit der Jahre 1771/72 geworden sein, in deren Folge Kartoffeln vermehrt angebaut wurden (OBERschelP, Bd. 2, S. 20).

382 Wetterleuchten. 
1) ausser den Catechumenen von ausländischen Filialdörfern, keine Kinder aus den gegenseitigen Landen zur Confirmation zugelassen werden sollten.

2) Die Catechumenen von ausländischen Filialdörfern vor ihrer Confirmation dem Superintend: des. Inspeckt. zur Prüfung gestellet werden sollte.

Anno 1800.

In der Nacht vom 8ten auf den 9ten Febr: ist der Herr Pastor, Ludewig Eberhard Mylius in Grone, ein Sohn des weil. Pastoris an der Aegidienkirche in Hannover, an den Folgen der Verletzung eines Fersen auf einem Wege nach Göttingen, welche nachher in ein Brustfieber ${ }^{383}$ ausartete, im 63 sten Lebensund 37 sten Dienstjahre gestorben. Schon war er zum Superintendenten in Münder ${ }^{384}$, an die Stelle des von da nach Ebstorf denominirten Superintend: Borchers ${ }^{385}$ ernannt.

Unterm 22 Febr: wurden folgende 2 Consistor: Ausschreiben per Circulare communicirt; näml.

1. d.d. 14Jan: 1800., nach welchem alle Verordnungen, welche von den Kanzeln zu publiciren befohlen worden, abgelesen - dagegen aber alle übrige, bei welchen sich dieser Befehl nicht befindet, von den Amtsdienern nach verrichtetem Gottesdienste auf den Kirchhöfen abgelesen werden - keine Publicanda aber von der Ortsobrigkeit, vielweniger unschickliche Privatangelegenheiten aber von den Kanzeln bekannt gemacht werden sollen.

[179v]

Pag. 6 Posteritati de 1800.

2. d.d. 16Jan: 1800, nach welchem es der christl. Freiheit der Prediger überlassen ist, sowol in Ansehung kirchl. Ceremonien, als auch liturgischer Formulare solche Veränderungen zu treffen, die die Kirchenordnungen in sofern gestatten, als jener wahre Absichten dadurch nicht verfehlt werden.

383 Lungenentzündung (MeTzKe, S. 60).

384 Heute Bad Münder bei Springe.

385 Georg August Borchers (MEYer, Pastoren 225). 
Am 18ten Febr: ist der Herr Past: Christi: Albr: Erhard ${ }^{386}$ in Bischhausen, Insp: Göttingen 2 Theils, im 77sen Lebens- u: 50sten Amtsjahre gestorben.

Als der - am 30 Jan: in meiner Abwesenheit von dHn. Past: Schlie $^{387}$ in L: Schneen mit Anne Engel Sophi Heddenhausen copulirte Joh: Heinr: Fehrensen, ausser den 2 Thl. Cass. M: für Proclamation und Copulation, die für die Brautsuppe verlangten $24 \mathrm{Mg}$. mir verweigerte, und nur $12 \mathrm{~g}$. dafür geben wollte: habe ich ihn desfals bei dHn. Gerichtsschulzen Zachariä belangt, worauf er mir die verlangten $24 \mathrm{~g}$. ins Haus zu schicken war befehliget worden. ${ }^{388}$

Am 27 Febr: starb der Häusling u. alte Dragonerinvalide Welker. Seine Witwe u. Tochter liessen ihn darauf ausläuten. Der hier auf Urlaub liegende - obgleich hier wohnhafte Corporal Frölich vom Gten Dragonerregimente kam darauf zu mir, gab vor, daß er von seinem Hn. Hauptmann v. Maydel ordre habe, die Leiche zu beerdigen, und durch Dragoner hintragen zu lassen; und bestand darauf, daß aus eben genannten Ursachen die Leiche von der juribus stolae ${ }^{389}$ befreiet sey. Ich erwiederte aber, daß nach der Verordnung von 1734, die ich ihm vorlegte, die Gebüren an den Clerus hauptsächlich aus den 2 Gründen entrichtet werden müsten, weil

386 Christian Albrecht Erhard (Meyer, Pastoren 97).

387 Heinrich Christoph Schlie (Meyer, Pastoren, II 30).

388 Über das Thema „Brautsuppe’ führte Pastor Proffen einen intensiven Briefwechsel mit den Kirchenkommissarien und dem Konsistorium in Hannover; in einem Nachweis über die Einnahmen der Obernjesaer Pfarre verzeichnete er dann folgendes: 5. Für Proclamation und Copulation, wenn beide Verlobte aus einer Gemeine sind, 1 Th.12g; eine Brautsuppe, bestehend in einer Suppe, einem Stück Rindfleisch von 4-6 Pfund, 2 Hochzeitsbröden, 1 Kuchen und einer Flasche Bier. An Opfer giebt die Braut 2 auch $3 \mathrm{mg}$. Geld; einen Schnupftuch, der 12g. an Werth haben muß; einen Rosmarienstrauch oder auch 1 Citrone. Auch der Bräutigam gibt ein Opfer von 2 oder 3g.; und jeder Begleiter 1-4d. Zuweilen nimt Pastor auch wohl 24g. statt der Brautsuppe.

Heirathet aber die eine Person ausser das Dorf, so daß nur Proclamation von dem Prediger geschiehet: bekommt er nach uralter Observanz gleichwol 1Thl., und einen Schnupftuch, gar selten aber 1 Kuchen dabei. Conf. Past. Armbrecht Pfarr inventarium von Dramfeld de 1706.

Nota. Zu meiner Zeit gaben die Hochzeitsbegleiter, zumabl in Dramfeld, nicht einmahl 1d Opfer. Auch weigern sich die Dramfelder bei Heirathen ausser das Dorf bei blossen Proclamationen das Schnupftuch und den Kuchen zu geben (KiKrAGött, P. A. Obernjesa A.401, Verzeichniß der sämtlichen jährlichen Fixi Einnahmen bei der Pfarre in Obernjesa aufgesetzt von J.F. Proffen, p:t. Past.)

389 Stolgebühren, hier die Beerdigungsgebühr. 
1. die Leiche civiliter ausgeläutet sey, und

2. der Verstorbene pflichtige - und zwar Lehngründe habe

Weil er nun meinem Andringen nicht widerstehn konnte, und ich verlangte, daß die Gebüren noch vor der Beerdigung entrichtet würden, versprach er endlich als ein ehrlicher und beeidigter Mann, daß die Gebüren noch ehe ich von Dramfeld zurückkäme (woselbst ich den Mittag eine Leiche zu beerdigen hatte) entrichtet seyn sollten. Dennoch waren sie bei meiner Zuhausekunft nicht allein noch nicht entrichtet

\section{[180]}

Pag: 7. Posteritati de 1800

sondern die Leiche war auch schon beerdigt. Da sich nun erst seine Absicht, mich hintergehn - und um die jura stolae betrügen zu wollen, aufhellete: so verklagte ich ihn bei seinem Capitaine $v$. Maydel in Jühnde. Ein paar Tage darauf brachte mir denn des Verstorbenen Tochter die 2 Gebühren Thl. - und dem Schulmeister Mündemann den 1/2 Thl. Gebüren ins Haus.

Auch in diesem Winter war, wie in dem von 1799, ein so hoher Grad - und eine solche Dauer von Kälte, daß sich auch die aeltesten Leute dergleichen nicht entsinnen konnten. Nur erst am Ende des März ließ die Kälte nach, und schien es, Frühling zu werden.

Im Circular vom 26 März wurde 1) ein K.Ch: Consistor: Ausschreiben vom 27 Febr: communicirt, nach welchem eine Beckencolleckte zur unumgänglichen Hauptreparation und Erweiterung des Kirchengebäudes zu Adelebsen Inspeckt. Göttingen 1sten Theils bewilliget wurde. Die Colleckte geschah Fer: 2 Pasch $^{390}$; und betrug aus Obernjesa 35g., und aus Dramfeld 29g.2d. Summa 1 Th.28g. 2 d.

2. noch ein anders unterm 6 $\underline{\text { sten }}$ März, nach welchem für das Schulhaus zu Sebexen, Insp. Hohnstedt, eine Kirchenvorrathscolleckte verordnet wurde. 3. noch ein unterm 11ten März, nach welchem behuf einer nothwendigen Hauptreparation des Kirchengebäudes zu Ludolfshausen, unsrer Inspeckt. Göttingen 1 Theils eine Kirchenvorrathscolleckte verordnet wurde. Noch wurde einem - durch den Superintend. Bialloblatzky ${ }^{391}$ bekannt gemachten Ausschreiben als Kön: Consistor. vom 6 Febr: zufolge

390 Feria 2 Pasche, am zweiten Ostertag.

391 Johann Heinrich Siegfried (Siegmund) Biallablotzky (MEyer, Pastoren, S. 438, II S. 539). 
eine Colleckte von den Schullehrers, Organisten und Custoden für den abgebrannten Cantor Woltmann in Hiddestorf bewilliget. Der hiesige Schullehrer Mündemann gab 15mg.

Auch wurde zur Anschaffung des von dem Schlosorganisten [!] Böttner in Hannover herauszugebende neuen Choralbuchs 1 Th: Cassenmünze Praenumeration ex aerario ${ }^{392}$ der reichen Kirchen, und also auch der Obernjesischen Kirche vom Königl. Consist. verwilliget.

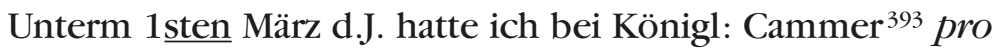
Memoriale nachgesucht, mir bei gänzlichem Mangel des KluftHolzes $^{394}$ bei hiesiger Pfarre einige Klafter, sey es auch gegen Forstzins, aus den benachbarten Herrschaftlichen Forsten, entweder der

\section{[180v]}

Pag: 8. Posteritati de 1800.

Brackenbergischen oder Reinhäusischen, ad dies vitae vel officii $^{395}$ zu bewilligen. Allein unterm 8ten Apr: erfolgte abschlägige Resolution ${ }^{396}$; welches beides ich in der Registratur deponirt habe.

In der Nacht vom 23 - 24 Apr: war das 1ste Gewitter, mit vielem Regen u Schlossen begleitet

Am 29sten Apr: aber gegend Abend hat sich in unsrer Nachbarschaft und zwar in der nordwestlichen Gegend ein so heftiges Gewitter im Wolkenbruch und schweren Hagelkörner nieder gelassen $^{397}$, daß nicht allein in Rose Menschen (wie z.b. in Rosdorf

392 Die Vorausbestellung wurde aus der Kirchenkasse finanziert.

393 Die Königliche Kammer war für die Finanzverwaltung des Landes zuständig.

394 Gespaltenes Holz.

395 Während seiner Amtszeit.

396 Ein Grund für die Ablehnung könnte darin bestehen, dass die Forstbezirke selbst für die Berechtigten nicht mehr ausreichend Brennholz liefern konnten (vgl. KürsCHNER 1976, S. 82).

397 Der Göttinger Professor der Weltweisheit Christoph Meiners veröffentlichte einen ausführlichen 51 Seiten langen Bericht über das Unwetter im Neuen Hannoverischen Magazin und in Berlin. Vermutlich ist die Veröffentlichung in der Hannoverschen Zeitschrift die Quelle aller später folgenden Berichte in Chroniken und Heimatgeschichten gewesen (Meiners, Kurze Geschichte..., Berlin 1801, S. 448-499.) Nach Meiners erfolgte das 
in der MittelNiedermühle etwa 6 zugleich, nemlich die Frau, die Mutter, die 2 kleinen Söhne und der Knecht des Müllers nebst einem Mahlgast im Hause selbst, und zwar im Backhause) sondern auch Vieh, ertrunken und theils in den Ställen selbst ertrunken - theils von dem Strome fortgerissen - und nachher todt auf der Erde gefunden sind. Wohnungen, Häuser und Ställe sind dadurch sehr beschädigt und Hausgeräthe, Handwerksinstrumente und Lebensmittel weg und die Länderei überschwemmet - das Winterfeld vom Hagel zerschlagen - das bereits mit Haber bestellte Sommerfeld samt dem urbaren und gedüngten Lande in der Braak verflossen. ${ }^{398}$ Dieß Unglück hat namentlich die Oerter Settmarshausen, Ohlenhausen, Lemshausen, Mengershausen, Siboldshausen, Volkerode, Mariengarten und Dramfeld betroffen Jühnde und Barlissen betroffen. Adelebsen

Nicht allein sind viele Mensehen, und in der Ro Auf dem Klosterhofe in Mariengarten allein sind 70 Kühe und 96 Schweine in den Ställen ersoffen; und vieles Federvieh theils ertrunken, theils weggeschwemmt; das Molkenhaus fast zerstört, und selbst das Wohnhaus und die Ställe von den schweren Hagelkörnern und dem grossen Wasser sehr beschädiget. Vor Dramfeld ein Theil des Winterfeldes sehr beschädiget; das mit Haber bestellte Sommerfeld sehr verletzt, und das Ackerland auch in der Braack von dem guten und fetten

\section{[181]}

Pag. 9 Posteritati de 1800.

Lande entblößt. In Dramfeld ist die Mittelmühle fast bis zum Unsturz verwüstet; wie auch das Haus des Schmids Ludewig Lüdeke und der Witwe Ludewig Bühren sehr beschädigt. Lüdeken sein gesamtes Vieh, 3 Kühe und

erste Gewitter am Abend des 17. April, und das zweite dann am 25. April - beide mit örtlich völlig verschiedenen Auswirkungen.

398 In diesem Zusammenhang rühmte Professor Meiners die Hilfsbereitschaft der benachbarten Dörfer, die sofort für Ersatz gesorgt hatten: Alles dieses hätte nicht in so kurzer Zeit zu Stande gebracht werden können, wenn nicht die Einwohner von Geismar, Diemarn [!], und anderen Dörfern, die keine Noth gelitten hatten, am Tage nach der Ueberschwemmung herbeigeeilt wären, und den Rostorfern mit der größten Anstrengung, und obne alle Ansprüche von Vergeltung geholfen bätten (MEINERs, Kurze Geschichte..., S. 461). 
ein Zugkalb ${ }^{399}$ und 2 Ferken waren in den Ställen er-

soffen; und sein Handwerksgeräthe und vieles von seinem

und anderer Leute Hausgeräthe weggeflossen. ${ }^{400}$ Nur das

Auge konnte sich von dem Umfange des Unglüks überzeugen.

Durch das grosse Wasser, welches von jenen Oertern her-

strömte sind denn auch vor Obern- und Niedernjesa man-

che Wiesen und Ländereien überschlemt. Am Sonntage darauf, Dom:Jubilate ${ }^{401}$, predigte ich über die Worte Röm: XII,

15. ${ }^{402}$ Weinet mit den Weinenden, und ermahnte sowol die

Gemeine in Obernjesa, als auch die Einwohner in Dramfeld,

die mit dem Unglück verschont geblieben wären, zu herzlichem

Mitleite und thätiger Unterstützung der Nothleidenden in

Dramfeld; u. schlug zu dem Ende auf den künftigen Sonntag eine

öffentliche Beckencolleckte vor. Nachdem ich aber die Sache reif-

licher überlegt hatte, änderte ich die öffentl. Beckencolleckte in

eine Privatcolleckte $403 \mathrm{um}$, und ermahnte an folgenden Sonn-

tage Cantate nach 2 Cor. IX, 5- $7^{404}$ in beide Gemeinen zum

reichlichen Dargeben. Leider aber hat dies alles nichts, gar nichts

gefruchtet: denn auch Niemand aus beiden Gemeinen hat $1 \mathrm{mg}$.

gegeben. ${ }^{405}$

399 Kleines noch saugendes Kalb.

400 Professor Meiners berichtet, dass ein Gerücht entstanden war, in Dramfeld seien 17 Menschen ertrunken - was sich aber sehr bald als falsch erweisen sollte (MEINERs, Kurze Geschichte..., S. 455).

401 Dritter Sonntag nach Ostern.

402 Vers 15 lautet vollständig: Freuet euch mit den Fröhlichen und weinet mit den Weinenden.

403 Laut Schlegel dürfen die Pastoren aufgrund eines landesherrlichen Rescripts vom 25. September 1721 bei einer Privatkollekte ibre guten Freunde um eine freywillige Gabe und Geschenk (...) ansprechen (SCHLEgel, 4. Teil, S. 118).

404 So habe ich es nun für nötig angesehen, die Brüder zu ermabnen, daß sie voranzögen zu euch, ( ), denn einen fröhlichen Geber hat Gott lieb.

405 Im Gegensatz dazu berichtet Professor Meiners, dass dem Mariengartener Amtmann und Klosterpächter von den Amtleuten und Güterbesitzern weit und breit umgehend mit Vieh, Geräten und Hausrat ausgeholfen wurde. (Meiners, Kurze Geschichte..., S. 489). Allerdings stellt er im gleichen Atemzug fest, dass man hier die Treue und Dienstfertigkeit der nächsten Dorfschaften nicht rübmen könne, im Gegenteil: Es ist aber nur zu wabr, daß man manche von Mariengarten weggeschwemmte Sachen aufgefangen, und behalten, und selbst viele Dinge, welche die Dienstboten und Arbeiter des Amthofes wieder gefunden, und zurückgebracht hatten, von dem allenthalben offenen Amthofe in der Dunkelheit der Nacht entwendet hat (MEINERs, Kurze Geschichte..., S. 490). 
Auf Anrathen dHGen. Sup: Wagemann muste ich bei Kön: Consistorio um die Vacanzengelder von Johannis 1798 bis zum 27sten Jul: d. J. nachsuchen, so wie mein Antecessor, der den 3 ten Jun.- in Hedemünden introducirt war ${ }^{406}$, eben um die Vacanzengelder von da an bis zum 24 Jun: als Johannis darum nachgesucht hatte. Allein Beiden ward dies vom K. Consist: laut eines Rescripts abgeschlagen; (es war vom 6sten May) und vielmehr befehten den Kirchencommissarien befohlen, die von dHn. Gen. Sup: berechnete Summe der Vacanzengelder von 46 Thl: 20g: zum Besten des hiesigen Pfarrwitwenthums zu belegen.

\section{$[181 \mathrm{v}]$}

Pag. 10 Posteritati de 1800.

Im Junio trat eine so heftige Kälte ein, daß man nicht allein in den Zimmern einhitzen muste, sondern auch die Vitsbohnen, Gurken und das Kartoffelnkraut ${ }^{407}$ erfroren.

\section{Am 15ten Junii starb in Hannover der H. Pastor von Rosdorf,} Ernst Heinrich [xxx] Georg Leopold ${ }^{408}$, da er eben bei seiner Frauen Bruder, dem Syndicus des Altstädter Magistrats, Kriegssecretair Meisner, zum Besuch war. Er war nur etwa 4 1/2 Jahr Pastor in Rosdorf - vorher aber einige 20 Jahr lang am Pädagogio in Ilfeld Lehrer, und zwar zuletzt Conrector, gewesen. Er war eines Predigers Sohn aus Niedersaxwerfen in der Grafschaft Hohnstein. Dem Ausschreiben dHn. Gener. Super: Wagemann zufolge musten folgende 4 Prediger unsrer Inspecktion alle 14 Woch Tage die Vacanzzeit hindurch daselbst vicariiren, und zwar in folg. Ordnung; als 1) dH. Past: Adj:Jatbo in Siboldshausen Dom: 3 p: Tr.

2. H. Past. Schlie in Lütgenschneen, D: 5 p: Tr., 3) Ego; D. 7 p: Tr. und 4. H. P. Schröter ${ }^{409}$ in Jühnde D. 9 p: Tr:, u. s: w. $^{410}$ Jedoch sollte

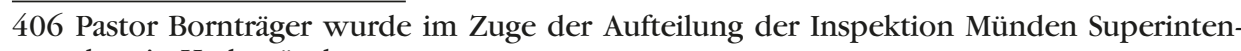
dent in Hedemünden.

407 Wie bereits im September des vorhergehenden Jahres und im Mai 1802.

408 Lt. Dolezel, S. 70, wurde Ernst Friedrich Georg Leopold am Sonntag Palmarum 1796 durch Superintendent Lutter (Luther) in Rosdorf eingeführt; er hatte seinerzeit bei der Einführung Pastor Proffens am 13. Sonntag nach Trinitatis 1797 im Gottesdienst assistiert s.o. $[176 \mathrm{v}]$.

409 Wilhelm August Schröter (Meyer, Pastoren, II 577).

410 Die Vertretungen sollten in folgender Reihenfolge erfolgen: 1) der Herr Pastor adjunctus Jatho in Sieboldshausen am 3. Sonntag nach Trinitatis; 2) Herr Pastor Schlie in Klein 
Letzterer wieder austreten, und seine Stelle durch den neuen Past:

Oppermann, sobald dieser in Grone introducirt seyn würde, wieder ersetzt werden, woselbst bis dahin der P: Quentin in Elliehausen, Insp. Harste - der Past: Strüver in Settmarshausen der P. Mublert ${ }^{111}$ in Mengershausen u. der P. Leopold in Rosdorf vicariiren musten. In Grone hatte der $P$. Strüver - und in Rosdorf der P. Jatho die wöchent: actus minister: ${ }^{412}$ zu besorgen.

Am 20ten Jun: ist der Hofrath u. Prof: Abrab: Gotthelf Kestner in Göttingen im 83 Jahre seines Lebens gestorben. Er war ein sehr berühmter Prof: Phys:, Mathes: $u$. Astronomiae

Mit Sr Kön: Maj: Genehmigung ist auf Verordnung

Kön: Chf: Landesregierung auf den 20 Jul: als Dom: 6 p: Trin:

in unserm ganzen Lande ein Dankfest für der göttl. Vorsehung für die glück. Erettung unsers Königes ${ }^{413}$ von einer nahen Todesgefahr, da nämlich am 15ten May ein Bösewicht, Namens James Hatfield, nach ihm im Comödienhause geschossen hatte, angesetzt. ${ }^{414}$ Königl. Consistorium hat darauf unterm 17ten Jun: dies Dankfest dem Aerar

\section{[182]}

\section{Pag: 11 Posteritati de 1800.}

bekannt machen lassen, und dessen gottesdienstl. Einrichtung in einer eignen gedruckten Beilage, nebst dem besonders abgedruckten Gebete, vorgeschrieben. Alles dies ist in der Registratur deponirt. Meine beiden Gemeinen bezeichneten diesen Tag mit einigen Feierlichkeiten und Lustbarkeiten. ${ }^{415}$

Schneen am 5. Sonntag nach Trinitatis 3) ich am 7. Sonntag nach Trinitatis und 4) Herr Pastor Schröter in Jühnde am 9. Sonntag nach Trinitatis, u.s.w.

411 Friedrich Wilhelm Muhlert (Meyer, Pastoren II 140)

412 Gottesdienstliche Handlungen.

413 Georg III.

414 Der Täter James Hadfield wurde wegen Schuldunfähigkeit freigesprochen (not guilty by reason of insanity). Vgl. Eigen, Joel Peter: Hadfield, James (1771/72-1841), in: Oxford Dictionary of National Biography (ODNB), Oxford University Press, 2004 [http://www.oxforddnb.com/view/article/41013, (11.12.2013).

415 Das gleiche geschah 1786, als das Konsistorium für den 12. Sonntag nach Trinitatis ein öffentliches Dankfest verordnete wegen glücklicher Bewabrung des Lebens und der Gesundheit unsers Allergnädigsten Königs, bey der am 2. Aug. von einer wabnsinnigen Person Ihm bevorgestandenen nahen Todesgefahr... Willich, Supplement 1792, S. 24. 
In diesem Sommer hat die Obernjesische Gemeine auch auf für den hiesigen Schullehrer, Andr: Christof Mündemann, in dem Kleinen Garten, zwischen dem Schulhause und des Bauermstrs, Joh: Christof Zimmermann, Scheure einen ganz neuen Brunnen graben, ausmauern und anlegen lassen. Voriges Jahr hat sie auch einen dielenen Fusboden in der Werkstube des Schulhauses legen lassen.

Am 7 ten Aug: ward ein Circular und in demselben ein Ausschreiben Königl: Consist: vom 22sten Apr: d. J. praesentirt, in welchem verordnet wurde, daß jede Kirche aus ihren Mitteln die von dem Consistorialentgeltsecretär und zeitigen Kirchenrechnungsrevisor Schädler herausgegebenen Zinsberechnungstabellen anschaffen und mit 12g: Cass: M: bezahlen sollte

Am 10ten Aug: ist als Dom: 9 post Trin: ist der Candidat Jac: Oppermann, der Sohn eines Maurers in Hedemünden, als Pastor in Grone, unsrer Inspecktion Göttingen 1sten Theils von dHn: Gener: Superintend: Wagemann in Göttingen introducirt.

Am 26sten Aug: wurde per Circulares ein Consistorialausschreiben vom 1sten Julii d.J. zu und neben demselben eine Pastoralinstruction zunächst für angehende Prediger den Predigern des Hannoverschen Consistorii mitgetheilt. Diese Instruction hatte der $\mathrm{H}$. Abt und Cons. Rath Salfeld ${ }^{416}$ bereits vorhin in des ersten Bandes erstes Heft seiner Beiträge zur Kenntniß u. Verbesserung des Kirchen- und Schulwesens in den Kön: Brschw. Lüneb: Churlande, Hannover 1800 einrücken lassen

Am 9ten Sept: starb an der Ruhr der Superintend: der Mün-

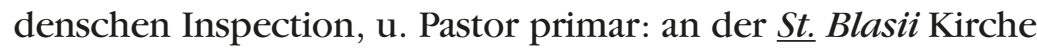
in Münden, Mag: Paul Caspar Dürr, ein Sachse, mit Hinterlassung 1 Witwe, und 7 unversorgter Waysen im 51sten

Vgl. EIGEN, Joel Peter: Nicholson, Margaret (1750?-1828), ODNB, Oxford University Press, 2004 (http://www.oxforddnb.com.oxforddictionaryofnationalbiography.han. sub.uni-goettingen.de/view/article/20145) (23.9.2015).

416 Johann Christoph Salfeld war von 1792-1829 Abt zu Loccum (vgl. KRUmwiede, S. 252). 


\section{[182v]}

Pag. 12 Posteritati de 1800

Lebensjahre. Er war zuerst Repetent der theologischen Facultät in Göttingen; und von 1782 bis 1789 Pastor an der Aegidienkirche, und Garnisonprediger in Münden. Er hat sich im Jahr 1778 durch eine lateinische Piece: De Genealogia Jesu bekannt gemacht. ${ }^{417}$

Am 28sten Sept: ist der Superintend: u. Pastor in Herzberg, Joh: Friedr: Raven an Steinschmerzen mit Hinterlassung 1 Witwe und 7 Kinder im 70sten Lebens- und 44

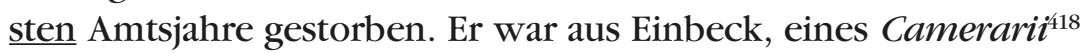
ältester Sohn, mein würdiger Landsmann ${ }^{419}$ und treuer Freund. Seit 1756 war er Pastor in Niederbörry bei Hameln; seit 1780 Pastor und seit 1795 Superintendent in Herzberg.

Am 1sten Oct: starb der Pastor primar: an der Marktkirche in Hannover, Joachim Friedrich Lehzen, im 69sten Lebensjahre. Er war zuerst Feldprediger im 7jährigen Kriege bei den Dragonern der Legion britannique; dann Collaborator bei der Hamburger Gemeine in London; dann seit 1766 Pastor in Langenhagen; dann seit 1771 2ter Diaconus in Celle; dann seit 1775 2ter und seit 1789 erster Prediger an der Marktkirche in Hannover.

Am 9ten und 10ten Nov: hat in hiesiger Gegend ein fürchterlicher Sturm gewüthet, der an Dächern, Häusern und Gärtens vielen Schaden verursachet hat. Ungleich fürchterlicher aber hat dieser Orcan, öffentlichen Nachrichten zufolge, in eben dieser Zeit zur See gehauset, und nicht allein Hätrer umgeste Schiffe zertrümmert, sondern auch mit Mann und Maus in die Tiefe begraben. So lauten die Nachrichten aus England, Frankreich, Holland, u.s.w. In andern Gegenden hat er auf dem festen Lande Häuser eingestürzt, und Menschen unter ihren Trümmern begraben.

417 Paul Caspar DürR: Genealogia Jesu bominis O.M. cum chronologico vaticinorum de Messia indice, Gottingae 1778.

418 Stadtschreiber, Kämmerer.

419 Pastor Proffen stammte auch aus Einbeck. 
Einer Verordnung Sr. Maj: des Königs vom [Angabe fehlt] zufolge sollen alle Superintendenten, Direcktors oder Recktors, jene wenn Landskinder nur Privatunterricht - diese aber, wenn sie Unterricht auf öffentlichen Schulen genossen haben, und nun zur Academie in Göttingen, um Theologie zu studiren, abgehn wollen,

\section{[183]}

\section{Pag: 13 Posteritati de 1800}

14 Tage vor deren Abgange einen Bericht von ihrem Herkommen, ihren Aeltern, Vermögensumständen, Talenten, erlernten Wissenschaften und Sprachen, von ihrem Fleisse und Wandel an das desfals von Sr Maj: verordnete Ephorat $^{420}$ in Göttingen versiegelt, ohne Notitz des Subjects, einschicken. Der aus der theologischen Facultät bestellte Ephorus aber soll, seiner Instruction zufolge, den jungen Theologen bei seiner Ankunft auf der Academie tentiren ${ }^{421}$; Rath und Anleitung zu dem Gange seiner Studien geben; wenigstens alle 14 Tage ein Disputatorium mit den theologischen Landeskindern anstellen, ihren Wandel sorgfältig beachten, und von dem allen einen Bericht an Kön: Chf: Consistorium abschicken. Nach absolvirten Studien soll dann der junge Theolog 14 Tage nach seinem Abgange von der Universität sich bei dem Consistorio melden, seine Testimonia produciren, und ein so genanntes examen praevium ${ }^{422}$, das ihn jedoch von seinen künftigen beiden Candidaten examinibus nicht liberirt, ausstehn. Auch an die Superintendenten, Directores und Rectores scholae sind die behufigen Befehle und Instructions ergangen. Zum academischen Ephorus ist der zeitige H. Consistorialrath und Prof: theol: primar:, Theophil: Jacob Planck ${ }^{423}$ in Göttingen ernannt. Die Königl: Ver-

420 Gemeint sein kann sowohl das Predigerkollegium, das bereits zur Gründungszeit der Universität der theologischen Fakultät angegliedert wurde als auch das Pastoralinstitut, dessen Einrichtung 1782 von dem Professor der Theologie Heinrich Philip Sextro (1747-1838) angeregt worden war (HammanN, in: Göttingen Bd. 2, S. 538). Der Leiter wurde als Ephorus bezeichnet.

421 Im Sinne von: unter seine Fittiche nehmen.

422 Vorexamen.

423 Auch Gottlieb Jacob Planck, 1751-1833 (http://d-nb.info/gnd/116203757 (16.11.2015)). 
ordnung selbst aber ist den Predigern per circulares noch nicht communicirt, dagegen aber sogar in den Dorfschenken affigirt. $^{424}$

Am 13ten Dec: wurde per Circulares ein Ausschreiben K: Consistorii vom 13ten Nov. communicirt, kraft welches der Anfang eines neuen Jahrhunderts auf den 1sten Jan: 1801 angezeigt, und zugleich ein Formular des öffentlichen Kirchengebets auf den Anfang des neuen Jahrhunderts mitgeteilt - und daneben verordnet wurde, die neue Epoche nur kurz in der Predigt zu berühren.

[183v]

Pag. 14 Posteritati de 1801

$$
\underline{\text { ANNO } 1801 .} .
$$

Als im vorigen Jahre der Musketier Andr: Fehrensen, beim Gerichtsschulzenamte einen Vermessungs- u. Besteinigungsbefehl an den Feldmesser Mündemann in Rosdorf ausgewirkt hatte; und so hat dieser darauf nicht allein den - jenem Fehrensen gehörigen an einem Pfarr 1 1/2 Vorlingstücke herausgehenden Morgen im Dramfelde unterhalb des Weges - sondern auch die der Pfarre im dieser Dramfelde sämtlich zugehörenden 15 Morgen - ja die dasige sämtliche Lageländerey vermessen. Als nun aber durch diese Vermessung $\mathrm{u}$. Besteinigung die 2 aneinander her liegende 1 1/2 Vorlingstücke ein ganzes 1/2 Vorling verloren - Mündemann auch einen in der Ferche gestandnen Grenzstein ausgehoben und vorne an den Fahrweg als Grenzstein gesetzt hatte: so protestirte ich gegen diese Vermessung und Besteinigung, und bat bei der Kirchencommission um Vermessung und Besteinigung der 15 Morgen Pfarrländerei im Dramfelde. Meine Protestation fand aber nicht allein kein Gehör: sondern sie kostete mir auch 2Thl; und mein Gesuch um Vermessung pp ward von der Kirchencommission verworfen.

Ich wandte mich darauf an Kön: Consistorium; denunciirte jenen Vorgang nebst Einsendung der Acten; und bat nicht allein um Verhaltungsbefehle, sondern auch um die Restitution der 2Thl. Kosten aus dem Kirchen aerario. Kön: Consistorium

424 Durch Anschlag bekannt gemacht. 
foderte darauf Bericht von den Kirchencommissarien; und nachdem solcher eingegangen war: wurde ich nieht allein vom Consistorio, nicht allein zur Ruhe verwiesen, sondern auch noch in die Kosten, die, der Rechnung des Gerichtsschulzen gemäß, außer jenen 2Thl: noch $6 \mathrm{Thl}: 27 \mathrm{~g}$. betrugen, condemnirt.

Die Acten darüber habe ich in der Registratur niedergelegt. Am 18ten Jan: als Dom: 2 p. Ep:425 ist der Cand: Stephan als Past: in Bischbausen von dem Superintend: Schlegel introducirt.

Am 19ten Apr: als Dom: Miseric: Dom: ${ }^{426}$ ist der bisherige Past: in Adelepsen, Mag: Osann als Past: in Rosdorf von dem Gener: Super: Wagemann, unter Assistenz des Past: Adj: Jatho in

\section{[184]}

Pag: 15 Posteritati de 1801.

Sieboldshausen, u. des Past: Oppermann in Grone, introduc:

Dom: Jubilate ${ }^{427}$ ist darauf der von dem Consistorio dem Patron von Adelepsen zum Pastor präsentirte Candidat Cohrs von dem Gener: Super: Wagemann introducirt.

Im Julius d. J. hat die hiesige Gemeine die Hausdiehle im Schulhause, die bisher noch aus dem blossen Erdboden bestand, mit Sandquadersteinen aus dem Reinhausischen Bruche, durch den Amtsmauermeister Möser in Reiffenhausen, belegen lassen auch durch den hiesigen Amtszimmeister [!] Salzmann die Schwellen auf dem netren Fundament des neuen Schulbrunnens, wie auch das Gehäuse auf demselben verfertigen lassen.

Im August dieses J. sind die Schwellen unter der Sakristei in Dramfeld, weil solche nebst dem Fundament gesunken waren, durch den Amtszimmeister [!] Salzmann wieder erhöhet - und nächstdem auch die Lücke des Fundaments

425 Zweiter Sonntag nach Epiphanias.

426 Misericordias Domini: Zweiter Sonntag nach Ostern.

427 Jubilate: Dritter Sonntag nach Ostern. 
wieder ausgemauert worden, und zwar auf Kosten der dasigen Kirche.

In demselben Monat ist die Kammer an der Gesindestube auf Befehl der Kirchencommissarien auf Kosten der beiden Gemeinen durch den hiesigen Tischler, Joh. Heinr: Schäfer, zu einer Schlafkammer für die Kinder aptirt, und daher der Fusboden mit ganz neuen Dielen belegt.

Im Oct: ist auch im Backhause der Brau- und Kochheerd durch des Mauermeisters Linnen in Reiffenhausen Lehrpurschen, J. Treckers ausgebessert, der Heerd im Kamin als Wohnstubenofens - und das Pflaster in 1 Schweinkofen neu ausgepflastert; durch Friedr. Hampen Sen: die Wand im Schafstalle an dem Schoppen neu ausgelementirt, und durch Heinr. Schäfer eine neue Thür vor den Schafstall auf der Seite der Dröschdiele gemacht.

Einem Landesgesetz zufolge, daß der Clerus, gleich jedem Reihemann, und zwar ohne Entgeld, an jeder Gemeinheit Theil nehmen sollte, hielt ich bei Kön: Kirchencommission für den hiesigen Prediger, die hiesige

\section{[184v]}

Pag: 16 Posteritati de 1801.

Predigerwitwe, und den Schullehrer um das - uns gebürende Antheil, sowie an Huth und Weide, und dem Jesenholze, und dem Bruche, also auch an dem neuen Anger her und dem Grummet des Pfingstangers an. Vom Gericht Leineberg aber wurden darauf, der Bauermeister, Christof Zimmermann, und der Vorsteher Andr. Schäfer, über diese Ansprüche vernommen. Nachdem nun diese unsre Ansprüche verworfen- und ihre Erklärung uns communicirt - wir auch zur Duplick aufgefordert worden: widerlegte ich ihre Widersprüche; und nachdem der Bauermeister und Vorsteher Säuffer abermahls dagegen sich verantwortet hatten: ward mir darauf der Bescheid vom Gericht, mich ad causam mit mein Scheuer K. Consistori zu legitimiren. Bis dahin beruhet nun die Sache. Ich habe indessen aus meiner Tasche 29g. Cass. M: Kosten dafür bisher gehabt.

Unterm 18ten Dec: ward ein Ausschreiben K. Consist: per Circul. communicirt, nach welchem ein Dank- und Friedensfest am 
3ten Jan. 1802. für den algemeinen Frieden ${ }^{428}$, jedoch mit unveränderter Einrichtung des gewöhnlichen öffentl. Gottesdienstes, nur mit Absingung des Te Deum ${ }^{429}$ vormittags, und: Nun danket Alle Gott, Nachmittags, und mit Ablesung des vorgeschriebenen Gebets gefeiert werden sollte.

\section{$\underline{A_{N N O} 1802}$}

Einem Circularbriefe des Hn. Gen: Super: Wagemann vom 18ten Febr: war ein Rescript Kön: Chf: Consistorii beigelegt, in welchem den Predigern dieser Inspection bekannt gemacht wurde, daß $\mathrm{S} \underline{r}$ Kön: Maj: den bisherigen Prediger zu St Nicolai in Göttingen, Ehrn Dr. Joh: Friedr: Christof Gräffe (er war von 1784 bis 1792 Pastor hirselbst gewesen) nicht nur zum Prediger zu St Albani in Göttingen - sondern auch zugleich zum Superintendenten der neu angeordneten Inspection Göttingen 3ten Theils bestellt - und derselben folgende 8 Pfarren aus der bisherigen - dem Hn. Gener: Super. Wagemann zugehörten Inspect. Göttingen 1sten Theils beigelegt hätten, als 1) Ballenbausen. 2. Deiderode, 3. Gr: Schneen.

4) Lütg: Schneen, 5. Niedernjesa. 6. Obernjesa ${ }^{430}$. 7. Reckers-

bausen, 8. Reifenhausen, jedoch mit dem Vorbehalt, daß dgl.

[185]

Pag: 17 Posteritati de 1802

Gener: Super: Wagemann die Emolutemente aus dieser neuen Inspect: behalten sollte. Die Prediger musten nun nicht allein das Rescript K. Consist., und den Circularbrief dHn: Gen: Super: mit ihren Praesentatis ${ }^{431}$ versehn, sondern auch auf einem eigenen

428 In der Literatur heißt es zur politischen Lage: In den (...) Kriegen, die seit 1799 keine revolutionären Kriege, sondern von Napoleon gefübrte Hegemonialkriege waren, die das europäische Staatensystem erschütterten und das Deutsche Reich zur Auflösung brachten, war der Kurstaat Hannover bis 1803 nicht aktiv beteiligt... Die im französischpreußischen Separatfrieden von Basel 1795 vereinbarte Neutralität Norddeutschlands ließ erwarten, dass nach der Besetzung des linken Rheinufers die französischen Truppen nicht weiter vordringen würden, weil dies zum Krieg mit England führen musste (Vierhaus, in: Göttingen Bd. 2, S. 38).

429 Ein Te Deum Laudamus (Herr, wir loben Dich) wurde an speziellen Gedenktagen angestimmt; in Göttingen gab es nach dem Dreißigjährigen Krieg acht Te Deum-Termine, die 1775 auf vier reduziert wurden (HammanN, in: Göttingen Bd. 2, S. 529).

430 Obernjesa hatte bisher zur Inspektion Münden II. Teils gehört.

431 Eingangsvermerk. 
Bogen obedientiam ${ }^{432}$ et reverentiam ${ }^{433}$ schriftlich angeloben. ${ }^{434}$ Der Herr D. Gräffe ist darauf Dom: Invocavit ${ }^{435}$ als am 7 ten März als Pastor zu $\underline{S t}$ Albani introducirt worden.

Auch die bisherige Inspection Münden ward nach Absterben des Superintend: Mag: Dürr in 2 andre vertheilt, und die eine, die Inspection Dransfeld genannt; dem bisherigen Superint: der Insp: Harste, und Pastori zu St Marien in Göttingen, Ludw: Gerhard Wagemann (einem Bruder d: Gener: Superint:) beigelegt, und folgende Pfarren dazu bestimt: 1. Bühren. 2. Dankelshausen.

3. Dransfeld. 4. Fürstenhagen. 5. Hemeln. 6. Jühnde.

7. Meensen (diese 2 hat $\mathrm{dH}$. Gen: Sup: dazu abgegeben.) 8 Varlosen.

Die andre Inspect. ward die Insp: Hedemünden genannt; die dasigen Pastori, Joh. Christi: Friedr: Bornträger beigelegt, und folgende Pfarren dahin ausgesetzt, als 1. Gimbte. 2. Hedemünden. 3. Landwernhagen. 4. Lutternberg. 5. Speele. 6. Uschlag. 7. Wiershausen. Die bisherige Inspect: Harste aber dem Pastori in Gladebeck, von Einem, als Superintend: conferirt

Kurz vorher aber noch wurden unterm 24 Jan: 2 Königl. Verordnungen, beide d.d. Weymouth ${ }^{436}$ d. 11ten Aug: 1801 praesentirt. eine war eine Erneuerung und nähere Erklärung der Verordnung vom 6/17 Jun: 1738 betreffend das - denen Superintendenten - und Predigerwitwen und Erben zukommende resp: ganze und halbe Gnadenjahr. Die andre aber enthielt eine nähere Bestimmung der ältern Verordnung de dato 4/13 Jul: 1738 wegen Taxirung der Pfarrmelioramente.

Am 1sten Apr: d. J. wurden von dem neuen Hn. Superint:

Dr Gräffe per Circulares 3 Consistorialverordnungen, alle vom 8ten Dec: 1801 praesentirt, und in die Pfarregistratur gelegt

Die

432 Gehorsam.

433 Ehrerbietung.

434 Dies war eine durchaus bemerkenswerte Berufung; normalerweise wurde bei der Einführung eines Pastors in seine Gemeinde das Versprechen von Gehorsam und Ehrerbietung (Respekt) lediglich per Handschlag verlangt (vgl. die Einführungspapiere für Pastor Proffen 1798; HStAH, Hann 83 III Nr. 417 II, S. 467 und 468).

435 Erster Sonntag der Passionszeit.

436 Dort verbrachte Georg III. zwischen 1789 und1805 die Sommermonate. 


\section{[185v]}

Pag. 18 Posteritati de 1802

Die 1ste betraf das so genannte eiserne Pfarrinventarium der exspirirten Melioramente ${ }^{437}$, und Besteinigung der Pfarrgrundstücke aus dem Kirchen aerario.

Die 2te betraf ein - von dem Prediger zu führendes Wirthschaftsbuch, nebst dem Modell desselben. 438

Die 3 te betraf die Auseinandersetzung des Cleri minoris in Translocations- und Sterbefällen.

Laut eines doppelten Consistorialausschreibens wurde zur Erbauung einer ganz neuen Kirche in Niedernjesa unsrer Inspecktion nicht allein eine doppelte Kirchenvorraths- sondern auch eine Beckencolleckte gnädigst bewilliget. Diese veranstaltete ich denn auch am 2 ten Ostertage. Sie betrug in Obernjesa 1Thl:15g: und in Dramfeld $27 \mathrm{~g}$ :

Als im Frühjahre 1802 die Gemeine ihr Loosholz gehauen hatte, und die Hauung einen Theil des Reviers traf, der an die Hornbreite des Pfarrlandes am Dramfeldschen Wege grenzt, und zwar von Wissels Lande an, und weiter hinauf: so hatte sie auch zugleich dasjenige Holz mit abgehauen, welches diesseits des Grabens, der die $G$ gewachsen war. Da ich nun aber von dem ältesten Mitgliede der Gemeine, dem Schmid, Ludolf Dehne, erfuhr, daß der Graben die Grenze zwischen dem Gemeineholze und dem Pfarrlande bestimme, (welcher Meinung denn auch mehrere Mitglieder der Gemeine nachher beistimmten) und daß folglich das disseits des Grabens abgehauene Holz der Pfarre zugehöre; auch Herr Pastor Stollberg Jun: vor 28 Jahren das Holz an eben dieser Stelle habe hauen lassen: so zeigte ich diesen Vorgang dem zeitigen Ephoro $^{439}$ unsrer Inspecktion, dem Hn: Superintendenten, Dr Gräffe, in Göttingen an, der vorhin mein Praeantecessor in officio gewesen war. Dieser bestätigte denn die Aussage des Ludolf Dehne; behauptete nicht allein, daß der Grabe die Gren-

437 Vgl. EвнаRdt, Band 4, Hannover 1840, S. 162ff. Zum Beispiel Bäume. 438 Ein Exemplar dieses Wirtschaftsbuches war bisher nicht zu finden.

439 Dr. Gräffe war Inspektor des Pastoralinstituts, d.h. Leiter der Stipendiatenstiftung der Theologischen Fakultät der Universität Göttingen (KRUmwiede Bd. 1, S. 244 und 252). 
ze zwischen dem Pfarrlande und dem Gemeineholze bestimme, sondern auch, daß er selbst vor 14 Jahren das Holz daselbst bis in die Mitte des Grabens habe hauen lassen. Ich bat ihn

\section{[186]}

Pag: 19. Posteritati de 1802.

daher nicht allein als Superintendent, sondern auch als vormahliger Prediger hieselbst das Interesse der Pfarre bei dem Gericht Leineberg zu besorgen. Dies geschah: denn auf gerichtlichen Befehl muste der Feldmesser Mündemann in Rosdorf sowol das Locale, als auch den Graben und das abgehauene Holz besichtigen, und dann davon berichten. Da nun auch die beiden anwesenden Gemeinevorstehers, Sätfff Andreas Säuffer und Andr: Schäfer gegen die Behauptung der Gerechtsame der Pfarre nichts einzuwenden wusten, vielmehr sich mit der Unwissenheit entschuldigten: so wurde auf der Stelle resolvirt, sowol die Grenze durch 7 Mahlsteine ${ }^{440}$, die ganze Pfarrbreite hinauf zu bestimmen, als auch nächstden das abgehauene Holz der Pfarre zu restituiren. Dies geschah denn auch wirklich am 14ten May, die 7 Mahlsteine wurden mitten in den Graben in meiner, des Pastoris Proffen - des Bauermeisters Joh: Christof Zimmermann - des Vorstehers Joh: Andreas Säuffer - des Vorstehers Joh: Andreas Schäfer - und des Feldgeschworenen Joh: Heinrich Biermann Gegenwart von dem Feldmesser Mündemann aus Rosdorf, auf Kosten der Gemeine, gesetzt. Doch blieb es jetzt noch unentschieden, wer den Graben in der Folge frisch aufzugraben verpflichtet sey.

Vid. Bericht und gerichtl: Confirmat. d.d. 30. Aug: a.c. in der Registratur. J. F. Proffen

An eben dem 14ten May wurde von obigen 3 Gemeinevorstehers resolvirt, den Weg, auf welchem sie im künftigen und folgenden Jahre das Holz aus dem Jeserberge von der Holzecke ab nach Süden übers Land fahren wollten, durch Mahlsteine zu bezeichnen, so daß diese die Mitte der Wagenspur anzeigen solten. So wurden denn auch wirklich von

440 Grenzsteine. 
dem Feldmesser Mündemann an 3 Orten auf dem Wege Steine gesetzt, indem Jene behaupteten: die Gemeine müsse sich die Fahrt über das Land gefallen lassen. Weil aber der Fahrweg mit dem Holze auch die Pfarr-

\section{[186v]}

Pag. 20. Posteritati de 1802

breite am Dramfeldschen Wege, die Kleine Breite genannt, treffen würde: so protestirte ich nicht allein, bis zu ausgemachter Sache, gegen die Fahrt mit der halben Spur über die Pfarrbreite von 4 Vorlingen, obsie gleich deren Observanz vorgaben, sondern auch vielmehr gegen das Setzen eines Steins am oder auf dem Pfarrlande. Indessen bewilligte ich das Setzen eines Steins auf Gemeine Grund und Boden im Dreisch, am Ende des so genannten Pfarrkielmorgens, weil ich glaubte, daß dadurch dem Pfarrlande keine Beeinträchtigung geschähe; und solcher nur die Spur zur Fahrt anzeigen solte.

Noch ist nachzuholen, daß ein K: Chf: Consistor: Ausschreiben d.d. 18 Dec: 1801 zufolge, am 3ten Jan: 1802, als Festo Epiph: auf Befehl des Königs ein Dankfest für den - mit der französischen Republick gestifteten algemeinen Frieden gefeiert würde ${ }^{441}$, doch so, daß die gewöhnliche Einrichtung des öffentlichen Gottesdienstes unverändert bliebe; und nur der Schluß der Predigten über die gewöhnlichen biblischen Texte, auch der Catechisationen auf eine erbauliche Weise eingerichtet - das verordnete Dankgebet Vorund Nachmittags vorgelesen - und Vormittags nach der Predigt das Te Deum - und Nachmittags das Nun danket Alle Gott, abgesungen würde.

In der Nacht vom 14 auf den 15 May trat eine solche Kälte ein, daß die Vietsbohnen und das Kartoffelnkraut erfroren. In einer der folgenden geschah eben dasselbe, wie denn auch die aufgegangenen Gurken erfroren.

Am 18ten May trat auch ein starkes - mit vielem Frost verbundenes Schneewetter ein.

In diesem Jahre hat die Gemeine Obernjesa eine ganz neue Thurmuhr statt der bisherigen abgängigen und fehlerhaften

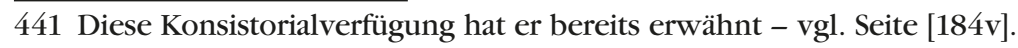


angeschaft. Sie schlägt nicht allein alle Stunde, sondern auch Viertelstunden. Der Kleinschmid und Uhrmacher Tewes in Varlosen hat sie verfertigt. Die Gemeine gibt ihm dafür laut $A c$ cords 125 Thaler, und die alte Uhr zurück. Zu diesen $125 \mathrm{Th}$ : hat König: Consistorium der Gemeine 45 Th. als ein Geschenk aus dem aerario der Kirche, jedoch ohne Consequenz, bewilliget, und zwar in Cassenmünze. Am 17ten May wurde die Uhr

\section{[187]}

\section{Pag: 21 Posteritati de 1802}

von dem Vorsteher, Joh: Andr: Schäfer hieselbst, auf einen 2 spänigen Wagen chausseefre $i^{442}$ hierher gebracht; am 18ten und 19ten aufgestellt und in Gang gebracht, so daß es am Abend des 19 ten sowohl volle als Viertelstunden schlug. Jedoch ist die Uhr, weil sie auch $1 / 4$ Stunden schlagen solte, und desfals zur Uhrkammer ein größerer Raum erforderlich war, 2 Etagen höher hinauf, unter den Boden des Klockthurms, obgleich mit vieler Mühe, angelegt worden. Die neue Uhrkammer hat der Tischler, Christian Friedr: Lüdeke, in Dramfeld - den neuen Hammer, der die $1 / 4$ Stunden an die Kleine Klocke schlagen sollte, der Schmid, Ludolf Dehne, hieselbst verfertigt die beiden Zieferblätter aber gegen Osten und Norden mit neuen Farben renovirt der Tischler Kleinhans in Gr: Schneen. Diese neue Uhr geht 48 Stunden. Prediger war jetzt: ich, Joh: Friedrich Proffen; Schullehrer und Küster, Andr: Christof Mündemann; Kirchenvorsteher, eben dieser und Johann Andreas Harriehausen; Bauermeister, Joh: Christof Zimmermann; und Gemeinevorsteher, Joh: Andr: Säuffer und Joh: Andr: Schäfer.

Als die Mäuse u. Schnecken im Jahr 1801 auch in der Saat des Winterfeldes, zumahl nach Rosdorf zu, und besonders da und an mehrern Orten, einen unsäglichen Schaden angerichtet hatten, so daß im Frühjahre d. J. mehrere Aecker Roggen umgepflügt - und mit Sommer- und Braackfrüchten bestellet werden musten: so stieg der Preis des Himtens Roggen bis auf 2Thl.6 - 9g. Nur erst gegen die Ernte d.J. fiel er auf 1Thl.24g.

442 Ohne das Chausseegeld für die Benutzung der Chaussee zu zahlen. 
Am 17ten Jul: gegen Morgen zwischen 1-2 Uhr hatte sich ein Bösewicht durch Eröfnung der Thür des Kuhstalls auf die Hausdiehle in das Haus der Rel. Johannes Engelhard und deren einzigen - am 28 Febr: d.J: an den verabschiedeten Dragoner des 6ten Reg: Georg Christian Frölich, verheiratheten Tochter, Marie Charlotte, geschlichen, weil er vermuthlich gewust hatte, daß der junge Ehemann gerade in der Nacht im Pferdestalle seines ältesten Bruders, des Krügers u: Dragoners, Friedr: Fröhlich, übernachtete. Er war darauf in die unverschlossene Stube gegangen, in

\section{[187v]}

\section{Pag. 22 Posteritati de 1802}

welcher Mutter u. Tochter im Bette lagen, hatte die Schieblade unterm Tische herausgezogen, und Geld darin gesucht: Als er aber nicht dieses - sondern die Uhr des Ehemannes darin findet, nimt er diese heraus, legt sie auf den Tisch, und fragt: Wo habt ihr das erborgte Geld? Als darauf die Mutter antwortet:

wir haben kein Geld, geht er nicht auf diese, ob sie gleich ihm nahe stand, sondern auf jene, die noch im Bette war, mit einem Messer los; sagt zu ihr: so sollst Du auch sterben; und stößt der jungen Frau, die zugleich schwanger seyn soll, das Messer zu 3 mahlen in die Brust. Als diese darauf in ihrer Angst das Fenster eröfnet, und um Hülfe schreit: geht er aus dem Hause weg. Einer der Nachbarn, Georg Hahn, geht darauf hin, den Ehemann zu holen: schon begegnet er ihm aber im Dorfe in den Dragonermantel seines Bruders gehüllt, ohne Beinkleid; und eilt nach dem Hause seiner Frau, unter dem Vorgeben: er habe vor Angst und Unruhe nicht zu bleiben gewust. Auf dem Rückwege nach seines Bruders Hauß will er einen Fall gethan, und an einem - an der Erde liegenden - Heinr: Apel zugehörenden Baume sich eine Wunde auf der rechten Hand verursacht haben. Sein Bruder Friedrich muß daher den Escadr. Chirurg: Wallrath ${ }^{443}$ beim 6sten Reg: von Niedernjesa hohlen, um ihn und seine Frau zu verbinden. Da die Nachricht von dieser That bald darauf durch den hiesigen Bauermstr., Christof Zimmermann, dem Gerichte angemeldet war, hatten der Leibmedicus Strohmeyer ${ }^{444}$ und Stadtchi-

443 Chirurg der Schwadron mit Namen Wallrath.

444 Doktor Strohmeyer ist einer der Nachfolger des Doktor Papen. 
rurgus Warneke die vorhandnen Wunden - der Amtschreiber Böhmer aber und der Obervogt Tusch die geschehene That untersucht. Weil nun aller Verdacht auf den Ehemann selbst fiel: wurde derselbe am 18ten ej: nach dem nachmittägigen Gottesdienste von dem Obervogte arretirt, von dem Untervogte geschlossen, und von demselben, durch 2 reitende Dragoner mit gezogenen Degen nach Grone ins Gerichtshaus escortirt, und ins Criminalgefängniß gesetzt. Die Wunden der zu ermordenden sind jedoch nicht tödtlich erfunden. Ich hielt darauf am 25. ej. als Dom: 6 p: $\operatorname{Tn}^{445}$ die Casualpredigt über Matth: II, 13 - Ende..$^{446}$

\section{[188]}

\section{Pag: 23 Posteritati de 1802}

Einem Ausschreiben des K. Consistorii $d$. $22 \mathrm{Jul}$ : zufolge wurde mit Genehmigung K. Staatsministerii verordnet, daß der am Quatember - Mittewochen vor Michaelis zu feiernde Bustag ${ }^{447}$ für dasmahl, nicht wegen Verspätung der diesjährigen Ernte, besonders in Ansehung der Sommerfrüchte, deren Wachsthum durch die lange angehaltene Dürre aufgehalten worden, nicht am 15 Sept: sondern erst am 3 ten Nov: algemein gefeiert werden solle.

Einem K. Ch: Consistorialausschreiben vom 25 May zufolge soll die jährlich Dom: 2 p. Epiph: neben der Eheverlöbniß constitution zu verlesende Anzeige in Ansehung einiger verbotenen Ehe hinführo cessiren.

Auch wurde in eben dem Circular, einem K.Ch: Consist: ausschreiben zufolge, in unsrer - so wie in den Inspecktionen der Fürstenthümer Calenberg, Göttingen, Grubenhagen, und der Grafschaften Hoya und Diepholz eine Colleckte von dem Clero majore für den Prediger, Ehrn Vogel in Wassel, Insp: Pattensen ${ }^{448}$, der in einer Feuersbrunst einen Schaden von 391 1/2 Thl. erlitten hatte, gesammelt. Mein Beitrag dazu war ein Gulden Cassenmünze.

445 Sechster Sonntag nach Trinitatis.

446 Da sie aber hinweggezogen waren, siehe da erschien der Engel des Herrn dem Joseph im Traum..

447 Vierter Termin der vier Bußtage, die im Jahr begangen wurden.

448 Johann Heinrich Vogel (Meyer, Pastoren II, S. 480). 
Zugleich wurde auch, einer Consistorialbewilligung zufolge, von dem Superintend: Brase in Wunstorf in eben jenen Fürstenthümern für den abgebrannten Schullehrer Burgtorf in Kleinen Heidorn + eine Colleckte von dem Clero minore gesammelt. + Kirchspiels Wunstorf.

Mit Bewilligung des Hn. Superint., Dr Gräffe, sind Heyms Predigten ${ }^{49}$ sowol über die evangel: als epistol: Texte zum Vorlesen an den Sonntagen von dem Schulmeister, angeschaft, und von dem Buchbinder Junker in Göttingen samt dem Einbande aus den Mitteln hiesiger Kirche bezahlt erkauft mit 2Thl:15g. Conv: $M$.

Die Lerchenbreite im Sieboldshäus: Felde sollte zwar vermessen und besteiniget werden, da sie, nach Aussage des bisherigen Pächters Seuffer, zu klein ist. Da indessen deren Seite nach Sieboldshausen zu mit der daran grenzenden nicht einerlei Lage hat: so habe ich es bewilliget, daß an gedachter Seite an der Pfarrbreite hinauf 3 Mahlsteine gesetzt worden sind. Das Fehlende am Acker muß also auf der andern Seite nach Niedernjesa hin gesucht werden.

[188v]

Pag. 24 Posteritati de 1802

Am 10ten Oct. ist der von dem Seniore der von Mengershäusischen Familie, Joh: Detlev von Mengershausen in Hildesheim, dem Kön: Consistorio zum Adjuncto cum spe succed: ${ }^{450}$ auf die Pfarre zu Niedernjesa präsentirte Candidat, nachdem er zuvor examinirt und am 15 Sept. ordinirt, am 10ten Oct: als Dom: 17 post Trin: von den Herrn Kirchencommissarien, dem Hn. Superintend: Dr Gräffe in Göttingen, und Hn. Oberhauptmann von Uslar in Friedland introducirt, und dafür von dem Hn. Past: Sen: v. Mengershausen und mir dem Past: Proffen assistirt worden. Der Adjunctus heißt Joh: Heinrich Christof Geissel, ein Sohn des Cantors in Wiegleben ${ }^{451}$ im Gothaschen, und Bruder des zeitigen Pastors in Bremke,

449 Hier könnte es sich um M. Johann Gottlob Heym: Vollständige Sammlung von Predigten für christliche Landleute über alle Sonn- und Festtagsevangelia des ganzen Jahres. Zur häuslichen Erbauung verfertigt und dem Druck übergeben, Züllichau, Freystadt: N.S. Frommanns Erben [z.B.] 1792 handeln, das mehrere Auflagen erlebte.

450 Hilfsgeistlicher mit der Aussicht, die Nachfolge antreten zu können.

451 Heute ein Ortsteil der Stadt Bad Langensalza im Unstrut-Hainich-Kreis. 
und war der Erste in unsrer neu errichteten Inspection, den unser neue Ephorus introducirte

Im Novemb: ist statt des verstorbenen Vorstehers, Matthias Bock der Zimmermann, Lorenz Dehne, wieder zum Vorsteher erwählt und beeidigt.

Am 29 Nov: sind von dem Feldmesser Mündemann mit meiner und des Bauermeisters, Joh. Christof Zimmermann, Bewilligung zwei Grenzsteine gesetzt. Der erste am Gemeine Brückenwege nach Stockhausen zu zwischen Heinrich Schäfers Kirchenwiese, und des Bauermeisters Wiese. Der 2te oben zugleich zur Grenze zwischen $1 \mathrm{M}$. Pfarrwiese, der Papenwinkel genannt, den Friedr: Fröhlich in Pacht hat, und des Bauermeisters Wiese.

Eod: sind auch von demselben 2 Grenzsteine zwischen der Schulwiese und Engelhards Lehnwiese gesetzt. Der eine auf der Elle der Anhöhe, und der andre am Ende des Knies etwa 1 Fuß vom Weidenbaume.

Am 30 Nov. ist auch von demselben 1 Grenzstein zwischen der - von Heinr. Schäfer in Pacht habenden Kirchenwiese - und der 1 Morgen haltenden Pfarrwiese, der Papenwinkel genannt, oben auf dem Ufer der Leine, nahe an einer jungen Pfarrweide gesetzt. Die beiden - von Heinr: Schäfer gesetzten Weidenbäume, die in der Mitte mit Hieben bemerkt sind, gehören also von nun an der Pfarre.

[189]

Pag: 25 Posteritati de 1802.

Eodem ist zur Grenze zwischen eben diesem Papenwinkel und des Joh: Heinr. Apels Wiese ein Stein gesetzt.

Eodem ist sowol das 1 Vorling Kirchenwiese, welches Joh: Heinr:

Schäfer in Pacht hat, und auf den Papenwinkel stößt, als auch das daran grenzende 1 Vorling Magercourd.sche Wiese, welche der Krüger Engelhard in Stockhausen in Pacht hat, und unten auf den Gemeine Brückenweg - oben aber auf die Leine stößt, von dem Feldmesser Mündemann ausgemessen - und die Grenze zwischen beiden mit 6 Steinen bezeichnet worden, wovon der oberste nahe oben auf dem Ufer hart an einer ....[Wort fehlt] steht. Der Inhalt des Kirchenwiesen Vorlings ist 54 Ruthen $\square$. Eodem ist zur Grenze zwischen der hiesigen Schulwiese hinter dem Pfingstanger, und Engelhards Lehnwiese noch ein 3ter Grenzstein unten am Ende, und noch ein 4ter oben ans Ende am 
Gemeine Brückenwege, der zugleich und vornehmlich die Grenze zwischen der Oberjeser und Stockhauser Gemeine bestimmt, und seit seiner der vorigen Vermessung und Besteinung vom Landmesser Willich in Göttingen, verloren gegangen war, vom Landmesser Mündemann gesetzt worden.

Eodem sind auch von Ebendemselben, nachdem er einige Tage vorher sowol das Wisselsche, als auch das Fehrensche Lehnland von $1 \frac{1 / 2}{2}$ Vorlingen, und das 1 Vorling th Kirchenland, welches jetzt Joh: Heinr: Fehrensen Jun: Witwe in Pacht hat, ausgemessen hatte, zwischen dem Wissel- und Kirchenlande, und wiederum zwischen diesem und dem Fehrenschen Lehnlande, und zwar zwischen jedem drei Steine gesetzt. Das, was dem Kirchen- und Fehrenschen Lande fe an seinem wahren Gehalte fehlte, wurde theils vom Lübecks Wissellande, theils von Joh. Heinr: Biermanns Vorrathe ersetzt, so daß nun das Kirchenvorling 53 Ruthen, 58 1/4 Fuß enthält.

Von allen jenen seit dem 29 Nov. a.c: auf gericht: Befehl geschehenen Vermessungen und Besteinigungen liegt der Bericht des Feldmessers Mündemann nebst der gerichtlichen Confirmation d.d. 12 März 1803 in der Registratur.

[eingelegte Briefe]

[142]

Hochehrwürdiger Herr, Hochzuehrender Herr Amtsbruder!

Ew. Hochehrwürden haben uns in dieser Woche einen Brief zugeschickt, auf den ich sogleich zu antworten nicht Zeit hatte, aber jetzt einiges zu erwiedern habe.

1. Da die Rel. Kipp schon beerdigt ist, auch wahrscheinlich, weil kein Datum des Sterbetages in demselben Briefe stand, am 5 Jul. schon beerdigt gewesen ist und unter die eximirten Armen gehört hat, so mag die stille Beerdigung dieses mal gratis statt finden. Künftig wollen Ew. Hochehrwürden es so halten, daß die Armen in der Stille beerdigt werden können, wenn sie mit einem platten Sarge begraben werden. Ist dies nicht, so dürfen wir 
wohl nicht die Fisci-Gebühren für stille Beer-

digung erlassen.

2. Die Frau Schepeler werde ich um die genannten

Stücke befragen, wie es darum steht, und wie Sie

sich darüber erklärt.

3) In Ansehung des Gartenplatzes beim Witwenhause

kömmt es erst darauf an, ob die Gemeinde sich

auch wirklich diesen Platz anmassen will, oder

ob es bloß Sage ist, wie es Ihr Brief enthält.

[Rückseite]

4) Wenn die Eltern der enormen Absenten unter den Schulkindern von jetzt an ihre Kinder nicht fleißiger schicken, so werden sie Ende dieses halben Jahrs in einem Verzeichnisse der Obrigkeit übergeben.

5) Was den Bauermeister betrifft, der zur Zeit, wie die Betstunde angehen will, durch die Trommel die Gemeinde auf den Thie berufen hat, so ist das erste, was hier zu thun ist, den Bauermeister zu erinnern, daß der Gottesdienst nicht gestört werden dürfe. Würde er sich dann an Ihre $A d$ monitio nicht kehren, und dergleichen wiederhohlen, so wird er bei der Obrigkeit belangt. Ueberall aber müssen die primi gradus admonitiones ${ }^{452}$ vorhergehen.

6) Der Invalide Lorenz Fehrensen kann sich, wenn er noch nicht zum Abendmahle kömmt, damit entschuldigen, daß er, wie Ihr Brief besagt, erst die gerichtliche Entscheidung über die angeschuldigte Paternitaet abwarten wolle.

Setzen Sie, Herr Amtsbruder, Ihre Ermahnungen und Vorstellungen fort. Vielleicht lässt er sich gewinnen.

7) Was den Salzmann junior betrifft, der sich mit seiner Mutter Bruder Tochter ${ }^{453}$ verehlichen will, es ohne erst Dispensation zu haben, zu ihr

452 Überall aber müssen als erster Schritt die Zurechtweisungen vorhergehen.

453 Seine Cousine. 


\section{[143]}

ins Haus gezogen ist, so haben Ew. Hochehrwürden

recht gethan, daß Sie der Obrigkeit dies zur Anzei-

ge gebracht haben, da wir Geistliche kein bra-

chium saeculare ${ }^{454}$ haben.

Hochachtungsvoll beharre ich

Ew. Hochehrwürden

ergebenster Diner

D Gräffe.

Göttingen d. 5 th Jul. 1803

An

den Herrn Pastor Proffen

Hochehrwürden

in Obernjesa.

\section{[144]}

Ew. Hochehrwürden

Bescheinige ich den richtigen Empfang von

1 rth als ....[?] stions Gebühr von [...?]

Con... [?] für die stille Beerdigung

Dero sel. Frau Schwiegermutter; und

versichere zugleich: das alle extracte

aus dem Leichen-Buche von dem

der sie verlangt, dem Prediger zu

gesant werden müssen. Solte

Bode zu mir kommen, so wer-

de ich ihm dises verständigen.

Sehr angenehm wird es mir sein, wenn ich in der nächsten Woche den Bericht von Niedernjesa erhielte. Ich empfehle mich

Göttingen d 22t. Febr. 1802.

... [?]

Wagemann

454 Weltlicher Arm. 
[189v]

P: 26 Posteritati de 1802.

Nachdem auf einen von mir ausgewirkten Befehl des Gerichts Leineberg der mehrgenannte Feldmesser sowol die 3 Vorlinge Pfarrwiesen, auf den Geeren genannt, als auch die 3 Vorlinge Kipps Wiesen, die daran grenzen, von ihm aber seit der Uberschwemmung am 29 April 1800 umgepflügt waren, ausgemessen hatte, um dadurch auszumachen, Wem von Beiden die 3 vorhandenen Weidebäume, die zwischen beiden Wiesen stehn, gehörten; und nächstdem die wahre Grenze zu besteinigen: so ist nun vor einigen Tagen von ihm die Vermessung geschehn; und, da sich fand daß Kipp zu viel hatte, die Ubermasse, mit 5 Ruthen 99 Zoll Fuß an die Pfarre zurückgegeben, die 3 Weidenbäume der Pfarre zuerkannt, und die Grenze sowol zwischen Kipp und der Pfarre mit 3 Steinen als auch zwischen der Pfarre und Boden Lehnwiese mit 3 Steinen am 1sten Decemb: bestimmt. Es enthält also nun laut Vermessungsbericht die 3 Vorlingspfarrwiese 199 Ruthen 54 Fuß; und Dan: Kipps 3 Vorlinge Pachtland eben so viel, und Angerrecht noch 9 Ruthen 19 Fuß.

Vid. Bericht des Feldmessers Mündemann d.d. 28 Dec: 1802 nebst angehängter gerichtl. Confirmation d.d. 12 März 1803, nun auch des Messers darüber entworfenen Riß, samt dem gericht. Decrete an Dan. Kipp d.d. 31 März 1803, in der Pfarrregistratur.

\section{[190]}

P: 27. Posteritati de 1803.

ANNO 1803. Unterm 4ten $A p r$ : wurde der hiesigen Parochie per circulares ein Ausschreiben des Kön. Staatsministerii an alle Obrigkeiten vor 3 Meilen von Göttingen, item an das geistl. Ministerium in Göttingen communicirt, nach welchem sie von den in den Monathen vom April bis September vorkommenden Cadavern, nächst über 10 Jahre sind, dem Doct: Langenbeck in Göttingen 
Anzeige zugehn lassen solten. ${ }^{455}$ Das Ausschreiben war vom 3ten Febr. 1803.

Am 10ten May wurde der hiesigen Pfarre eine erneuerte König: Verordnung d.d: St James ${ }^{456}$ d. 4 März 1803 die Feier der Sonn- und Fest- auch Buß- und Bet-Tage betreffend, die nicht allein jährlich auf Trinitatis verlesen sondern deren Verlesung auch 8 Tage vorher von den Kanzeln bekannt gemacht werden soll, per circulares praesentirt.

Nachdem der Gemeinevorsteher, Christof Diekmann in Dramfeld, weil er zugleich Krüger war ${ }^{457}$, dimittirt worden, ist der Schmid, Daniel Lüdeke, wieder als Vorsteher erwählt und beeidigt.

Als die Franzosen, weil die zu dem $A \underline{\underline{O}} .1801$ geschlossenen Frieden ${ }^{458}$ noch gehörenden Separatartikel mit England noch nicht alle berichtiget waren, und desfals neuer Zwist zwischen beiden Reichen aufglimmte, jene nun unsers Königs deutsche Staaten aufs neue mit Krieg bedroheten: so sind nicht aus Vorsicht nicht allein unsre Truppen zum Marsch gegen sie im Monat März aufgebrochen, sondern auch auf hohen Befehl von allen Obrigkeiten im Lande die junge

455 Dr. Konrad Johann Martin Langenbeck (1776-1851) war von 1802 bis 1807 Wundarzt am akademischen Hospital; er begann 1803 seine Lehrtätigkeit in Göttingen mit anatomischen und chirurgischen Demonstrationen; in der Literatur wird er als hervorragender und weithin bekannter Operateur bezeichnet. Da die praktische Ausbildung von Studenten der Chirurgie, Anatomie und sonstiger ärztlicher Disziplinen (mit Ausnahme der Frauenärzte) an Leichen erfolgen musste, und die benötigte Anzahl nicht immer zur Verfügung stand, wurden die Sommercadaver und die Wintercadaver kontingentiert und per königlicher Verordnung bestimmten Wissenschaftlern zugesprochen. Die oben erwähnte Verordnung soll sicherstellen, dass während der warmen Monate alle Leichen von über 10jährigen Personen (April bis September) allein Dr. Langenbeck zu Forschungszwecken zur Verfügung standen (vgl. KuTZER, Michael: Langenbeck, Conrad Martin Johann, in: Neue Deutsche Biographie 13 (1982), S. 582-583 (http://www. deutsche-biographie.de/pnd116706988.html)(6.2.2016) und WAGENER, in: GöJb 43, 1995, S. 63ff).

456 Der St. James Palace war die Residenz der Deutschen Kanzlei des Kurfürsten sowie die des Königs in London.

457 Christoph (und Justus) Dieckmann sind als Gastwirte in Dramfeld von 1799 bis 1814 belegt, wobei nicht klar ist, welcher von beiden den oberen bzw. den unteren Krug bewirtschaftete (KLeIneKe: Von den Dramfelder Gastwirtschaften. Dramfelder Fliegende Blätter, Beiträge zur Ortsgeschichte No. 5/2008, S. 8).

458 Frieden von Luneville. 
Mannschaft ausgehoben worden. Diese betrug ohne diejenigen, welche sich freiwillig anwerben liessen, aus dieser Gemeine Obernjesa 9, und aus der in Dramfeld 16. Erstere wurden am 26sten May zu Grone ausgesucht, und an demselben Tage an das 2te Baitaillon des 1sten Regiments v. Scheither abgeliefert ; und Letztere, weil sie bereits in Dramfeld ausgesetzt waren, giengen am 27. $e j$ : nach Göttingen ab; wurden aber, so wie alle von den Obrigkeiten unsers Landes gelieferte Rekruten, weil die Franzosen bereits ins Land gerückt aren sie aber noch nicht mondirt $\mathrm{u}$. armirt waren, am 4 ten Jun: wieder entlassen. 459

\section{[190v]}

\section{P. 28. Posteritati de 1803.}

Unterm... ten [Datum fehlt], wurde ein Consist. Ausschreiben per circulares communicirt, nach welchem die Kirchenrechnungsführer befehliget wurden, bei gegenwärtigen Kriegbesorgenden Zeiten sofort die vorräthigen Kirchengelder, nach dem beigelegten Sortenzettel, in das Kön: Consistorium einzuschicken.

Am 4ten Jun:, als am Geburtstage unsers Königs, sind die Franzosen in Hannover unter Commando des Generals Mortier ${ }^{460}$, unsre Truppen aber, da sie sich ihnen nicht zur Wehr stellen konnten, ins Braunschweigische und Lauenburgsche eingerückt.

Bald darauf erschien im Publico folgende Proclamation.

Französische Republick

Eduard Mortier

Commendant en Chef der französischen Armee an die Hannover:

Hannoveraner

Eine französische Armee zieht in Euer Land. Sie kommt nicht, um in Euren Gegenden Furcht und Schrecken zu verbreiten, sondern nur den Theil des Landes, den Ihr bewohnt, der Regierung von

459 Die Männer waren noch nicht mit Uniformen und Waffen versehen und wurden nach Haus geschickt, weil die Armee aufgelöst werden musste.

460 Edouard Adolphe Casimir Joseph Mortier, Marschall von Frankreich seit 1804; zur Zeit der Besetzung Hannovers war er noch General (Hannoversches biographisches Lexikon, S. 260.) 
Engelland zu entziehen, als welches sich nunmehro als Feindinn von ganz Europa zeigt, und sich rühmt, alle Grundsätze der Völker- und Menschen-Rechte mit Füssen zu treten.

Der erste Consul, getreu der Gesinnung der Bescheidenheit und Menschlichkeit, die ihn aber so sehr, als seine Kriegerischen und politischen Talente auszeichnen, der erste Consul hat alle Mittel angewandt, um den Bruch aufs neue zu verhindern. Der König von England, ungetreu seinen Verheissungen, hat den Eid der Treue gebrochen, indem er sich weigert, Maltha zu räumen, wie er in dem Tractat von Amiens feierlich versprochen hatte. Der König hat zuerst die Feindseligkeiten wieder angefangen; und von diesem Augenblicke an macht er sich sowol vor Gott als Menschen für alles das Elend, welches der neue Krieg unter seinen Staaten anrichten wird, verantwortlich.

Ich weiß es, daß an Euch von Seiten Englands aus blinder Wuth und Raserei Proclamationen ergangen sind, um Euch in Streitigkeiten zu ziehen, die Euch nichts angehn sollten.

Fern sey von Euch ein Angrif, der Euch so wenig nützt,

[191]

P: 29. Posteritati de 1803.

als er aus blossem Unsinn geschiehet, indem ihr allein das Opfer davon seyn würdet.

Hannoveraner. ich verspreche Euch algemeine Sicherheit und Schutz, wenn Ihr in Erwägung Eures eigenen Interesses Eure Sache von der Angelegenheit Eures Königs losmacht, der Euch schon eben dadurch von der Verbindlichkeit und Treue losmacht, weil er selbst alle Grundsätze der Treue gebrochen hat.

Die strengste Ordnung und Mannszucht wird unter meinen Truppen herrschen; Personen und Eigenthum werden unverletzt bleiben. Dagegen fordere ich auch von Euch ein solches artiges Betragen, welches man billig von einem ruhigen und friedliebenden Volke erwarten kann und soll, welches an der Treulosigkeit seines Fürsten keinen Antheil haben will.

$$
\text { (L. S.) den } 28 \text { May. }
$$




\section{Capitulation.}

1. Die Armee ist als gefangen anzusehn, und zieht sich über die Elbe ins Lauenburg.sche.

2. Sämtliche Landescassen werden den Franzosen überliefert welche eine Regierungscommission für das ganze Land in Hannover niedersetzen.

3. Alle öffentliche Bediente leisten einen Eid, ihren Dienst wärend der französischen Administration treu zu verwalten, und nichts vorzunehmen, was der französischen Republick nachtheilig ist.

4. Die französische Regierungscommission setzt öffentliche Bediente nach Gefallen $a b$, und andere an.

5. Die Stadt Göttingen völlig frei und ohne die mindeste Besatzung.

6. Die freie Religionscultur wird gesichert, so wie alles Privateigenthum.

\section{[191v]}

Pag. 30. Posteritati de 1803.

Nachher erschien noch im Publico folgende auch den hannoverschen Anzeigen und hamburg: Zeitungen ${ }^{461}$ inserirte Convention,

geschlossen zwischen den Civil- und Militär- Deputirten der Regierung von Hannover, und dem Gener: Lieutenant Mortier, Commandanten en Chef der französischen Armee von Hannover.

1.

Das Churfürstenthum Hannover sowol, als die festen Plätze, die darin befindlich sind, werden v.d. französ: Armee besetzt.

2.

Die hannoverschen Truppen werden sich hinter die Elbe zurückziehn; und sich auf ihr Ehrenwort verpflichten: so lange der Krieg zwischen England und Frankreich dauern wird, keine Feindseligkeiten gegen die französische Republick und deren Alliirte zu unternehmen; und sie werden nicht eher von diesem Eide entbunden, bis man sie gegen so viele französische Generäle,

461 Vgl. [178]. Pastor Proffen hatte offenbar Zugang zu mehreren Zeitungen. 
Officiere, Soldaten und Matrosen, welche in die englische Gefangenschaft gerathen mögten, auswechseln kann.

3.

Kein Mitglied der hannoverschen Truppen wird den Ort, der ihm bestimmt ist, verlassen, wenn nicht der französische General Commandant en Chef davon unterrichtet ist

4.

Die hannoversche Armee wird sich zurückziehn mit allen Kriegsehren; und die Regimenter werden ihre Feldstücke ${ }^{462}$ behalten.

5.

Die Artillerie, das Pulver, die Waffen, und Munition aller Art werden der Disposit: der französ: Armee überlassen.

6.

Alles, was dem Könige von England gehöret, wird der Disposition der französischen Armee überlassen.

7.

Auf alle Cassen wird ein Sequester gelegt; die Universitätscasse behält ihre Bestimmung. ${ }^{463}$

8.

Jede englische Militärperson oder jeder Agent, welcher im engl: Solde steht, wird arretirt und auf Befehl des Generalcommendanten en Chef nach Frankreich geschickt.

[192]

Pag: 31 Posteritati de 1803

9

Der Commendant en Chef behält sichs vor, in der Regierung, und den vom Churfürsten angestellten öffentl. Beamten solche Veränderungen vorzunehmen, als er für gut finden wird.

462 Geschütze.

463 Vgl. Hunger, in: Göttingen Bd. 2, S. 186. 
10

Die ganze französische Cavallerie wird auf Kosten von Hannover beritten gemacht: Auch wird das Churfürstenthum zugleich für den Sold, die Kleidung und Nahrung der französ: Armee sorgen.

\section{1}

Die verschiedenen Religionen werden auf den bisherigen Fuß erhalten.

12.

Alle Personen, alles Eigenthum, und die Familie der hannover: Officiere werden unter französischem Schutze gesichert.

\section{3}

Alle Revenüen des Landes, sowol aus den Domänen des Churfürstenthums, als auch aus öffentl. Steuern, werden der Disposition der französ: Regierung überlassen. Die hierüber vorhandenen Einrichtungen werden respecktirt.

14.

Die gegenwärtige hannöver: Regierung entsagt allen Arten von Gewalt in dem ganzen Lande, das von den Franzosen besetzt ist.

15.

Der General Commendant en Chef wird auf das Churfürstenthum Hannover solche Contributionen legen, welche er für die Bedürfnisse der französischen Armee für nöthig finden wird.

16.

Alle Artikel, worüber man Zweifel haben könnte, werden für die Einwohner des Churfürstenthums günstig ausgelegt.

17.

Die vorhergeh: Artikel sollen den Stipulationen ${ }^{464}$ nicht nachtheilig seyn, welche zu Gunsten des Churfürstenth. zwischen dem 1sten Consul und den vermittelnden Mächten eingegangen werden könnten.

Im Hauptquartier zu Sublingen den 14ten Prairial des 11ten Jahres (3ten Jun: 1803)

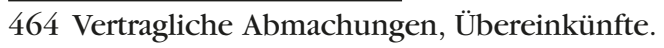


Unter Annahme des 1sten Consuls der Gener. Lieut: und Commendant en Chef, Eduard Mortier

v. Bremer, Hofrichter

Der Brigade General und Chef

v. Bock, Commandeur des

Churfürstl: Regiments Garde

des Generalstaabs

du Corps

\section{L: Berthier}

\section{[192v]}

Pag: 32. Posteritati 1803.

Am 9ten Jul: ist ein neues - von dem Tischlermstr. Kleinhans in Gr: Schneen verfertigtes Fenster mit Spiegelscheiben in der Eckstube an der Erle an der Südseite nach dem Brunnen zu von demselben eingesetzt.

In der Mitte dieses Monaths wurde unsre ganze Hannoversche Armee, die bisher im Lauenburgschen hinter der Elbe sich zusammengehalten hatte, laut einer zwischen dem französischen General Mortier und dem hannoverschen Feldmarschall, Grafen von Wallmoden - Gimborn geschlossenen Convention, als französische Kriegsgefangene, jedoch mit allen Ehren, ein jeder zu seiner Heimath, entlassen mit Pässen versehen, entlassen, so daß die Ober- u. Unterofficiers ihre Seitengewehre behielten; die Gemeinen aber nicht.

Am 26 ej: wurde ein Ausschreiben des Landes Consistorii vom 16ten Jun: präsentirt, in welchem den Predigern und Schullehrern ihr Verhalten in den gegenwärtigen Zeitumständen vorgeschrieben wurde.

Am 8 Aug: wurde ein Consistor: Ausschreiben vom 21. Jul: p. circulare communicirt, daß zu den einzugehenden Ehen der auf Urlaub ins Land zurückgekehrten Militärpersonen der gewöhnliche Militärconsens fernerhin, wie bisher, erforderlich sey.

Eod: wurde noch ein anderes Consist: Ausschreiben vom 21 Jul: praesentirt, in welchem befohlen ward, ein Verzeichniß von sämtlichen Kirchen- Pfarr- Pfarrwitwenthums- Küster- Orga- 
nisten- Schul- und andern geistl. Gütern, sofern sie in Zehnten oder Grundstücken bestehen, den resp: Aemtern und Gerichten fordersamst mitzutheilen; und eine Abschrift davon spätestens binnen 14 Tagen den Superintend. behuf Einsendung an das Landesconsistorium einzureichen.

Am 21 Aug: wurde vom Landesconsistorio in Hannover unterm 8ten ej. ein Ausschreiben- und neben demselben eine Verordnung der Executiv-Commission in Hannover vom 3ten Aug: p. circulare communicirt in welcher bey der gegenwärtig cessirenden Militär- Instanz ein Provisorium in Abschrift des Gerichtsstandes der mit Pässen

\section{[193]}

\section{Pag: 33. Posteritati de 1803}

versehenen - und ins Land zurückgekehrten hannoverischen Truppen erlassen - und für nöthig erachtet wurde, daß selbiges von den Kanzeln bekannt gemacht werde.

Einer Verordnung der Executiv-Commission in Hannover zufolge, (die aber nicht, wie sonst bei Landesverordnungen geschah, dem Clero majori durch das Landesconsistorium - sondern deren Inhalt nur durch die Beamte communicirt ist) muste jeder Unterthan, und auch die Geistlichkeit, ausser der vorhin eingeführten - und noch auf 4 Jahre verlängerten Landesdefensionssteuer, die für die hiesige Pfarre jährlich 4Th. Cass: M: betrug, annoch eine extraordinäre Kriegssteuer behuf Unterhaltung der im Lande befindlichen französischen Armee herbeischaffen. Auch diese Steuer betrug für hiesige Pfarre jährlich 4Th., die in 2 Terminen an das Gericht Leineberg abgeliefert werden musten.

Ausser dieser extraordinairen Kriegssteuer musten auch noch die Unterthanen im Fürstenthum Göttingen und Grubenhagen, einer anderweitigen Verordnung der Executiv Commission zufolge, die aber ebenfals nicht durchs Consistorium der Geistlichkeit communicirt - und nun durch die Beamte den Bauermeistern zugeschickt ist, eine monathliche so genannte Hülfsbeisteuer für unsre - mit wirklichen französischen Einquartirungen belasteten Landesbewoh- 
ner, und weil die Bewohner unsrer beide Fürstenthümer bisher von französischen Einquartirungen verschont geblieben waren, aufbringen. Dies betrug für die hiesige Pfarre monatlich 1Th., für die hiesige Schule $6 \mathrm{~g}$., und für das Witwenhaus $4 \mathrm{~g}$.4d., und nahm mit dem Monathe Junius seinen Anfang.

\section{[193v]}

\section{Pag: 34 Posteritati de 1803}

Nachdem die bisherige hiesige Pfarrwitwe, die Witwe des weil: Pastors Heinr: Philip Stolberg, Marie Sophie geborne Winkler ${ }^{45}$ aus Göttingen, den $17 \underline{\text { ten }}$ May d. J. mit Tode abgegangen war: so fielen nunmehro diejenigen 6 Morgen hiesiges Pfarrland, welche laut Resolution K. Landesregierung, und Rescripts K. Consistorii de 5 Sept. 1737 der damahligen Witwe des weil. Past: Lotzius, und allen successiven hiesigen Predigerwitwen zur Alimentation und Sustentation ad dies vitae ${ }^{466}$ zuerkannt waren, an die Pfarre, und eo ipso an mich, den zeitigen Pastor Proffen, zurück. Weil nun diese Witwe diese 6 Morgen in 3 Feldern bisher an den hiesigen Ackermann, Joh: Andr: Boden, unter den Bedingungen verpachtet hatte, daß 1. sie statt des Pachtgeldes von jedem Stücke dieser Länderei das 3te und 10te Bund Früchte auf dem Felde in natu$r a$ als Ernte zehntete, 2. daß Bode diesen Zehnten ihr einführe, und 3. auch das Dienstgeld von diesen 6 Morgen mit 19g. 4d Cass: M. jährlich an die Pfarre entrichtete: so habe auch ich unter diesen Bedingungen dem Andr: Boden für dies Jahr 1803 die Aberntung des von ihm bereits bestellten Landes zugestanden; und den zufolge von der Ernte des J. das 3te und 10te Bund gezehntet. Nächstdem aber habe ich am 3 ten Oct: dess. J: diese 6 Morgen auf die 6 Jahre von Gath Mich. 1803 bis dahin 1809 (damit das künftigjährige Winterfeld noch zeitig bestellt - und das künftigjährige Sommerfeld noch zu rechter Zeit gefolget werden könne) einzeln dem Meistbietenden verpachtet, um und für die Summe von 40Th.26g. Cass. M.

465 Laut eigener Unterschrift: Maria Sophia Stolberg, geb. Winiker, wie sie sich z.B. in KiKrAGött, P.A.Obernjesa, Kirchenrechnung 1782, Beleg Nro. 25 vom 12. Februar 1782 findet.

466 Zu Lebzeiten. 
Der - unterm 10 Sept: 1803 von Calenberg Grubenhagenscher Landesdeputation ${ }^{467}$ edirten Verordnung zufolge sollen, zur Verpflegung der im Lande befindlichen französischen Truppen, alle sowol pflichtige als unpflichtige Unterthanen eine Fouragelieferung prästiren. ${ }^{468}$ Die Bestimmung und Subrepartition derselben wurde der Obrigkeit jedes Orts überlassen. Doch solten atteh alle geistliche Güter, die nicht so viele Morgen als den 4ten Theil eines Vollmeierhofes betrügen, von den Beiträgen zur Naturallieferung

\section{[194]}

\section{Pag. 35. Posteritati de 1803 u. 1804}

frei seyn; und besonders die Güter und Grundstücke der Superintendenten und Prediger, weil sie solche als partem salarii im Nießbrauch hätten, nur die Hälfte einer Quotae vom Morgen zur Fourageleistung beisteuern. Diesem gemäs wurden vom Gericht Leineberg der hiesigen Pfarre von 4 Hufen oder 120 Morgen à $43 / 4 \mathrm{~d}$ monathlich für das erste $1 / 4 \mathrm{Jahr}$ vom 6 Aug: bis 6 Nov: 1803, 5Th.33g:6d Cass: M - der hiesigen Kirche aber von 21 1/4 Morgen, ob diese gleich kein Vierthel eines Vollmeierhofes ausmachen, von jedem Morgen 91/2 d monathlich, für eben das 1/4 Jahr 2Th.3g:, $55 / 8 \mathrm{~d}$ gefordert. Indessen sollen auch die Pächter sowol ganzer - als einzeln verpächteter Güter $1 / 3$ zu dieser Fourageprästation praestiren concurriren. So habe denn also ich

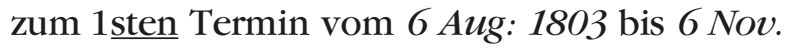
5 Th:33g.6d diese Kirche 2 Th. 3 g. $55 / 8 \mathrm{~d}$ und die Dramfeldsche

zu der Fouragelieferung beigetragen.

zum 2ten Termin vom 6 Nov: 1803 bis 6 Febr: 1804, 5Th.33g.6d, und die beiden Kirchen eben die vorige Quote, beigetragen.

467 Das Landesdeputations-Kollegium: An Stelle der außer Funktion gesetzten Minister trat ein Ausschuss aus böheren Beamten und Vertretern der Stände, (...), das die Franzosen schalten und walten ließen, solange es die geforderten Kontributionszablungen aufbrachte (LAMPE, in: Göttingen Band 2, S. 43)

468 Eine Fouragelieferung leisten. 
ANNO 1804

Auch habe ich zu den - laut Ausschreibens vom 3 März d.J. aus dem Gerichte Leineberg gestellten Pferden nach dem - bei der Fourage lieferung bestimmten Verhältniß, 17g.5d Cassenmünze am Ende des März im Gerichte einliefern müssen.

Statt des abgegangenen Gemeinevorstehers, Joh: Andr: Schäfer, ist der Feldgeschworne Joh: Heinr: Bührmann, wieder angesetzt und beeidigt.

Am 23 und 25 Apr: ist der Pfarrmorgen im Thale zwischen Hn. Past: Mengershausen und Welkers Lehn Morgen - wie auch das Vorling oberhalb an Zimmermanns 4 einzelnen Vorlingen vermessen und $r s p$ : besteiniget. Der Pfarrmorgen enthält nach dem vom Feldmesser Mündemann aufgesetzten und in der Registratur befindlichen Vermessungberichte $d$. 30 Apr. 1804, 97 Ruthen 45 Fuß; das 1 Vorling aber zwischen einem andern Vorlinge und 4 Vorl. Zimmermanns hat $5 \square$ Ruthen gewonnen, und enthält

\section{[194v]}

P. 36) Posteritati de 1804.

Zum 3 ten Termin der Fouragelieferung vom 6 Febr. bis 6 May 1804 habe ich bezahlt

5Th:19g:

Am 18 May wurde der bisherige 1ste Consul der französischen Republick, Napoleon Buonaparte, ein geborner Corse, in Paris zum Kayser der Franzosen proclamirt unter dem Titel: Napoleon von Gottes Gnaden und durch die Constitution des Reichs ernannter Kayser der Franzosen. Er war jetzt 35 - und seine Gemahlinn, Josephine, eine geborne la Pagerie, $44 \mathrm{Jahr}$ alt. Er hatte 4 Brüder. Der ältere als er, Joseph; die jüngern aber, Ludewig, Lucian und Hieronymus Buonaparte. Da nun er selbst, Napoleon noch keine Leibeserben hatte: so ward durch jenes Senatusconsult festgesetzt, daß nur seine beiden älteren Brüder, Joseph und Louis nebst ihren rechtmässigen Descendenten männlichen Geschlechts zur Thronfolge zugelassen werden sollten. Eben dies Senatusconsult beschloß ferner, daß der Kayser jährlich aus der Civilliste 25 Millionen - und jeder seiner Brüder 3 Millionen livres Einkünfte haben sollten. 
Am 19Jun: ist der bisherige Obergeneral der französischen Armee im Hannöverschen, Desfolles, zur Reserve Armee nach Osnabrück abgegangen, und dagegen der - seit der Ernennung Bonaparte zum Kayser der Franzosen zum Reichsmarschall erhobene General Bernadotte in Hannover wiederangekommen.

Zum 4 ten Termin der Fouragelieferung vom 6 May bis 6 Aug: 1804 habe ich bezahlt 5Th:19g.

Zum 5ten Termin der Fouragelieferung vom 6 Aug: 1804 bis zum 6 Nov: e.a. habe ich bezahlt 6Th.11g:3d

Und zu den Chenillen ${ }^{469}$ für die Franzosen 1Th. 24.-

Anm: Vorstehende 1Th:24g: sind nachher behuf der Hülfsbeisteuer den Unterthanen, und folglich auch mir, wieder zu Gute gerechnet.

\begin{tabular}{|c|c|c|c|}
\hline Zum 6ten Termin der Fourageliefer: & vom 6 Nov:4 & bis $6 \mathrm{Feb}: 57$ & 6Th.11g:3d \\
\hline zum 7 ten Termin der Fourageliefer: & vom 6 Febr 5 & bis 6 May & 7Th.2g.6d \\
\hline Im 8ten Termin der Fourageliefer: & vom 6 May & bis 6 Aug: & 7Th.2g.6d \\
\hline Term & vom 6 Aug: & bis 6 Nov: & 5Th.13g. \\
\hline
\end{tabular}

Bis hierher für die Franzosen: Von nun aber für die Preussen S: Pag: 42

\section{[195]}

\section{P: 37 Posteritati de 1805}

\section{ANNO 1805}

Am 5 Febr. ließ die hiesige Witwe Joh.-Heinr: Zimmermann, geborne Schloten aus Dramfeld, durch ihren Grosknecht, Christian Hinterthür aus Sieboldshausen, 1 Fuder Roggen nach Göttingen fahren. Sie selbst mit ihrer Tochter Rosine hatte sich auf den Wagen gesetzt. Als es

469 Helmzier aus Seidenband; siehe auch Lotze, S. 184: Zur Komplettierung der von dem Marschall Bernadotte in Rücksicht der anfänglich genossenen Befreiung von der Einquartierung, wurde der Stadt und dem Amte Münden statt einer Lieferung von 1500 Chenillen an die französische Armee, eine baare Summe von 5250 Tlr. Kassen-Münze auferlegt. Eine einzelne Chenille hätte damit einen Beschaffungswert von 3,5 Talern gehabt. 
nun an dem Morgen des Tages viel geregnet - und der Regen den vorhandenen vielen Schnee in Wasser aufgelöset hatte: so war die Leine so sehr angeschwollen, und aus den Ufern getreten: daß es unmöglich ward, durch die Leine bei Niedernjesa zurückzufahren. Sie hatten also unter einander beschlossen, aus dem Groner Thore hinaus durch die Beileine ${ }^{470}$, nicht weit vom Gurken Kruge ${ }^{471}$ und dem Stege über die Leine, zu fahren. Es geschieht. Christian Hinterthür fährt dreiste mit seinen Pferden und dem Wagen, auf welchen folgende Personen aus hiesigem Orte, als 1. die Witwe Joh. Heinr: Zimmermann selbst, 2. ihre Tochter Rosine, 3. ihr Schwiegersohn, Joh: Heinr: Harriehausen, 4. Joh: Heinr: Fehrensen Sen: und 5. dessen Tochter Dorothee, 6. des Vorstehers, Lorenz Dehnen Sohn, Heinrich, 7. die Witwe, Friedrich Andreas Utermöhlen, Anne Margarethe geborne Poppen, aus Sieboldshausen, sich sicherheitshalber gesetzt hatten, durch die Beileine. Schon hatten auch die beiden vorderen Pferde am andern Ufer festen Fuß gefasst, als auf einmahl das Wasser in vollem Strome (der Walkemüller hatte auf befehl die Schütte aufgezogen) heranströmt, und das Treibeis herbeiführt. Dies hatte nun die Pferde samt dem Fuhrmann umgeworfen; er aber, der starke rüstige Kerl, hatte sich wieder ermannt; auch seine Pferde wieder auf die Beine gebracht. Nachdem aber die hintern Pferde vor Schrecken den Wagen zurück - und in den vollen Strom schieben: Kommt ein neuer Sturz von Treibeis, und wirft den Wagen selbst um, daß nun alle darauf befindliche Menschen in die Leine fallen: Ein Zimmergeselle, Namens Jühne in Sieboldshausen, der aus Vorsicht vorhin über den Leinesteg gegangen war; und bereits am Ufer stand, rettet zuvörderst seinen Kameraden, den Joh: Heinr: Dehnen, indem er ihm seinen Zimmerstock vorhält, und durch Festhaltung desselben ihn herauszieht. Gerettet geht nun Heinr: Dehne der im Wasser der ihm entgegenschwimmenden Rel. Heinr: Zimmermann, an deren Kleidern sich ihre Tochter fest-

470 Auch als ,Alte Leine' bezeichnet. SAathoff, S. 39, meint allerdings, die Beileine sei ,eine zum, Leinekanal' ausgebaute Abzweigung der Leine, auch Kubleine genannt.

471 Vgl. Grothenn, Blatt 63. Zur Bedeutung des Kruges: 1793 liegt er vor der Stadt und soll von geringer Art sein (WaGener: Pedelle, Mägde und Lakaien, S. 262). 1798 bestätigt die Regierung in Hannover der Stadt Göttingen das Recht, die Gastwirtschaften Weibergram und Gurkenkrug polizeilich zu visitieren (StAGött. AAA Leinebergensia Nr. 51). 1824 wird der Krug im Statistischen Handbuch des Königreichs Hannover (JANSEN, S. 230), erwähnt und liegt im Gericht Leineberg. 


\section{[195v]}

\section{Pag. 38 Posteritati de 1805}

gehalten hatte, zur Hülfe entgegen; reicht ihr seinen Handstock zu; und er selbst hält sich mit der andern Hand an dem Stocke eines Cameraden fest; und auf solche Art rettet er die Frau samt ihrer Tochter aus der augenscheinl: Lebensgefahr. Joh: Heinr: Fehrensen rettet sich selbst und seine Tochter; und Heinr: Harriehausen, der am Stege mit seinen Füssen festgehangen war, wird von Einem, Namens Wenzel in Sieboldshausen, wieder losgemacht und gerettet. Die Witwe Utermöhlen aber war sogleich in den vollen Strom gerathen, und ohne mögliche Rettung ertrunken; so wie auch der Grosknecht, der noch immer sich ermannet - und Pferde und Wagen hatte retten wollen, endlich dennoch von der Menge und der Gewalt des Treibeisens in den Strom niedergedrückt und ertrunken war. Der Witwe Utermöhlen 3 leibliche Töchter verloren nun unglücklicherweise eine Mutter; und die Witwe Zimmermann einen getreuen und erfahrnen Ackerknecht nebst 2 guten starken Pferden und einem halben Wagen. Die beiden Leichen aber waren heute am 4 März noch nirgendswo ansichtig geworden. Am 21sten März endlich ist der Körper des Hinterthürs, auf der Leine schwimmend von den Schäfers gesehen und mit ihren Schäferhakens heraus gezogen - und am 23. ej: auf dem Kirchhofe in Grone begraben worden.

Am 23. Febr: ist der Pastor in Ballenhausen, Herr Georg Conrad Rittmeyer, im 75 sten Lebens- und 39 Amtsjahre im Coelibat gestorben. Er war aus Münden gebürtig. Folgende Herren Prediger wurden aus unsrer Inspeckt: Göttingen, 3 ten Theils zum Vicarium wärend der Vacanz in folgender Ordnung von dem Super: Dr Gräffe bestellt. 1. Ich, der Past: Proffen, Dom: Reminisc: ${ }^{472}$, an welchem ich zugleich als des Verstorb: Confessionar: ihm die Gedächtnißpredigt hielt; ferner Dom. Cantate $^{473}$, Fest:Joann: ${ }^{474}$,

472 Reminiscere: zweiter Sonntag in der Passionszeit.

473 Cantate: vierter Sonntag nach Ostern.

474 Johannistag: 24. Juni. 
2. der H. P. Schlie in L: Schneen, Dom: Laetare ${ }^{475}$, Fest: Ascens: ${ }^{476}$, D: 6 Tr: ${ }^{477}$

3. der H. P. Adj: Geissel in Niedernj:, Dom: Palm. ${ }^{478}$, Fer: 2 Pent: ${ }^{479}$,

4. der H. P. Dedekind in Gr: Schneen, Fer: 2 Pasch: ${ }^{480}$, Dom: Miseric: ${ }^{481}$, D: 1 Tr. $^{482}$

[196]

Pag. 39. Posteritati de 1805

Am 18 Julius ist der - seit dem 18ten Jul: 1802 auf seine Frau intendirten Mordes beschuldigt und inhaftirt gewesene Georg Christian Frölich, Einwohner und gewesener Dragoner hieselbst, (vid: Pag: 22) nachdem er etwa 14 Tage zuvor die real territion $^{483}$ ausgestanden und dennoch die beschuldigte That geleugnet hatte, auf Erkenntniß der hannöverschen Justitzcanzlei, welches ihm am nämlichen Tage durch den Amtschreiber Böhmer des Gerichts Leineberg bekannt gemacht war, losgesprochen und auf freie Füsse gestellt worden, mit dem Beifügen jedoch, daß er die Kosten bezahlen müsse. Er ist darauf noch an eben demselben Tage Nachts um 11 Uhr hier zu Hause angekommen.

Da der römsche Kayser Franz dem französischen Kayser Napoleon den Krieg erklärt hatte, und der russische Kayser Alexander mit dem Erstern in Alliance getreten war: so rückte nun die hannoverisch französische Armee ${ }^{484}$ unter dem Commando ihres bisherigen Heerführers des Marschalls Bernadotte in Hannover aus; marschirten 16000 Mann stark aus dem Lande; jedoch behielten sie die Festung Hameln mit etwa 6000 Mann besetzt. Die ganze Armee marschirte darauf

475 Laetare: vierter Sonntag in der Passionszeit.

476 Ascensio, Himmelfahrt.

477 Sechster Sonntag nach Trinitatis.

478 Palmarum: sechster Sonntag in der Passionszeit.

479 Feria 2 Pentecoste: Zweiter Pfingsttag.

480 Feria 2 Pasche: zweiter Ostertag.

481 Misericordias Domini: zweiter Sonntag nach Ostern.

482 Erster Sonntag nach Trinitatis.

483 Dem Delinquenten wurden die Folterinstrumente nicht nur gezeigt sondern auch angelegt, allerdings ohne ihm Schmerzen zu verursachen (ZedLER, Bd. 30, Spalte 1225). Ein noch im 18. Jahrbundert übliches Verfahren. Schrecken wurde erzeugt, um Geständnisse zu erzwingen (Schubert 2007, S. 164).

484 Die französische Armee hatte den Namen ,Armee d'Hannovre' angenommen (LoTzE, S. 183). 
durch das Göttingische auf Münden zu durchs Hessische (wozu ihnen der Churfürst von Hessen die Erlaubniß gegeben hatte) ins Fränkische in Bayern hinein. Auch in unsern Ort rückten zuerst 2 Compagnien Infanterie vom 8ten Regiment. Bei der einen Compagnie standen der Hauptmann Penot und der Lieut: Mercier; welche beide ich bis und bei der andern - der Capit: Talivet und Lieut: Moreau. Die beiden Erstern hatte ich im Quartier seit dem 12ten Sept. Die andern beiden aber waren in Lorenz Harriehausen quartirt; rückten aber am folgenden Tage nach Stockhausen. Am 15ten Sept: aber marschirten beide Compagnien weiter auf Münden u.s.w. An deren Stelle aber rückten schon nach ein Paar Stunden rothe Husaren vom 4ten Regimente ein, wovon ich den Obersten Burthe ins Quartier und die übrigen - zum Staabe gehörigen Officiers, den Major Couleau, den Major Maulnoir und den Regimentschirurgus Mortheureux, Mittags zu Tische hatte: Aber bereits

\section{[196v]}

\section{Pag. 40. Posteritati de 1805}

am folgenden Morgen, am $16 \mathrm{Sept}$. rückten auch diese Husaren wieder aus, und marschirten mit den übrigen Truppen durchs Hessische u.s.w. Seit der Zeit bekamen wir keine französische Einquartirung mehr; ja das ganze hannoversche Land, Hameln ausgenommen, ward davon entblößt.

Seit der Zeit übernahm nun das K.Chf. Staatsministerium, das seit der französischen Invasion sich entfernt hatte, statt der binnen der Zeit die Regierung des Landes besorgt habende executif Commission, die Ruder der Regierung. Die Preussischen Truppen unter Commando des Herzogs v. Braunschweig ${ }^{485}$ besetzten nun 60000 Mann stark, unser Land. Auch in dies Dorf rückten am 15 Nov. ein Lieutenant, der Lieut. von Bremen, ein geborner Mecklenburger, mit 3 Unterofficiers und 27 Mann Gemeinen von der Escadron des Rittmeisters von Stechow in Gr: Schneen. Diese aber muste am 23 ej: wieder ausrücken, und in Stockhausen ihr Quartier nehmen. Dagegen rückten am 24 ej: wiederum 1 Lieut: Namens $v$. Eisenhart mit 40

485 Herzog Karl Ferdinand von Braunschweig (Тнімme, S. 10). 
Mann Husaren von eben dem Regimente des Obersten $v$. Rudorf oder vormahligen berühmten Leibhusaren Regiment von Ziethen, und der Eskadron des Oberstlieutenants von Jörgas, hier ein. Der Lieutenant v. Eisenhart war ein Berliner. Der Oberstlieut. lag auf dem Amte in Reinhausen im Quartier. Neun Fouragelieferungen waren bereits für die Franzosen erfolgt:

Die 10te aber ward für die Preussen ausgeschrieben, so dennoch daß sie, obgleich nur zu einem sehr geringen Preise (denn der Marktpreis war jetzt der Htn Roggen $2 \frac{1}{2}$ Th., Gerste $1 \frac{1}{3}$ Th. Haber 1.Th.) den Hten Roggen zu 11/4 Th., den Hten Haber zu 24g. bezahlten.

Bei Veranlassung der Preussischen Besitznahme unsers Landes ward eine starke Naturallieferung aus Roggen, Haber, Heu und Stroh ausgeschrieben, und bei Strafe der Execution in den nächsten Tagen eingefordert. Dies Ausschreiben vom 26 Nov: forderte von mir allein $2 \mathrm{Ht}$ : Roggen, $14 \mathrm{ht}$. Haber, 502/5 שु $\mathrm{Heu}$, und $724 / 5 \mathbb{E}$ Stroh, die ich aber nicht lieferte, auch nicht liefern konnte, obgleich nächstdem Bezahlung dafür erfolgen sollte.

[197]

Pag: 41 Posteritati de 1805.

Die auf der vorigen Seite benannte Einquartirung Preussischer Husaren hirselbst und in hiesiger Gegend muste nun wie alle übrigen Escadrons desselben Regiments, am 2ten Dec: wieder abmarschiren, und rückten denselben Tag nach Hohengandern. An deren Statt rückte vom Preussischen Dragoner Regimente dHn. Gener: Lieut: von PrüBrüsewitz am 4ten Dec: die Escadron dHn: Majors von Wurmb ein, wobei folgende Officiers waren. 1. der Major selbst; 2. der Hauptmann $v$. Porck, 3. der Lieut: v. Ziehten, 4. der Lieut: v. Troschke, u. noch ein 5 ter, den ich aber, weil er am Fusse unpäslich war, nicht kennen gelernt habe. Diesmahl zwar wurde kein Officier bei mir - sondern der 1te im Schulhause, der 2te beim Zimmermstr. Salzmann, der 3te bei Georg Zimmermann, der 4te bei Heinr: Harriehausen, und der 5 te bei Christof Harriehausen Erben einquartirt: weil aber des Schulmeisters Mündemann Magd das von der Gemeine angeschafte zum Mittagsessen angeschafte Fleisch und die Mahlzeit überall nicht anständig bereiten konn- 
te: so übernahm es meine Frau; und die 4 ersten Herren wurden also in meinem Hause zu ihrer grösten Zufriedenheit gespeiset. Am 5 ten frühe aber zogen die Herren mit der Escadron nach Dankelshausen ab; sie waren hirher von Seeburg im Eichsfeldschen gekommen.

Am 9 Dec. rückte abermahls $\widetilde{t}$ Compagnie preussischer Grenadiers, 100 Mann stark, vom Regiment dHn. Generals v. Putkammer, hier ein. Der ältere Lieuten: Brockhausen war bei Lorenz Harriehausen - und der jüngere, Manikowsky bei dem Zimmermeister, Andr: Salzman, quartiert. Am 10. hielten sie Rasttag, und am $11 \underline{\text { ten }}$ frühe marschirten sie nach Heiligenstadt $a b$.

$[197 \mathrm{v}]$

Pag. 42. Posteritati de 1805 u. 1806.

Conf. Pag. 36. Für die Preussischen Truppen ward nun eine extraordinaire Proviant- und Fouragelieferung ausgeschrieben, welche laut pag. 40 der hiesigen Pfarre 2 hbt Roggen, 14 ht. Haber, 502/5£ Heu, und $721 / 5 £$ Stroh betrug, die ich aber in nat: nicht lieffern konnte, folglich auch die dafür versprochene Bezahlung nicht erhielt.

Nächstdem wurde für die Preussen die 10e ordin: Lieferung angeordnet. Diese betrug in Gelde 7Th.22g.3d Cass. M. wofür, weil auferlegt von den Pretssen, obgleich nur nach einer geringen Tax, bezahlt wurde, nachher vergütet wurden 6 Tht. 24 g. Cass. M.

ANNO 1806.

Am 7 ten Febr. rückten abermahls 2 Compagnien vom Preussischen Infanterieregiment des Gener: Lieut: Alt Larisch auf 1 Nachtquartier hier ein, und zwar die Compagnien des Hauptmanns von Held, welcher bei mir einquartirt war, und die des Hauptmanns von Heldrit, Die Subalternen waren die Lieutenants v: Reckow, v: Fertenbach, von Roc und von Oppen; die Fähndrichs v: Suckow u. v. Bährenhorst.

Da also Vorstehende am 8ten wieder ab- und nach Hannover marschirten: so rückten an demselbigen Tage 1 Eskadron vom Husarenregimente des Generalmajors v: Pletz, abermahls auf 1 Nacht ein. Der Chef war der Major v. Görz, welcher bei mir 
bequartirt war. Die Subalternen im Dorfe waren die Lieutenants v. Pannwitz u. v. Otto, und der Cornet v. Prittwitz. Diese Escadron marschirte am folgenden Tage wieder ab ins Standquartier in den Aemtern Calenberg und Coldingen.

Vorläuffig nur occupirten nur die Preussen das hannoversche Land mit Genehmigung des Kaysers der Franzosen, und Königs von Italien, Napoleon ${ }^{486}$, und nahmen die öffentlichen Cassen in Administration, unter Anführung des Generals der Cavallerie, Grafen v. d. Schulenburg Kehnert in Hannover, und der unter ihm stehenden Preussischen Administrationscommission. ${ }^{487}$ Diese nahm am 19ten Februar ihren Anfang, und bestand aus folgendem Personale; 1) $\mathrm{dH}$. geheime Oberfinanzrath u. Cammerpräsident $v$. Ingersleben, als Präsidenten. 2) dem geheimen Oberfinanzrath Wilckens. 3) dem Oberrechnungscammerdirecktor u. Geheimen Oberrechnungsrath Schönn 4. dem Kriegs- u. Domainencammerdirecktor Hoyer. 5 dem geheimen Oberrechnungsrath Gieseke, 5) dem geheimen Regierungsrath $v$. Bülow, und 7. dem geheimen Kriegesrath Clemen.

\section{[198]}

\section{Pag: 43. Posteritati de 1806.}

Als aber zufolge einer Uebereinkunft des Kaysers Napoleon mit dem Könige Friedrich Wilbelm von Preussen Letzterer das Fürstenthum Anspach an den neuen König v. Bayern, Maximilian Joseph das Herzogthum Cleve an den Prinzen Murat, Schwager des Kaysers, nun genannten HerzogJoachim von Cleve und Berg (letzteres trat der König von Bayern ab) - und das Fürstenthum Neufschatel, und die Grafschaft Valengin an Frankreich abtrat: so hat ihm dagegen der Kayser Napoleon sein erobertes Churfürstenthum Hannover als ein Aequivalent und völliges Eigenthum übergeben, welches er als ein solches am 1ten Apr: 1806 in Besitz genommen zu haben durch eine gedruckte Proclamation den hannoverschen Staaten bekannt machte.

486 Seit 1. April 1806 (lt. LotZe, S. 186).

487 Der preussische Staatsminister und General der Kavallerie Graf von der SchulenburgKehnert war vom preussischen König Friedrich Wilhelm III. mit der Ziviladministration des Kurfürstentums beauftragt worden (Тнімme, S. 10). Zur Arbeit der Administrationskommission vgl. Thimme, S. 22ff. und Gerhard, in: Göttingen, Bd. 2, S. 280. 
Da nun aber zwischen obigen beiden Mächten ein Bruch unvermeidlich schien: so räumten die preussischen Truppen nicht allein das Herzogthum Sachsen Lauenburg den schwedischen zur Besitznahme für den König von England; sondern entblößten auch das übrige Land, ausser die beiden Festungen, Hameln und Nienburg, von Besatzungen, obgleich die preussische Administrations- und Organisations Commission der hannoverschen Lande in Hannover blieb. Die ganze preussische Armee, folglich auch das Corps d'Armée im Hannöverschen, wurde daher zum Marsch beordert. Letzteres marschirte daher theils auf Heiliggenstadt, theils auf Cassel an die Sächsische Grenze. Von dem Corps, das im Hannoverschen gelegen war, rückten am 18ten Sept: auf 1 Nachtlager hier ein die Compagnie des Majors von Morstein vom Infanterieregiment von Treuenfels. Er selbst wurde bei mir - und die Lieutenans $v$. Larisch, $v$. Haugwitz, $v$. Kölichen u. der Fähndr: $v$. Tsirschky im Dorfe einquartirt. Am 19. früh marschirten sie wieder ab, und nach Steinbach bei Heiligenstadt.

Von dem Corps d'Armée des Generals v: Blücher in Westphalen rückte darauf am 24. Sept: die Eskadron des abwesenden Rittmstrs $v$. Wollky vom Husarenregiment v. Blücher hier ein. Der commandirende Prem: Lieut: $v$. Wins ward bei mir - der Sec. Lieut: $v$. Krottenaurer bei Lorenz Harriehausen - und der Cornet $v$. $d$. Heyden, bei Heinr: Harriehausen bequartirt. Am 3ten Oct: aber marschirten sie ab bis Roßdorf, und von da am folgenden Tage über Münden nach Cassel, um sich mit den Hessen zu verbinden, und so den Franzosen entgegen zu rücken.

\section{[198v]}

\section{Pag: 44 Posteritati de 1806}

Die Preussen marschirten nun sämtlich nach Sachsen, jedoch ohne Vereinigung der Hessen mit ihnen, denn diese wollten vor der Hand ruhig und neutral bleiben. Da in Sachsen verband sich aber die Sächsische Armee mit ihnen: allein etwa nach 14 Tagen, am 14 - 16 Octob:, wurden beide Armeen, die vom Könige von Preussen commandirt wurden, von dem französischen Kayser, Napoleon Bonaparte, so total geschlagen, daß sie algemein flohen. ${ }^{488}$ Der Kayser Napoleon nahm darauf dem Könige Friedrich Wilhelm II

488 Die Schlachten bei Jena und Auerstädt (vgl. auch Lotze, S. 186). 
alle seine Länder, die Mark Brandenburg, Schlesien, Pommern, Pohlen weg, und jagte ihn bis in sein Königreich Preussen. Seine Festungen, Magdeburg, Breslau, Glogau, Brieg u. andere, eroberte er eine nach der andern. Die Sachsen machten nun sogleich Frieden mit dem französischen Kayser; der bisherige Churfürst von Sachsen, Friedrich August, ward nun König; trat, wie der König von Bayern, König von Würtenberg, Fürsten von Sachsen, Grosherzog von Hessen Darmstadt, u. andre deutsche Fürsten, in den von Napoleon errichteten Rheinbund; gab also auch, wie Jene alle sein starkes Contingent zu der französischen Armee. Nach obiger Schlacht im Octob: 1806, die bei Auerstedt und Jena geschah wurden denn auch die Hessencasselschen Eänder vom franzësisehen Marsehall und nächstdem auch die Braunschweigschen Länder vom französischen Marschall Mortier eingenommen, und sowol das Hessische als Braunschweigsche Militär entwafnet. Der Churfürst von Hessen ${ }^{489}$ sowol als der Herzog von Braunschweig flohen, Letzterer aber starb bald darauf an seiner bei Jena erhaltenen Kopfwunde in Altona. Auch die Meklenburgschen und Oldenburgschen Länder wurden von den Franzosen, so wie auch das Hannoversche, eingenommen. Schon in Pohlen stieß jene sehr starke russische Armee zu dem Uberreste der Preussischen Armee, die sich nun wieder zu 40 - 60000 Mann gesammelt haben soll. Aber auch ganz Pohlnisch Preussen gieng nach einigen unglücklichen Schlachten verloren. Nun wurden die Russen und Preussen bis ins Königreich Preussen gedrängt, worin nun auch Thoren, Marienwerder, Braunsberg und andere Städte verloren giengen.

489 Wie die Flucht des hessischen Kurfürsten von statten ging, beschreibt Lotze, S. 187: In der Nacht vom 31. Oktober zum 1. November fubr der französische Chargé d'affaires, St. Genest, Schlag $12 \mathrm{Ubr}$ mit dem Reisewagen und in Reisekleidern vor das Hotel des Staatsministers von Waitz in Cassel, um den daselbst versammelten Ministern im Namen des Kaisers Napoleon die Note zu überreichen, daß Sr. Majestät dem Kaiser die Anhänglichkeit des Hessen-Casselschen Hofes an der Verbindung mit Preußen vollkommen bekannt sei und er die nur zu bekannten feindlichen Gesinnungen zu strafen beschlossen habe. Der Marschall Mortier habe die Weisung, das Land militärisch zu besetzen, mit der Drohung, daß man sich der Person Sr. Kurfürstlichen Durchlaucht bemächtigen werde, wenn er länger in seiner Residenz zu verweilen wagen würde. Am 1. November 1806, morgens $7 \mathrm{Uhr}$, wurde das Leipziger Tor von einer Kompagnie französischer Grenadiere besetzt und um $1 / 28 \mathrm{Uhr}$ verließ Kurfürst Wilhelm I. seine Residenzstadt Cassel. 


\section{[199]}

Nur die wichtige Festung Danzig hielt sich noch. Aber auch diese gieng

\section{ANNO 1807}

am 26. May, nachdem freilich die Franzosen eine ungeheure Menge Menschen wärend der Belagerung davor gelassen hatten, und nachdem die Besatzung gänzlichen Mangel an Munition hatte, und ein englisches 24 Kanonenschif, das solches der Besatzung zubringen sollte, von den Franzosen an den Weichselufern war zerschossen - und zur Ergebung gezwungen wurde, an den französischen Marschall Lefebre ${ }^{490}$ über

[Ende der Eintragungen des Pastors Proffen]

490 Marschall Francois-Joseph Lefebvre, 1755-1820; nach der Einnahme Danzigs ernannte ihn Napoleon unter dem Datum vom 28. Mai 1807 zum Herzog von Danzig (NibuATNIAS: Siège de Dantzick, en $1807 \ldots$, Paris 1818, S. 165, 166). 


\section{Quellen}

Hauptstaatsarchiv Hannover (HStAH)

Hann. 83III Nr. 417 II

Universitätsarchiv Göttingen (UAG)

SA 635 , 1. f. 27-33.

Phil. Dek. 78, Nr. 3.

Staats- und Universitätsbibliothek Göttingen (SUBGött)

VD 1890216741

Kirchenkreisarchiv Göttingen (KiKrAGött)

P. A. Obernjesa A. 102

P. A. Obernjesa A. 112

P. A. Obernjesa A. 120

P. A. Obernjesa A.333

P. A. Obernjesa A. 410

P. A. Obernjesa A. 51320

P. A. Obernjesa B.4.2 (Amt Reinhausen)

P. A. Obernjesa K. R. I.a. 1 (Pfarrchronik)

P. A. Obernjesa K. R.I.a. 5

P. A. Obernjesa K. R. III. 2

Sup.Spez. Obernjesa I.2.a

Sup.Spez. Obernjesa I.2.b

Sup.Spez. Obernjesa I.4.b

P. A. Dramfeld Dr. A. 410

P. A. Dramfeld Dr. A. 512

P. A. Dramfeld K.R.I.a. 2

P. A. Dramfeld K. R. I.a.4

P. A. Dramfeld K.R.I.a. 5

P. A.Dramfeld K. R. I.a. 6

P. A. Dramfeld K.R.I.a. 7

P. A. Dramfeld K. R. III. 1

P. A. Dramfeld K. R. III. 2

Dramfeld B. 1 (Amt Reinhausen)

P. A. Dramfeld S. K. 3 (1780)

P. A. Barterode 202 


\section{Pfarrregistratur Obernjesa}

Corpus bonorum Bey der Kirche zu Dramfeld Inspection Münden 2tn. Theils Amts Friedland.

\section{Stadtarchiv Göttingen (StAGött)}

Dep. 114

\section{Ortsarchiv Dramfeld}

IX, 32 (157).

\section{Abbildungen}

Die Wiedergabe der Fotos aus der Pfarrchronik erfolgt mit freundlicher Genehmigung des Kirchenkreisarchivs Göttingen.

\section{Gesetzessammlungen und Lexika}

Allgemeine Deutsche Biographie (ADB), herausgegeben von der Historischen Kommission bei der Bayerischen Akademie der Wissenschaften. Digitale Volltextausgabe in Wikisource

Churfürstliche Braunschweig-Lüneburgische Landes-Gesetze und Verordnungen Calenbergischen und Grubenhagenschen Theils in einen Auszug nach alphabetischer Ordnung gebracht von Friedrich Christoph Willich der Rechte Doctor, und Actuarius der Georg-August Universität. Erster Band A-G, Johann Christian Dieterich, Göttingen 1780. [Willich 1]

Churfürstliche Braunschweig-Lüneburgische Landes-Gesetze und Verordnungen Calenbergischen und Grubenhagenschen Theils in einen Auszug nach alphabetischer Ordnung gebracht von Friedrich Christoph Willich der Rechte Doctor, und Actuarius der Georg-August Universität. Zweyter Band H-Q. Göttingen und Dessau, bey dem Verfasser und in der Buchhandlung der Gelehrten 1782. [WILLICH 2]

Churfürstliche Braunschweig-Lüneburgische Landes-Gesetze und Verordnungen Calenbergischen und Grubenhagenschen Theils in einen Auszug nach alphabetischer Ordnung gebracht von Friedrich Christoph Willich der Rechte Doctor, und Universitäts Vice-Syndicus. Supplement A-/. nebst Anhang. Göttingen 1792. [WILLICH 3]

Churfürstliche Braunschweig-Lüneburgischer Landes-Gesetze und Verordnungen Calenbergischen und Grubenhagenschen Theils nach chronologischer Ordnung und mit ihrem summarischen Inhalte verzeichnet. Suppl. o. O., o.J. [Willich, anhang] 
Churhannoversches Kirchenrecht. Von Johann Karl Fürchtegott Schlegel.

Erster Theil. Hannover 1801; Zweyter Theil. Hannover 1802; Dritter Theil. Hannover 1803; Vierter Theil. Hannover 1804; Fünfter und letzter Theil. Hannover 1806. [SCHLEGEL]

Cokayne, G.E., Gibbs, V. et al. (Hg.): The Complete Peerage, 12 Bde., London 19101959, hier Bd. 5 [Cokayne, Peerage].

Deutsches Wörterbuch von Jacob und Wilhelm Grimm. dtb München 1984. [Grimm].

Gesetze, Verordnungen und Ausschreiben für den Bezirk des Königl. Consistorii zu Hannover, welche in Kirchen- und Schulsachen ergangen sind. Zusammengestellt und mit Genehmigung des Königlichen Consistorii herausgegeben von Christian Hermann Ebhardt, Advocaten und Notare zu Hannover. Zweiter Band. Hannover 1845. Band 4, Hannover 1840. Im Verlage der Helwing'schen Hofbuchhandlung. [EBHARDT]

Hannoversches biographisches Lexikon: von den Anfängen bis in die Gegenwart. Schlüter, Hannover 2002.

Jansen, C. H. C. F.: Statistisches Handbuch des Königreichs Hannover, in Commission der Helwing'schen Hofbuchhandlung, Hannover 1824.

JöCKLe, Clemens: Das große Heiligen Lexikon. Parkland, Köln 2003.

Meusel, Johann Georg: Lexikon der vom Jahr 1750 bis 1800 verstorbenen teutschen Schriftsteller, Bd. XI.; reprograf. Nachdruck, Georg Olms Verlagsbuchhandlung, Hildesheim 1968.

Meyer, Philipp: Die Pastoren der Landeskirchen Hannovers und Schaumburg-Lippes seit der Reformation. 3 Bde. Göttingen 1941, 1942, 1953. [Meyer, Pastoren]

Sснамвасн, Georg (Hg.): Wörterbuch der niederdeutschen Mundart der Fürstenthümer Göttingen und Grubenhagen oder Göttingisch-Grubenhagen'sches Idiotikon, Rümpler, Hannover 1858.

ZedLer, Johann Heinrich: Grosses vollständiges Universal Lexicon aller Wissenschafften und Künste, Halle und Leipzig, 1732-1754 [ZedLer]. 


\section{Literatur}

Амт, Stefan: Die Bauverwaltung des hannoverschen Konsistoriums bis zur Zeit Conrad Wilhelm Hases, bhb-Hannover 1998; auch in: Festschrift für Günther Kokkeling, Hannover 1998, 121-131.

ARndT, Karl (Hg.): Katalog der Bildnisse im Besitz der Georg-August-Universität Göttingen. Vandenhoeck \& Ruprecht in Göttingen $1994=$ Göttinger Universitätsschriften / C.

Arnim, Max (Bearb.): Corpus Academicum Gottingense (1737-1928), Vandenhoeck \& Ruprecht, Göttingen 1930.

Beer, Günther: Paulinerkloster mit altem Gymnasium, Barfüßerkloster, Hospital St. Crucis in Göttingen und deren Umgebungen, in: Göttinger Jahrbuch 32, 1984, 71-98.

BeEr, Günther: Die erste Göttinger Doktorpromotion und die erste Göttinger Doktor-Dissertation von Christoph Henrich Papen 1735, in: Museum der Göttinger Chemie, Museumsbrief Nr. 16, 1997, 2-10.

BeEr, Günther: „Nachbleibsel der Sündfluth“. Das „Naturalien-Cabinet“ des Göttinger Tuchfabrikanten Johann Heinrich Grätzel, das erste Museum Göttingens 1737, in: Göttinger Jahrbuch 56, 2008, 171-189.

Böнme, Ernst, Scholz, Michael und Jens Wenner: Dorf und Kloster Weende von den Anfängen bis ins 19. Jahrhundert. Göttingen 1992.

Boetticher, Manfred von: Kloster und Grundherrschaft Mariengarten. Entstehung und Wandel eines kirchlichen Güterkomplexes im südlichen Niedersachsen vom 13. bis ins 19. Jahrhundert. Verlag August Lax, Hildesheim 1989.

Bolle, Rainer: Der Göttinger Magistrat im Siebenjährigen Krieg 1756-1763, in: Göttinger Jahrbuch 38, 1990, S. 101-125.

Brüdermann, Stefan: Göttinger Studenten und Akademische Gerichtsbarkeit im 18. Jahrhundert $=$ Göttinger Universitätsschriften Serie A, Bd. 15, Vandenhoeck \& Ruprecht, Göttingen 1990.

Busch, Ralf: Kriegs- und Alltagsleben in Bovenden. Eine Quelle zur Bovender Geschichte des 18. und 19. Jahrhunderts, in: Beiträge zur Bovender Geschichte, Plesse-Archiv Heft 5, 1970, S. 83-97. 
Büsıng, Johann Conrad Ludewig: Beschreibung der Stadt Eldagsen, in: Büsching, Anton Friedrich, Magazin für die neue Historie und Geographie, Band 7 (Halle 1773), 525-534.

Der Göttinger Student oder Bemerkungen, Ratschläge und Belehrungen über Göttingen und das Studentenleben auf der Georgia Augusta. (Nachdruck von 1813 und 1913). Vandenhoeck \& Ruprecht, Göttingen 1981.

Dolezel, Heidrun: Nachrichten aus der Kirchturmkugel 1699-1955. Zur Geschichte von Rosdorf, Band 1, Rosdorf 1994.

Fährmann, Sigrid: Aspekte kulturellen Lebens in Göttingen im 19. Jahrhundert: Musik, Theater, Kunst und Vereine, in: Ernst Böhme und Rudolf Vierhaus (Hg.): Göttingen, Geschichte einer Universitätsstadt Bd. 2. Vom Dreißigjährigen Krieg bis zum Anschluss an Preußen - Der Wiederaufstieg als Universitätsstadt (1648-1866). Vandenhoeck \& Ruprecht in Göttingen 2002, 905-944.

FAUST, Ingrid: Zoologische Einblattdrucke und Flugschriften vor 1800. Unter Mitarbeit von Klaus Barthelmess und Klaus Stopp. Band V, Unpaarhufer: Nashörner, Tapire, Pferdeartige. Sammelblätter. Monster. Generalregister zu Band I-V. Anton Hiersemann, Verlag Stuttgart 2003.

FlüGEL, Wolfgang, Marperger, Bernhard Walther (Walter), in: Sächsische Biografie, hrsg. vom Institut für Sächsische Geschichte und Volkskunde e.V., bearb. von Martina Schattkowsky (http://www.isgv.de/saebi/(23.7.2013).

Fuchs, Thomas: Bücher aus der Bibliothek von Gottfried Wilhelm Leibniz und der Hofbibliothek in Hannover im Ilfeld-Bestand der Forschungsbibliothek Gotha, in: Hartbecke, Karin: Zwischen Fürstenwillkür und Menschheitswohl: Gottfried Wilhelm Leibniz als Bibliothekar. Klostermann, Frankfurt am Main 2008, 243-268.

Füssel, Marian: Der Siebenjährige Krieg: ein Weltkrieg im 18. Jahrhundert. Beck, München 1987.

Garbe, Daniela, unter Mitarbeit von Bernd Wiechert: Der Director musices, Organist und Kantor Johann Friedrich Schweinitz. Ein Beitrag zur Musikgeschichte Göttingens im 18. Jahrhundert, in: Göttinger Jahrbuch 37, 1989, 71-90.

Gerhard, Hans Jürgen [2001]: Vom Reichstaler zum Euro. Drei Jahrhunderte Geld in Göttingen, in: 200 Jahre Sparkasse Göttingen, herausgegeben von Karl Heinrich Kaufhold im Auftrag der Sparkasse Göttingen. Deutscher Sparkassen Verlag, Stuttgart 2001, 408-433. 
Gerhard, Hans-Jürgen [2002]: Grundzüge der Verfassung, Verwaltung und Wirtschaft der Stadt Göttingen 1650-1866, in: Ernst Böhme und Rudolf Vierhaus (Hg.): Göttingen, Geschichte einer Universitätsstadt Bd. 2. Vom Dreißigjährigen Krieg bis zum Anschluss an Preußen - Der Wiederaufstieg als Universitätsstadt (1648-1866). Vandenhoeck \& Ruprecht in Göttingen 2002, 256-340.

Gerhard, Hans-Jürgen [2006]: Geld und Währungen, Maße und Gewichte der Frühen Neuzeit in Südniedersachsen, in: Hans-Heinrich Hillegeist (Hg.): Heimat- und Regionalforschung in Südniedersachsen. Mecke Druck und Verlag, Duderstadt 2006, 161-175.

GierL, Martin: Die moralisch-literarischen Journale in Göttingen von 1732 bis zum siebenjährigen Krieg: eine sozialhistorische Untersuchung. Göttingen 1988.

Göttingen. Geschichte einer Universitätsstadt, Band 2. Vom Dreißigjährigen Krieg bis zum Anschluss an Preußen - Der Wiederaufstieg als Universitätsstadt (16481866). Herausgegeben von Ernst Böhme und Rudolf Vierhaus. Vandenhoeck \& Ruprecht in Göttingen 2002. [GÖTTINGEN Bd. 2]

Göttinger Gelehrte. Die Akademie der Wissenschaften zu Göttingen in Bildnissen und Würdigungen 1751-2001. Herausgegeben von Karl Arndt, Gerhard Gottschalk und Rudolf Smend. Zwei Bände. Wallstein Verlag, Göttingen 2001.

Grotefend, Hermann: Taschenbuch der Zeitrechnung des deutschen Mittelalters und der Neuzeit. Hahnsche Buchhandlung, Hannover 2007.

Grothenn, Dieter: Der Topographische Atlas des Königreichs Hannover und Herzogtums Braunschweig von August Papen. Erläuterungsheft zur Neuausgabe. Landesvermessung und Geobasisinformation Niedersachsen - LGN (Hg.), Hannover 1997.

HaAse, Carl: Ernst Brandes 1758-1810, 1. und 2. Band. August Lax Verlagsbuchhandlung, Hildesheim 1973 und 1974.

Hagedorn, Angelika und Arweg Henking (Hg.): 100 Jahre St. Jacobi-Kantorei Göttingen: 1891-1991. Göttingen 1991.

Haller, A. v. oder Joh. David Michaelis (zugeschrieben): A Short Account of his Maiesty's late Journey to Goettingen and of the State of the new University there in a Letter to my Lord, o.O. 1748.

Hammann, Konrad: Geschichte der evangelischen Kirche in Göttingen (ca. 16501866), in: Göttingen. Geschichte einer Universitätsstadt, Bd. 2. Vom Dreißigjährigen Krieg bis zum Anschluss an Preußen - Der Wiederaufstieg als Universitäts- 
stadt (1648-1866). Hg. von Ernst Böhme und Rudolf Vierhaus. Vandenhoeck \& Ruprecht in Göttingen 2002, 525-586.

Hemeling, Johann: Kleines Rechenbuch für Bürger und Landschulen. In Commission der Hahn'schen Hofbuchhandlung. Hannover 1836.

Hessen, Rainer von (Hg.): Wir Wilhelm von Gottes Gnaden. Die Lebenserinnerungen Kurfürst Wilhelms I. von Hessen 1743-1821. Campus Verlag Frankfurt/New York 1996.

Heuvel, Christine van den: Aspekte einer adligen Karriere zwischen Anpassung und Selbstbehauptung, in: Bothmer, Wilken von und Marcus Köhler (Hg.): Im Auftrag der Krone. Friedrich Karl von Hardenberg und das Leben in Hannover um 1750. Hinstorff, Rostock 2011, 9-18.

Heynatz, Johann Friedrich: Handbuch zu richtiger Verfertigung und Beurtheilung aller Arten von schriftlichen Aufsätzen des gemeinen Lebens überhaupt, und der Briefe insbesondre. Bey Arnold Wever, Berlin 1773.

HöLsCHER, Steffen: Zwischen Legitimation und Lustbarkeit, in: Göttinger Jahrbuch 59, 2011, 41-69.

Hofmeister, Andrea: Ländliche Alphabetisierung in Südniedersachsen: ,Großraum' Göttingen und nordwestliches Harzvorland, in: Alphabetisierung und Literalisierung in Deutschland in der Frühen Neuzeit. Max Niemeyer Verlag, Tübingen 1999, 11-32.

Hollmann, Samuel Christian (Hg.): Wöchentliche Göttingische Nachrichten nebst allerhand vorangesetzten philosophischen Betrachtungen auf das 1735te Jahr, jetzt mit einer Vorrede, und Verzeichnüß der abgehandelten Materien, versehen. Göttingen, bey Johann Michael Fritschen, Göttingen 1735.

Holthausen, Ferdinand, in: Beiträge zur Geschichte der deutschen Sprache und Literatur, Bd. 46, 1922, 25-146.

Hünemörder, Kai F.: Zwischen „abergläubischem Abwehrzauber“ und der „Inokulation der Hornviehseuche“. Entwicklungslinien der Rinderpestbekämpfung im 18. Jahrhundert, in: Engelken, Katharina, Hünninger, Dominik und Steffi Windelen (Hg.): Beten, Impfen, Sammeln. Zur Viehseuchen- und Schädlingsbekämpfung in der Frühen Neuzeit. Universitätsverlag Göttingen 2007, 21-56.

Hunger, Ulrich: Die Georg-August-Universität als Landesherrliche Gründung, in: Elmar Mittler (Hg.), „Eine Welt allein ist nicht genug“. Großbritannien, Hannover und Göttingen 1714-1837. Katalog, Göttingen 2005. 
Jünemann, Joachim: Dransfeld als Garnison und Etappe, in: Göttinger Jahrbuch 27, 1979, 97-140.

Kimber, Edward: The Peerage of England. A complete view of the several orders of Nobility, their Descents, Marriages, Issues, and Relations; their Creations, London 1766. [Kimber Peerage]

KLeineke, Dagmar: Abgerissen und wieder aufgebaut? Zur Reparatur- und Baugeschichte der Dramfelder Kirche St. Nikolai, in: Göttinger Jahrbuch 63, 2015, S. 37-62.

Косн, Diether: Das Göttinger Honoratiorentum vom 17. bis zur Mitte des 19. Jahrhunderts: eine sozialgeschichtliche Untersuchung mit besonderer Berücksichtigung der ersten Göttinger Unternehmer. Vandenhoeck \& Ruprecht, Göttingen 1958.

Krancke, Friedrich: Arithmetisches Exempelbuch für Volksschulen. Im Verlage der Hahn'schen Hof-Buchhandlung. Hannover 1859.

Kruckenberg, Adolf: Geschichte der Entwicklung des hannoverschen Volksschulwesens seit der Reformation. Verlag des Hannoverschen Provinzial-Lehrervereins, in Kommission bei Fr. Cruse's Buchhandlung (A. Troschütz, Hannover), Hannover 1925.

Krumwiede, Hans-Walter: Kirchengeschichte Niedersachsens. Bd. 1: Von der Sachsenmission bis zum Ende des Reiches 1806, Vandenhoeck \& Ruprecht, Göttingen 1995. Bd. 2: Vom Deutschen Bund 1815 bis zur Gründung der Evangelischen Kirche in Deutschland 1948, Vandenhoeck \& Ruprecht, Göttingen 1996.

Kürschner, Klaus: Ein Beitrag zur Geschichte des Reinhäuser Waldes. Diss. Göttingen 1976.

LEYDECKER, Günter: Erdbebenkatalog für Deutschland mit Randgebieten für die Jahre 800 bis $2008=$ Geologisches Jahrbuch Reihe E Geophysik, Heft 59, Hannover 2011.

Mastnak, Jens und Michael A. Tänzer: Celle im Siebenjährigen Krieg. Das Tagebuch des Garnisonsauditors Johann Philipp Schowart, Celle $2010=$ Bomann Museum Celle (Hg.), Forschungen zur Hannoverschen Militärgeschichte Bd. 1. [Mastnak, Celle]

MAYer, Tobias: Versuch einer Erklärung des Erdbebens, in: A.C. v. Wüllen (Hg.): Nützliche Sammlungen, Neunzehntes Stück. Freytag, den 5 ten Martius, Hannover 1756. 
Meiners, C.: Kurze Geschichte, und Beschreibung der Stadt Göttingen und der umliegenden Gegend. Bei Haude und Spener, Berlin 1801.

MLYNeK, Klaus, in: Hannoversches biographisches Lexikon. Von den Anfängen bis in die Gegenwart. Schlüter, Hannover 2002.

Moeller, Bernd: Johann Lorenz von Mosheim 1694-1755. Kirchengeschichte. Ehrenmitglied seit 1751, in: Arndt, Karl, Gottschalk, Gerhard und Rudolf Smend (Hg.): Göttinger Gelehrte: Die Akademie der Wissenschaften zu Göttingen in Bildnissen und Würdigungen 1751-2001. Wallstein Verlag, Göttingen 2001, S. 10.

Nibuatnias: Siège de Dantzick, en 1807, précédé d'une introduction sur les évènmens qui ont amené les francais devant cette ville, et d'un précis sur l'histoire de Dantzick; orné d'une carte; rédigé sur le journal du siége de M. le Maréchal duc de Dantzick, et sur les mémoires authentiques de plusieurs officiers généraux. Paris 1818.

OвеRsсhelp, Reinhard: Niedersachsen 1760-1820. Wirtschaft, Gesellschaft, Kultur im Land Hannover und Nachbargebieten. Band 1, Verlag August Lax, Hildesheim 1982.

Отте, Hans: Milde Aufklärung: Theologie und Kirchenleitung bei Johann Hinrich Pratje (1710-1791), Generalsuperintendent der Herzogtümer Bremen und Verden. Vandenhoeck und Ruprecht, Göttingen 1989.

Pannenborg, A.: Des Göttinger Universitäts-Professors und Gymnasial-Direktors Rudolf Wedekind Tagregister von dem gegenwärtigen Kriege: als Beitrag zur Geschichte Göttingens im siebenjährigen Kriege. Dieterich, Göttingen 1896.

Promies, Wolfgang: Georg Christoph Lichtenberg mit Selbstzeugnissen und Bilddokumenten. Rowohlt Taschenbuch Verlag GmbH, Reinbek bei Hamburg 1964. [Promies 1987]

RIEs, Rotraud: Hofjuden als Vorreiter? Bedingungen und Kommunikationen, Gewinn und Verlust auf dem Weg in die Moderne, in: Herzig, Arno, Horch, Hans Otto und Robert Jütte (Hg.): Judentum und Aufklärung. Jüdisches Selbstverständnis in der bürgerlichen Öffentlichkeit. Vandenhoeck \& Ruprecht, Göttingen 2002, 30-65.

SAATHOFF, Albrecht: Aus Göttingens Kirchengeschichte. Festschrift zur 400 jährigen Gedächtnisfeier der Reformation am 21. Oktober 1929. Verlag des Göttinger Gemeindeblattes, Göttingen 1929.

SaAthoff, Albrecht: Geschichte der Stadt Göttingen bis zur Gründung der Universität. Vandenhoeck \& Ruprecht, Göttingen 1937. 
SaAthoff, Albrecht: Geschichte der Stadt Göttingen seit der Gründung der Universität, Vandenhoeck \& Ruprecht, Göttingen 1940.

Schandelmaier, Hela: Niedersächsische Fayencen , Braunschweig I und II, Hannoversch Münden, Wrisbergholzen (Sammlungskatalog) mit einleitenden Texten von Helga Hilschenz-Mlynek, in: Kestner Museum (Hg.): Niedersächsische Fayencen. Hannover 1993. [Niedersächsische Fayencen]

Scheuermann, Ulrich: Melioramentenvergleiche als Quelle für die Ortsgeschichte, in: Göttinger Jahrbuch 61, 2013, 183-212.

Schmeling, Hans-Georg: Stadt und Universität im Spiegel der ersten Göttinger Wochenblätter, in: Göttingen im 18. Jahrhundert. Eine Stadt verändert ihr Gesicht. Texte und Materialien zur Ausstellung im Städtischen Museum und im Stadtarchiv. Göttingen 1987, 31-72.

Schöne, A. (Hg.): Die Universität Göttingen im siebenjährigen Kriege. Aus der handschriftlichen Chronik des Professor Samuel Christian Hollmann (1696-1787) mit Erläuterungen und Beilagen, Verlag von S. Hirzel, Leipzig 1887.

SCHRÖDER, Eckart: Mittelalterliche Dorf- und Kirchhofbefestigungen im Landkreis Göttingen, in: Göttinger Jahrbuch 38, 1990, 25-37.

SChubert, Ernst: Räuber, Henker, arme Sünder. Verbrechen und Strafe im Mittelalter. Wissenschaftliche Buchgesellschaft, Darmstadt 2007.

SICHART, L. von: Geschichte der Königlich-Hannoverschen Armee. Zweiter Band. Dritter Zeitraum. 1705-1756. Hahn'sche Hofbuchhandlung, Hannover 1870.

STEInmetz, Erwin: Geschichte des Landkreises Göttingen von 1807 bis zur Gegenwart im Überblick, in: Göttinger Jahrbuch 34, 1986, 145-182.

Tнгмme, Friedrich: Die Okkupation des Kurfürstentums Hannover durch die Preussen im Jahre 1806. Jänecke, Hannover 1893.

Titz-Matuszak, Ingeborg: Mobilität der Armut. Das Almosenwesen im 17. und 18. Jahrhundert im südniedersächsischen Raum, in: Plesse-Archiv Bovenden 24, 1988, 9-338.

Tütken, Hans: Geschichte des Dorfes und Patrimonialgerichtes Geismar bis zur Gerichtsauflösung im Jahre 1839. Vandenhoeck \& Ruprecht, Göttingen $1967=$ Studien zur Geschichte der Stadt Göttingen Bd. 7.

Tütken, Johannes: Privatdozenten im Schatten der Georgia Augusta: Zur älteren Privatdozentur (1734 bis 1831). Teil II. Biographische Materialien zu den Privatdozenten des Sommersemesters 1812. Universitätsverlag Göttingen 2005. 
Wagener, Silke: Pedelle, Mägde und Lakaien: das Dienstpersonal an der Georg-August-Universität Göttingen 1737-1866. Vandenhoeck und Ruprecht, Göttingen 1996.

Wagenmann, Julius August, Graeffe, Johann Friedrich Christoph, in: Allgemeine Deutsche Biographie 9 (1879), S. 571-572 http://www.deutsche-biographie. de/pnd119559781.html?anchor=adb (17.12.2015).

Wähner, Georg Andreas, Tagebuch aus dem Siebenjährigen Krieg. Bearbeitet von Sigrid Dahmen = Quellen zur Geschichte der Stadt Göttingen Bd. 2. Universitätsverlag Göttingen 2012. [Wähner Tagebuch]

Wehking, Sabine: Die Entwicklung der katholischen Gemeinde in Göttingen 17461866, in: Göttingen. Geschichte einer Universitätsstadt, Bd. 2. Vom Dreißigjährigen Krieg bis zum Anschluss an Preußen - Der Wiederaufstieg als Universitätsstadt (1648-1866). Hg. von Ernst Böhme und Rudolf Vierhaus. Vandenhoeck \& Ruprecht in Göttingen 2002, 587-608.

Wellenreuther, Hermann: Vom Handwerkerstädtchen zur Universitätsstadt. Die Inaugurationsfeier der Georg-August-Universität von 1737 und die Vision Göttingens als „Leine-Athen“, in: Göttinger Jahrbuch 49, 2001, 21-38.

Wellenreuther; Hermann (Hg.): Göttingen 1690-1755. Studien zur Sozialgeschichte einer Stadt. Vandenhoeck \& Ruprecht, Göttingen 1988. 


\section{Glossar}

Circulare und Rescripte, Consistorial-Befehle und Verordnungen Zu verschiedenen Gegenständen und Themen

Flurnamen

HANDWERKER

Kollekten (wegen grosser Brände)

Kriegszeiten

Pfarralltag

Pfarre und Umland, Verschiedenes

Pfarrgüter

Pfarrhaus, Pfarrhausbau

Pfarrhof, Wirtschaftshof

Pfarrland, Pfarr-Länderey

Professoren, Geistliche und Ärzte

Sonstige Personen

WETTER

Circulare und Rescripte, Consistorial-Befehle und Verordnungen ZU Verschiedenen Gegenständen und Themen

Arme 20, 52

arme Kinder, Absenten 129, 132, 133, 152, 155, 156, 159, 194

arme Priesterwitwen 20

arme Schulmeister 41, 79

Armenkasse 133, 154

Armenkasten 135

Armenordnung 131

Aufgebot 32

Bau der Stockhäuser Kirche 31,45 , 55,78

Beginn des Jahrhunderts 180

Begutachtung der Dächer von Pfarre und Schule 147

Bußtage 19, 76, 88, 197

Capitalia 31, 163
Cattun und Zitz 17, 18

Copulation 32, 46, 79, 81, 84, 168

Dank- und Friedensfest, Religionsfrieden, Kirchenfrieden $44,74,75$, 117, 176, 182, 183, 187

Ephorat, Ephorus 179

Freimaurer 28

Freitisch für Lehrer 134

Gnadenjahr 17, 184

Herrnhuter 18, 19, 44

Hofagent 158

Kirchenbuch 46, 144

Kirchengeld 61, 150, 151, 153, 198

Kirchenvorrat $31,32,138,140,149$, 198 
Kollekte, Beckenkollekte, Hauskollekte, Kirchenvorratskollekte, Privatkollekte $17,18,21,24,31,33,35$, $37,40,44-46,48,50,51,53,58$, 59, 60, 64, 67, 74, 82, 85, 144, 149, $171,172,174,185,190,191$

Legat 42

Melioramente 16, 17, 184, 185

Militair-Witwenkasse 144, 145, 158

Münzedikt XLI, XLII, 18

Pardon für die Deserteure 20

Parochiallisten 149

philosophisches Journal 166, 167

Pietisten und Separatisten 18, 19

Praenumeration (Vorbestellung) 16, 172

Predigerwitwenkasse 164

Pretii der Catechumenorum,

Konfirmandengebühr 15

Ruhr 25, 177

Scheffelschatz 17

Schulgeld 64, 131-134

Schulregister 145,147

Sommerschule $64,152,153,156,163$

Sortenzettel 150, 198

Verhaltensvorschrift $45,148,180$, 203

Viehseuche 50, 53, 60

von der Kanzel zu verlesen 59, 122 , 169, 190, 197, 204

Weinkauf 66

Wirtschaftsbuch 185

\section{Flurnamen}

Am Dramfeldschen Wege 185, 187

Am Jäger Wege 13

Am Schaastalle [!] 13

Am Stockhäuser Wege 13
Andreas Fischers Lande 13

Auf den Geeren 196

Bey dem weissen Steine 13

Beyflusse, Bieflote 36

Beym Nesselbusche 13

Boden Lehnwiese 196

Bruch 182

Bühren Lande 13

Die Kleine Breite 186

Die Strüllen 13

Dranßfelder Lande 13

Dreisch 187

Engelhards Lehnwiese 192

Fehrensches Lehnland 180, 193

Gemeine Brückenweg 192, 193

Gemeineholz 185, 186

Hilwarthausisches Lande 13

Holzecke 186

Horl 35, 109

Im Dramfelde 12

Im Niederjesischen oder Horl Felde 13

Im Sieboldshäuser Felde 191

Jägerberg, Jeser Berg, Jesenholz 13, 104, 182

Knickgarten, Knickhof $52,94,145$, 146, 166

Kogels Lande 13

Lerchenbreite 191

Magercourdsche Wiese 192

Neuer Anger 182

Niederjesischer Braucke 36

Papenwinkel 192

Pfarrkielmorgen 187

Pfingstanger 182

Siboldeshäusisches Feld 13

Über dem Göttingischen Weg 13

Welkers Lehnmorgen 207

Wissels Lande 13, 185, 193 
HANDWERKER

Backhaus, Meister, Tischler 27, 35

Bode, Meister, Hitzelrode 168

Bühre, Hausschlachter, Dramfeld 38

Bühre 37

Dehne, Ludolph, Schmied, Obernjesa 185,188

Dehne, Lorenz jun., Zimmermeister, Obernjesa 124, 192, 209

Frede, Meister 43

Grube, Schuster 50

Hampe, Friedrich Sen. 166, 182

Junker, Buchbinder, Göttingen 191

Kleinhans, Tischler, Groß

Schneen 188, 203

Köhler, Johann Rudolf, Turmdeckermeister 63, 64

Krüger, Daniel Christoph, Brunnen und Röhrenmeister 130

Künkler, Johannes, Brunnengräber 130

Linne, Maurermeister, Reiffenhausen 182

Lücke, Christoph, Brunnenmeister, Göttingen 123

Lüdeke, Christian Friedrich, Tischler, Dramfeld 188

Lüdeke, Daniel, Schmied und Vorsteher, Dramfeld 197

Lüdeke, Johann Ludewig, Grobschmied, Dramfeld 173

Möser, Amtsmaurermeister, Reiffenhausen 181

Münscher, Johann Henrich, Weißbindermeister, Hitzelrode 61, 64, 122

Puscher, Meister 123

Rammenschweig, Zimmermeister, Friedland 34
Salzmann, Amtszimmermeister, Obernjesa XLI, 181

Salzmann, Andreas, Zimmermeister, Obernjesa 213, 214

Schäfer, Johann Heinrich, Tischler oder Zimmermann, Obernjesa 166, 182

Tewes, Kleinschmied und Uhrmacher, Varlosen 188

Trecker, J., Lehrjunge bei Maurermeister Linne, Reiffenhausen 182

Wetter, Valentin, Meister, Brunnenmaurer 130

Kollekten (Wegen grosser Brände)

Börry 44

Eldagsen 22

Harpstedt 17

Moringen 37

Wildemann 17

Kriegszeiten

Administrationskommission 215, 216

Armee d'Hannovre 211

ausheben 83, 198

Bonaparte, Napoleon 211, 215-217

Braunschweig, Herzog Karl Ferdinand von 109,212

Convention 200, 203

Cumberland, Herzog von 87,90

Dragoner XXXVIII, 22, 43, 53, 54, 68, 87, 104, 170, 178, 190, 213

Einquartierung XL, 105, 204, 205, 212-214, 216

Executiv-Commission 204, 212

Festung Hameln 87, 88, 211, 212, 216

Festung Nienburg 216 
Festung Stade 88

Fourage, Fourageld, Fouragelieferung $\mathrm{XL}, 91,105,107,111,112$, 167, 206-208, 213, 214

fouragieren, plündern XXXIX, 104, 109, 113

Französische Besetzung XIII, XVIII, XXXIX, 104, 117, 200, 202, 211

Hastenbeck 87

Hilfsbeisteuer XL, 204, 208

Kapitulation XIII, 200

Kontribution 105, 107, 110, 113, 202

Kriegssteuer XL, 163, 204

Landesdefensionssteuer XL, 204

Landesdeputations-Kollegium 206

Lefebvre, Francois-Joseph, Herzog von Danzig 218

Luckner, Johann Nikolaus 107, 109

Mortier, Edouard Adolphe 198, 200, 203, 217

Preussische Besetzung 208, 212-216

Proclamation 198, 215

Rheinbund 217

Salvegardengeld 105, 107,

Siebenjähriger Krieg in Göttin-

gen $88-91,104,105,110,111$, 113-117

Siebenjähriger Krieg in Obernjesa, Dramfeld und Umgebung 88, 89, 103-111, 111-114, 116, 117

Soldaten, auch hessische, Rekruten XXXIX, XL, 20, 54, 81, 83, 104, 198

Traitementgeld 105,107

\section{Pfarralltag}

Arme, arme Kinder, arme Schulabsenten, arme Schulkinder XXVI,
XXXIII, XXXIV, 23, 43, 133, 134, 150, 153, 191

Armenbeerdigung 191

Armenkasse, Armenkasten XXVI, XXXIII, XXXIV, 133, 134

Armenordnung 134

Altarist $\quad 45,73,79,168$

Beerdigung, stille $80,83,165$, 193-195

Brautsuppe XXIX, XXX, 170

Corpus bonorum X, XI, XXI, XXXII, XXXIII

Disposition (der Predigt) 74, 76

Evangelienbücher XXII, XXXII, 191

Filia XI, XXI, 2, 14, 138, 169

Gebühren XXVII, XXIX, XXXIV, XLI, $157,170,171,194$

Kirchenkommissarien, Kirchenkommission XVI, XXI, XXV, XXVI, XXXVI, 139, 147

Kirchenland XV, XXIX, 193

Kirchenübertritt 22, 23, 56

Legat XXVI, 42, 43, 135

Lizentfreiheit 45, 57

Mahlzeitgelder XVII

Melioramente $10-12,16,17,124$, 184,185

Methodenbuch XXXII, 153

Pastoralinstruktion XXXII, 153, 177, 179

Pfarrbericht XVIII, XXV, XXXIV, XL, $131,132,135,137,138,147,152$, $157,158,159,163,164,166,179$

Pfarrhaus, altes 2, 24, 26, 27, 33, 166

Pfarrinventar X, XI, XII, XVIII, XXVI, XXXI, 10-12, 170, 185

Pfarrregistratur X, XI, XII, 11, 146, 166, 172, 176, 181, 184, 186, 193, 196, 207

Pfarrunterricht im Sitzen XXXV, 157 
Pfarrwittwentum 5, 7, 11, 13, 147,

175, 182, 203, 205

Pfarrwitwenhaus XIII, 16, 34, 38, 96, 122, 139, 140, 194, 205

Proklamation 156, 170, 198, 199, 215

Sakristei XV, XXX, 137, 138, 139, 181

Schule; Unterricht XXXI, XXXIII,

$145,152,153,156,159$

Schulbrunnen 177,181

Schulgarten 38, 96

Schulgeld 15,134

Schulhaus 19, 20, 33, 48, 176

Schulwiese 192

Sommerschule $64,152,153,156$, 163

Te Deum 25, 183, 187

Vakanz 41, 93, 162, 175, 210

Visitation XI, XXI-XXV, XXXIII, 14, 26,

$31,43,47,52,71,115,136,137,157$

Visitationsmahlzeit XXII, 47

Pfarrgüter 14

Pfarrhaus, Pfarrhausbau

24, 29, 31, 33-35, 39, 43, 64, 79, 122,

182,203

\section{Pfarrhof, Wirtschaftshof}

$\mathrm{XXX}, 20,24,27,31,37,49,55,58,61$, $64,69,71,77,86,91,92-94,113$, $122-124,130,145,146,162,166$, 168, 172, 182, 185, 186

Kosten für Material und Arbeitslöhne $23,37,52,55,69,86,94$, $122,123,130,166$
Preise für Lebensmittel, Futter und Kleidung 87, 88, 110-112, 167, 188,213

\section{Pfarrland und Pfarrländerey $7,8,11$}

Gemeinheit 182

Loosholz 185

Sommerfeld 5, 104, 108, 109, 173, 188, 190, 205

Verpachtung XXVIII, XXIX, 137, 144, $145,147,157,166,191,192,193$, 196, 205

Winterfeld 5, 106, 108, 113, 173, 188, 205

Grenzstreitigkeiten $35,36,37,38$, 144, 180, 186, 187, 191, 192, 193, 196, 207

\section{Pfarre, Verschiedenes}

Amt Friedland $\mathrm{X}, \mathrm{XXI}, \mathrm{XXII}, \mathrm{XXV}$, XXXIV, 29, 38, 47, 52, 109, 129, 162,191

Amt Münden XXII, XXXIX, 5, 7, 12, 23, 109, 208

Armenhospital XIV

Attentat $\mathbf{1 7 6}$

Beileine 209

Bremische Bibliothek 58

Cantor figuralis XIV, 28

Contagion 25

Dienstgeld 7, 13, 84, 205

Dispensation 194

Dragoner XXXVIII, 22, 43, 53, 54, 68, 78, 87, 104, 170, 178, 189, 190, 211, 213

Einbruch 71, 164, 
Einwohnerzahlen, Statistik $46,79,81$, $84,85,125-129$

Eichsfeld, Eißfeld 22, 68

Erdbeben 80

Feuer in Obernjesa 27

Filial Dörfer 2, 14, 169

Gericht Leineberg XXII, XXIX, XXXIV, 21, 23, 36, 40, 84, 109, 121, 125, 145, 182, 186, 196, 204, 206, 207, 209, 211

Grone (auch Hinrichtung) 21, 53, 190, 198, 210

Gurkenkrug 209

Hessen 81, 87, 108, 212, 216, 217

Heuschrecken 24

Hofagent 158

kalter Brand 56

Kassengeld XLV

Konsistorialkirche 78

Leinedörfer 21

Mariengarten, Kloster XXVIII, XXXVII, XXXVIII, 14, 57, 69, 70, 86, 104, 173, 174

Militärwitwen $144,145,158$

Mord 50, 189, 190, 211

Münzen, Wechselkurs XLII-XLV

Nashorn 56

Pietisten XXVI, XXVII, 91, 92, 96

Real Territion 211

Ruhr 177

Salve Garde, Salva Gardia 39, 91

Seyffert (Musiker, Göttingische Chor Schüler) $28,29,52,53$

Socinianer 44

Sortenzettel XLIII, XLIV

St. Crucis, Heiligkreuzkirche XIV, 1

Turmuhr 187, 188

Universität, Inauguration XIII, 4

Weende, Kloster 7, 83

Wirtschaftsförderung 118-121
Professoren, Geistliche und Ärzte

[Da die Akademiker, insbesondere die Geistlichen, wiederholt versetzt wurden, wird für diese Personen kein Wohnort angegeben.]

Appuhn, Johann Ernst XX, 20, 21, 28, 29, 31, 33, 40, 43, 44, 46, 49, 60, $62,63,68,83,87,103$

Armbrecht, Johann Georg XXIX, 2, 12, 39, 91, 93, 170

Berkelmann, Johann Friedrich 85

Biallablotzky, Johann Heinrich Siegfried (Siegmann) 171

Blauel, Johannes Christoph August XX, XXXVI

Bode, Johann Friedrich 44

Boehmer (Böhmer), Georg Ludwig, Professor 8, 9

Borchers, Georg August 169

Born, Salomon 1

Bornträger, Johann Christian $\mathrm{X}, \mathrm{XII}$, XVII, XXVII, XLIII, XLVI, 142-160, $162,175,184$

Breigel, Hilfsgeistlicher XX

Dedekind, Karl Ludolf Christoph 211

Dürr, Johann Christoph $177,178,184$

Eikemeyer, Gottlieb Karl 155

Engelbrecht, Balthasar Rudolf 82,84

Erhard, Christian Albrecht 170

Feuerl(e)in, Jacob Wilhelm, Professor $4,24,51,88$

Fichte, Johann Gottlieb, Professor XXVII, 166, 167

Flügge, Henning 69

Flügge, Henrich Hermann $23,70,79$

Fuchs, Johann Nicolaus 63

Gatterer, Johann Christoph, Professor 165

Gautsch, Friedrich Benjamin 73 
Gersting, Heinrich Friedrich 82

Glieme, Christian Erich 29, 80

Goetten (Götten), Gabriel Wil-

helm 30

Gräffe (Graeffe), Johann Friedrich

Christoph X, XII, XIII, XV-XVII, XXX, XXXIV, 45, 147, 183, 184,

$185,191,195,210$

Gudewill, Arzt und Chirurg 71, 82

Günther, Hilfsgeistlicher XX

Hagemann, Theophilus Andreas XX, $5,15,21$

Hampe, Caspar Heinrich 55

Hampe, Nicolaus 28

Hansemann, Eberhard Heinrich 66

Hardt von der, Hermann, Profes-

sor 30

Hartel(1), Franz Konrad XX, 21, 22

Heumann, Christoph August, Profes-

sor $3,51,77,88,89$

Hüpeden, Ludolf Wilhelm 22

Jani, Joachim Christoph 2, 146

Jatho, Johann 162, 175, 176, 181

Kästner, Abraham Gotthelf, Profes-

sor 176

Köhler, Jakob David 87

Köhler, Johann David, Professor 70

Korthold, Christian 58

Langenbeck, Konrad Johann Martin

Dr., Chirurg 196

Lehzen, Joachim Friedrich 178

Leonhard, Johann Christoph, Professor 65

Leopold, Ernst Heinrich Georg 162 , 175,176

Lichtenberg, Georg Christoph, Professor 165

Lotze, Johann Julius $\quad 2,7,37,92,95$

Lütkemüller, Johann Christian 79
Lutter (Luther), Clemens Christian

Julius 16, 131, 151, 156, 175

Marperger, Bernhard Walther, sächsischer Konsistorialrat 30

Matthäi(us), Johann Friedrich 26

Meiners, Christoph, Professor XXXVIII, 168, 172-174

Mengershausen, Johann Heinrich Senior 21,26

Mengershausen, Ludolph Heinrich 78, 80, 86, 191 (?), 207

Mengershausen, Johann Detlev von, Senior der Familie 191

Mentzer, Balthasar 65

Mosheim, Johann Lorentz von, Kanzler 35, 42

Muhlert, Friedrich Wilhelm 154, 155, 176

Muhlert, Johann Christian 22

Mylius, Johann Gottfried 40, 169

Mylius, Ludwig Eberhard 155, 169

Niethammer, Friedrich Immanuel, Professor XXVII, 167

Oporin, Joachim, Professor 65

Oppermann, Jacob 176, 177, 181

Osann, Johann Bernhard Gott-

fried 181

Papen, Christoph Henricus Dr., Amtsarzt 71

Pastoren nach der Reformation 1-3

Planck, Gottlieb (Theophilus) Jacob,

Professor 179

Pleßke, Meinhard 88

Pratje, Johann Hinrich 58

Prätorius, Johann Jacob 3

Proffen, Johannes Friedrich 161-218

Rathlef, Ernst Ludwig 65

Raven, Johann Friedrich 178

Reinholt, Justus Christoph 32 
Riebow (Ribov), Georg Heinrich, Pro-

fessor XX, XXV, 21, 23, 25, 26, 28, 29, 42, 45, 47, 50, 57, 58, 66, 72, 73,86

Rittmeyer, Georg Conrad 210

Salfeld, Johann Christoph, Abt 177

Schaar, Clemens Caspar 22, 59, 62

Schierholz, Johann Ludwig 72

Schilling, Christian Heinrich 51

Schlie, Heinrich Christoph XVIII, XXIX, 170, 175, 211

Schlüter, Conrad XI, 2

Schmauß, Johann Jacob, Professor 86

Schmidt, Johann Christoph 81,83

Schmidt, Johann Justus $57,62,83,84$

Schwachheim, Johann Georg 24, 27

Schwartz, Matthäus 2

Sieburg, Andreas 2, 94

Sothen, Justus He(i)nrich 70, 71

Stolberg, Heinrich Philipp X, XI, XIII, XIV, XV, XXVI, XXVIII, XXX, XXXIII, XXXIX, XLII, XLIV, 51, 100 $-140$

Stollberg, Johann Paulus IX, XII-XV, XVII, XXV, XXVI, XXVII, XXXIII, XXXVII, 1-96

Strohmeyer, Dr., Leibmedikus 189

Ströver, Joachim 53

Stutzbach, Johann Friedrich 29

Thielo, Johann Franz Friedrich 58, 59

Vogel, Johann Heinrich 190

Wagemann, Johann Gottfried Wilhelm 159, 162, 175, 177, 181, 183, 195

Wagemann, Ludwig Gerhard 184

Wallrath, Schwadronschirurg 189

Warneke, Stadtchirurg 190

Wedekind, Rudolf, Professor 65, 88, 90, 91

Zwinck(g)mann, Heinrich Lorenz 70

\section{Sonstige Personen}

Arenhold, Gerhard Justus, Konsistorialsekretär 40,72

Blum, Johann Friederich, Amtschreiber 63

Böhmer, Amtschreiber 190, 211

Bothe, Leutnant 57, 67, 68

Bus(s)che, Christian Dieterich v.d., Präsident des hannoverschen Konsistoriums 134, 137, 139, 140

Conradi, Ernst Christian, Gerichtsschulze 121

Dannhauer, Richter 33, 81

David, Salomon Michael, Hofagent 158

Ebersmann, Lizenteinnehmer, Gross Schneen 45

Engelhard, Krüger, Stockhausen 192

Fleury de, André-Hercule, französischer Kardinal 23

Grätzel, Johann Heinrich 55

Hadfield, James, Attentäter 176

Hake von, Levin Adolph, Präsident des Hannoverschen Konsistoriums 67

Hannesen, Johann Andreas, Vizesyndikus 59

Hansemann, Jungfer 33

Hanstein, Carl Friedrich von, Drost (Amtmann) 5, 12, 15

Hartmann, Amtmann XXV, 29, 47, 72

Heumann, Frau, Göttingen 51

Hinterthür, Christian, Sieboldshausen 208-210

Hinüber, Christian Erich (Carl Ernst), Amtmann 62

Iden, Christian Just, Gerichtsschulze 26, 29, 36, 44

Insinger, Hofgerichtsassessor 57 
Keil, Barbara Catharina, Gross Sömmern 56

Lüder, Carl Wilhelm, Amtschreiber 162,164

Münchhausen, Adolph Gerlach von, Hannoverscher Minister 4, 42, 87, 89, 121

Mündemann, Landmesser, Feldmesser $146,180,186,187,192,193$, 196, 207

Nannen, Oberamtmann, Herzberg 46

Neubaur (Neubour), Friedrich Christoph, Dr., Gerichtsschulze 36

Nicholson, Margaret, Attentäterin 177

Oppermann, Justus Friedrich, Verwalter auf Mariengarten 69

Pieper, Christoph, Soldat 68

Poppe und Löning, Sieboldshausen 147, 166

Sckölln, Capitain 54

Seyffert (Seiffart, Seyfart), Adam Wolfgang, Stadtmusikus 28, 53

Tappe, Johann Peter, Mitglied des Hannoverschen Konsistoriums 4, 6, 12

Uslar, Ludolf Wedekind von, Oberhauptmann 162, 191

Utermöhlen, Anne Margarethe, geb. Poppe, Sieboldshausen 209

Willich, Landmesser 193

Wüllen, Albert Christoph von, Landsyndikus 114

Zachariä, Friedrich Christian Wilhelm, Gerichtsschulze $145,162,170$

\section{Dramfeld:}

Bühre, Ludwig Rel. 173

Busse, Förster XXIII, 47, 83

Curtius, Lehrer IX, 1

Deppe, Krüger 38
Diekmann, Christof, Krüger und Vorsteher 197

Engel, Johann Lucas 22, 23

Hartung, alter Schulze 48

Heddenhausen, Anne Engel Sophie 170

Henne, Schulze 34, 47

Hofmeister, Altarist XLIII, XLIV, 45

Lüdicke, Meister, Altarist 45

Utermöhlen, Christian, Vorsteher 34

\section{Obernjesa:}

Biermann, Johann Heinrich, Feldgeschworener 186, 193

Biermann, Ludolph 50

Bock, Matthias, Vorsteher 192

Bode, Johann Andreas 205

Bode, Matthias $34,35,38,39,50,91$, 96

Bornemann, Christian, Bauermeister 34,50

Bornemann, Zeugmacher 50, 53

Briecke, Johann Ernst 23

Bühre, Andreas 126, 128

Bühre, Hans, Altarist 79

Bühre, Wilhelm Rel. 126

Bührmann, Johann Heinrich, Feldgeschworner 207

Dehne, Johann Heinrich 209

Dehne, Lorentz sen., Vorsteher 34, 128, 192, 209

Engelhard, Johannes Rel. 189

Engelhard, Marie Charlotte 189

Fehrensen, Andreas, Musketier 180

Fehrensen, Dorothee 209

Fehrensen, Johann Heinrich 170, 193

Fehrensen, Johann Heinrich sen. 209, 210

Fehrensen, Lorenz, Invalide 126, 194

Fischer, Friedrich 144 
Fischer, Johann Jürgen 26, 27

Fischer, Johann Jürgen Erben 126

Frölich, Friedrich, Krüger und Dragoner 189

Frölich, Georg Christian, Dragoner 189,211

Hampe, Mattias, Erben 128

Hampe, Friedrich sen. 182

Harriehausen, Christoph, Schulze XLI, 213

Harriehausen, Johann Andreas, Kirchenvorsteher 188,

Harriehausen, Johann Heinrich 126, 144, 162, 209, 210, 213, 216

Harriehausen, Lorenz 212, 214, 216

Harriehausen, Rosine, geb. Zimmermann 208

Heine, Georg, Vorsteher 124, 126

Hentze, Andreas, Vorsteher 34

Hentzig, Marie Elisabeth 23

Lotze, Pastorenwitwe XXIX, 5, 6, 9, 10, 12, 38, 94, 139, 205

Mündemann, Andreas Christoph, Lehrer XLI, 171, 172, 177, 188, 213

Salzmann, Christoph 126

Salzmann, Geschwister 145, 146, 166 ,

Schäfer, Johann Andreas, Vorsteher 182, 186, 188, 207

Schlote, Johann Friedrich, Hilfslehrer 72

Schlote, Lehrer IX, 1, 38, 48

Seufer (Säuffer), Johann Andreas, Vorsteher 124, 128, 182, 186, 188

Stolberg, Marie Sophie XV, 71, 147, 205

Stollberg, Hedwig Elisabeth XV, 71, 139

Utermöhlen, arme Witwe 27
Welker, Dragonerinvalide 170

Zimmermann, Christoph 68, 111, 126

Zimmermann, Georg XLI, 213

Zimmermann, Johann Christoph, Bauermeister $166,176,182,186,188$, 189, 192

Zimmermann, Johann Heinrich Rel., geb. Schlote 208, 209

Zimmermann, Johann Rel. 78, 126

Zimmermann, Johann, Bauermeister 55,94

Zimmermann, Johann, Vorsteher 34

Zimmermann, Valentin XIX, 54

\section{WETTER}

Gewitter 46, 47, 165, 172-174

Hagel, Schlossen 82, 172, 173

Himmel 59, 67

Kälte 31, 33, 41, 46, 49, 52, 73, 165, $168,171,175,187$

Nordlicht 49

Regen 172, 209

Regenbogen 67

Schnee 33, 41, 69, 187, 209

schönes Wetter 4, 52

Stern 59, 60, 67

Sturm, Wind $37,52,58,63,84,86$, 165,178

Treibeis 209, 210

Wetterleuchten 168 


\title{
Dank
}

\begin{abstract}
Als Volkswirtin, deren Interesse bisher hauptsächlich der jüngeren lokalen Wirtschafts- und Sozialgeschichte gegolten hatte, bedurfte ich bei der Bearbeitung des Chroniktextes der Unterstützung einer ganzen Reihe von Fachleuten. Daher danke ich den folgenden Personen sehr herzlich:

Karl-Heinz Bielefeld, der mich immer wieder auf einzelne Bestände im Kirchenkreisarchiv Göttingen hinwies, die die Erklärung für manche der Eintragungen enthielten; Dr. Mechthild Weß, die unverdrossen Konvolut auf Konvolut der Kirchenrechnungen aus dem Magazin heranschleppte, und dem Ehepar Heidrun und Dr. Stephan Dolezel, das die Übersetzungen der lateinischen Zitate besorgte oder kontrollierte. Darüber hinaus danke ich Dr. Sigrid Dahmen, Dr. Hans-Jürgen Gerhard und Dr. Ulrich Scheuermann sowie den Leitern und Mitarbeitern des Universitätsarchivs und des Stadtarchivs für Kritik, Korrekturen und Hinweise.
\end{abstract}

Die Finanzierung des Druckes wurde in großzügiger Weise durch die Mariann Steegmann Foundation unterstützt; außerdem durch die Ortsräte von Dramfeld und Obernjesa sowie durch den Vorstand des Ev.-luth. Kirchengemeindeverbandes Parochie Obernjesa und den Heimatverein Obernjesa, wofür ich mich an dieser Stelle vielmals bedanke.

Dagmar Kleineke

Juni 2016

Abb. 8 Blick nach Dramfeld vom Jägerberg, Quelle: Dagmar Kleineke, Januar 2016

Abb.9 Ausschnitt aus der Kurhannoverschen Landesaufnahme (1764-1786) mit den Dörfern Obernjesa und Dramfeld 



ie Pfarrchronik - das sind Eintragungen von vier Pastoren der Pfarre Obernjesa/ Dramfeld aus den Jahren 1737 bis 1807 in ein altes Rechnungsbuch.

Die Pastoren notierten, was ihnen wichtig schien, und von dem sie meinten, es ihren Nachfolgern mitteilen zu sollen: Alltagserfahrungen wie Grenzstreitigkeiten mit den Nachbarn, Meliorationsauseinandersetzungen mit der Frau des Vorgängers, die Schwerfälligkeit der kirchlichen Verwaltung. Dazu kamen die Neuigkeiten aus der Universitätsstadt Göttingen wie die Nachrichten vom Tode berühmter Professoren oder die Zurschaustellung des Nashorns Clara. Erdbeben, Nordlichter, heftige Unwetter nicht zuletzt die eigenen Erfahrungen des Siebenjährigen Krieges wurden verzeichnet. Reskripte, Dekrete oder Ausschreibungen von Kollekten lassen erkennen, wie weltliche und kirchliche Verwaltungen mit der Armut und dem geringen Alphabetisierungsgrad der Landbevölkerung umgingen.

Die Vielzahl der Themen, die die Pastoren berührten, sowie statistische Angaben (Bevölkerungszahlen und Preise) machen die Chronik zu einem zeitgeschichtlichen Dokument.

Eine Einführung sowie die umfangreiche Kommentierung erleichtern den Zugang zur Transkription, die buchstaben- und zeichengetreu ausgeführt wurde. 